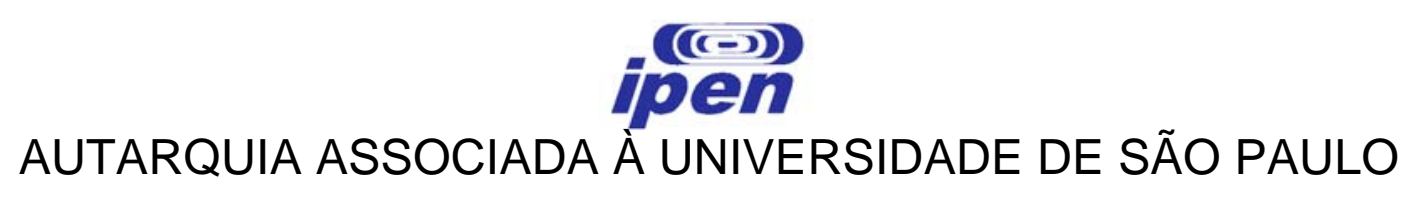

SÍNTESE E CARACTERIZAÇÃO DE TROCADORES IÔNICOS INORGÂNICOS A BASE DE ÓXIDOS MISTOS ESTANHO-TITÂNIO PARA UTILIZAÇÃO NA RECUPERAÇÃO DE CÁDMIO E NÍQUEL E ESTUDOS FOTOLUMINESCENTES

PAULA PINHEIRO PAGANINI

Dissertação apresentada como parte dos requisitos para obtenção do grau de Mestre em Ciências na Área de Tecnologia Nuclear Materiais

Orientadora:

Dra. Maria Cláudia França da Cunha Felinto

São Paulo

2007 
A minha família que sempre esteve ao meu lado incentivando e ajudando na realização deste trabalho. 


\section{AGRADECIMENTOS}

À Dra. Maria Cláudia França da Cunha Felinto pela amizade, incentivo, confiança e orientação.

Ao Instituto de Pesquisas Energéticas e Nucleares (IPEN/CNEN-SP) pela oportunidade de poder desenvolver esta dissertação.

Ao Conselho Nacional de Desenvolvimento Científico e Tecnológico (CNPq) pelo apoio financeiro.

Ao Dr. Hermi Felinto de Brito, do Instituto de Química da Universidade de São Paulo (IQ-USP), pela obtenção dos espectros de emissão e excitação.

Aos Laboratórios do Instituto de Pesquisas Energéticas e Nucleares (IPEN/CNEN-SP): Laboratório de MEV, Laboratório de Raios-X (CCTM), Laboratório de Polímeros do CQMA e Laboratório de Fluorescência de Raios-X, pelas análises.

À Central Analítica do Instituto de Química da Universidade de São Paulo (IQ-USP), pelos espectros de infravermelho.

À FAPESP, Instituto do Milênio dos Materiais Complexos II e RENAMI.

Ao Dr José Oscar Veja Bustillos pelo incentivo e ajuda com as análises.

Aos colegas de pós-graduação do IPEN/CNEN-SP pelo incentivo dado durante o desenvolvimento deste trabalho.

À minha família e amigos pelo apoio, incentivo e ajuda no decorrer de todo o trabalho.

À todas as pessoas que de alguma forma auxiliaram na realização deste trabalho. 


\title{
SÍNTESE E CARACTERIZAÇÃO DE TROCADORES IÔNICOS INORGÂNICOS À BASE DE ÓXIDOS MISTOS ESTANHO-TITÂNIO PARA UTILIZAÇÃO NA RECUPERAÇÃO DE CÁDMIO E NÍQUEL E ESTUDOS FOTOLUMINESCENTE
}

\author{
Paula Pinheiro Paganini
}

\begin{abstract}
RESUMO
Este trabalho apresenta a síntese, caracterização e estudos de adssorção de trocadores iônicos inorgânicos a base de óxidos mistos estanhotitânio para recuperação dos metais cádmio e níquel de efluentes aquosos, descartados no meio ambiente principalmente através de baterias de $\mathrm{Ni}-\mathrm{Cd}$. Os trocadores foram sintetizados via método sol-gel modificado da mistura de cloreto de estanho(IV) e cloreto de titânio(III) com hidróxido de amônio. Os materiais obtidos: $\mathrm{SnO}_{2} / \mathrm{TiO}_{2}$ e $\mathrm{SnO}_{2} / \mathrm{TiO}_{2}: \mathrm{Eu}^{3+}$ foram caracterizados via espectroscopia de infravermelho, análise térmica, microscopia eletrônica de varredura (MEV), difração de raios-X (DRX) (método do pó) e espectroscopia eletrônica (excitação e emissão) para o trocador dopado com európio. Os mesmo materiais também foram sintetizados em matriz polimérica para a sua utilização em coluna, devido os materiais sintetizados apresentarem tamanho de cristalito na escala nanométrica. Determinaram-se as razões de distribuição dos metais, tomando-se como parâmetros a influência do pH, da concentração dos metais (determinandose as isotermas de adsorção) e do tempo de contato (determinando-se a cinética de adsorção). Os trocadores apresentaram alta capacidade de troca, com porcentagens de adsorção acima de 90\%, cinética rápida, superfícies de troca energeticamente heterogenias, adsorção física e processo de troca espontâneo. Para o trocador dopado foram estudadas as propriedades espectroscópicas e calculado os parâmetros de intensidade também se obteve um rendimento quântico satisfatório.
\end{abstract}




\title{
SYNTHESIS AND CHARACTERIZATION OF INORGANIC ION EXCHANGERS BASED ON MIXED OXIDE TIN-TITANIUM TO BE USED IN RECOVERY OF CADMIUM AND NICKEL AND PHOTOLUMINESCENT STUDIES
}

\author{
Paula Pinheiro Paganini
}

\begin{abstract}
This work presents the synthesis, characterization and adsorption studies of inorganic ion exchangers based on mixed tin-titanium oxide for recovery of cadmium and nickel metals from aqueous effluents, discarded in the environment mainly through $\mathrm{Ni}-\mathrm{Cd}$ battery. The exchangers were synthesized by sol-gel modified method using a mixture of tin(IV) chloride and titanium(III) chloride and ammonium hydroxide, as precursors reagents. The materials obtained: $\mathrm{SnO}_{2} / \mathrm{TiO}_{2}$ e $\mathrm{SnO}_{2} / \mathrm{TiO}_{2}: \mathrm{Eu}^{3+}$ were characterized by infrared spectroscopy, thermal analysis, scattering electronic microscopy (SEM), X-ray powder diffraction (XRD) (powder method) and electronic spectroscopy (excitation and emission) for the europium doped exchanger. The same materials also were synthesized in polymeric matrix too and can be used in column, because the synthesized materials showed crystals size in nanometric scale. It was determined by the distribution ratios for metals taking as parameters the influence of $\mathrm{pH}$, the concentration of metals (by adsorption isotherms) and the contact time (by adsorption kinetic). The inorganic ion exchanger presented high exchange capacity with adsorption percent above $90 \%$ for the studied conditions, quickly kinetic, heterogeneous exchange surfaces, physic adsorption and spontaneous process of exchange. To the doped exchanger spectroscopy properties were studied and also it was calculated the intensity parameters and it was found a satisfactory quantum yield.
\end{abstract}




\section{SUMÁRIO}

Página

LISTA DE TABELAS

LISTA DE FIGURAS

1 INTRODUÇÃO

REFERENCIAS BIBLIOGRÁFICAS ................................................... 18

2 OBJETIVOS

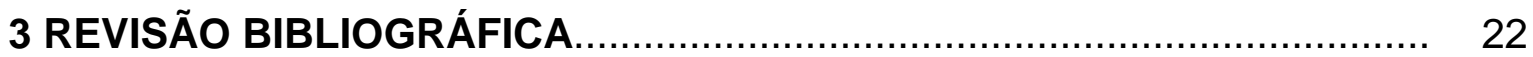

3.1 Trocadores iônicos inorgânicos......................................................... 22

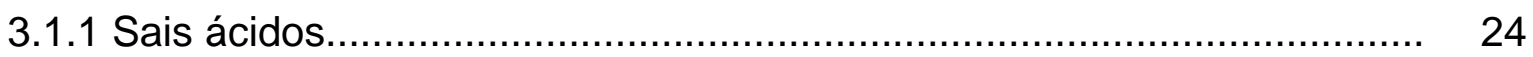

3.1.2 Ferrocianetos insolúveis.............................................................. 24

3.1.3 Aluminosilicatos sintéticos.............................................................. 25

3.1.4 Sais de heteropoliácidos.............................................................. 25

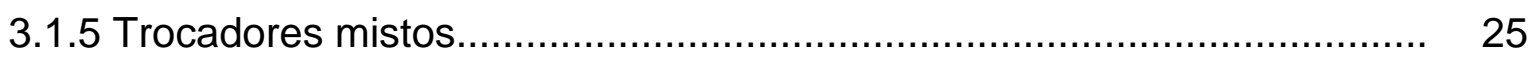

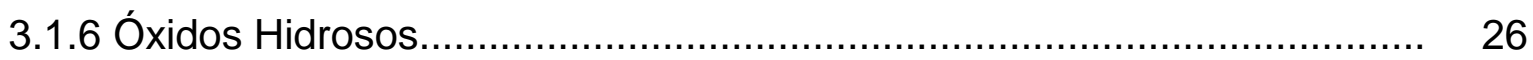

3.1.6.1 Óxido estânico................................................................................ 28

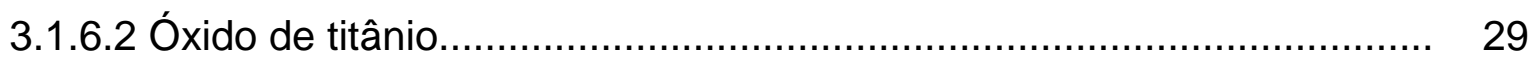

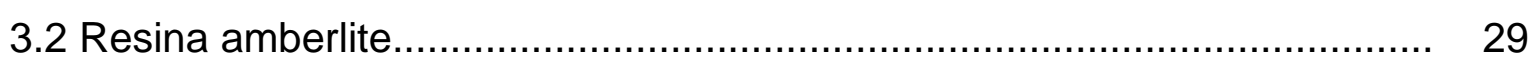

3.2.1 Regeneração e agentes eluentes....................................................... 31

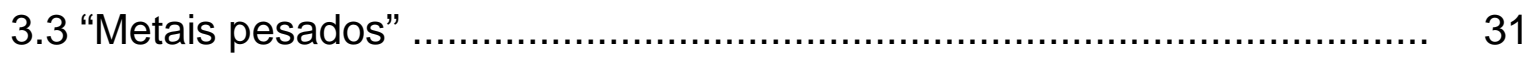

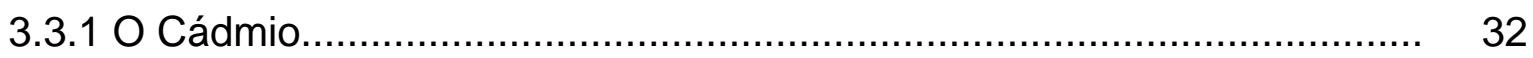

3.3.1.1 Ocorrência................................................................................ 33

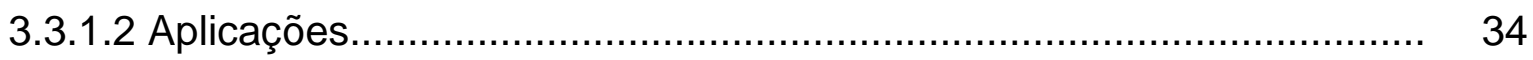

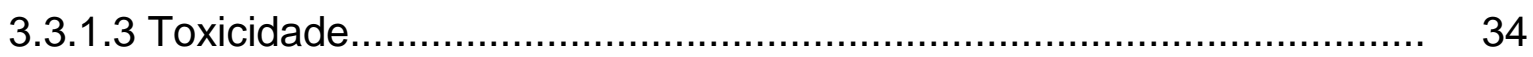

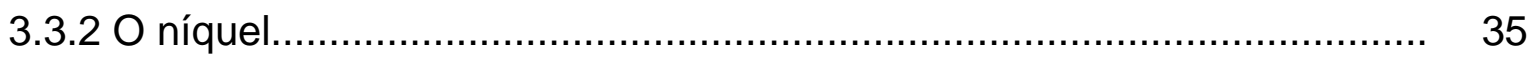

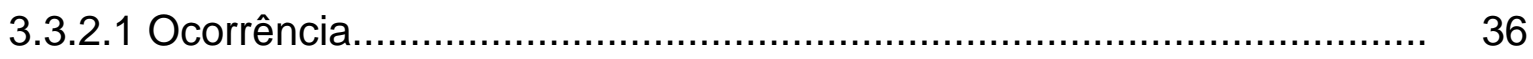

3.3.2.2 Aplicações.......................................................................... 37

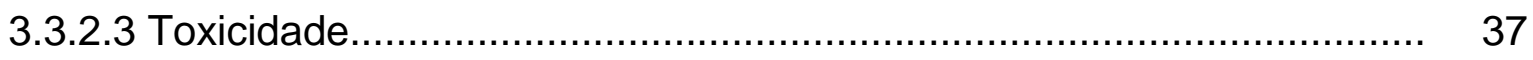

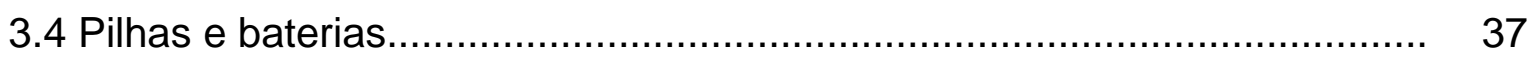

3.4.1 Reciclagem de baterias............................................................................. $\quad 39$ 
3.4.1.1 Reciclagem de baterias de $\mathrm{Ni}-\mathrm{Cd}$......................................................... 39

3.4.2 Baterias Ni-Cd: química e composição....................................................... 40

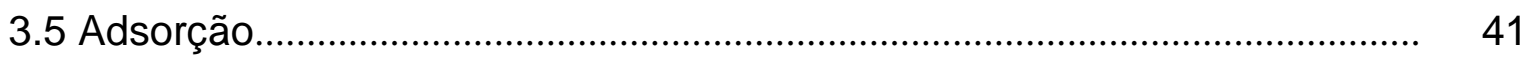

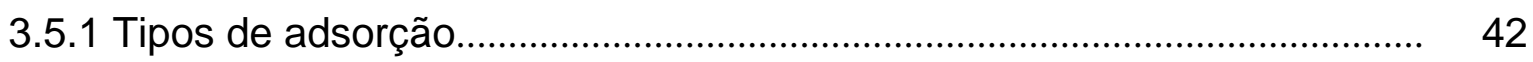

3.5.2 Isotermas de adsorção............................................................ 44

3.5.3 Modelos de isotermas de adsorção.......................................... 45

3.5.3.1 Modelo de Freundlich................................................................................ 45

3.5.3.2 Modelo de Langmuir............................................................................... 46

3.5.3.3 Modelo de Dubinin-Radushkevich (D-R) ............................................. 48

3.6 Espectroscopia de luminescência................................................... 50

3.6.1 A Absorção na região do UV-VIS............................................. 50

3.6.2 Estado eletrônico excitado singlete.............................................. 51

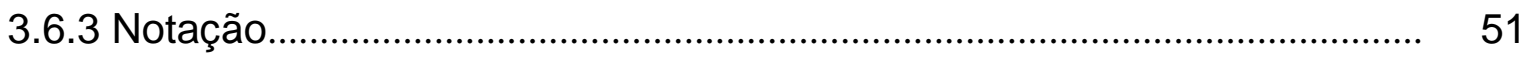

3.6.4 Análise de espectro.............................................................................. 52

3.6.5 Espectro de emissão................................................................................ 53

3.6.6 Espectro de excitação............................................................................ 54

3.6.7 Mecanismos de excitação e emissão.............................................. 55

3.6.8 Efeito das impurezas....................................................................... 56

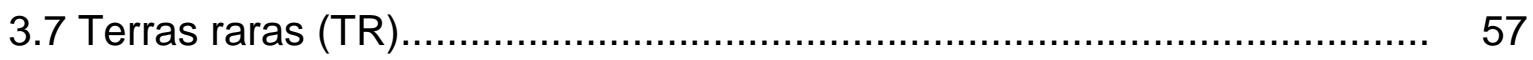

3.7.1 Fundamentos sobre Espectroscopia de Terras Raras......................... 59

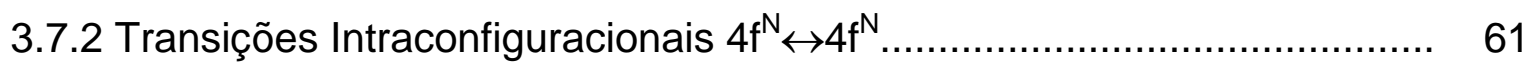

3.7.3 Regras de seleção................................................................... 62

3.7.3.1 Transições de dipolo elétrico (DE) ............................................... 63

3.7.3.2 Transições de dipolo magnético (DM) ..................................... 63

3.8 Materiais Luminescentes........................................................ 63

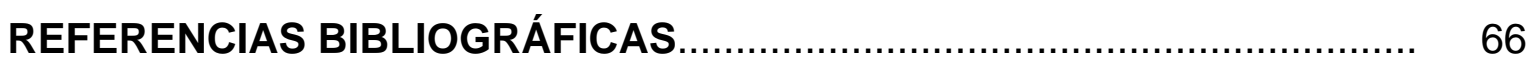

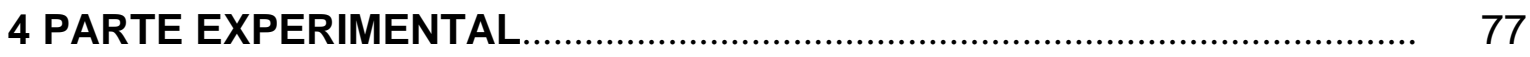

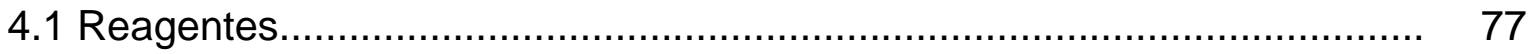

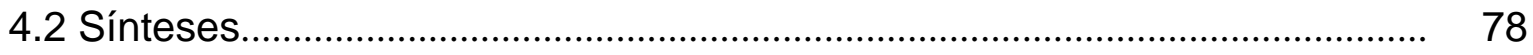

4.2.1 Síntese dos trocadores iônicos inorgânicos $\mathrm{SnO}_{2} / \mathrm{TiO}_{2}$ e

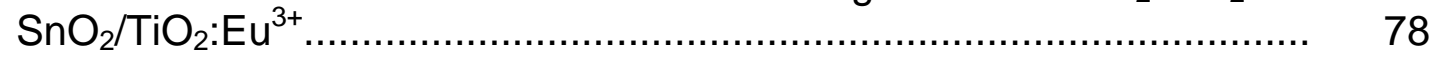

4.2.2 Síntese dos trocadores híbridos $\mathrm{SnO}_{2} / \mathrm{TiO}_{2}$ e $\mathrm{SnO}_{2} / \mathrm{TiO}_{2}: \mathrm{Eu}^{3+} \ldots \ldots \ldots \ldots \ldots . . . . . .78$ 
4.3 Caracterização.

4.3.1 Espectroscopia de infravermelho.............................................. 81

4.3.2 Difração de raios-X................................................................................ 81

4.3.3 Análise Térmica................................................................................... 81

4.3.4 Microscopia Eletrônica de Varredura............................................. 81

4.4 Estudo das variáveis de adsorção do $\mathrm{Cd}^{2+} \mathrm{e} \mathrm{Ni}^{2+}$ nos trocadores iônicos

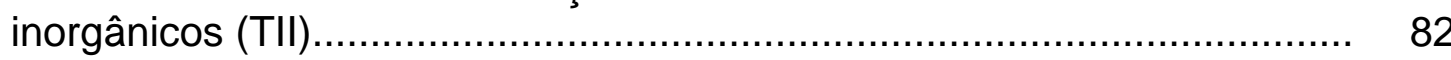

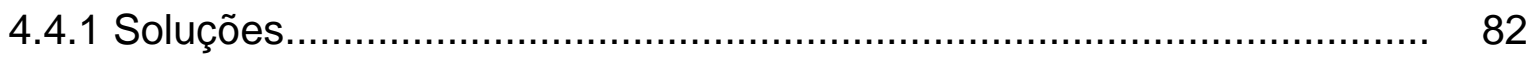

4.4.1.1 Análise de cádmio............................................................. 82

4.4.1.2 Análise de níquel................................................................ 83

4.4.2 Estudos de adsorção de cádmio pelos trocadores iônicos inorgânicos... 83

4.4.2.1 Estudo das variáveis.......................................................... 83

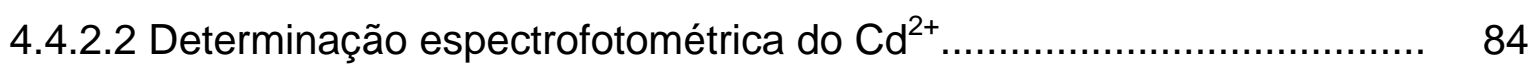

4.4.2.3 Determinação por espectrometria de fluorescência de raios-X ("EDXR")

4.4.3 Estudos de adsorção de níquel pelos trocadores iônicos inorgânicos..... 85

4.4.3.1 Estudo das variáveis......................................................... 85

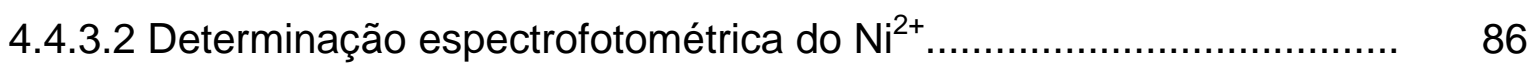

4.5 Espectroscopia de luminescência.................................................. 88

REFERÊNCIAS BIBLIOGRÁFICAS .............................................. 89

5 RESULTADOS E DISCUSSÕES .................................................. 90

5.1. Composto de $\mathrm{TiO}_{2} / \mathrm{SnO}_{2}$ e $\mathrm{TiO}_{2} / \mathrm{SnO}_{2}: \mathrm{Eu}^{3+}$ preparado pelo método sol-gel.

5.2. Caracterização dos óxidos mistos $\mathrm{TiO}_{2} / \mathrm{SnO}_{2}$ e $\mathrm{TiO}_{2} / \mathrm{SnO}_{2}: \mathrm{Eu}^{3+}$ e dos compósitos $\mathrm{TiO}_{2} / \mathrm{SnO}_{2}$ e $\mathrm{TiO}_{2} / \mathrm{SnO}_{2}: \mathrm{Eu}^{3+}$ preparados pelo método sol-gel.

5.2.1 Espectroscopia de infravermelho............................................. 91

5.2 .2 Difração de raios-X................................................................ 92

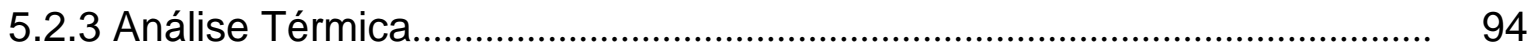

5.2.4 Microscopia Eletrônica de Varredura............................................... 99

5.3 Estudos de Adsorção................................................................ 100

5.3.1 Estudos de adsorção de $\mathrm{Cd}^{2+}$ pelos trocadores iônicos inorgânicos....... 100

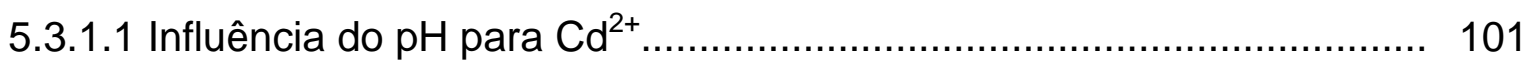

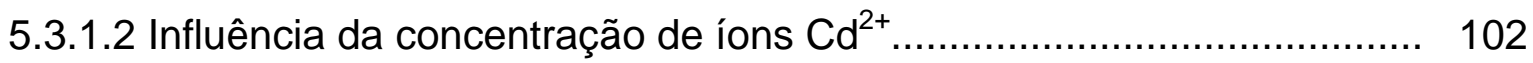




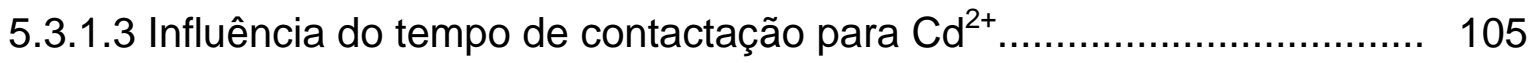

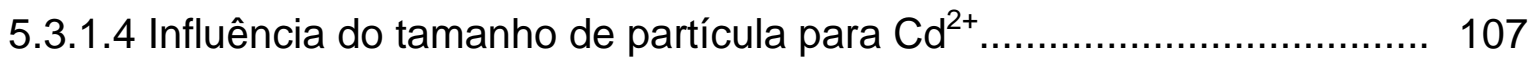

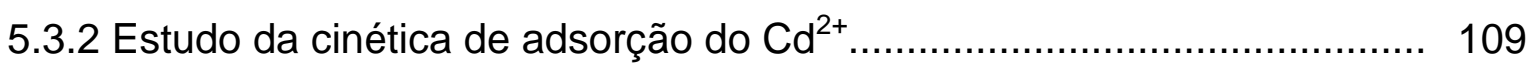

5.3.2.1 Aplicação do modelo cinético de Pseudo-Primeira Ordem para $\mathrm{Cd}^{2+} \ldots 111$

5.3.2.2 Aplicação do modelo cinético de Pseudo-Segunda Ordem para $\mathrm{Cd}^{2+}$.. 112

5.3.2.3 Aplicação do modelo cinético de Difusão intrapartícula para $\mathrm{Cd}^{2+} \ldots \ldots .115$

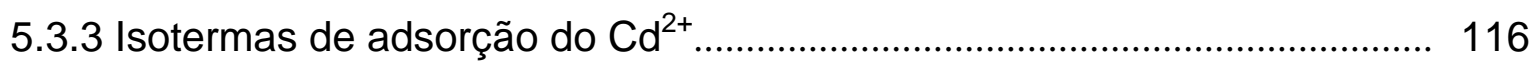

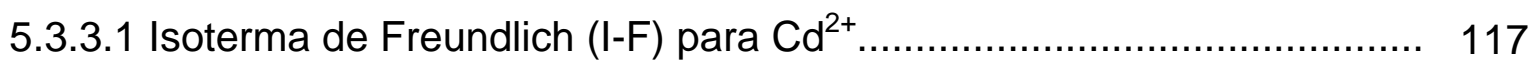

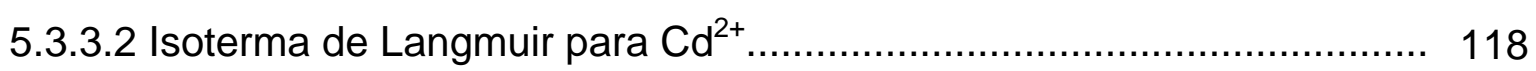

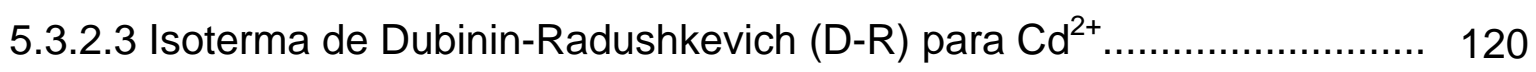

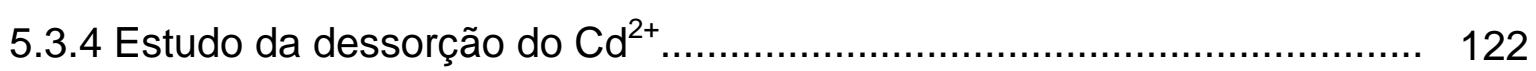

5.3.5 Estudos de adsorção de $\mathrm{Ni}^{2+}$ pelos trocadores iônicos inorgânicos........ 122

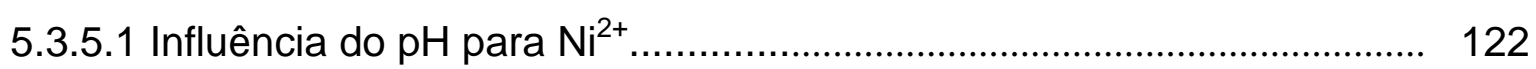

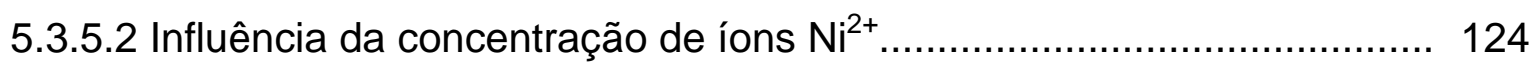

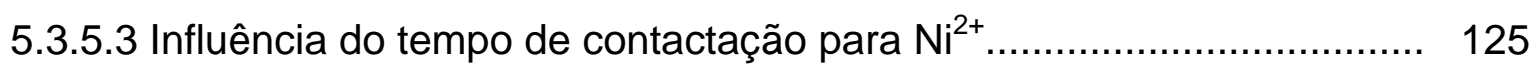

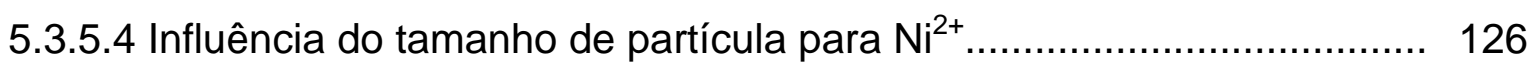

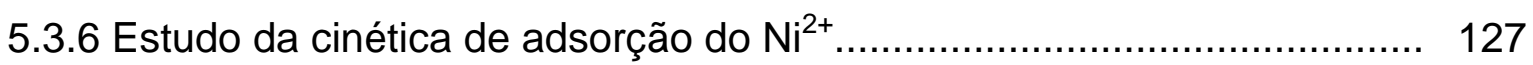

5.3.6.1 Aplicação do modelo cinético de Pseudo-Primeira Ordem para $\mathrm{Ni}^{2+} \ldots 127$

5.3.6.2 Aplicação do modelo cinético de Pseudo-Segunda Ordem para $\mathrm{Ni}^{2+} \ldots 128$

5.3.6.3 Aplicação do modelo cinético de Difusão Intrapartícula para $\mathrm{Ni}^{2+} \ldots \ldots \ldots 129$

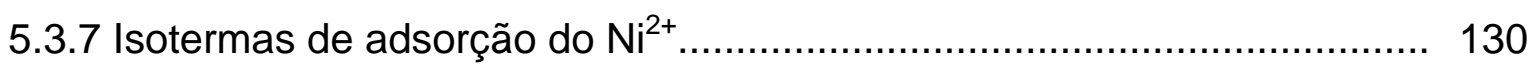

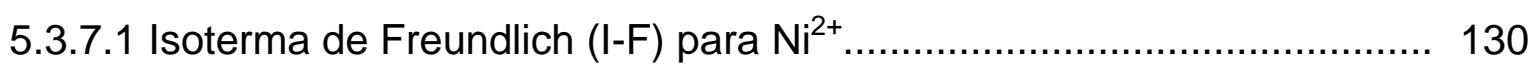

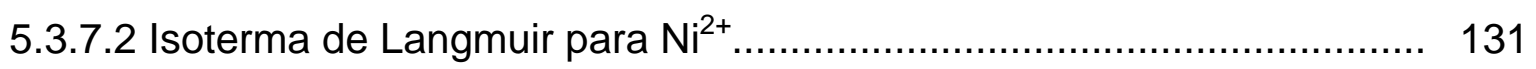

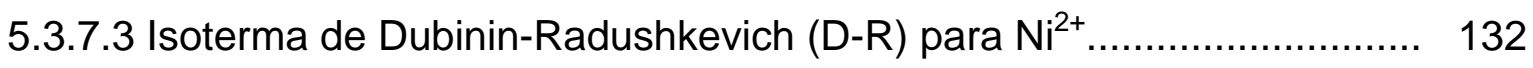

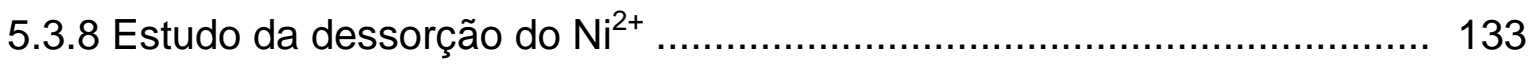

5.3.9 Influência do $\mathrm{Cd}^{2+}$, como interferente, na adsorção do $\mathrm{Ni}^{2+} \ldots \ldots \ldots \ldots \ldots \ldots . . . . . . .134$

5.4. Espectroscopia de luminescência.................................................. 135

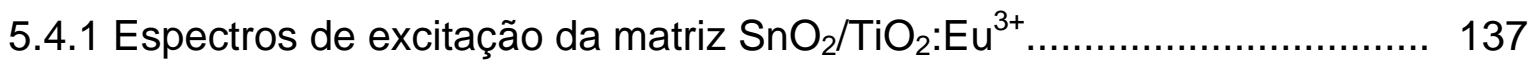

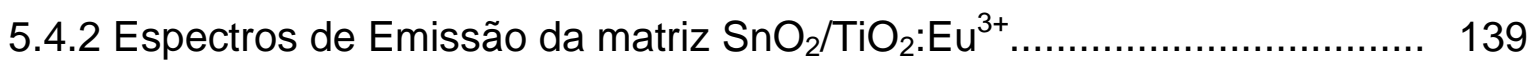

5.4.3 Parâmetros de intensidade experimentais do íon $\mathrm{Eu}^{3+} \ldots \ldots \ldots \ldots \ldots \ldots \ldots . . . . . . . . . . .141$

REFERENCIAS BIBLIOGRÁFICAS ............................................. 145

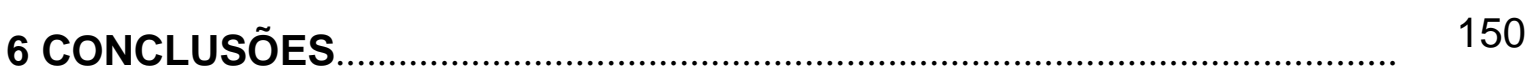




\section{LISTA DE TABELAS}

Página

TABELA 3.1 Principais diferenças entre a adsorção física e a adsorção química.

TABELA 3.2 Luminescência característica das transições ${ }^{5} \mathrm{D}_{0,1} \rightarrow{ }^{7} \mathrm{~F}_{\mathrm{J}}$ para complexos de Eu(III)....................................... 62

TABELA 4.1 Lista de reagentes utilizados nas etapas do trabalho.......... 77

TABELA 5.1 Parâmetros da equação de pseudo-segunda ordem para os trocadores híbridos na adsorção do $\mathrm{Cd}^{2+}$

TABELA 5.2 Parâmetros da equação de Freundlich para os trocadores na adsorção do $\mathrm{Cd}^{2+}$.

TABELA 5.3 Parâmetros da equação de Langmuir para os trocadores na adsorção do $\mathrm{Cd}^{2+}$

TABELA 5.4 Parâmetros da equação de Dubinin-Radushkevich (D-R) para os TII na adsorção do $\mathrm{Cd}^{2+}$

TABELA 5.5 Dessorção do $\mathrm{Cd}^{2+}$.

TABELA 5.6 Parâmetros da equação de pseudo-segunda ordem para os trocadores na adsorção do $\mathrm{Ni}^{2+}$....

TABELA 5.7 Parâmetros da equação de Freundlich para os trocadores na adsorção do $\mathrm{Ni}^{2+}$

TABELA 5.8 Parâmetros da equação de Langmuir para os trocadores na adsorção do $\mathrm{Ni}^{2+}$

TABELA 5.9 Parâmetros da equação de Dubinin-Radushkevich (DR) para os trocadores na adsorção do $\mathrm{Ni}^{2+}$.

TABELA 5.10 Dessorção do $\mathrm{Ni}^{2+}$.....

TABELA 5.11 Energias de transições dos microestados ${ }^{5} \mathrm{D}_{\mathrm{J}} \leftarrow{ }^{7} \mathrm{~F}_{\mathrm{J}}$ " (em $\mathrm{cm}^{-1}$ ) observadas nos espectros de excitação.

TABELA 5.12 Energias de transições dos microestados ${ }^{5} D_{\mathrm{J}}-{ }^{7} \mathrm{~F}_{\mathrm{J}}$ (em $\mathrm{cm}^{-1}$ ) observadas nos espectros de emissão.

TABELA 5.13 Parâmetros de intensidades experimentais e tempos de vida do estado emissor ${ }^{5} \mathrm{D}_{0}$ dos trocadores a base de estanho dopados com $\mathrm{Eu}^{3+}$ 


\section{LISTA DE FIGURAS}

Página

FIGURA 1.1 Ilustração de contaminação do solo com metais tóxicos e substâncias químicas por diferentes meios.... 15

FIGURA 1.2 Aplicação das terras raras em diferentes áreas de pesquisa..

FIGURA 3.1 a) zeolita tipo $A$, b) zeolita tipo $X$ e c)mecanismo de troca iônica.

FIGURA 3.2 Relação entre valência e raio iônico efetivo dos elementos....

FIGURA 3.3 Estrutura química da resina Amberlite XAD-7.

FIGURA 3.4 Gráfico da especiação de cádmio em função do pH em meio aquoso.

FIGURA 3.5 Curvas de distribuição das espécies em função do pH para o sistema, contendo 0,1 mmol de ácido fítico e 0,1 mmol de $\mathrm{Ni}(\mathrm{II}), \mu=0,100 \mathrm{~mol} / \mathrm{L}$ a $36^{\circ} \mathrm{C}$

FIGURA 3.6 Representação do processo de adsorção..

FIGURA 3.7 Formas mais comuns de isotermas de adsorção.

FIGURA 3.8 Diagrama de Jablonski para o sistema de níveis de energia para a molécula de benzeno.

FIGURA 3.9 Processo de excitação e emissão para um material hipotético.

FIGURA 3.10 Representação esquemática dos níveis de energia gerados por impurezas doadoras e aceptoras em um material semicondutor. Eg é a energia da banda gap.....

FIGURA 3.11 Diagramas parciais de energia para os íons $\mathrm{Eu}^{3+}\left(4 \mathrm{f}^{6}\right)$ mostrando a magnitude relativa das repulsões intereletrônicas, acoplamento spin-órbita e efeitos do campo cristalino.

FIGURA 3.12 Representação do processo de luminescência: a) um ativador $(A)$ excitado diretamente em uma rede hospedeira $(\mathrm{H})$; b)emissão do ativador $(\mathrm{A})$ excitado indiretamente pelo sensibilizador $(\mathrm{S})$ em uma rede hospedeira $(\mathrm{H})$.

FIGURA 4.1 Fluxograma de síntese dos trocadores $\mathrm{SnO}_{2} / \mathrm{TiO}_{2}$ e $\mathrm{SnO}_{2} / \mathrm{TiO}_{2}: \mathrm{Eu}^{3+}$ e foto da lavagem do precipitado com membrana de celofane.

FIGURA 4.2 Fluxograma de síntese dos trocadores híbridos $\mathrm{SnO}_{2} / \mathrm{TiO}_{2} \mathrm{e}$ $\mathrm{SnO}_{2} / \mathrm{TiO}_{2}: \mathrm{Eu}^{3+}$ 
FIGURA 4.3 Espectro de absorção do complexo ditizonato de cádmio....... 84

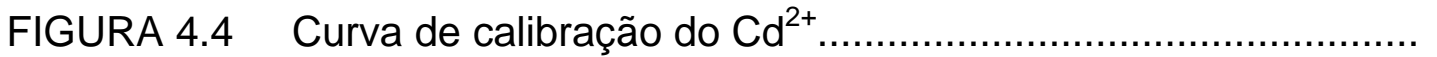

FIGURA 4.5 Espectro de absorção do complexo dimetilglioximato de níquel.

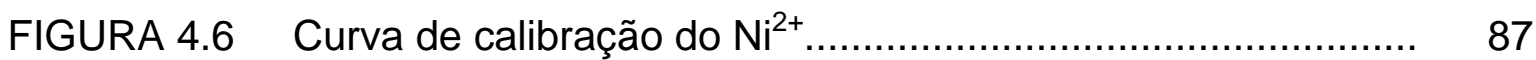

FIGURA 5.1 Foto do trocador $\mathrm{SnO}_{2} / \mathrm{TiO}_{2}: \mathrm{Eu}^{3+}$ sintetizado no formato pó....

FIGURA 5.2 Foto do trocador $\mathrm{SnO}_{2} / \mathrm{TiO}_{2}$ na matriz polimérica amberlite XAD-7.

FIGURA 5.3 Espectros de infravermelho dos trocadores $\mathrm{SnO}_{2} / \mathrm{TiO}_{2}$ e $\mathrm{TiO}_{2} / \mathrm{SnO}_{2}: \mathrm{Eu}^{3+}$

FIGURA 5.4 Difratogramas de raios-X dos trocadores $\mathrm{SnO}_{2} / \mathrm{TiO}_{2}$ e $\mathrm{SnO}_{2} / \mathrm{TiO}_{2}: \mathrm{Eu}^{3+}$

FIGURA 5.5 Curvas TGA e DTGA dos trocadores estudados.................... 95

FIGURA 5.6 Curvas TGA e DTGA dos trocadores híbridos........................ 96

FIGURA 5.7 Curvas DSC dos trocadores estudados............................... 97

FIGURA 5.8 Curvas DSC das matrizes suportadas com os trocadores estudados

FIGURA 5.9 MEVs dos trocadores $\mathrm{SnO}_{2} / \mathrm{TiO}_{2}(\mathrm{~A})$ e $\mathrm{SnO}_{2} / \mathrm{TiO}_{2}: \mathrm{Eu}^{3+}(\mathrm{B}) \ldots .$.

FIGURA 5.10 MEVs da matriz poliméricas suportadas com os trocadores $\mathrm{SnO}_{2} / \mathrm{TiO}_{2}(\mathrm{~A}),(\mathrm{C})$ e $\mathrm{SnO}_{2} / \mathrm{TiO}_{2}: \mathrm{Eu}^{3+}$ (B), (D).

FIGURA 5.11 Variação do pH em função do log Dw e da \% Adsorção para o $\mathrm{Cd}^{2+}$

FIGURA 5.12 Variação da concentração de $\mathrm{Cd}^{2+}$ em função do log Dw e da \% Adsorção em pH 4 para os trocadores não híbridos.

FIGURA 5.13 Variação da concentração de $\mathrm{Cd}^{2+}$ em função do log Dw e da \% Adsorção em pH 9 para os trocadores não híbridos......

FIGURA 5.14 Variação do tempo de contato em função do log Dw e da \% Adsorção para o $\mathrm{Cd}^{2+}$ em pH 4 nos trocadores híbridos.....

FIGURA 5.15 Variação do tempo de contato em função do log Dw e da \% Adsorção para o $\mathrm{Cd}^{2+} \mathrm{em}$ pH 9 nos trocadores híbridos.....

FIGURA 5.16 Variação da granulometria em função da adsorção do $\mathrm{Cd}^{2+}$ em pH 4 .

FIGURA 5.17 Variação da granulometria em função da adsorção do $\mathrm{Cd}^{2+}$ em pH 9 .

FIGURA 5.18 Variação da massa de $\mathrm{Cd}^{2+}$ adsorvida por massa de trocador $(\mathrm{g} / \mathrm{g})$ em função do tempo. 
FIGURA 5.19 Modelo de pseudo-primeira ordem para o trocador híbrido $\mathrm{SnO}_{2} / \mathrm{TiO}_{2}$ em pH 4 e pH 9 respectivamente para o $\mathrm{Cd}^{2+} \ldots \ldots$.

FIGURA 5.20 Modelo de pseudo-primeira ordem para o trocador híbrido $\mathrm{SnO}_{2} / \mathrm{TiO}_{2}: \mathrm{Eu}^{3+}$ em $\mathrm{pH} 4$ e $\mathrm{pH} 9$ respectivamente para o $\mathrm{Cd}^{2+}$

FIGURA 5.21 Modelo de pseudo-segunda ordem para o trocador híbrido $\mathrm{SnO}_{2} / \mathrm{TiO}_{2}$ em pH 4 e pH 9 respectivamente para o $\mathrm{Cd}^{2+} \ldots \ldots$.

FIGURA 5.22 Modelo de pseudo-segunda ordem para o trocador híbrido $\mathrm{SnO}_{2} / \mathrm{TiO}_{2}: \mathrm{Eu}^{3+}$ em $\mathrm{pH} 4$ e $\mathrm{pH} 9$ respectivamente para o $\mathrm{Cd}^{2+}$

FIGURA 5.23 Modelo de difusão intrapartícula para os trocadores híbridos em $\mathrm{pH} 4$ e pH 9 para o $\mathrm{Cd}^{2+}$

FIGURA 5.24 Isotermas de Freundlich para o trocador $\mathrm{SnO}_{2} / \mathrm{TiO}_{2}$ em $\mathrm{pH} 4$ e $\mathrm{pH} 9$ respectivamente para o $\mathrm{Cd}^{2+}$

FIGURA 5.25 Isotermas de Freundlich para o trocador $\mathrm{SnO}_{2} / \mathrm{TiO}_{2}: \mathrm{Eu}^{3+} \mathrm{em}$ $\mathrm{pH} 4$ e pH 9 respectivamente para o $\mathrm{Cd}^{2+}$

FIGURA 5.26 Isotermas de Langmuir para o trocador $\mathrm{SnO}_{2} / \mathrm{TiO}_{2}$ em $\mathrm{pH} 4 \mathrm{e} \mathrm{pH} 9$ respectivamente para o $\mathrm{Cd}^{2+}$

FIGURA 5.27 Isotermas de Langmuir para o trocador $\mathrm{SnO}_{2} / \mathrm{TiO}_{2}: \mathrm{Eu}^{3+} \mathrm{em}$ $\mathrm{pH} 4$ e pH 9 respectivamente para o $\mathrm{Cd}^{2+}$

FIGURA 5.28 Isotermas de D-R para o trocador $\mathrm{SnO}_{2} / \mathrm{TiO}_{2}$ em pH 4 e pH 9 respectivamente para o $\mathrm{Cd}^{2+}$

FIGURA 5.29 Isotermas de D-R para o trocador $\mathrm{SnO}_{2} / \mathrm{TiO}_{2}: \mathrm{Eu}^{3+}$ em pH 4 e $\mathrm{pH} 9$ respectivamente para o $\mathrm{Cd}^{2+}$

FIGURA 5.30 Variação de pH em função do log Dw e da \% Adsorção para $0 \mathrm{Ni}^{2+}$

FIGURA 5.31 Variação da concentração em função do log Dw e da \% Adsorção em $\mathrm{pH} 7$ para os trocadores estudados para o $\mathrm{Ni}^{2+}$.

FIGURA 5.32 Variação do tempo de contato em função do log Dw e da \% Adsorção em $\mathrm{pH} 7$ para os trocadores estudados para o $\mathrm{Ni}^{2+}$.

FIGURA 5.33 Variação da granulometria em função da adsorção em pH 7.. 125

FIGURA 5.34 Variação da massa de $\mathrm{Ni}^{2+}$ adsorvida por massa de trocador $(\mathrm{g} / \mathrm{g})$ em função do tempo.

FIGURA 5.35 Modelo de pseudo-primeira ordem para os trocadores híbridos $\mathrm{SnO}_{2} / \mathrm{TiO}_{2}$ e $\mathrm{SnO}_{2} / \mathrm{TiO}_{2}: \mathrm{Eu}^{3+}$ respectivamente em $\mathrm{pH} 7$ para o $\mathrm{Ni}^{2+}$

FIGURA 5.36 Modelo de pseudo-segunda ordem para os trocadores híbridos $\mathrm{SnO} 2 / \mathrm{TiO} 2$ e SnO2/TiO2:Eu3+ respectivamente em $\mathrm{pH} 7$ para o $\mathrm{Ni}^{2+}$ 
FIGURA 5.37 Modelo de difusão intrapartícula para os trocadores híbridos em $\mathrm{pH} 7$ para o $\mathrm{Ni}^{2+}$

FIGURA 5.38 Isotermas de Freundlich para os trocadores $\mathrm{SnO}_{2} / \mathrm{TiO}_{2}$ e $\mathrm{SnO}_{2} / \mathrm{TiO}_{2}: \mathrm{Eu}^{3+}$ respectivamente, em pH 7 para $\mathrm{Ni}^{2+}$

FIGURA 5.39 Isotermas de Langmuir para os trocadores $\mathrm{SnO}_{2} / \mathrm{TiO}_{2}$ e $\mathrm{SnO}_{2} / \mathrm{TiO}_{2}: \mathrm{Eu}^{3+}$ respectivamente, em pH 7 para $\mathrm{Ni}^{2+} \ldots \ldots \ldots \ldots . . . .132$

FIGURA 5.40 Isotermas de D-R para os trocadores $\mathrm{SnO}_{2} / \mathrm{TiO}_{2}$ e $\mathrm{SnO}_{2} / \mathrm{TiO}_{2}: \mathrm{Eu}^{3+}$ respectivamente, em pH 7..................... 133

FIGURA 5.41 Estudo da influência da concentração de $\mathrm{Cd}^{2+}$ na adsorção de $\mathrm{Ni}^{2+}$

FIGURA 5.42 Espectro de excitação com emissão monitorada em 614nm. 138

FIGURA 5.43 Espectro de excitação com emissão monitorada em 614nm para o trocador sem európio.

FIGURA 5.44 Espectro de emissão com excitação monitorada em 393nm... 140 


\section{INTRODUÇÃO}

Dentre os principais problemas enfrentados pela humanidade, atualmente, encontra-se em destaque a poluição do meio ambiente que tem desequilibrado os sistemas ecológicos naturais. O aumento desordenado da população e como conseqüência a industrialização da sociedade tem causado severos danos às nossas fontes naturais de água. Significantes quantidades de poluentes, especialmente íons de metais pesados, encontram seu caminho no sistema biológico (FIG 1.1). A contaminação do solo por metais pesados é um dos maiores problemas ambientais visto que ocorre a transferência desses para os organismos através da cadeia alimentar, pois algumas plantas são capazes de absorver e acumular esses metais em grande quantidade. O cádmio é um dos metais com maior grau de toxicidade e vem sendo espalhado no ambiente pelo desenvolvimento de atividades agroindustriais, metalúrgicas, da indústria química e também via processo de incineração do lixo. Mesmo os elementos necessários ao desenvolvimento de vegetais como zinco e níquel podem se tornar muito tóxicos devido à exposição demasiada. ${ }^{[1-5]}$

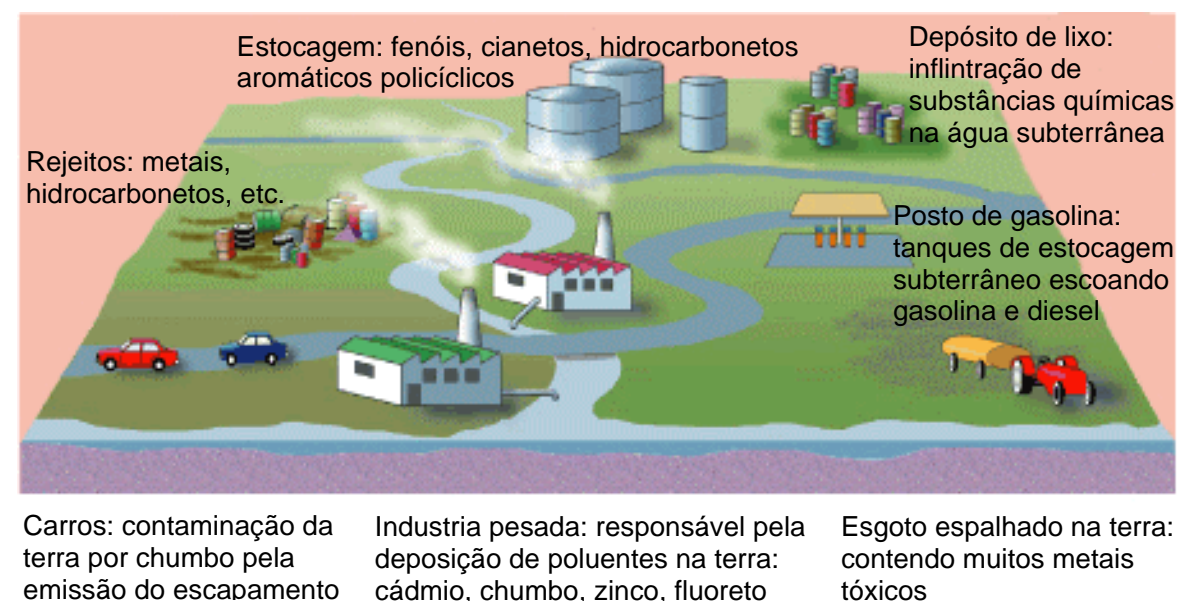

FIGURA 1.1 - Ilustração de contaminação do solo com metais tóxicos e substâncias químicas por diferentes meios. ${ }^{[6]}$ 
O fenômeno de adsorção/dessorção entre íons metálicos em solução aquosa e óxidos de metais hidratados na interface com a água são conhecidos e tidos como processo de grande importância no destino dos traços de íons metálicos no sistema aquático natural. ${ }^{[7,8]}$

Entre os adsorvedores mais utilizados encontram-se os trocadores iônicos inorgânicos, que normalmente apresentam uma alta capacidade e velocidade de troca iônica e são superiores às resinas orgânicas em sua estabilidade térmica, química e radioativa. Eles também apresentam alta seletividade para diferentes íons, podendo sofrer modificações por transformação química ou composição cristalográfica do material trocador. As propriedades dos íons trocadores também dependem do método e condições de preparação. ${ }^{[9,10]}$

Uma classe importante dos trocadores iônicos inorgânicos sintéticos são os óxidos precipitados a partir de sistemas aquosos, os chamados óxidos hidrosos, que são bastante utilizados na área de tecnologia de separação, aplicação catalítica, precursores de óxidos inorgânicos e processamento químico no ciclo do combustível nuclear. ${ }^{[11]} \mathrm{A}$ fácil troca de íons nas classes de compostos como as zeólitas, os óxidos hidratados e os fosfatos ácidos, pode ser entendida em termos da presença de gaiolas interconectadas, canais ou camadas de dimensões suficientes para permitir o transporte de íons. ${ }^{[12]}$

Os trocadores mistos pertencem a uma classe de adsorvedores desenvolvidos para melhorar processos de separação e concentrar ou remover íons metálicos de soluções. Alguns são formados como precipitados outros como géis que são lavados, secos e triturados antes de serem usados. Esses trocadores altamente seletivos têm a desvantagem de possuir pouca estabilidade física e grãos irregulares que limitam a sua utilização em colunas. Porém, essas desvantagens podem ser contornadas suportando esses trocadores inorgânicos em matrizes adequadas, por exemplo, resinas ou polímeros sintéticos. ${ }^{[11-16]}$

Os íons terras raras têm desempenhado funções importantes em diversas áreas de pesquisa. Nos últimos anos os trabalhos estão voltados para 0 desenvolvimento de materiais visando às seguintes aplicações: i) novos luminóforos para iluminação; ${ }^{[17]}$ ii) dispositivos eletroluminescentes com alta eficiência; ${ }^{[18]}$ 
iii) agente de contraste para ressonância magnética nuclear de imagem; ${ }^{[19]}$ iv) marcadores para proteínas e aminoácidos; ${ }^{[20]}$ v) sensores emissores de luz em fluoroimunoensaios; ${ }^{[21,22]}$ etc (FIG 2.1).

A utilização de terras raras em trocadores inorgânicos está sendo estudada pelo nosso grupo de pesquisa visto que estes íons, por exemplo, aumentam os sítios ácidos na estrutura de catalisadores, ${ }^{[23]}$ possibilitando uma melhor adsorção dos adsorbatos estudados.

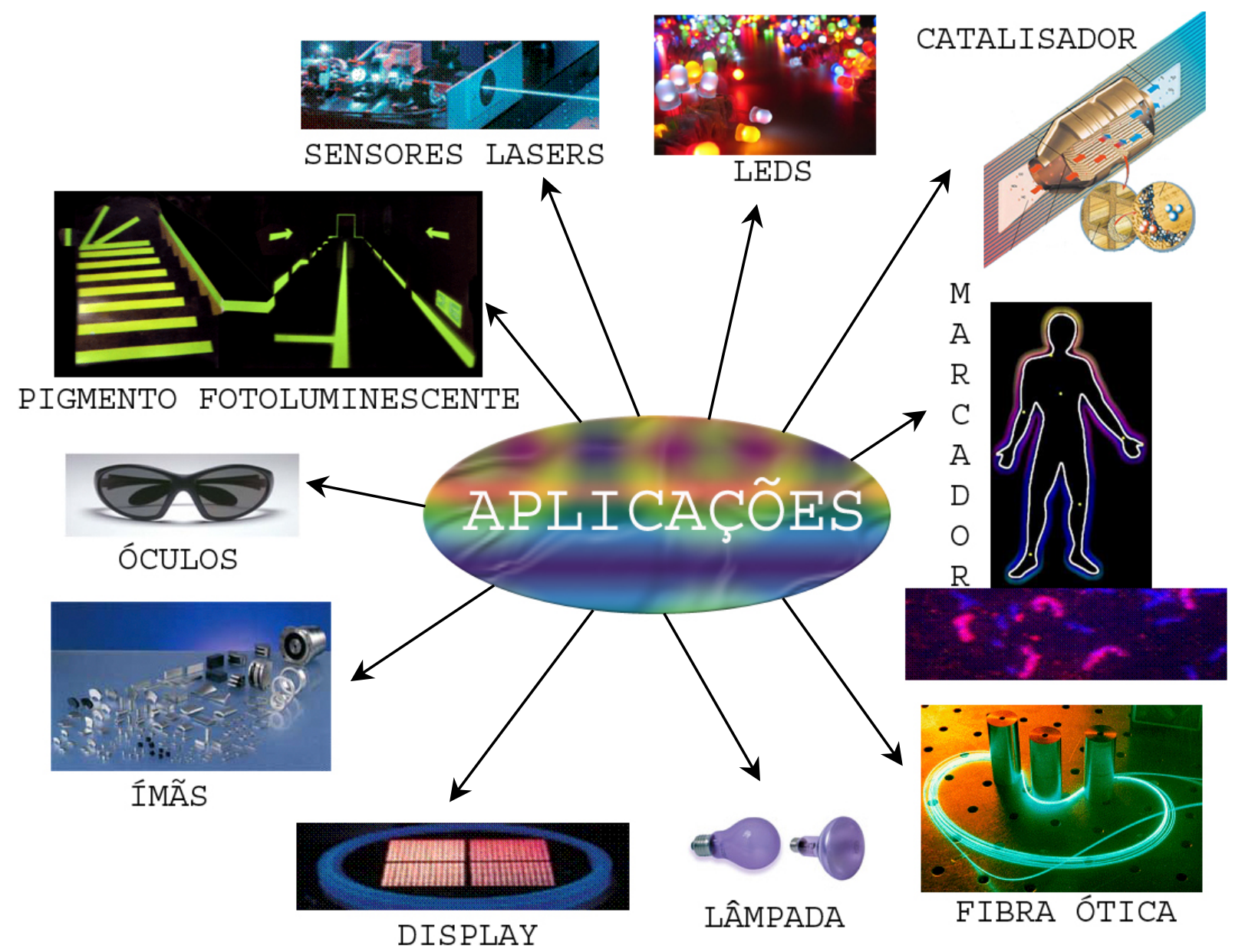

FIGURA 1.2 - Aplicação das terras raras em diferentes áreas de pesquisa. ${ }^{[24]}$ 


\section{REFERÊNCIAS BIBLIOGRÁFICAS}

[1] SOUZA, J. F.; MOBILON, C. ; CORTELAZZO, A. L. Alterações morfológicas em plântulas de rabanete e milho desenvolvidas na presença de Zinco, Cádmio ou Níquel. Instituto de Biologia, Unicamp, Campinas-SP. Disponível em: $<$ http://www.adaltech.com.br/evento/museugoeldi/resumoshtm/resumos/R0963-

2.htm> Acesso em: 25 out. 2006.

[2] COUTINHO, J.; CORTELAZZO, A. L. SILVA, T. R. G. Efeitos morfofisiológicos do Cádmio em plântulas de nabo e rabanete. Disponível em: $<$ http://www.puccamp.br/pesquisa/i_semana_cientifica/iniciacao_resumos/2506D5F5A461-4786-8644-CCC79F3CD950.pdf> Acesso em: 25 out. 2006

[3] AMBROSIO, R. C. E TICIANELLI, E. A. Baterias de níquel-hidreto metálico, uma alternativa para as baterias de níquel-cádmio. Química Nova, v. 24, n. 2, p. 243246, 2001.

[4] SOUZA, R. M. P.; LEÃO, V. A.; PINA, P. S. Remoção de metais pesados em resíduos sólidos: o caso das baterias de celular. Revista Escola de Minas, Ouro Preto, MG, v. 58, n. 4, p. 375-379, 2005.

[5] GONÇALVES, C. K.; TENÓRIO, J.A.S. Reciclagem de baterias de Ni-Cd extração por solventes. Disponível em:

<http://www.poli.usp.br/PesquisaPoli/Publicacoescpq/ProducaolC2002/deptos/pmt.ht m> Acesso em: 29 set. 2006.

[6] Contaminated Sites. Disponível em:

<http://soer.justice.tas.gov.au/2003/image/532/o-contaminated_sites-m.jpg> Acesso em: 31 ago. 2007.

[7] KUMAR, K. V. ; SUBANANDAM, K.; RAMAMURTHI, V. e SIVANESAN, S. Solid liquid adsorption for wastewater treatment: Principle design and operation. Disponível em: <http:// > Acesso em: 03 out. 2006.

[8] HEBENSTREIT, E. L. D.; HEBENSTREIT, W. and DIEBOLD, U. Adsorption of sulfur on $\mathrm{TiO}_{2}(110)$ studied with STM, LEED and XPS: temperature-dependent change of adsorption site combined with O-S exchange. Surface Science, v. 461, p.87-97, 2000. 
[9] PAGANINI, P. P. Estudo da adsorção do gálio em trocadores iônicos inorgânicos a base de estanho. 2004. Monografia (Conclusão de curso de Engenharia Química) - Faculdades Oswaldo Cruz, São Paulo.

[10] TAGLIAfERRO, G. V.; SILVA, M. L. C. P. E SILVA, G. L. J. P. Influência do agente precipitante na preparação do óxido de nióbio (v) hidratado pelo método da precipitação em solução homogênea. Química Nova, v. 28, n. 2, p. 250-254, 2005.

[11] SANTOS, J. L. Trocadores iônicos inorgânicos à base de manganês e potássio para recuperação e remoção de metais poluentes de efluentes aquosos. 2001. Dissertação (Mestrado) - Instituto de Pesquisas Energéticas e Nucleares, IPEN/CNEN-SP, São Paulo.

[12] SCHNITZLER, D. C.; MERUVIA, M. S.; HU"MMELGEN, I. A. AND ZARBIN, A. J. G. Preparation and Characterization of Novel Hybrid Materials Formed from (Ti,Sn)O2 Nanoparticles and Polyaniline. Chem. Mater. v.15, p. 4658-4665, 2003.

[13] CAO, L.; WAN, H.; HUO, L. and XI, S. A novel method for preparing ordered $\mathrm{SnO}_{2} / \mathrm{TiO}_{2}$ alternate nanoparticulates films. Journal of Colloid and Interface Science, v. 244, p. 97-101, 2001.

[14] SUBASRI, R. and SHINOHARA, T. Investigations on $\mathrm{SnO}_{2}-\mathrm{TiO}_{2}$ composite photoelectrodes for corrosion protection. Electrochemistry Communications, v. 5, p. 897-902, 2003.

[15] EDELMAN, F.; HAHN, H. et al. Structural evolution of $\mathrm{SnO}_{2}-\mathrm{TiO}_{2}$ nanocrystalline films for gas sensors. Materials Science and Engineering, v. B69-70, p. 386-391, 2000.

[16] SENSATO, F. R.; CUSTODIO, R.; LONGO, E.; BELTRAN, A. and ANDRES J. Electronic and structural properties of $\mathrm{Sn}_{\mathrm{x}} \mathrm{Ti}_{1-\mathrm{x}} \mathrm{O}_{2}$ solid solutions: a periodic DFT study. Catalysis Today, v. 85, p.145-152, 2003.

[17] JÜSTEL, T.; NIKOL, H.; RONDA, C.; New developments in the field of luminescent materials for lighting and displays. Angew. Chem., Int. Ed. Engl., v. 37 , n. 22, p. 3085-3103, 1998.

[18] CAPECCHI, S.; RENAULT, O.; MOON, D. G.; HALIM, M.; ETCHELLS, M.; DOBSON, P. J.; SALATA, O. V., CHRISOU V. High-efficiency organic electroluminescent devices using an organoterbium emitter. Adv. Mater, v. 12, n. 21, p. 1591, 2000. 
[19] CARAVAN, P.; ELLISON, J. J.; MCMURRY, T. J.; LAUFFER, R. B. Gadolinium(III) chelates as MRI contrast agents: Structure, dynamics, and applications. Chem. Rev., v. 99, n. 9, p. 2293-2352, 1999.

[20] YAM, V. W. W.; LO, K. K. W.; Recent advances in utilization of transition metal complexes and lanthanides as diagnostic tools. Coord. Chem. Rev., v. 184, p. 157240, 1999.

[21] PARKER, D.; Luminescent lanthanide sensors for $\mathrm{pH}, \mathrm{pO}_{2}$ and selected anions. Coord. Chem. Rev., v. 205, p. 109-130, 2000.

[22] HAMILLA, I. I.; STAHLBERG, T.; MOTTRAM, P.; Bioanalytical Applications of Labeling Technologies, Wallac Oy, Turku, 1995.

[23] Effects of Rare Earth Oxides in FCC Catalysts.

Disponível em: <http://www.refiningonline.com/engelhardkb/crep/TCR4_23.htm>. Acesso em: 3 jul. 2007.

[24] Pesquisa de imagens do Google. Disponível em: <http://www.google.com.br> Acesso em 31 ago. 2007. 


\section{OBJETIVOS}

O objetivo geral deste trabalho é desenvolver materiais inorgânicos à base de estanho para serem utilizados como trocadores inorgânicos em processos de tratamentos de efluentes que contém metais tóxicos, trabalho este que vem sendo desenvolvido pelo Centro de Química e Meio Ambiente do IPEN/SP além de realizar estudos fotoluminescentes com o trocador dopado com európio.

Como objetivos específicos tem-se:

A síntese de dois trocadores iônicos inorgânicos mistos, à base de estanho e titânio.

Caracterização dos trocadores utilizando-se as técnicas de espectroscopia de absorção na região do infravermelho, difração de raio-X, microscopia eletrônica de varredura e analise térmica.

O estudo do comportamento destes trocadores na recuperação de metais $(\mathrm{Cd}$ e $\mathrm{Ni}$ ) em efluentes industriais, representado pela capacidade de retenção dos trocadores, cinética de troca, curvas de adsorção, mecanismos de adsorção etc.

Estudar as propriedades espectroscópicas destes materiais, que apresentam característica de semicondutores e propriedades fotofísicas para se fazer uma prospecção quanto ao uso dos mesmos como materiais fotônicos. 


\section{REVISÃO BIBLIOGRÁFICA}

\subsection{Trocadores iônicos inorgânicos}

O primeiro experimento científico com trocadores iônicos inorgânicos foi feito por Thompson, Way e Eichhorn ${ }^{[1]}$ em meados do século IX, com um tipo de zeólita (chabazite). A fraca estabilidade química dos primeiros trocadores inorgânicos levou ao desenvolvimento e síntese de trocadores iônicos orgânicos nos anos 30 . Com poucas exceções, resinas orgânicas, baseadas na boa estabilidade química da coluna de poliestirenodivinilbenzeno (SDVB), substituíram os trocadores iônicos inorgânicos.

A necessidade das industrias nucleares por trocadores com alta seletividade, tolerância à radiação e a altas temperaturas foi a base para o avanço do desenvolvimento dos trocadores inorgânicos. Em meados dos anos 60, depois que as técnicas analíticas e o conhecimento dos processos de troca iônica tornaram-se disponíveis, novos materiais inorgânicos foram sintetizados e estudados com principal atenção na relação da estrutura do material com as propriedades do trocador. ${ }^{[2,3]}$ Muitos materiais inorgânicos foram sintetizados, estudados e testados para serem usados no tratamento de lixo radioativo. ${ }^{[4]}$ A partir dos anos 80 , o interesse industrial por trocadores inorgânicos cresceu rapidamente, pois, com o aumento da consciência ambiental surgiram regulamentações mais rígidas sobre descarte de lixo e métodos mais eficientes se tornaram necessários. ${ }^{[5]}$

Os trocadores iônicos inorgânicos normalmente apresentam uma alta velocidade e capacidade de troca, além de serem superiores às resinas orgânicas em sua estabilidade térmica e radiativa. Eles também apresentam alta seletividade para diferentes íons e pode ser modificado por transformação química ou composição cristalográfica do material trocador. As propriedades dos trocadores iônicos inorgânicos também dependem do método e das condições na preparação. 
Os trocadores inorgânicos estão divididos em dois grupos: os trocadores inorgânicos naturais e os trocadores inorgânicos sintéticos, que são os de interesse deste trabalho.

Entre os trocadores iônicos naturais, pode-se citar os solos que são capazes de atuar como trocadores iônicos. Segundo Kressman ${ }^{[6]}$, o cátion do mineral ativo do solo possui uma camada de estrutura cristalina. Muitos minerais possuem camadas cristalinas compostas de dois planos tetraédricos unidos em um octaedro plano, ficando os íons trocáveis entre as camadas destes planos. Para ocorrer a troca iônica em um mineral, a estrutura molecular precisa ser suficientemente aberta para permitir o acesso dos íons a serem trocados. Em geral apresentam pequena capacidade de troca. São atacados por ácidos e bases tendo sua capacidade de troca afetada por valores de $\mathrm{pH}$ diferentes de 7. ${ }^{[7]}$

Os trocadores iônicos sintéticos podem ser divididos em várias categorias: sais ácidos, ferrocianetos insolúveis, aluminosilicatos sintéticos, sais de heteropoliácidos, trocadores mistos e óxidos hidrosos.

Alguns materiais são classificados com base em suas propriedades físicas e químicas e caem em diversas categorias, muitas vezes não se pode definir precisamente a que classe ele pertence.

A FIG 3.1 ilustra modelos estruturais de zeolitas exemplificando a estrutura de trocadores inorgânicos e o mecanismo de troca iônica.
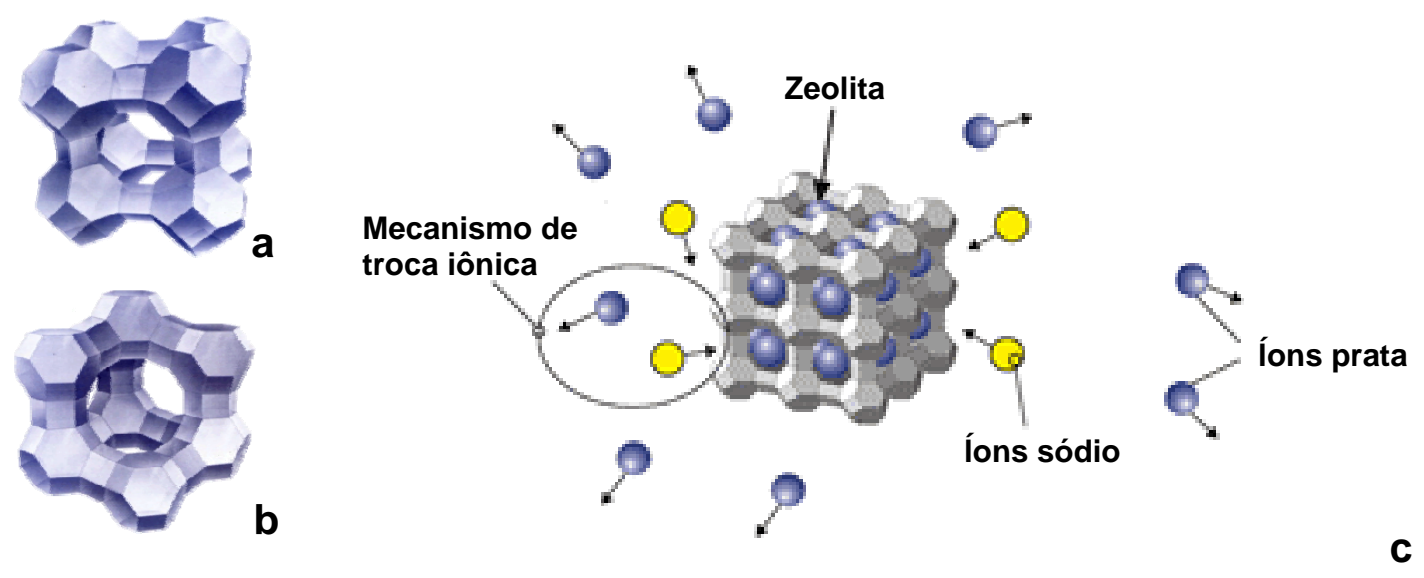

FIGURA 3.1 - a) zeolita tipo A, b) zeolita tipo X e c)mecanismo de troca iônica. ${ }^{[8,9]}$ 


\subsubsection{Sais ácidos}

Os sais ácidos são um grupo grande de trocadores iônicos e dentre os mais estudados estão aqueles com os cátions tetravalentes $\mathrm{Zr}$, Th, Ti, Sn, seguido por alguns cátions trivalentes como o $\mathrm{Al}$ e $\mathrm{Cr}$. Os ânions mais empregados são os fosfatos, arsenatos, antimoniatos, vanadatos, molibdatos, tungstatos, teluratos, silicatos, oxalatos, etc.

O cátion reage com o ânion formando sais cristalinos na forma de camadas, agindo como trocadores catiônicos. Estes trocadores têm a forma de gel ou estrutura microcristalina e sua composição e propriedades são facilmente modificadas pelas condições de sínteses. ${ }^{[4,10]}$

Sua composição muito provavelmente não é estequiométrica e a proporção de cátions, ânions e água varia muito afetando as propriedades iônicas de troca do material.

Para os grupos aniônicos os átomos de hidrogênio provavelmente são responsáveis pelas propriedades de troca iônica enquanto que a seletividade depende do tamanho do cátion trocador, da cavidade e da distância entre as camadas do material. Particularmente, a hidratação e a energia de troca iônica tem um grande efeito na seletividade da estrutura túnel-camada do material. Se o material tem uma alta densidade de carga ele pode remover total ou parcialmente a camada de hidratação do cátion, diminuindo o seu tamanho e permitindo o acesso a estrutura interna do material. ${ }^{[4]}$ Os sais ácidos de metais tetravalentes têm estrutura definida como $\mathrm{M}^{\mathrm{IV}}\left(\mathrm{HX}^{\mathrm{V}} \mathrm{O}_{4}\right)_{2} \cdot \mathrm{yH}_{2} \mathrm{O}$ e dentre os trocadores iônicos inorgânicos sintéticos são o grupo mais estudado. ${ }^{[11]}$

\subsubsection{Ferrocianetos insolúveis}

Os complexos hexacianoferratos podem ser sintetizados misturando solução de $\mathrm{H}_{4}\left[\mathrm{Fe}(\mathrm{CN})_{6}\right], \mathrm{Na}_{4}\left[\mathrm{Fe}(\mathrm{CN})_{6}\right]$ ou $\mathrm{K}_{4}\left[\mathrm{Fe}(\mathrm{CN})_{6}\right]$ com uma solução de sal de metal de transição, formando precipitados com várias composições sendo estas dependentes da proporção inicial dos reagentes, da acidez e da ordem de mistura.

Os ferrocianetos mais extensivamente estudados são os de metais divalentes, ou cátions como $\mathrm{UO}_{2}{ }^{2+} \mathrm{e} \mathrm{TiO}^{2+}$. Precipitados a partir de hexacianoferratos 
em meio neutro e alcalino foram estudados, mas com alguns grânulos de metais pesados os hexacianoferratos tomam um fator limite em torno de $\mathrm{pH} 13 .{ }^{[4]}$ Portanto são estáveis em meio ácido, mas observa-se progressiva hidrólise em meio alcalino. ${ }^{[11]}$

\subsubsection{Aluminosilicatos sintéticos}

Possuem propriedades de troca catiônica, sendo que sua principal diferença está na estrutura, podendo ser amorfos, com camada bidimensional (similar a argilas minerais) e os que possuem estrutura rígida e tridimensional como as zeólitas, ${ }^{[12]}$ sendo estas o grupo mais estudado.

\subsubsection{Sais de heteropoliácidos}

Os sais de heteropoliácidos são estáveis até em soluções concentradas de ácido, mas se dissolvem em solução alcalina. Possuem estrutura similar a das zeólidas, apresentando uma alta afinidade para metais alcalinos, tálio e prata.

A fórmula geral para este grupo é $\mathrm{M}_{n} \mathrm{XY}_{12} \mathrm{O}_{40} \cdot \mathrm{yH}_{2} \mathrm{O}(\mathrm{n}=3,4,5)$. O M pode ser $\mathrm{H}^{+}, \mathrm{Na}^{+}, \mathrm{NH}_{4}{ }^{+}$; o $X$ pode ser $\mathrm{P}, \mathrm{As}, \mathrm{Si}, \mathrm{B}$ ou $\mathrm{Ge}$ e o $\mathrm{Y}$ pode ser uma variedade de elementos tais como Mo, $\mathrm{W}$ ou $\mathrm{V} .{ }^{[12,13]}$

Um bom exemplo desta estrutura é o molibdofosfato $\left(\left(\mathrm{NH}_{4}\right)_{3} \mathrm{PMo}_{12} \mathrm{O}_{40}\right.$, AMP), que é conhecido por ser muito seletivo a grandes cátions monovalentes em condições ácidas. ${ }^{[14]}$ Esta estrutura cristalina é também cúbica e constituída de unidades aniônicas $\left[\mathrm{P}\left(\mathrm{Mo}_{3} \mathrm{O}_{10}\right)_{4}\right]^{3-}$, que formam uma estrutura com canais interconectados. Os cátions $\mathrm{NH}_{4}{ }^{+}$ocupam as cavidades relativamente grandes. Apesar da alta seletividade por césio, o pH de uso limite do AMP para soluções ácidas devido à dissolução do molibdênio na estrutura é $\mathrm{pH}>6$. ${ }^{[15]}$

\subsubsection{Trocadores mistos}

As combinações de óxidos têm sido estudadas especialmente por Rawat e Singh ${ }^{[16]}$ e Quresh et al. ${ }^{[17]}$, e cada um segue um modelo distinto de seletividade. Essas combinações incluem $\mathrm{Zr}^{4+}-\mathrm{Sb}^{5+}, \mathrm{Fe}^{3+}-\mathrm{As}^{5+} ; \mathrm{Sn}^{4+}-\mathrm{Sb}^{5+} ; \mathrm{Bi}^{3+}-\mathrm{W}^{6+}$; $\mathrm{Sn}^{4+}-\mathrm{V}^{5+}-\mathrm{As}^{5+}$, etc. Muitas destas combinações têm o inconveniente de serem 
altamente poluentes em água e possuírem pouca estabilidade física, o que as torna difícil de utilizar em colunas. Algumas são formadas como precipitados outras como géis que são lavados, secos e quebrados antes de serem usados. Os precipitados são geralmente refluxados antes da filtração para proporcionar o crescimento dos cristais.

Esta classe de adsorvedores foi desenvolvida para melhorar processos de separação e concentrar ou remover íons metálicos de soluções. Esses trocadores são altamente seletivos, mas além de apresentarem pouca estabilidade física possuem grãos irregulares que limitam sua utilização em coluna, porém isto pode ser contornado suportando estes trocadores em matrizes adequadas, como por exemplo, resinas ou polímeros sintéticos. ${ }^{[18]}$

\subsection{6 Óxidos Hidrosos}

Os óxidos precipitados a partir de sistemas aquosos, os chamados óxidos hidrosos, são uma importante classe de trocadores iônicos inorgânicos sintéticos e bastante utilizados na área de tecnologia de separação, aplicação catalítica e processamento químico no ciclo do combustível nuclear. ${ }^{[11]}$

Em princípio os óxidos hidrosos e hidróxidos de metais polivalente no sistema metal oxido-água comportam-se como trocadores catiônicos ou aniônicos, dependendo da basicidade do átomo do metal central e da força da ligação metaloxigênio em relação à ligação hidrogênio-oxigênio no grupo hidroxila. A concentração de um ácido aumenta com o aumento dos átomos de oxigênio por hidrogênio substituído e com a eletronegatividade do átomo central. $\mathrm{O}$ aumento da combinação dos átomos de oxigênio com o metal central provoca o aumento na concentração do ácido.

Se óxidos hidrosos e hidróxidos são empregados no material de um trocador iônico, estes materiais devem ser estáveis na solução em uma extensa região abaixo de $\mathrm{pH}$ 7. Para ilustrar este princípio, o raio iônico efetivo do metal central nos óxidos são plotados em função da valência do metal na FIG.3.2. Os metais com valência baixa e raio grande são solúveis em hidróxidos (região I), enquanto metais com valência alta e raio pequeno são solúveis em oxiácidos 
(região III). Metais na região intermediária são óxidos hidrosos ou hidróxidos insolúveis. Os óxidos listados na região II são mais adequados para o uso como materiais para troca iônica. ${ }^{[2]}$

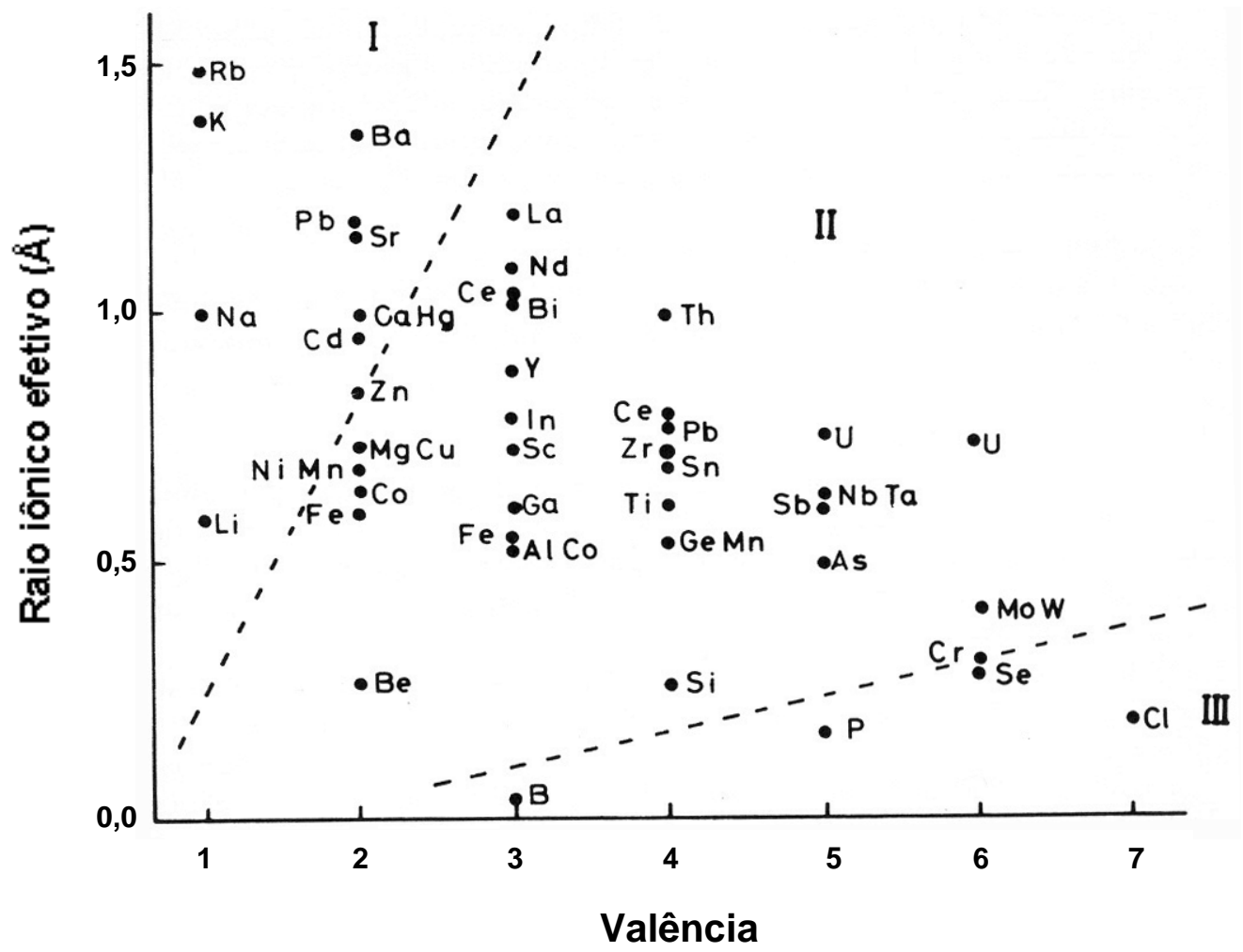

FIGURA 3.2 - Relação entre valência e raio iônico efetivo dos elementos.

Genericamente falando os óxidos dos elementos da região II são obtidos por adição em excesso de base na solução de seus sais. Os precipitados gelatinosos então obtidos, embora freqüentemente representados por $\mathrm{SiO}_{2}, \mathrm{SnO}_{2}, \mathrm{TiO}_{2}, \mathrm{ThO}_{2} \mathrm{e}$ $\mathrm{ZrO}_{2}$, não são por definição exatamente sólidos. Suas composições químicas e propriedades dependem do método de preparação, bem como de um maior tratamento do precipitado gelatinoso. Produtos amorfos são mais comumente obtidos dessas precipitações, mas é também possível, em alguns casos, obter formas cristalinas. ${ }^{[2]}$

As propriedades de troca iônica desses óxidos são de particular interesse devido à maioria deles possuir comportamento anfótero. Esses grupos podem ser dissociados de acordo com as equações: 


$$
\begin{aligned}
\mathrm{M}-\mathrm{OH} & \leftrightarrow \mathrm{M}^{+}+\mathrm{OH}^{-} \\
\mathrm{M}-\mathrm{OH} & \leftrightarrow \mathrm{M}^{-} \mathrm{O}^{-}+\mathrm{H}^{+}
\end{aligned}
$$

Onde M é o átomo central.

Reações favorecidas em pH baixo são características de troca aniônica (equação 3.1) e em pH alto de troca catiônica (equação 3.2). ${ }^{\text {[10] }}$

Óxidos de elementos tetravalentes são, na maior parte, trocadores anfóteros. Abe e Ito ${ }^{[19]}$ deduziram as seguintes séries de afinidade:

$$
\mathrm{SiO}_{2}>\mathrm{MnO}_{2}>\mathrm{SnO}_{2}>\mathrm{TiO}_{2}>\mathrm{ZrO}_{2}>\mathrm{CeO}_{2}>\mathrm{ThO}_{2}
$$

O material mais usado entre os óxidos hidratados é a sílica gel. Os diferentes grupos de hidrogéis e xerogéis são os compostos mais estudados em comparação com outros materiais de troca iônica do grupo do óxido.

Os óxidos hidrosos são classificados em dois grupos principais: um formado pela maior parte dos metais do grupo 3, 4, 13 e 14 em que a troca ocorre somente na surperfície como os óxidos de zircônio e estanho chamados de partículas hidratadas e outro geralmente formados pelo metais do grupo 5 e $15 \mathrm{em}$ seus estados de oxidação mais altos, no qual os óxidos possuem cavidades ou túneis como os de antimônio chamados de estruturas hidratadas.

As partículas hidratadas caracterizam-se por terem uma estrutura semelhante aos óxidos cerâmicos, porém, sua superfície é totalmente revestida com grupos hidroxilas e moléculas de água coordenadas e ligadas ao hidrogênio. [20] Essas partículas, especialmente os óxidos de zircônio e titânio, têm sido bastante utilizadas em aplicações catalíticas. ${ }^{[13,20,21]}$ Nas estruturas hidratadas os íons hidrônio estão distribuídos entre os sítios cristalográficos. Essas estruturas são geralmente mal cristalizadas, porém tratamentos hidrotérmicos ou refluxo em meio ácido melhoram a cristalinidade desses materiais. ${ }^{[13,20]}$

\subsubsection{1 Óxido estânico}

Óxido estânico, $\mathrm{SnO}_{2}$, comporta-se tanto como trocador catiônico como aniônico. ${ }^{[22,23]}$ Esses trocadores foram usados para separação de elementos de 
transição bivalentes. ${ }^{[24]} \mathrm{A}$ série de seletividade é $\mathrm{Cu}(\mathrm{II})>\mathrm{Zn}(\mathrm{II})>\mathrm{Co}(\mathrm{II})>\mathrm{Fe}(\mathrm{II})>$ $\mathrm{Ni}($ II $)>\mathrm{Mn}$ (II) seguindo a ordem de constante de equilíbrio de reações hidrolíticas:

$$
\mathrm{M}^{2+}+\mathrm{H}_{2} \mathrm{O} \leftrightarrow \mathrm{M}(\mathrm{OH})^{+}+\mathrm{H}^{+}
$$

O mecanismo de retenção de cátion poderia ser descrito em termos de processo de hidrólise. Cátions de metais alcalinos terrosos são fracamente

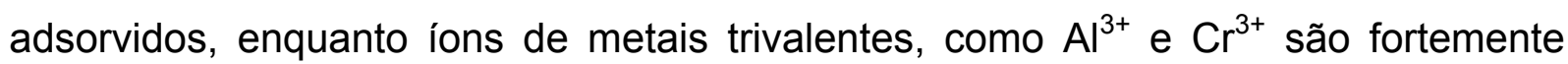
adsorvidos.

\subsubsection{2 Óxido de titânio}

Óxido de titânio é muito usado em operação de colunas e pode ser facilmente regenerado para reuso. ${ }^{[25]}$

No processo de titulação, foi obtida uma curva com três pontos finais característicos, indicando o caráter polifuncional do trocador. ${ }^{[26,27]}$ Isto mostrou que o óxido de titânio hidroso possui 3 prótons de troca para cada 10 átomos de titânio e uma constante de dissociação para cada etapa de dissociação.

A capacidade de troca do óxido de titânio hidroso, assim como para outros

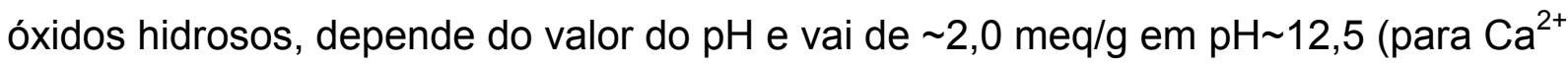
e $\mathrm{Sr}^{2+}$ ) a $\sim 1,5 \mathrm{meq} / \mathrm{g}$ em pH 4 (para $\mathrm{Co}^{2+}, \mathrm{Ni}^{2+}$ e $\mathrm{Cu}^{2+}$ ). A série de afinidade obtida para íons de metais alcalinos $\mathrm{Na}^{+}>\mathrm{Rb}^{+}>\mathrm{Cs}^{+}$e um íon de metal de transição coincidem com outras estabilidades do complexo, $\mathrm{Cu}>\mathrm{Ni}>\mathrm{Co}$. Um número de constante de equilíbrio termodinâmico foi determinado para diferentes sistemas de isortemas de adsorção de 3 etapas de troca. ${ }^{[28]}$

\subsection{Resina amberlite}

Como dito anteriormente problema com o empacotamento de coluna pode ser contornado suportando estes trocadores em matrizes adequadas, como por exemplo, resinas ou polímeros sintéticos. O trocador em estudo foi suportado na resina polimérica Amberlite XAD-7. 
A resina Amberlite XAD-7 é um material macroreticular acrílico, apresenta área superficial grande ${ }^{[29]} \mathrm{e}$ interage favoravelmente com compostos de massa molar baixa e polaridade intermediária. É composta de éster acrílico (momento dipolo 1,8). A FIG 3.3 apresenta a estrutura da resina Amberlite XAD-7.

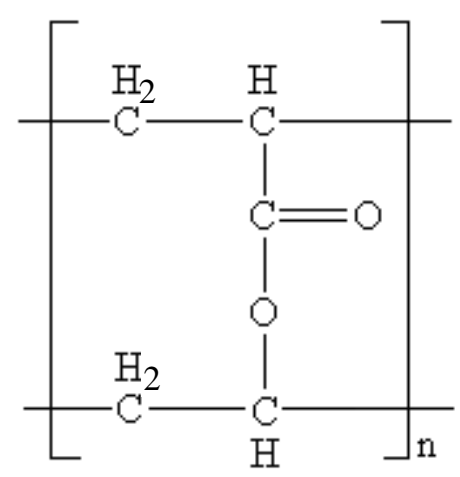

FIGURA 3.3 - Estrutura química da resina Amberlite XAD-7.

A resina apresenta-se como esferas brancas translúcidas, às vezes com coloração levemente amarela. São estáveis por vários anos quando bem estocadas, a temperatura ambiente. Elas são geralmente embebidas em produtos como sais de cloreto de sódio e carbonato de sódio para retardar crescimento de bactérias. Estes sais devem ser extraídos da malha da resina antes do uso como absorventes.

Três parâmetros afetam a capacidade da resina para materiais específicos: o momento dipolo, o tamanho do poro e a área superficial. O material a ser adsorvido necessita migrar pelos poros na superfície adsorvente. Para adsorventes de tamanho de poros iguais, uma grande área superficial tem maior capacidade para solutos.

Há uma relação inversa entre a área superficial e o tamanho do poro: quanto menor o tamanho do poro, maior a área superficial.

As resinas XAD não-polares são geralmente usadas para adsorção de substâncias orgânicas de sistemas aquosos e solventes polares. Para compostos hidrofóbicos com massa molecular (MM) até 20.000, a resina XAD-2 foi muito usada, embora tenha sido descartada por Rohm e Haas. ${ }^{[30]}$

Recomenda-se que para massa molecular relativamente baixa utilize-se XAD-4; para MM pequena e média, XAD-16 e para MM relativamente grande, X1180. 
XAD-7 é a única resina XAD "moderadamente polar" disponível no mercado atualmente. Ela é usada na remoção de compostos polares de solventes não-aquosos, para extrair compostos não-aromáticos de solventes polares, na remoção de poluentes orgânicos de efluentes aquosos, lençóis freáticos e jatos de

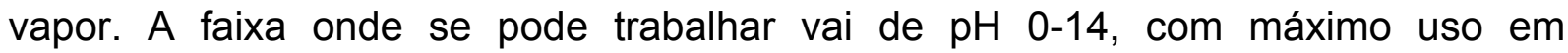
temperatura $149^{\circ} \mathrm{C}$. Um produto similar é Diaion HP2MG, que tem maior diâmetro de poro, embora a área superficial seja semelhante. Essa é usada para adsorver moléculas até MM 60.000 e é utilizada para recuperar insulina, íons metálicos, filtrar rejeito sólido, remoção e recuperação de orgânicos e recuperação de antibiótico.

\subsubsection{Regeneração e agentes eluentes}

Estas resinas são normalmente regeneradas usando metanol ou outro solvente orgânico miscível em água (acetona, isopropanol etc). Se ácidos fracos forem adsorvidos, bases diluídas $(0,1-0,5 \% \mathrm{NaOH})$ são efetivas; inversamente, se bases forem adsorvidas, ácidos diluídos $(0,1-0,5 \% \mathrm{HCl})$ são recomendados. A água pode ser usada depois da adsorção em uma solução iônica. $A$ água quente ou no estado de vapor é geralmente útil para materiais voláteis. [31] Como dito anteriormente a XAD-7 é comercializada úmida e contendo os sais cloreto de sódio e carbonato de sódio para evitar a proliferação de bactérias e fungos. Estes sais devem ser removidos antes da utilização do adsorvente, ${ }^{[30,31]}$ assim a limpeza e ativação do suporte sólido constituem uma etapa de purificação que visa eliminar possíveis interferentes e/ou contaminantes presentes na resina, assim como garantir que os sítios ativos estejam livres para que ocorra o processo de adsorção. [32]

\section{3 "Metais pesados"}

O termo "metais pesados" é freqüentemente usado com a conotação de poluição e toxicidade, isto provoca uma grande confusão em sua definição, visto o significado do termo em si, "pesado", em uso convencional implica em alta densidade, "metal", em uso convencional refere-se ao elemento puro ou uma liga de elemento metálico. Conhecimento de densidade contribui pouco para a previsão de efeitos biológicos de metais, especialmente metais elementares ou suas ligas. 
Nenhum órgão, como por exemplo, IUPAC, definiu o termo "metais pesados". Durante 60 anos foi muito usado em química, obtendo muitos significados sem sentido, por diferentes autores. Sendo definido em termos de densidade (gravidade específica), peso atômico (relativo à massa atômica), número atômico, outras propriedades químicas, toxicidade e sem definição química (usado antes de 1936). Porém, nenhuma relação pôde ser encontrada entre densidade (gravidade específica) ou qualquer outro conceito físico-químico e a toxicidade ou ecotoxicidade que possa definir "metais pesados".

Entender a biodisponibilidade é a chave para estimar o potencial tóxico dos elementos metálicos e seus compostos. Disponibilidade depende de parâmetros biológicos e das propriedades físico-químicas dos elementos metálicos, seu íons e compostos. Estes dependem da estrutura atômica do elemento metálico, que é sistematicamente descrita pela tabela periódica. ${ }^{[33]}$

Portanto do ponto de vista químico, a denominação metal pesado não é muito apropriada. Dada a baixa concentração em meios ambientais são conhecidos freqüentemente como metais traço ou elementos traço, ${ }^{[34]}$ por exemplo, o limite máximo de nível de cádmio e níquel em efluentes aquosos é de $0,02 \mathrm{mg} \cdot \mathrm{L}^{-1}$ e $1,0 \mathrm{mg} \cdot \mathrm{L}^{-1}$ respectivamente. ${ }^{[35]}$

\subsubsection{Cádmio}

O cádmio, membro da segunda série dos metais de transição é muito semelhante ao zinco em se tratando de suas propriedades químicas e físicas. É um metal cinza esbranquiçado, mais dúctil e de fusão inferior ao zinco. Seu principal uso está no revestimento do ferro, no qual pode ser depositado como uma camada bem lisa que, como no caso do revestimento de zinco, protege cationicamente o ferro e é auto restaurável quando sofre arranhões.

Na maior parte de seus compostos, o cádmio exibe apenas o número de oxidação 2+. Em soluções alcalinas o $\mathrm{Cd}^{2+}$ é precipitado como $\mathrm{Cd}(\mathrm{OH})_{2}$, o qual, distintamente do $\mathrm{Zn}(\mathrm{OH})_{2}$, não é anfótero. Todavia, o $\mathrm{Cd}(\mathrm{OH})_{2}$ irá se dissolver em solução de $\mathrm{NH}_{3}$ para formar um aminocomplexo. $\mathrm{O}$ cádmio forma íons complexos 
tetraédricos semelhantes em muitos aspectos aos de zinco, entretanto, seus complexos com ligantes haletos são mais estáveis.

O cádmio apresenta um comportamento incomum, pois forma numerosos "sais fracos", os quais não se dissociam completamente em água. Por exemplo, medidas de condutividade mostram a existência de espécies do tipo $\mathrm{CdCl}^{+}$e $\mathrm{CdCl}_{2}$ em uma solução de cloreto de cádmio. Os compostos de cádmio apresentam alta toxicidade. ${ }^{[36]}$ Os cloreto, nitrato e sulfato de cádmio são solúveis em água; o sulfeto é insolúvel e apresenta uma coloração amarela característica. ${ }^{[37]}$

Na FIG 3.4 apresenta-se as espécies de cádmio em função do pH.

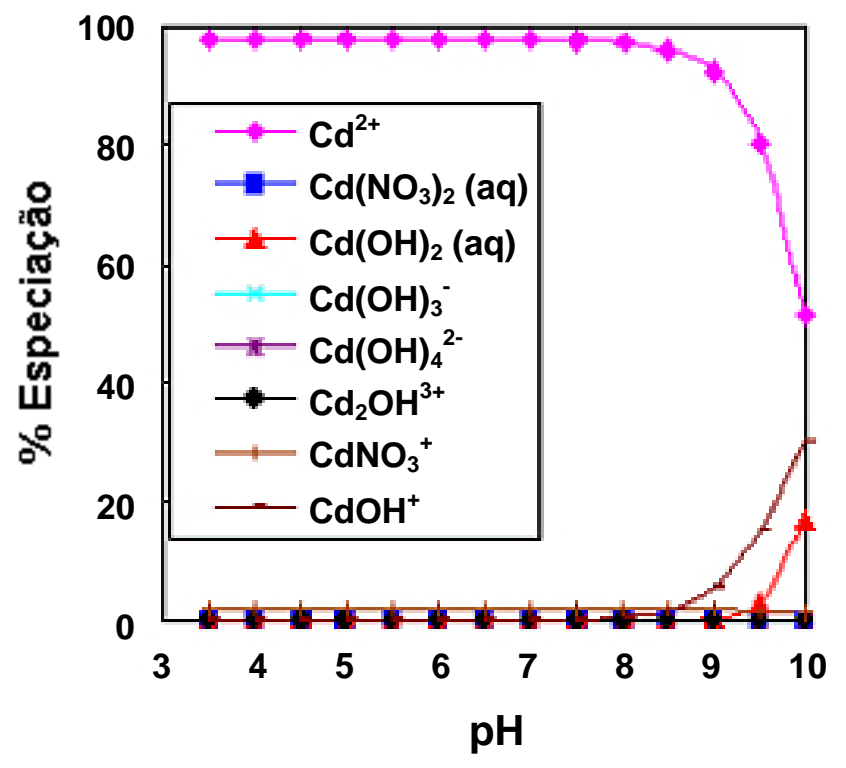

FIGURA 3.4 - Gráfico da especiação de cádmio em função do pH em meio aquoso.

\subsubsection{Ocorrência}

O cádmio é um elemento relativamente raro e sua abundância na litosfera estima-se em cerca de 0,5 ppm. Não existem minerais que contenham cádmio em quantidades comerciais, obtendo-se sempre como produto secundário da extração de outros elementos. O mineral mais comum é a greenockite, rica em sulfureto de cádmio, que ocorre associado ao sulfureto de zinco. Quase todos os depósitos de zinco contêm cádmio, apesar de a concentração deste não ultrapassar cerca de $1 \%$. ${ }^{[38]}$ 


\subsubsection{Aplicações}

Aproximadamente $75 \%$ de cádmio produzido é empregado na fabricação de baterias, especialmente nas baterias de níquel-cádmio; uma parte importante é empregada em galvanoplastia (como revestimento), além de ser empregado em pigmentos (em forma de sais, por exemplo, o sulfeto de cádmio é empregado como pigmento amarelo); em algumas ligas metálicas de baixo ponto de fusão; em ligas revestidas, devido a ser muito resistente à fadiga pelo fato do seu coeficiente de friç̧ão ser baixo; em muitos tipos de solda; em barras de controle em fissão nuclear; em televisores (alguns compostos fosforescentes de cádmio); em alguns semicondutores e em estabilizantes de plásticos como, por exemplo, no PVC.

\subsubsection{Toxicidade}

O cádmio é um metal que produz efeitos tóxicos nos organismos vivos, mesmo em concentrações muito pequenas. A exposição ao cádmio nos humanos ocorre geralmente através de duas fontes principais: a primeira é por via oral (por água e ingestão de alimentos contaminados), e a segunda por inalação. Os fumantes são os mais expostos ao cádmio porque os cigarros contêm este elemento.

Pequenas quantidades de cádmio são encontradas naturalmente no ar, na água, no solo e nos alimentos. Para a maioria das pessoas, a comida é a principal fonte de exposição ao cádmio porque muitos alimentos tendem a absorvê-lo e retêlo. As plantas absorvem este elemento principalmente do solo e da água.

A aplicação de certos fertilizantes ou de excrementos de animais no solo destinado ao cultivo de alimentos pode aumentar o nível de cádmio que, por sua vez, causa um aumento no nível deste elemento nos produtos cultivados. O cádmio não é encontrado em quantidades preocupantes na água, entretanto esta pode ser contaminada quando flui através de encanamentos soldados com materiais que contêm este metal ou quando entra em contato com lixos químicos.

A fonte mais importante de descarga do cádmio para o meio ambiente é através da queima de combustíveis fósseis (como carvão e petróleo) utilizados na incineração de lixo doméstico. O cádmio também contamina o ar quando se fundem rochas para extrair zinco, cobre ou chumbo. Trabalhar ou viver nas proximidades de 
uma destas fontes contaminantes pode resultar numa exposição significativa ao cádmio.

Apesar do Cd não ser essencial para o organismo dos mamíferos ele segue os mesmos caminhos no organismo de metais essenciais ao desenvolvimento como o zinco e o cobre. ${ }^{[39]}$

O cádmio entra na corrente sanguínea por absorção no estômago ou nos intestinos logo após a ingestão do alimento ou da água, ou por absorção nos pulmões após a inalação. Muito pouco cádmio entra no corpo através da pele. Usualmente só é absorvido pelo sangue aproximadamente 1 a $5 \%$ do cádmio ingerido por via oral, entretanto é absorvido de 30 a $50 \%$ quando inalado. ${ }^{[40]}$

A meia-vida do cádmio em seres humanos é de 20-30 anos, ele se acumula principalmente nos rins, no fígado e nos ossos, podendo levar a disfunções renais e osteoporose. ${ }^{[39]}$

\subsubsection{0 níquel}

O níquel é um metal duro, de cor prata-esbranquiçada, seu estado de oxidação mais comum é +2 , e a cor verde das soluções dos sais de níquel em água deve-se à presença de íons $\left[\mathrm{Ni}\left(\mathrm{H}_{2} \mathrm{O}\right)_{6}\right]^{2+}$. ${ }^{[41]}$

Quando uma base forte é adicionada a uma solução de $\mathrm{Ni}^{2+}$, precipita o hidróxido niqueloso, verde, $\mathrm{Ni}(\mathrm{OH})_{2}$. $\mathrm{O} \mathrm{Ni}(\mathrm{OH})_{2}$ não é anfótero, mas se dissolverá em amônia para formar aminocomplexos, tal como o $\left[\mathrm{Ni}\left(\mathrm{NH}_{3}\right)_{6}\right]^{2+}$. O Ni(II) forma complexos aniônicos, neutros e catiônicos. As geometrias incluem octaedro, tetraedro, quadrado-planar, e mesmo bipirâmide tetragonal. ${ }^{[36]}$

Em soluções aquosas de cloreto de níquel(II) têm-se cristais verdes hexahidratados. A estrutura do cristal ${ }^{[42]}$ de $\mathrm{NiCl}_{2} \cdot 6 \mathrm{H}_{2} \mathrm{O}$ contém unidades trans$\left[\mathrm{NiCl}_{2}\left(\mathrm{H}_{2} \mathrm{O}\right)_{4}\right]$, comprimento das ligações $\mathrm{Ni}-\mathrm{Cl}$ e $\mathrm{Ni}-\mathrm{O}$ são 2,38 e $2,10 \AA$ respectivamente. $\mathrm{O}$ complexo hexahidratado obedece a lei de Curie-Weiss sobre $6 \mathrm{~K}$ $\operatorname{com} \theta \sim 10 \mathrm{~K}$. Evaporação de soluções aquosas de cloreto de níquel (II) em torno de $40{ }^{\circ} \mathrm{C}$ obtém cristais tetrahidratado $\mathrm{NiCl}_{2} .4 \mathrm{H}_{2} \mathrm{O}$; este é também obtido quando soluções aquosas saturadas são tratadas com cloreto de hidrogênio. $O$ complexo dihidratado $\mathrm{NiCl}_{2} \cdot 2 \mathrm{H}_{2} \mathrm{O}$ é preparado facilmente por evaporação de uma solução de 
cloreto de níquel (II) a $75^{\circ} \mathrm{C}$. Ele tem uma estrutura bastante complicada consistente de cadeias poliméricas em que átomos de níquel são cercados por quatro cloretos em um plano quadrado distorcido e duas moléculas de água; as cadeias poliméricas são ligadas por ligações de hidrogênio. ${ }^{[42,43]} \mathrm{Na}$ FIG 3.5 apresenta-se as espécies de níquel em função do $\mathrm{pH}$.

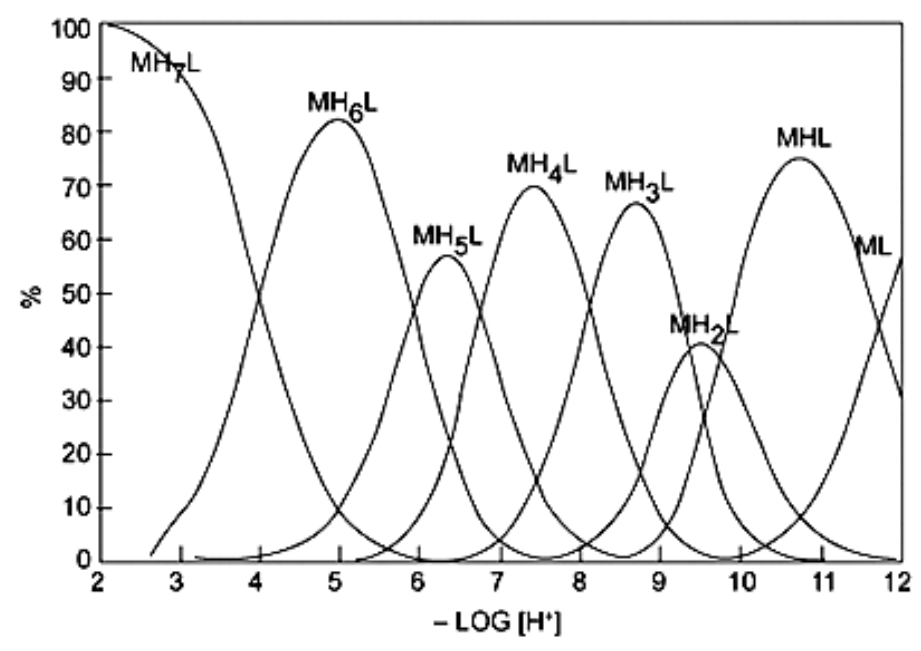

FIGURA 3.5 - Curvas de distribuição das espécies em função do pH para o sistema, contendo $0,1 \mathrm{mmol}$ de ácido fítico e $0,1 \mathrm{mmol}$ de $\mathrm{Ni}(\mathrm{II}), \mu=0,100 \mathrm{~mol} / \mathrm{L}$ a $36^{\circ} \mathrm{C}$. ${ }^{[44]}$

\subsubsection{Ocorrência}

O níquel ocorre numa estimativa de $0,016 \%$ a 10 milhas $(1,609 \mathrm{Km})$ de profundidade da crosta terrestre, classificado em vigésimo quarto na ordem de abundância dos elementos na crosta. A quantidade total de níquel é maior que a de cobre, zinco e chumbo combinados. Mas há relativamente poucos depósitos de níquel conhecidos que são capazes de serem economicamente usados. Minérios de níquel estão distribuídas em 3 classe - sulfetos, óxidos e silicatos, e arsenatos. ${ }^{[45]}$

Baseando-se em evidências geofísicas e análises de meteoritos é suposto que o níquel na forma de metal ocorra em abundância no núcleo terrestre, formando ligas metálicas com o ferro (kamacita e taenita). O níquel e o vanádio são os elementos-traço mais comuns encontrados na composição química do petróleo, em geral estando mais enriquecidos nos óleos pesados. Em combinação com outros 
elementos é encontrado em diversos minerais como garnierita, millerita, pentlandita e pirrotina. ${ }^{[46]}$

\subsubsection{Aplicações}

O Ni é usado principalmente na produção de aço inoxidável e em liga com o cobre para produzir os cuproníqueis, que são usadas em moedas (cuja composição é de cerca de $25 \%$ de níquel e $75 \%$ de cobre). A coloração amarelada dos cuproníqueis é removida por adição de pequenas quantidades de cobalto. $O$ níquel também é usado nas baterias de níquel-cádmio e como catalisador, especialmente na adição de hidrogênio a compostos orgânicos. Um exemplo é a fabricação de gorduras sólidas comestíveis por hidrogenação de óleos vegetais. ${ }^{[41]}$

\subsubsection{Toxicidade}

A exposição ao metal níquel e seus compostos solúveis não deve superar aos $0,05 \mathrm{mg} / \mathrm{cm}^{3}$, medidos em níveis de níquel equivalente para uma exposição labor de 8 horas diárias e 40 horas semanais. Os vapores e o pó de sulfeto de níquel suspeita-se que sejam carcinogênicos.

$\mathrm{O}\left(\mathrm{Ni}(\mathrm{CO})_{4}\right)$, gerado durante o processo de obtenção do metal, é um gás extremamente tóxico.

As pessoas sensíveis podem manifestar alergias ao níquel sendo que a quantidade de níquel admissível em produtos que podem entrar em contato com a pele está regulamentada na União Européia. ${ }^{[45]}$

\subsection{Pilhas e baterias}

As baterias recarregáveis possuem uma grande demanda devido à suas inúmeras aplicações, seja em uso doméstico em aparelhos eletrônicos portáteis, como por exemplo, celulares, computadores, telefones sem fio, filmadoras, câmeras fotográficas etc, quanto em uso industrial, podendo-se destacar sua utilização em veículos elétricos, equipamentos médicos de emergência e em aviação. ${ }^{[46]}$

As baterias $\mathrm{Ni}-\mathrm{Cd}$ eram as mais usadas há alguns anos atrás, porém, como apresentam problemas ambientais devido à presença do cádmio outros tipos 
de baterias recarregáveis portáteis começaram a ser desenvolvidas e vêm substituindo estas baterias, são elas as baterias de $\mathrm{NiMH}$ e mais atualmente, as baterias de lítio. Tendo em vista as milhares de toneladas que foram produzidas de bateria $\mathrm{Ni}-\mathrm{Cd}$ sem a completa reciclagem, além de muitos aparelhos antigos ainda no mercado, requerendo este tipo de bateria, elas continuam sendo uma ameaça ao meio ambiente e à saúde humana. Pode-se destacar também a reciclagem das novas baterias de $\mathrm{Ni}-\mathrm{MH}$, visto seu alto custo de produção e o alto valor agregado devido à presença de níquel, cobalto e terras raras. ${ }^{[47]}$

Baterias são dispositivos que utilizam uma reação química para produzir uma corrente elétrica e dependendo do tipo de elementos químicos envolvidos definem-se algumas características. O tipo de reação define inclusive a diferença de potencial em sua célula, isto é, a tensão elétrica fornecida. As baterias podem ser divididas em dois tipos: baterias primárias e baterias secundárias. Baterias primárias quando não são recarregáveis e baterias secundárias se são recarregáveis.

Usa-se a bateria primária em equipamentos que não podem sofrer manutenção, ou em que a mesma seria muito difícil, como sondas submarinas ou em alguns satélites. Em outros satélites e sondas espaciais pode-se ainda usar células foto-voltaicas para gerar energia a partir da luz solar e recarregar suas baterias. As baterias primárias mais conhecidas são as de Carbono-Zinco, as Alcalinas de Manganês e as de Lítio.

As secundárias são mais usadas para casos em que as primárias necessitem ser trocadas muitas vezes. Apesar das primárias serem muito mais baratas, em médio prazo as secundarias podem ser reaproveitadas e são preferíveis, se o fator custo for o único envolvido. As secundárias mais usadas são as de Chumbo-ácido (como em automóveis), Níquel-Cádmio ( $\mathrm{Ni}-\mathrm{Cd}$ ) e Níquel Metal Hidreto $(\mathrm{Ni}-\mathrm{MH})$, e mais recentemente, $\mathrm{Li}^{+}$(íon de Li). ${ }^{[48]}$

Entre as pilhas recarregáveis os dois principais tipos utilizados são as de níquel-cádmio e as de níquel-metal-hidreto. Enquanto as primeiras são constituídas basicamente de ferro, cádmio, níquel e cobalto, as segundas são formadas por uma mistura de níquel metálico e óxido de níquel, além de uma liga misch metal (liga de cério, lantânio e didímio). ${ }^{[49]}$ 


\subsubsection{Reciclagem de baterias}

Hoje em dia já existem algumas indústrias que recolhem suas pilhas e baterias usadas devido à pressões políticas e a novas legislações ambientais que regulamentam a destinação de pilhas e baterias em diversos países do mundo. ${ }^{[50]} \mathrm{O}$ Conselho Nacional de Meio Ambiente (CONAMA) em 30 de junho de 1999 baixou

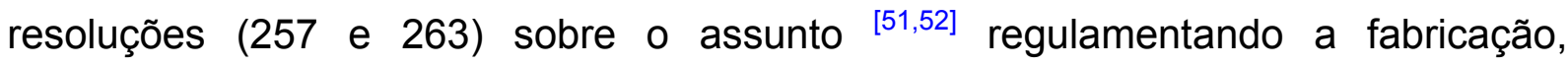
reciclagem e o descarte de pilhas e baterias. ${ }^{[39]}$

Os processos de reciclagem de pilhas e baterias podem seguir três linhas distintas: a minerometalúrgica que envolve processos físicos como a trituração, peneiração e separação, a hidrometalúrgica, na qual predominam reações químicas; e a pirometalúrgica, sendo os metais submetidos a altas temperaturas. $\mathrm{O}$ custo é maior nesta última, pois a demanda de energia é maior do que nas demais. $\mathrm{O}$ processo minerometalúrgico é o mais barato. ${ }^{[53]}$ Algumas vezes estes processos são específicos para reciclagem de pilhas, outras vezes as pilhas são recicladas juntamente com outros tipos de materiais. As baterias de $\mathrm{Ni}-\mathrm{Cd}$ muitas vezes são recuperadas separadamente das outras devido a dois fatores importantes, um é a presença do cádmio, que promove algumas dificuldades na recuperação do mercúrio e do zinco por destilação; o outro é dificuldade de se separar o ferro e o níquel. ${ }^{[39]}$

\subsubsection{Reciclagem de baterias de $\mathrm{Ni}-\mathrm{Cd}$}

Para este tipo de bateria os dois métodos estudados são a rota pirometalúrgica e a rota hidrometalúrgica. Os processos de reciclagem atualmente empregados são baseados na rota pirometalúrgica de destilação do cádmio visto que até o momento não foi possível o desenvolvimento de um processo economicamente viável utilizando a rota hidrometalúrgica. ${ }^{[39]}$

Em geral, os materiais produzidos na reciclagem dessas baterias são: cádmio com pureza superior à 99,95\%, que é vendido para as empresas que produzem baterias e níquel e ferro utilizados na fabricação de aço inoxidável. ${ }^{[54,55]}$

Tratando-se da separação de metais através de técnicas hidrometarlúgicas, os métodos que apresentam uma maior amplitude de aplicações são os processos de troca-iônica e extração por solvente. A troca-iônica é indicada 
para tratamento de soluções diluídas, uma vez que o agente orgânico é totalmente insolúvel em fase aquosa. Por outro lado, apesar de apresentar perdas apreciáveis em soluções diluídas, a extração por solventes aplica-se, universalmente, a sistemas mais concentrados, devido à sua alta seletividade, produzindo soluções concentradas que permitem a obtenção do metal com elevada pureza. ${ }^{[56]}$

\subsubsection{Baterias Ni-Cd: química e composição}

Baterias de $\mathrm{Ni}-\mathrm{Cd}$ usam uma reação eletroquímica reversível entre eletrodos de cádmio e níquel em um eletrólito alcalino (hidróxido de potássio ou hidróxido de lítio). Os materiais ativos são insolúveis no eletrólito, que age somente como um transportador de carga e não participa da reação eletroquímica de carga e descarga. ${ }^{[57]}$

No eletrodo de cádmio (o catodo) durante a descarga, o cádmio é oxidado combinando com dois íons hidróxila formando hidróxido de cádmio $\left[\mathrm{Cd}(\mathrm{OH})_{2}\right]$ liberando dois elétrons. Durante a carga o inverso acontece. Óxido de níquel hidratado é reduzido a hidróxido de níquel (II) no anodo. A equação de cargadescarga é:

$$
2 \mathrm{Ni}(\mathrm{OH})_{2(\mathrm{~s})}+\mathrm{Cd}(\mathrm{OH})_{2(\mathrm{~s}) \leftrightarrow 2 \mathrm{NiOOH}} \stackrel{\text { carga }}{\stackrel{\mathrm{s})}{<\text { descarga }}}
$$

A principal diferença entre os vários tipos de baterias $\mathrm{Ni}-\mathrm{Cd}$ é a natureza dos eletrodos. Os três principais tipos de eletrodos positivos (catodos) usados são placa pocket, placa sinterizada, e placa filamento. O óxido de níquel hidratado no anodo encantra-se normalmente em forma de pó e é retido em uma placa pocket ou suspenso em um gel ou pasta em eletrodos tipo pó sinterizado ou filamento.

O eletrodo negativo (catodo) usa placa pocket, pó sinterizado, placa de filamento, espuma ou suporte plástico para suportar o hidróxido de cádmio. Grafite ou óxido de ferro é normalmente adicionado para melhorar a condutividade dos dois hidróxidos de níquel e cádmio. Já que as células individuais são pré-recicladas antes 
da montagem das baterias, não é relevante, entretanto os catodos serem impregnados originalmente com $\mathrm{Cd}(\mathrm{OH})_{2}$ (o produto da reação de descarga) ou $\mathrm{Cd}$ (o produto da reação de carga).

O efeito memória normalmente associado às baterias de $\mathrm{Ni}-\mathrm{Cd}$ ocorre devido à formação de um composto níquel-cádmio, $\mathrm{Ni}_{5} \mathrm{Cd}_{21}$, que faz a atividade do material ser inviável. Uma possível solução para este problema é a minimização ou eliminação do hidróxido de níquel no eletrodo de cádmio.

O cobalto, embora em pequena porcentagem na fração mássica da bateria $\mathrm{Ni}-\mathrm{Cd}$, é importante porque é um metal valioso. Em baterias à base de níquel, o pó de cobalto, ou outra forma de cobalto, é usado para revestir externamente as partículas de hidróxido de níquel, para aumentar a diferença de potencial entre a reação de oxidação do hidróxido de níquel e a saída da descarga indesejada do oxigênio na estrutura polarizada anodicamente. A adição de cobalto é necessária para prevenir o início da perda de oxigênio causada pela condutividade limite da massa ativa.

\subsection{Adsorção}

Adsorção é o processo no qual moléculas de um fluido acumulam-se sobre uma superfície sólida. Tem-se a transferência de um ou mais constituintes (adsorbatos) de uma fase fluida (adsortivo) ou gasosa para a superfície de uma fase sólida (adsorvente) (FIG 3.6). ${ }^{[58]}$

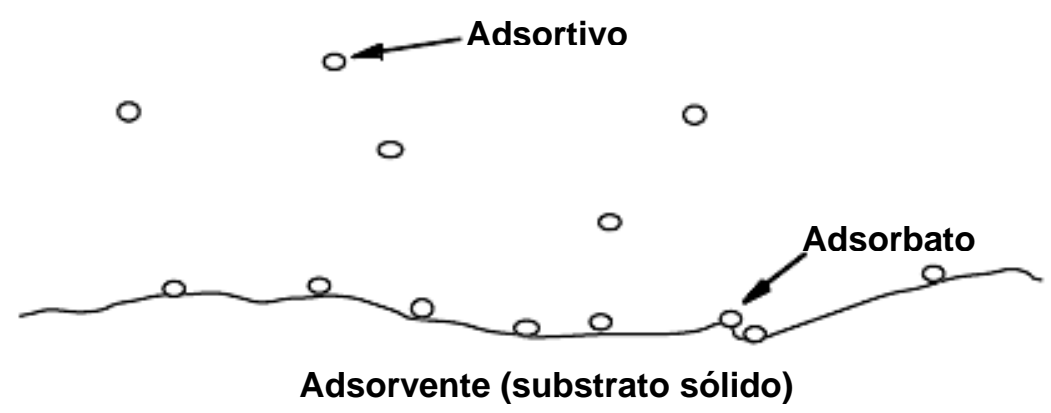

FIGURA 3.6 - Representação do processo de adsorção. ${ }^{[59]}$ 
As possíveis etapas do processo de adsorção de um adsorbato por um adsorvente são: 1)difusão do adsorbato até a superfície; 2)difusão do adsorbato para dentro dos poros; 3 ) adsorção do adsorbato sobre a superfície; 4) rearranjo ou reação química na camada adsorvida; 5)dessorção do adsorbato; 6)difusão do adsorbato para fora dos poros; 7)difusão do adsorbato para dentro da corrente do fluido. ${ }^{[60]}$

Vários fatores afetam a adsorção, tais como a estrutura molecular ou natureza do adsorvente, a solubilidade do soluto, o pH do meio e a temperatura. $\mathrm{A}$ estrutura molecular ou a natureza do adsorvente é particularmente importante na coordenação do grau de adsorção que pode ocorrer, enquanto que o tipo e a localização dos grupos funcionais responsáveis pela adsorção afeta sua adsorbabilidade. Além desses fatores, o diâmetro molecular do adsorbato também afeta a adsorção. Compostos com diâmetros moleculares menores têm mais facilidade em difundir-se para o interior do sólido e conseqüentemente a adsorção é maior. [61]

\subsubsection{Tipos de adsorção}

No processo de adsorção as moléculas presentes na fase fluida são atraídas para a zona interfacial devido à existência de forças atrativas. Dependendo da força das ligações entre as moléculas que estão sendo adsorvidas e o adsorvente, a adsorção pode ser física ou química.

$\mathrm{Na}$ TAB. 3.1 estão resumidas as principais diferenças entre a adsorção física e química. 
TABELA 3.1 - Principais diferenças entre a adsorção física e a adsorção química.

\begin{tabular}{|c|c|c|}
\hline Características & Adsorção Física & Adsorção Química \\
\hline Classificação & Fisiossorção/ Imobilização. & $\begin{array}{l}\text { Quimiossorção/ } \\
\text { Organofuncionalização. }\end{array}$ \\
\hline Tipo de interação & $\begin{array}{l}\text { Interações reversíveis causadas } \\
\text { por forças de Van der Waals, } \\
\text { possibilitando a dessorção. }\end{array}$ & $\begin{array}{l}\text { Ligações químicas } \\
\text { (geralmente covalentes). }\end{array}$ \\
\hline Sítios ativos & $\begin{array}{l}\text { Não apresenta sítios ativos } \\
\text { específicos de adsorção. As } \\
\text { moléculas adsorvidas estão livres } \\
\text { para cobrir a superfície toda do } \\
\text { sólido. }\end{array}$ & $\begin{array}{l}\text { As moléculas estão fixadas } \\
\text { em sítios específicos, não se } \\
\text { encontram livres para migrar } \\
\text { em torno da superfície. }\end{array}$ \\
\hline Calor de adsorção & 2 a $6 \mathrm{Kcal} \mathrm{mol}^{-1}$. & 10 a $200 \mathrm{Kcal} \mathrm{mol}^{-1}$. \\
\hline $\begin{array}{l}\text { Formação de } \\
\text { camadas }\end{array}$ & $\begin{array}{l}\text { Pode ocorrer formação de mono } \\
\text { ou multicamadas. }\end{array}$ & $\begin{array}{l}\text { Somente há formação de } \\
\text { monocamadas. }\end{array}$ \\
\hline $\begin{array}{l}\text { Cinética de } \\
\text { adsorção }\end{array}$ & lenta ou rápida. & lenta. \\
\hline Adsorvente & quase não é afetado. & altamente modificado. \\
\hline
\end{tabular}

No processo de adsorção há uma diminuição da energia livre superficial do sistema sendo, portanto, um processo espontâneo, isto é, o $\Delta G$ é menor do que zero. Entretanto, há uma diminuição do número de graus de liberdade do sistema, pois as moléculas do adsorbato só podem se deslocar sobre a superfície do adsorvente, isto é, o $\Delta \mathrm{S}$ é menor do que zero. Como $\Delta \mathrm{G}=\Delta \mathrm{H}-\mathrm{T} \Delta \mathrm{S}, \circ \Delta \mathrm{H}$ será negativo, mostrando que a adsorção é também um processo exotérmico. [62]

A quantidade de substância adsorvida na superfície decresce com o aumento da temperatura, já que todos os processos de adsorção são exotérmicos. $A$ uma temperatura constante a quantidade adsorvida aumenta com a concentração do adsorbato (em solução ou na fase gasosa), e a relação entre a quantidade adsorvida (x) e a concentração (c) é conhecida como a isoterma de adsorção. ${ }^{[63]}$ 


\subsubsection{Isotermas de adsorção}

A distribuição do adsorbato entre a fase fluida e a fase adsorvida envolve um equilíbrio de fases. As isotermas de adsorção são os registros destes dados de equilíbrio e são representadas por equações matemáticas, sendo modelos que descrevem as relações, no equilíbrio, entre a quantidade do elemento adsorvido por uma matriz sólida e a quantidade remanescente na solução, numa dada temperatura. ${ }^{[64,65]}$

A construção de uma isoterma de adsorção é de fundamental importância, quando o objetivo do estudo do fenômeno de adsorção é obter informações sobre a área específica e a estrutura porosa de um sólido, ${ }^{[66]}$ pois a forma da isoterma revela muitos detalhes sobre as características do material.

Existem fatores importantes que devem ser levados em consideração no estudo das isotermas tais como, natureza da interação entre o absorvente e o adsorbato, a velocidade de adsorção, a forma da isoterma e sua interpretação, extensão da adsorção (monocamada ou multicamada), interação do solvente com a superfície sólida e os efeitos da temperatura e $\mathrm{pH} .{ }^{[60]}$

Algumas formas mais comuns estão apresentadas na FIG.3.7. A isoterma linear passa pela origem e a quantidade adsorvida é proporcional à concentração do fluido. As isotermas convexas são favoráveis, pois grandes quantidades adsorvidas podem ser obtidas com baixas concentrações de soluto. ${ }^{[58]}$

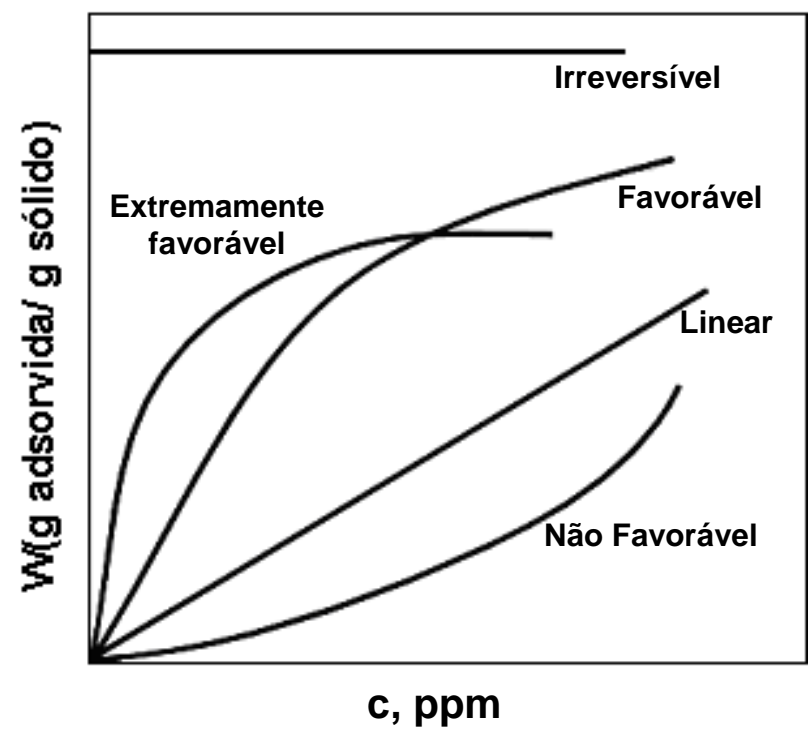

FIGURA 3.7 - Formas mais comuns de isotermas de adsorção. 
Em geral, para a adsorção física numa superfície homogênea em concentrações suficientemente baixas, a isoterma deve se aproximar à forma linear, onde a inclinação limite na região de baixa concentração é chamada de constante da lei de Henry $(K)$, ou constante de equilíbrio termodinâmico:

$$
\begin{gathered}
\mathrm{A}_{(\mathrm{s})}+\text { adsorvente } \underset{k d}{\stackrel{k a}{\rightleftarrows}} \mathrm{A}_{\text {adsorvido }} \\
K=\frac{k a}{k d}
\end{gathered}
$$

onde: $\mathrm{A}(\mathrm{s})=$ adsorbato na solução

$A_{\text {adsorvido }}=$ adsorbato no interior do sólido adsorvente

$k a=$ constante de velocidade de adsorção

$k d=$ constante de velocidade de dessorção

A lei de Henry corresponde fisicamente à situação em que a fase adsorvida está tão diluída que não existe competição por sítios adsortivos nem interações entre as moléculas adsorvidas. Em maiores concentrações ambos os efeitos tornam-se importantes, modificando a forma da isoterma. ${ }^{[61,62]}$

\subsubsection{Modelos de isotermas de adsorção}

Neste trabalho são apresentados três modelos de isotermas, os modelos mais utilizados, Freundlich, [67] Langmuir ${ }^{[68]}$ e um outro modelo relativamente mais recente (proposto em meados de 1946) de Dubinin-Radushkevich (D-R). ${ }^{[69]}$ Cada um dos quais dando determinadas informações sobre os sistemas.

\subsubsection{Modelo de Freundlich}

O modelo de Freundlich descreve uma adsorção reversível heterogênea, visto que não restringe a uma monocamada de cobertura do adsorvente. ${ }^{[70]}$ Este modelo representa uma relação quantitativa, em que a adsorção do soluto aumenta indefinidamente com o aumento da concentração.

A equação de Freundlich foi originalmente introduzida como uma correlação empírica de dados experimentais, sendo só muito mais tarde derivada 
matematicamente por Appel em 1973, admitindo-se uma distribuição logarítmica de sítios ativos, que constitui um tratamento válido quando não existe interação apreciável entre as moléculas de adsorbato. ${ }^{[71]}$

A isoterma é representada segundo a equação:

$$
M_{\mathrm{ads}}=K_{\mathrm{F}} \cdot C_{\mathrm{eq}}{ }^{1 / \mathrm{n}}
$$

$M_{\text {ads: }}$ massa do adsorbato adsorvido por grama de adsorvente $(\mathrm{g} / \mathrm{g})$.

$\mathrm{C}_{\text {eq: }}$ : concentração do adsorbato em equilíbrio com o adsorvente $\left(\mathrm{mol} \cdot \mathrm{L}^{-1}\right)$.

$1 / n$ :indica a heterogeneidade energética dos sítios de adsorção.

$\mathrm{K}_{\mathrm{F}}$ : constante de Freundlich.

Os valores de $\mathrm{K}_{\mathrm{F}}$ e $1 / \mathrm{n}$ são úteis para comparar diversos sistemas que envolvem processo de adsorção, desde que estudados nas mesmas condições experimentais. O expoente $1 / \mathrm{n}$ indica se a isoterma é favorável ou desfavorável, sendo que valores de n no intervalo de 1 a 10 representam condições de adsorção favorável. ${ }^{[61]}$

Linearizando-se a equação 3.6, obtém-se uma equação de reta, equação 3.7. Ao construir o gráfico $\log M_{\text {ads }}$ versus $\log C_{e q}$, obtem-se uma reta cujo coeficiente linear é o parâmetro log $\mathrm{K}_{\mathrm{F}}$ e o coeficiente angular é $1 / \mathrm{n}$ da equação:

$$
\log M_{a d s}=\log K_{F}+1 / n \cdot \log C_{e q}
$$

A desvantagem deste modelo empírico de isoterma é que ela não se reduz à Lei de Henry a concentrações próximas de zero ${ }^{[72]}$ e sua aplicabilidade é restrita a um intervalo de concentração limitado. ${ }^{[61]}$

\subsubsection{Modelo de Langmuir}

O modelo de Langmuir, ${ }^{[68,69]}$ um dos mais utilizados nos estudos de adsorção, onde se supõe que a superfície do adsorvente possua sítios energéticos idênticos e que cada molécula do adsorbato ocupe um único sítio, 
conseqüentemente prevê a formação de uma monocamada de cobertura de

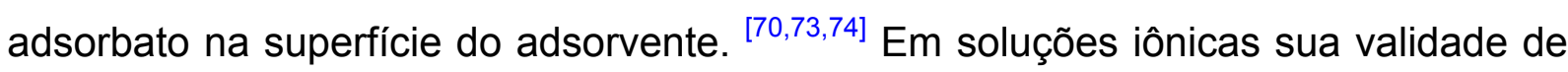
uso prende-se mais ao fato de constituir uma boa equação empírica do que atender às condições físicas pré-determinadas. ${ }^{[76]}$

A principal vantagem deste modelo é permitir a quantificação da capacidade de adsorção de espécies em adsorventes e avaliar a constante relacionada ao equilíbrio de adsorção. ${ }^{[65]}$ Este modelo não dá informações sobre o mecanismo de reação ${ }^{[60]}$ e constitui-se num procedimento de ajuste de curvas, no qual os parâmetros obtidos são válidos apenas para as condições nas quais o experimento foi desenvolvido.

Devido à heterogeneidade da superfície sob o ponto de vista físico e energético, a isoterma falha em muitos aspectos: ${ }^{[77]}$ a) tipos diferentes de centros ativos apresentam diferentes capacidades de adsorção para um determinado composto; b) a adsorção ocorre apenas em centros puramente específicos; c) devido à estrutura cristalina do adsorvente, formado por microcristais, a energia da superfície das faces é diferente da energia dos sítios, acarretando diferentes potenciais energéticos e capacidades de adsorção. Mesmo com estas limitações, a equação de Langmuir se ajusta razoavelmente bem a muitos sistemas. $\mathrm{Na}$ adsorção de proteínas em resinas trocadoras de íons, por exemplo, as condições requeridas pelo modelo são satisfeitas.

A equação de Langmuir está representada segundo equação 3.8 e apresenta uma relação entre a massa adsorvida de adsorbato por grama de adsorvente (eixo das ordenadas) e a concentração no equilíbrio (eixo das abscissas).

$$
M_{a d s}=\frac{M_{a d s}^{\max } \cdot K_{L} \cdot C_{e q}}{1+K_{L} \cdot C_{e q}}
$$

$M_{a d s}$ : massa de adsorbato adsorvida por grama de adsorvente $(\mathrm{g} / \mathrm{g})$;

$M_{a d s}^{\max }$ :massa máxima de adsorbato adsorvida por grama de adsorvente $(\mathrm{g} / \mathrm{g})$; 
$\mathrm{K}_{\mathrm{L}}$ : constante de Langmuir, relativa ao equilíbrio de adsorção $\left(\mathrm{L} . \mathrm{g}^{-1}\right)$;

$\mathrm{C}_{\text {eq }}$ : concentração de equilíbrio $\left(\mathrm{mol} \cdot \mathrm{L}^{-1}\right)$.

Pode-se aplicar a forma linearizada desse modelo representada na equação:

$$
\frac{1}{M_{a d s}}=\frac{1}{M_{a d s}^{\max } \cdot K_{L} \cdot C_{e q}}+\frac{1}{M_{a d s}^{\max }}
$$

Construindo-se a curva $\left(1 / \mathrm{M}_{\mathrm{ads}}\right)$ versus $\left(1 / \mathrm{C}_{\mathrm{eq}}\right)$ obtém-se uma reta cujo coeficiente linear fornece o parâmetro $\left(1 / M_{a d s}^{\max }\right)$ enquanto o coeficiente angular corresponde a [1/( $\left.\left.M_{a d s}^{\max } . \mathrm{K}_{\mathrm{L}}\right)\right]$. Desta forma obtém-se os valores de $M_{a d s}^{\max }$ e $\mathrm{K}_{\mathrm{L}}$, que são os parâmetros do modelo.

\subsubsection{Modelo de Dubinin-Radushkevich (D-R)}

Com o modelo de Dubinin-Radushkevich (D-R) pode-se estimar a porosidade característica do adsorvente e a energia livre de adsorção. ${ }^{[78]}$ Este modelo é de grande importância, pois, com a aplicação dos dados experimentais, pode-se distinguir entre a adsorção física e a química. ${ }^{[60]} A$ isoterma de D-R é mais geral que a de Langmuir uma vez que ela não assume uma superfície homogênea ou um potencial de adsorção constante ${ }^{[77]}$ e é representada segundo a equação:

$$
C_{\text {ads }}=K_{D R} \cdot e^{\left(-B x \varepsilon^{2}\right)}
$$

$\mathrm{C}_{\text {ads: }}$ concentração de adsorbato adsorvida por grama de adsorvente (mol. $\mathrm{L}^{-1} / \mathrm{g}$ adsorvente)

$\mathrm{K}_{\mathrm{DR}}$ : constante de Dubinin-Radushkevich, relativa à massa máxima adsorvida de adsorbato por grama de adsorvente.

$\varepsilon:$ potencial de Polanyi;

B: constante energética; relativa à energia de transferência do adsorbato para o adsorvente. 
O potencial de Polanyi é um potencial de sorção, resultante da diferença entre a energia livre na fase adsorvida e na fase líquida e é dado segundo a equação:

$$
\varepsilon=R T \ln \left[1+\frac{1}{\mathrm{Ceq}}\right]
$$

Sendo que $\mathrm{R}$ é a constante dos gases $\left(8,314 \mathrm{~J} \mathrm{~K}^{-1}\right)$ e $\mathrm{T}$ é a temperatura absoluta (Kelvin). ${ }^{[67]}$

A constante B é calculada através da equação 3.12 , onde E é considerado a variação da energia livre quando $1 \mathrm{~mol}$ de soluto é transferido da solução para a superfície do adsorvente. ${ }^{[60,78-81]}$

$$
E=\frac{1}{\sqrt{-2 B}}
$$

Aplicando o logaritmo natural à equação 3.10, obtêm-se uma relação linear entre a massa adsorvida por grama de adsorvente e o potencial de Polanyi:

$$
\ln C_{a d s}=\ln K_{D R}-B \times \varepsilon^{2}
$$

Construindo-se um gráfico de $\ln \mathrm{C}_{\text {ads }}$ versus $\varepsilon^{2}$ encontra-se uma reta. $\mathrm{O}$ tratamento dos respectivos dados por regressão fornece os coeficientes linear e angular que correspondem respectivamente, aos valores de $\mathrm{K}_{\mathrm{DR}}$ e $\mathrm{B}$.

Esse modelo descreve o processo como um efeito de preenchimento de poros, relacionado à energia livre de adsorção, mais do que uma adsorção camada a camada, de forma que a exatidão da equação $D-R$ varia para diferentes sistemas adsorvente-adsorbato e diferentes concentrações, ajustando-se apenas a concentrações baixas. ${ }^{[82]}$

O valor da energia de adsorção média, E, calculado pelo modelo de isotermas de D-R indicará se a interação adsorvente/ adsorbato é física ou química. Para adsorção física, os valores de $\mathrm{E}$ variam de $\left(8\right.$ a $\left.25 \mathrm{~kJ} \mathrm{~mol}^{-1}\right)$. ${ }^{\text {[66] }}$ 


\subsection{Espectroscopia de luminescência}

Luminescência é o nome dado ao fenômeno relacionado à capacidade que algumas substâncias apresentam em converter certos tipos de energia em emissão de radiação eletromagnética, com um excesso de radiação térmica. A luminescência é observada para todas as fases da matéria, seja gasosa, líquida ou sólida, para ambos compostos orgânicos e inorgânicos. A radiação eletromagnética emitida por um material luminescente, ocorre usualmente na região do visível, mas esta pode ocorrer também em outras regiões do espectro eletromagnético, tais como ultravioleta ou infravermelho.

O termo luminescência é utilizado como uma generalização do fenômeno. Há vários tipos de luminescência, que diferem entre si, na energia utilizada para a excitação. Por exemplo: a eletroluminescência é excitada por uma voltagem elétrica; a catodoluminescência por um feixe de elétrons de alta energia; a quimiluminescência pela energia de uma reação química; a termoluminescência não se refere à excitação térmica, mas sim à estimulação térmica de emissão luminescente a qual foi excitada por outro meio e a fotoluminescência é um resultado da absorção de fótons, utilizando-se uma radiação eletromagnética.

A fotoluminescência inclui tanto a fluorescência como fosforescência. A fluorescência difere da fosforescência, no fato de que as transições de energia eletrônica responsáveis pela fluorescência não envolvem a mudança de spin eletrônico. Como conseqüência, a fluorescência tem tempo de vida curto, cessando quase que imediatamente (<10-5 s). Em contraste, uma mudança de spin eletrônico, acompanha as emissões fosforescentes, a qual faz a radiação poder durar por um tempo facilmente detectável após o término da irradiação freqüente, vários segundos ou mais. ${ }^{[83]}$

\subsubsection{A Absorção na região do UV-VIS}

O processo de absorção de fótons por parte de um sistema qualquer que exige a presença do campo de radiação é sempre denominada absorção induzida. A intensidade da banda de absorção é proporcional ao coeficiente de absorção de Einstein para cada absorção induzida. 
A transição eletrônica ocorre por absorção de fótons e em condições normais de temperatura (ambiente ou próxima dela) as moléculas estão no estado vibracional de menor energia do estado eletrônico fundamental. Deste modo, a absorção do fóton de radiação irá excitar as moléculas para um estado eletrônico de energia maior, e para os diversos níveis vibracionais e rotacionais deste estado eletrônico. Este espectro de absorção será, portanto, compostos por um conjunto de bandas associadas às diversas transições vibracionais e rotacionais possíveis dos dois estados eletrônicos envolvidos na transição e dependerá das regras de seleção espectroscópicas válidas para cada caso. ${ }^{\left[{ }^{84,85]}\right.}$

Como o espaçamento entre os estados rotacionais é muito pequeno, normalmente estas transições não aparecem na forma de bandas resolvidas. Por outro lado, as transições vibracionais já envolvem espaçamentos um pouco maiores entre os níveis de energia. Desta forma, se os espaçamentos são maiores do que a resolução dos espectros, as transições vibracionais podem ser observadas como picos finos nos espectros. ${ }^{[85]}$

\subsubsection{Estado eletrônico excitado singleto}

A denominação de estado eletrônico singleto está relacionada com a multiplicidade de spins eletrônicos, segundo a relação $2 S+1$, sendo $S$ o momento angular de spin total. No caso dos estado singleto, o valor da multiplicidade é igual a 1, que é a situação mais comumente encontrada para moléculas orgânicas no estado eletrônico fundamental, para as quais todos os elétrons estão ocupando os estados de menor energia e os elétrons possuem spins emparelhados. ${ }^{[85]}$

Estado tripleto é a denominação que se dá a um estado em que a multiplicidade de spins eletrônicos $(2 S+1)$ é igual a 3 . Isto implica que os spins dos elétrons dos estados de maior energia são iguais. ${ }^{[86]}$

\subsubsection{Notação}

A designação dos estados utilizando-se letras e números tem o seguinte significado: ordena os estados em ordem crescente de energia e segundo a sua simetria ${ }^{[83,85]}$ (letras $\left.A, B, T, E\right)$; o número superior a esquerda fornece a 
multiplicidade do estado $\left({ }^{1} \mathrm{~A},{ }^{3} \mathrm{~B}\right.$, etc) (sendo 1 correspondente ao estado singleto, 3 corresponde ao estado tripleto, etc); o número inferior a direita ordena a seqüência de estados com a mesma simetria $\left(B_{1}, B_{2}\right.$, etc); a letra u ou g no lado inferior a direita fornece a paridade do estado $($ par $=g$, impar $=u$ ). Todas estas denominações dependem das propriedades da simetria das moléculas e das correspondentes funções de onda dos estados eletrônicos de acordo com a chamada teoria de grupos. ${ }^{[84,87]}$ Ex: $\left({ }^{1} \mathrm{~A}_{1 \mathrm{~g}}\right.$ e $\left.{ }^{1} \mathrm{~B}_{2 \mathrm{u}}\right)$.

\subsubsection{Análise de espectro}

Uma análise de espectro pode ser feita considerando-se os máximos das bandas vibracionais, as chamadas progressões vibracionais (conjunto de bandas finas que aparecem no espectro e que se repetem em intervalos aproximadamente constantes de energia). Para isto toma-se o valor do comprimento de onda da banda de absorção, em unidades de nanômetros (lembrar $1 \mathrm{~nm}=10^{-9} \mathrm{~m}$ ) e se faz à transformação para números de onda para $\mathrm{cm}^{-1}$. A diferença entre os números de ondas de cada uma das bandas é proporcional às diferenças de energias entre dois estados vibracionais correspondentes (equação de Planck 3.14): ${ }^{[87,88]}$

$$
\Delta E=h v=h \frac{c}{\lambda}=h c w
$$

Onde: $\Delta \mathrm{E}=$ diferença de energia entre os dois estados envolvidos na transição, $h=$ constante de Planck $=6,625610^{-27} \mathrm{erg}$. seg, $\mathrm{c}=$ velocidade da luz no vácuo $=2,99792510^{10} \mathrm{~cm} \mathrm{~s}^{-1} ; v=$ freqüência da radiação eletromagnética utilizada na excitação molecular; $\lambda=$ comprimento de onda da radiação eletromagnética utilizada na excitação molecular (unidades em nanômetros) e $\varpi=$ número de onda da radiação eletromagnética utilizada na excitação molecular (unidades $\mathrm{em}^{-1}$ ). Observe que apesar destas unidades não fazerem parte do Sistema Internacional de Unidades, elas são comumente empregadas nesta área e na maioria dos livros textos.

Estes valores podem ser comparados com os números de onda das bandas vibracionais obtidas por espectroscopia vibracional e, deste modo, pode-se 
identificar quais os movimentos vibracionais (ou modos normais de vibração) envolvidos com esta transição eletrônica. ${ }^{[85]}$

\subsubsection{Espectro de emissão}

Para se obter o espectro de emissão, em geral, costuma-se escolher como comprimento de onda para a excitação àquele coincidente com o máximo de absorção na banda de absorção. Esta energia irá excitar a espécie a um certo estado eletrônico. Posteriormente, a espécie vai dissipar parte desta energia até atingir o primeiro estado eletrônico excitado e a seguir a amostra poderá emitir em uma faixa de comprimentos de onda, que, como se mostra teoricamente para moléculas orgânicas, corresponde ao decaimento do primeiro estado eletrônico excitado.

O espectro de emissão se constitui em um registro das intensidades de emissão nos diversos comprimentos de onda, em um comprimento de onda fixo de excitação. Este espectro vai mostrar, portanto, uma banda, que pode ou não ter estrutura vibracional, e que estará correlacionada com a desativação radiativa da molécula a partir do primeiro estado eletrônico excitado. Se este estado tiver a mesma multiplicidade de spins do estado eletrônico fundamental, a emissão será denominada fluorescência, caso contrário à emissão será denominada fosforescência. ${ }^{[88-90]}$

Seguindo o esquema cinético proposto por Birks, ${ }^{[87,91]}$ uma vez que uma molécula seja excitada a um estado eletrônico excitado, existem diversos mecanismos de desativação até que a mesma retorne ao estado eletrônico de menor energia, que se denomina estado eletrônico fundamental.

A notação usada no diagrama da FIG.3.8 é característica da espectroscopia eletrônica de emissão, representando: as transições que resultam em emissão de radiação (radiativas) permitida por multiplicidade de spin $(\rightarrow$ ); transições radiativas proibidas por multiplicidade de spin $(--\rightarrow)$; transições não radiativas ( $\rightarrow$ ), isto é, aquelas em que a desativação se dá através de processos de liberação de calor para o ambiente; processos de absorção de radiação eletromagnética produzindo estados eletrônicos e vibracionais excitados; processos de desativação molecular de estados eletrônicos e vibracionais excitados através de processos 
radiativos ou não radiativos; e processos de relaxação vibracional, que ocorrem dentro da curva de energia potencial de um mesmo estado eletrônico e envolvem a desativação por liberação de calor através dos modos normais de vibração.

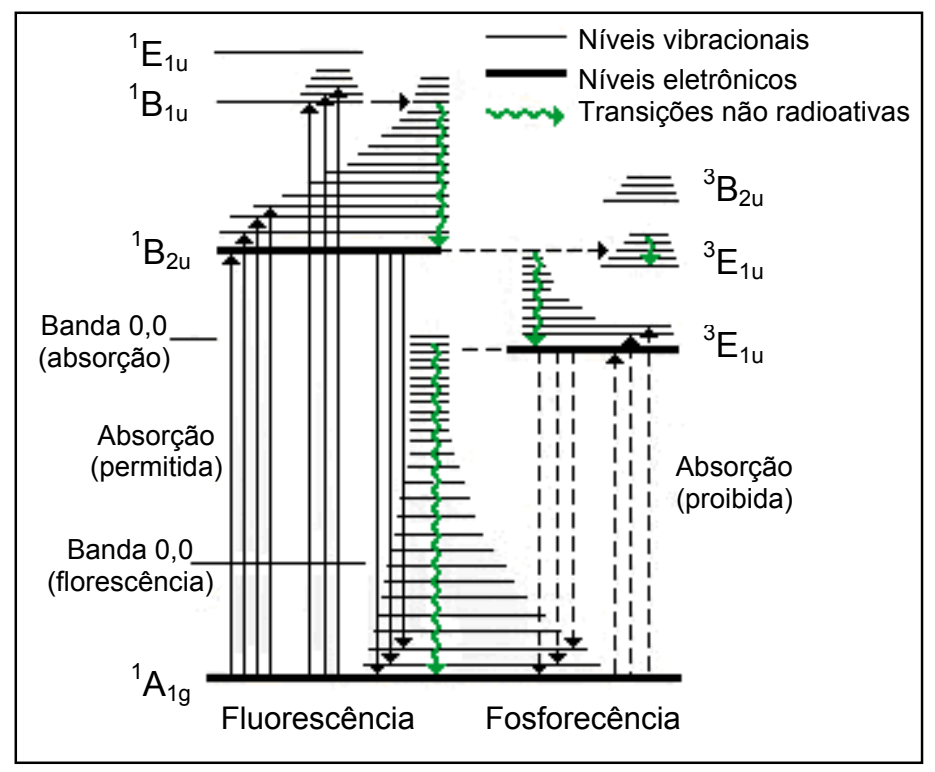

FIGURA 3.8 - Diagrama de Jablonski para o sistema de níveis de energia para a molécula de benzeno.

Alguns termos são também muito utilizados: cruzamento intersistemas (do inglês, intersystem crossing - ISC), que representa transições não radiativas, isoenergéticas, envolvendo estados de multiplicidades de spin diferentes; conversão interna (do inglês, internal convertion - IC) que representa transições isoenergéticas envolvendo estados de mesma multiplicidade de spin. Os processos que envolvem estados eletrônicos com mesma multiplicidade de spins são sempre permitidos, mesmo aqueles que não são radiativos, enquanto que aqueles que envolvem estados com multiplicidades de spins diferentes são sempre proibidos. É por isso que, a menos de condições muito especiais, não se observa à absorção direta para estado tripleto. ${ }^{\text {[92] }}$

\subsubsection{Espectro de excitação}

Uma outra possível forma de registro de espectros utilizando-se um espectrofluorímetro consiste na variação da intensidade de emissão em um 
comprimento de onda fixo, quando se varia o comprimento de onda de excitação, em toda a faixa do espectro de absorção da espécie.

Variar o comprimento de onda de excitação implica em excitar a espécie em comprimentos de onda em que sua absorbância tenha valores diferentes. Neste caso, deve-se lembrar que a molécula somente irá emitir se puder absorver a radiação incidente, o que permitirá que a mesma seja excitada a algum de seus estados eletrônicos excitados. Além disto, irá emitir sinais mais intensos se o comprimento de onda de excitação corresponder a uma transição com alta probabilidade de ocorrência e, portanto, correspondentes a uma banda de absorção intensa.

Sendo assim, em alguns casos, um espectro de excitação deve ser muito similar (a menos de fatores impostos pelos tipos de instrumentos que são diferentes) a um espectro de absorção, isto é, um espectro em que a intensidade de emissão seja proporcional à intensidade de absorção, atingindo o valor zero quando o comprimento de onda de excitação corresponder à absorbância zero e um valor máximo correspondente ao comprimento de onda de absorbância máxima. A este tipo de espectro se dá o nome de espectro de excitação e ele deve ser similar aos espectros de absorção.

O registro de um espectro de excitação é normalmente feito selecionandose o comprimento de onda de emissão correspondente ao máximo desta banda. ${ }^{\left[{ }^{[3]}\right.}$

\subsubsection{Mecanismos de excitação e emissão}

Na FIG.3.9, estão ilustrados os processos de excitação e de emissão para um material hipotético, com a representação esquemática dos níveis de energia. $E_{0}$ é o estado de energia fundamental e de $E_{1}$ a $E_{5}$ estão representados os estados de energia excitados. A baixas temperaturas e na ausência de uma energia de excitação só o nível $E_{0}$ é ocupado. Após a excitação, elétrons são ativados para o nível $E_{5}$. Os intervalos de energia entre os níveis adjacentes de $E_{2}$ ao $E_{5}$ são pequenos, enquanto que o intervalo entre $E_{2}$ e $E_{1}$ é grande. Se o intervalo entre um nível excitado e o mais próximo adjacente é pequeno, o material excitado tende a apresentar um decaimento não radiativo pela emissão de fóton, liberando energia na 
forma de calor. A radiação eletromagnética que é resultante de um decaimento radiativo de um nível eletrônico superior para o estado fundamental, pela emissão de um fóton, só ocorre quando o intervalo para o nível adjacente mais baixo está acima de um valor crítico. Quando o material da FIG.3.9, é excitado para o nível $E_{5}$, este perde energia na forma de cascata do nível 5 ao 2. Como o intervalo dos níveis 2 e 1 estão acima do valor crítico, então o material decai radiativamente do nível 2 , emitindo um fóton alcançando o nível 1 ou 0 . Se o material decai radiativamente para o nível 1 , este então decai não radiativamente através do pequeno intervalo para o estado fundamental. ${ }^{[83,]}$

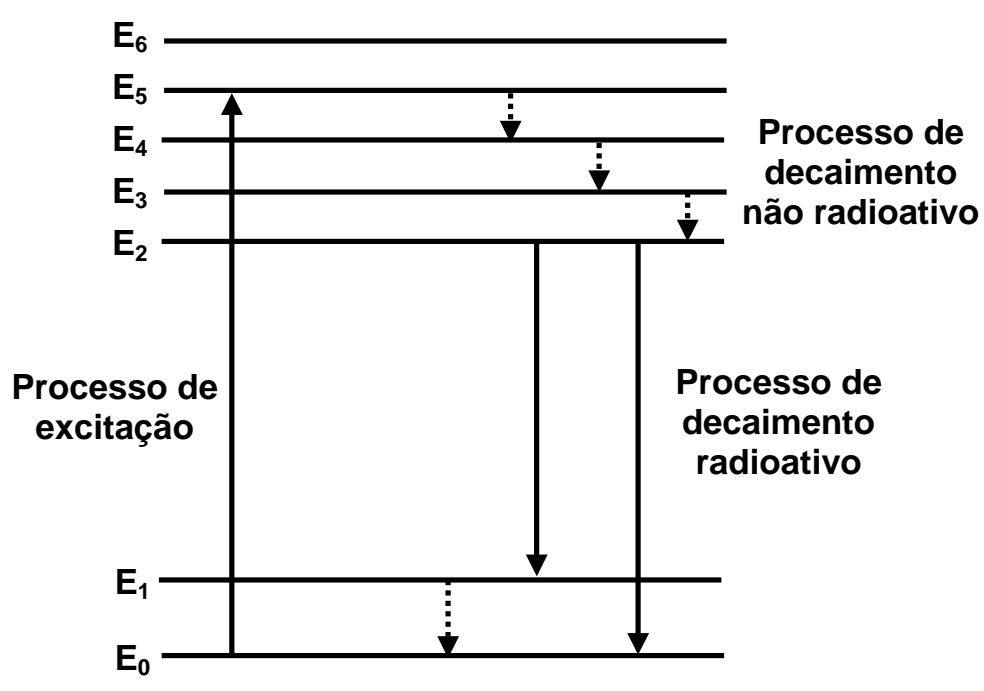

FIGURA 3.9 - Processo de excitação e emissão para um material hipotético.

\subsubsection{Efeito das impurezas}

A luminescência na maioria dos sólidos inorgânicos envolve impurezas ou defeitos estruturais, que são denominados ativadores. Estas imperfeições são de diversos tipos, atômicas e moleculares, as quais as características dependem da natureza e estrutura da imperfeição e dos estados eletrônicos do sólido. Sólidos semicondutores são caracterizados por uma banda de valência e uma banda de condução, separada por um gap de energia. ${ }^{[41]}$ A luminescência ocorre pela excitação de elétrons para a banda de condução vazia, deixando buracos na banda de valência completamente preenchida. A emissão ocorre pela recombinação do par 
elétron-buraco. Esta recombinação se dá devido à proximidade ou à presença de defeitos na estrutura cristalina.

As impurezas que ocasionam defeitos na estrutura cristalina de semicondutores podem ser divididas em três categorias: doadoras, aceptoras e isoeletrônicas. Doadoras são substâncias que podem doar um de seus elétrons para a banda de condução de um semicondutor. A energia necessária para esta transição eletrônica é denominada $E_{D}$ e está representada esquematicamente na FIG.3.10. Se as impurezas presentes são capazes de retirar um elétron da banda de valência de um semicondutor e deixar um buraco na mesma, são denominadas aceptoras. A energia necessária para a remoção deste elétron é denominada $E_{A}$ e está ilustrada na FIG.3.10. Impurezas isoeletrônicas são substâncias que não contribuem para a condutividade elétrica de um semicondutor, mas estas substâncias podem influenciar nas propriedades luminescentes do material atuando como centros de recombinação de elétrons excitados e buracos. ${ }^{[83]}$

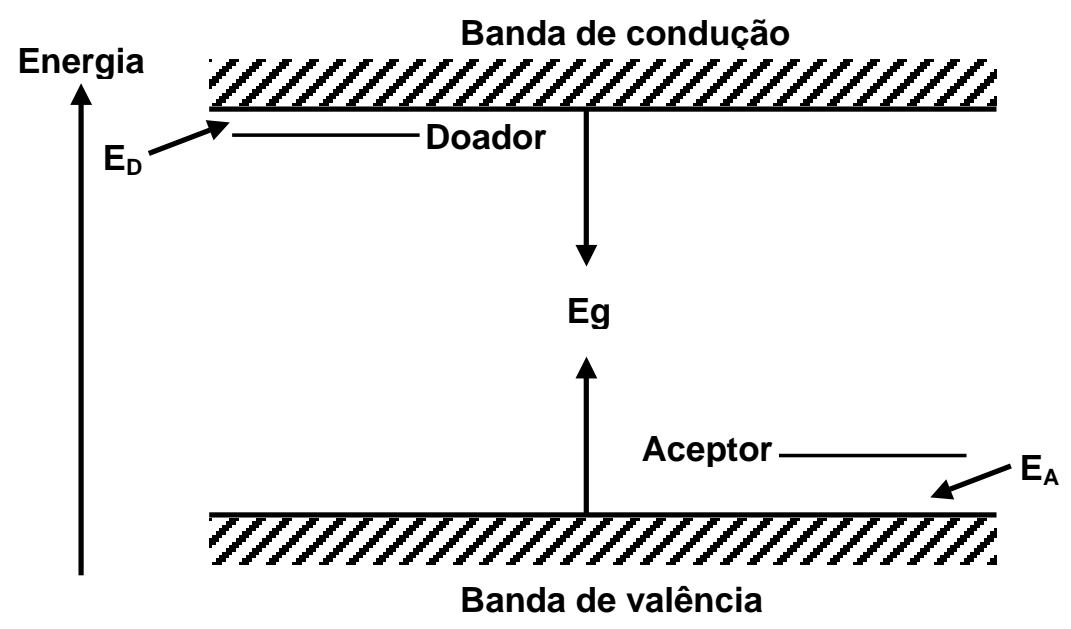

FIGURA 3.10 - Representação esquemática dos níveis de energia gerados por impurezas doadoras e aceptoras em um material semicondutor. Eg é a energia da banda gap.

\subsection{Terras raras (TR)}

As Terras Raras $(T R=S c, Y, L a-L u)$ formam um grupo especial de elementos que incluem os lantanídeos, Ln, (Ce a Lu) caracterizados por conter uma camada $4 \mathrm{f}$ preenchida (com exceção do Lu). A história das TR se inicia em 1788, ${ }^{\text {[9] }}$ 
quando o capitão Arrhenius encontrou uma pedra preta próximo a Ytterby na Suécia. Em 1794, J. Gadolin isolou um óxido daquele mineral preto e o nomeou "Ytterbia". Outro mineral foi encontrado por Klaproth em 1803 e foi chamado de "Ceria". Mais tarde, descobriu-se que do mineral "Ceria", poderiam ser extraídos lantânio, cério, didímio (mistura de $\mathrm{Nd}$ e $\mathrm{Pr}$ ), samário, európio e gadolínio. ${ }^{[95]} \mathrm{O}$ didímio foi separado em praseodímio e neodímio. Do mineral "ítria" foram isolados os elementos ítrio, térbio, érbio, itérbio, escândio, hólmio, túlio, disprósio e lutécio.

Passaram-se cerca de 150 anos para que todas as TR fossem isolados. A razão para justificar todo esse tempo é a similaridade nas suas propriedades químicas. Na série lantanídica ( $\mathrm{Ce}-\mathrm{Lu}$ ), os íons diferem no número de elétrons na camada 4f. A blindagem imperfeita de um elétron $4 \mathrm{f}$ por um outro elétron $4 \mathrm{f}$ causa uma diminuição do raio em torno de $20 \%$ de La a Lu, usualmente chamada de "contração lantanídica".

$O$ fato dos orbitais $4 f$ estarem protegidos pelas camadas mais externas faz com que os íns lantanídeos apresentem propriedades ópticas únicas, por exemplo, espectros de linhas finas e têm sido estudados desde o início do século 20. No início de 1900 Bethe, Kramers e Bequerel ${ }^{[96-98]}$ sugeriram que estes dados espectrais poderiam ser atribuídos às transições dentro da configuração $4 \mathrm{f}^{\mathrm{N}}$. Após esses trabalhos pioneiros, várias aplicações na área de espectroscopia luminescente contendo íons $\mathrm{TR}^{3+}$ foram reportadas. ${ }^{[99,100]}$ Atualmente, estes íons são largamente aplicados em televisões coloridas, tubos fluorescentes e "fósforos" de raios-X, eletroluminescência, fluoroimunoensaio, sondas espectroscópicas, etc.

Além das transições intraconfiguracionais $4 \mathrm{f}^{\mathrm{N}} \leftrightarrow 4 \mathrm{f}^{\mathrm{N}}$ para os sistemas com íons terras rara também podem ser observadas transições interconfiguracionais $4 \mathrm{f}^{\mathrm{N}} \rightarrow 4 \mathrm{f}^{\mathrm{N}-1} 5 \mathrm{~d}$ e de transferência de carga $(\mathrm{CT}) .{ }^{[101,102]}$ Ao contrário das transições f-f, essas transições são permitidas por paridade, gerando absorções e emissões intensas apresentando bandas alargadas, da ordem de $2.000 \mathrm{~cm}^{-1}$ e para o estado de transferência de carga LMCT em torno de $4.000 \mathrm{~cm}^{-1}$. A dificuldade da investigação experimental sobre as transições $4 \mathrm{f}^{\mathrm{N}} \rightarrow 4 \mathrm{f}^{\mathrm{N}-1} 5 \mathrm{~d}$ e de transferência de carga LMCT se deve ao fato dessas transições se localizarem nas regiões do UV e ultravioleta no vácuo (VUV). Além disso, devido a uma maior relaxação no estado 
excitado $4 \mathrm{f}^{\mathrm{N}} \rightarrow 4 \mathrm{f}^{\mathrm{N}-1} 5 \mathrm{~d}$ e LMCT, a maior parte da intensidade luminescente está nas bandas vibrônicas largas, tornando mais difícil a análise dos dados espectrais.

\subsubsection{Fundamentos sobre Espectroscopia de Terras Raras}

A espectroscopia óptica é uma ferramenta poderosa para estudar a estrutura eletrônica de um íon metálico opticamente ativo em uma fase condensada e, conseqüentemente, para estudar as interações entre um íon central e sua vizinhança química. Um estudo da análise sistemática das propriedades ópticas de íons $\mathrm{TR}^{3+}$ no estado sólido tem sido reportado na literatura. ${ }^{[103-113]}$

A principal característica dos elementos lantanídeos é a pequena extensão radial da camada $4 f$ (aberta) que contém os elétrons opticamente ativos. Esta particularidade está associada às transições intraconfiguracionais resultantes do preenchimento sucessivo da camada $4 \mathrm{f}$ ao longo da série lantanídica (de $4 \mathrm{f}^{1}$ a $4 \mathrm{f}^{13}$ para os íons $\mathrm{Ln}^{3+}$ ). É observado que em sistemas químicos contendo esses elementos os elétrons $4 \mathrm{f}$ pertencentes à camada mais interna estão protegidos da interação dos ligantes pelas camadas externas (fechadas) $5 s^{2} 5 p^{6}$. Conseqüentemente, os elétrons $4 f$ interagem fracamente com os elétrons dos átomos vizinhos e suas propriedades eletrônicas são moderadamente afetadas pela circunvizinhança química. Em particular, os espectros no estado sólido dos íons $4 \mathrm{f}$ retêm mais ou menos seu caráter atômico, que é bastante significativo na interpretação de sua estrutura eletrônica. Esta pequena perturbação na estrutura dos níveis de energia é utilizada para investigar o ambiente químico em torno do íon terra rara, o qual pode atuar como sonda local.

Em um cristal, o íon metálico perde a simetria esférica (íon livre) sob a influência do campo eletrostático não-homogêneo gerado pela distribuição de carga elétrica dos ligantes. A interação de campo cristalino remove a degenerescência dos

estados ${ }^{2 S+1} L_{J}$ do íon livre em um número de subníveis ${ }^{2 S+1} L_{J}(M J)$, que dependem da simetria do ambiente que o íon ocupa. O conhecimento da simetria do campo cristalino é muito útil na interpretação dos espectros ópticos. Através dos conceitos de teoria de grupos, baseados nas propriedades de simetria, os níveis do campo cristalino estão associados às representações irredutíveis. Em adição ao número de 
degenerescência dos níveis do campo cristalino oriundo de cada nível $\mathrm{J}$ do íon livre, a teoria de grupos permite estabelecer as regras de seleção que governam estes níveis. Com respeito à polarização da luz e orientação do cristal, os espectros ópticos revelam a natureza e a multipolaridade das transições (transições de dipolo elétrico são as mais intensas a menos que exista um centro de inversão).

A maioria das transições eletrônicas observadas para os íons $\mathrm{TR}^{3+}$ é de baixa intensidade. Isso é uma conseqüência da Regra de Laporte, que determina que transições de dipolo elétrico entre dois estados de mesma paridade são proibidas $(\Delta l= \pm 1)$. Portanto, as transições de zero-fônon observadas em um sítio não centrossimétrico são transições de dipolo elétrico forçado, significando que as funções de onda $4 \mathrm{f}$ não são puras e contêm uma contribuição da configuração excitada de paridade oposta. Porém, essa mistura, encontrada através do termo ímpar do Hamiltoniano descrendo a interação do campo cristalino, é suficientemente pequena e preserva o caráter dos níveis $4 \mathrm{f}$.

Os espectros eletrônicos dos íons $4 \mathrm{f}$ no estado sólido, normalmente contêm muito mais linhas que as esperadas oriundas dos níveis ${ }^{2 \mathrm{~S}+1} \mathrm{~L} J_{\jmath}$ do íon livre. $A$ presença de linhas extras pode ser atribuída a impurezas e defeitos cristalinos que alteram o sítio de simetria ou a transições vibrônicas, que são geradas pelo acoplamento das transições eletrônicas com os modos vibracionais da rede cristalina. Estas transições de baixa intensidade são usualmente mais fracas e alargadas e obedecem às regras de seleções de acordo com a representação do grupo espacial. Experimentos à baixa temperatura são valiosos para revelar a natureza vibrônica destas transições, especialmente para simetria local em compostos centrossimétricos.

A estrutura dos níveis de energia da configuração $4 \mathrm{f}$ pode ser entendida em termos dos níveis do íon livre com uma adicional perturbação devido à interação do campo cristalino. Os baricentros (centro de gravidade) dos subníveis ${ }^{2 S+1} L_{J}(M J)$ podem ser adaptados aos níveis ${ }^{2 S+1} L_{\jmath}$ degenerados do íon livre, que podem ser relacionados aos níveis de energia dos íons $\mathrm{TR}^{3+}$ no estado gasoso. 


\subsubsection{Transições Intraconfiguracionais $4 f^{N} \leftrightarrow 4 f^{N}$}

Nesta seção, serão priorizados exemplos com o íon európio trivalente devido à maior ênfase aos estudos espectroscópicos baseados nos dados espectrais (experimentais) de sistemas contendo este íon.

As configurações eletrônicas dos íons $\mathrm{Eu}^{3+}:[X e] 4 f^{6}$ possui 295 níveis ${ }^{2 \mathrm{~S}+1} \mathrm{~L}_{J}$ e sob a influência do campo cristalino apresenta uma degenerescência total de 3003 componentes ${ }^{2 S+1} L_{J(M J)}$. No estado gasoso, as configurações do primeiro estado excitado $4 f^{5} 5 d^{1}$ e $4 f^{7} 5 d^{1}$ são aproximadamente $70.000 \mathrm{~cm}^{-1}$ acima do estado fundamental. ${ }^{[114]}$ Nos compostos em que os íons $\mathrm{Ln}^{3+}$ estão quimicamente ligados, os estados de transferência de carga $\mathrm{L}^{-1} 4 \mathrm{f}^{7}$ e $\mathrm{L}^{-1} 4 \mathrm{f}^{9}$ podem estar situados a 40.000 $\mathrm{cm}^{-1}$ acima do estado fundamental. A separação de energia entre as configurações do estado fundamental $4 \mathrm{f}^{\mathrm{N}}$ e as primeiras configurações do estado excitado é suficientemente grande para permitir a omissão das configurações excitadas na descrição das propriedades espectroscópicas, ao menos como primeira aproximação (FIG. 3.11). Na TAB. 3.2 apresenta-se a luminescência característica das transições ${ }^{5} \mathrm{D}_{0,1} \rightarrow{ }^{7} \mathrm{~F}$ J para complexos de $\mathrm{Eu}^{3+}$.

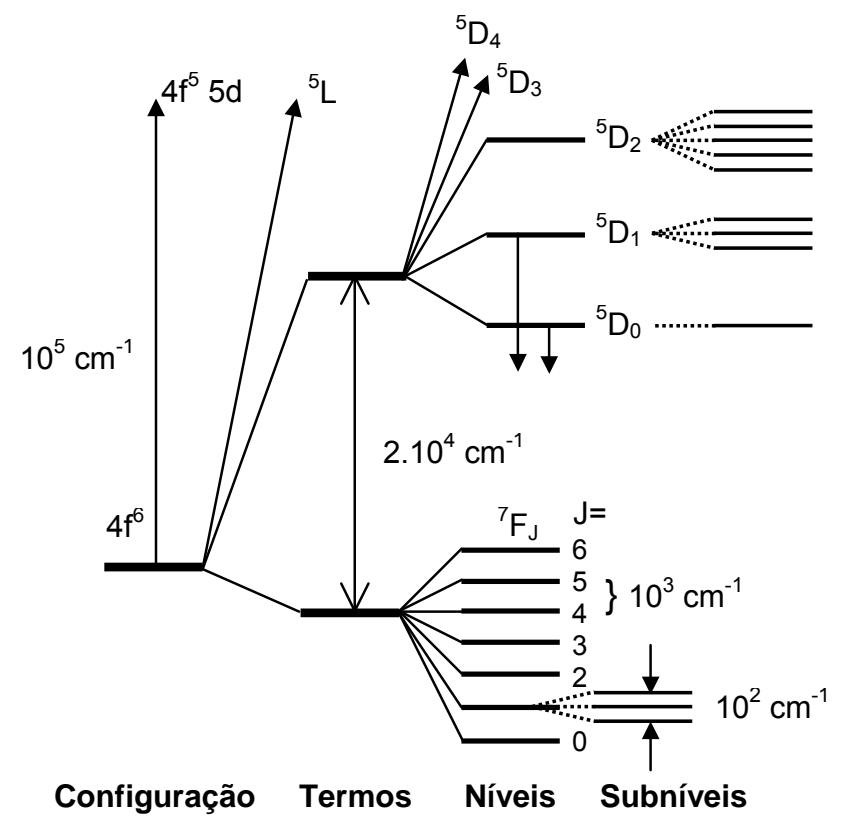

FIGURA 3.11 - Diagramas parciais de energia para os íons $\mathrm{Eu}^{3+}\left(4 f^{6}\right)$ mostrando a magnitude relativa das repulsões intereletrônicas, acoplamento spinórbita e efeitos do campo cristalino. 
TABELA 3.2 - Luminescência característica das transições ${ }^{5} D_{0,1} \rightarrow{ }^{7} F_{J}$ para complexos de $\mathrm{Eu}^{3+}$.

\begin{tabular}{|c|c|c|c|c|}
\hline $\mathrm{J}$ & $\mathrm{Di}^{\mathrm{a}}$ & Faixa (nm) & $I^{b}$ & Comentários \\
\hline \multicolumn{5}{|c|}{ Transições de ${ }^{5} \mathrm{D}_{0} \rightarrow{ }^{7} \mathrm{~F}_{\mathrm{J}}$} \\
\hline 0 & $\mathrm{DE}$ & $577-581$ & $(\mathrm{vw})$ & $\begin{array}{l}\text { Transição não-degenerada (proibida); ganha } \\
\text { intensidade através da mistura de J's nas } \\
\text { simetrias } C_{s}, C_{n} \text { e } C_{n v}\end{array}$ \\
\hline 1 & DM & $585-600$ & (s) & $\begin{array}{l}\text { Transição permitida; a intensidade é quase } \\
\text { independente do meio }\end{array}$ \\
\hline 2 & DE & $610-625$ & $(\mathrm{~s}-\mathrm{vs})$ & $\begin{array}{l}\text { Transição hipersensível }(\Delta \mathrm{J}=2) \text {; ausente se o } \\
\text { íon encontra-se em um centro de inversão }\end{array}$ \\
\hline 3 & DE & $640-655$ & $(v w)$ & $\begin{array}{l}\text { Transição proibida, normalmente muito fraca; } \\
\text { a mistura de J's adiciona um caráter de DM }\end{array}$ \\
\hline 4 & $\mathrm{DE}$ & $680-710$ & $(\mathrm{~m}-\mathrm{s})$ & Transição sensível ao ambiente do $\mathrm{Eu}(\Delta \mathrm{J}=4)$ \\
\hline 5 & DE & $740-770$ & $(v w)$ & Transição proibida, raramente observada \\
\hline 6 & $\mathrm{DE}$ & $810-840$ & $(v w)$ & Transição raramente registrada \\
\hline \multicolumn{5}{|c|}{ Transições de ${ }^{5} \mathrm{D}_{1} \rightarrow^{7} \mathrm{~F}_{\mathrm{J}}$} \\
\hline 0 & DM & $524-528$ & $(\mathrm{vw})$ & \\
\hline 1 & $\mathrm{DE}$ & $530-540$ & $(v w)$ & Sensível ao ambiente do íon Eu \\
\hline 2 & $\mathrm{DE}$ & $550-565$ & $(v w)$ & \\
\hline
\end{tabular}

${ }^{a}$ Caráter dipolar principal: $\mathrm{DE}=$ dipolo elétrico, $\mathrm{DM}=$ dipolo magnético.

${ }^{\mathrm{b}}$ Intensidade: $\mathrm{vw}=$ muito fraco, $\mathrm{m}=$ médio, $\mathrm{s}=$ forte, $\mathrm{vs}=$ muito forte.

\subsubsection{Regras de seleção}

Considera-se que teoricamente para mudar um sistema do estado inicial $\psi_{\mathrm{i}}$ para um final $\psi_{\mathrm{f}}$ teoricamente é necessário um operador $\mathrm{O}_{\mathrm{p}}$. Os dois operadores que mais contribuem para a transição são o operador dipolo elétrico (DE) e o dipolo magnético (DM). 


\subsubsection{Transições de dipolo elétrico (DE)}

As transições intraconfiguracionais $(4 \mathrm{f} \leftrightarrow 4 \mathrm{f})$ são proibidas, em princípio, pela regra de Laporte. No entanto, Judd e Ofelt ${ }^{[115,116]}$ desenvolveram uma teoria onde esta regra pode ser relaxada e transições entre estados de mesma paridade passam a ser permitidas, chamadas de transições por dipolo elétrico forçado. ${ }^{[117]}$

As regras de seleção para transições de dipolo elétrico são:

$\Delta \mathrm{l}= \pm 1$ Isto significa que as perturbações da configuração $f-f$ diferem somente por uma unidade (exemplo, interação de configuração f-d ou f-g)

$\Delta S=0 \quad$ Geralmente relaxada devido a interação spin-órbita

$\Delta \mathrm{L} \leq 6 \quad$ Válida desde que $\mathrm{J}$ seja um bom número quântico.

$\Delta \mathrm{J} \leq 6 \quad$ No caso de $\mathrm{J}=0 \rightarrow \mathrm{J}^{\prime}=0$ a transição é proibida. Para transições onde $\Delta \mathrm{J}=$ 2, 4, 6 se um nível $\mathrm{J}=0$ são permitidas, por exemplo, o íon $\mathrm{Eu}^{3+}$ apresentam as transições ${ }^{5} \mathrm{D}_{0} \rightarrow{ }^{7} \mathrm{~F}_{\jmath}$

\subsubsection{Transições de dipolo magnético (DM)}

As transições de dipolo magnético são permitidas entre estados de mesma paridade:

$\Delta \mathrm{l}=0$

$\Delta S=0$

$\Delta \mathrm{L}=0$

Válida desde que J seja um bom número quântico

$\Delta \mathrm{J}=0, \pm 1 \quad$ Quando $\mathrm{J}=0 \rightarrow \mathrm{J}$ ' $=0$ a transição também é proibida.

\subsection{Materiais Luminescentes}

No início de 1896, Pupin propôs a utilização do $\mathrm{CaWO}_{4}$ como fósforo para absorver raios-X e converte-los eficientemente em luz, tendo sido utilizado por 75 anos para esse propósito ${ }^{[118]}$. Até o início da década de 40 , a fabricação de fósforos ocorreu em pequena escala, sendo confinada a materiais para tintas fosforescentes e telas de raios-X. Dois desenvolvimentos transformaram a indústria nessa época: 
iluminação fluorescente fornecendo um maior avanço na eficiência de lâmpadas e o desenvolvimento da televisão doméstica.

Descobriu-se que a preparação de fósforos requer materiais de partida de alto grau de pureza, com impurezas particulares ou dopantes adicionados em concentrações controladas. No caso de alguns fósforos, uma ou duas partes em $10^{8}$ de uma impureza pode dominar a luminescência. Outros materiais podem tolerar 100 partes por milhão (ppm) de impurezas indesejáveis.

As propriedades luminescentes características dos fósforos são obtidas pela dopagem do material hospedeiro com um íon ativador e/ou um íon sensibilizador ${ }^{[119]}$. O íon ativador é um centro que absorve a energia de excitação e a converte em radiação de diferente comprimento de onda (FIG. 3.12a). Enquanto que o sensibilizador é um íon incorporado em uma rede hospedeira capaz de transferir sua energia de excitação para o ativador em sua vizinhança, induzindo a luminescência. Quando um ativador, com emissão desejada, não apresenta absorção significante para uma determinada energia de excitação, usa-se um sensibilizador que absorva a energia de excitação e então transfira esta energia para o ativador. Conseqüentemente o íon ativador emite sua luminescência característica (FIG. 3.12b).

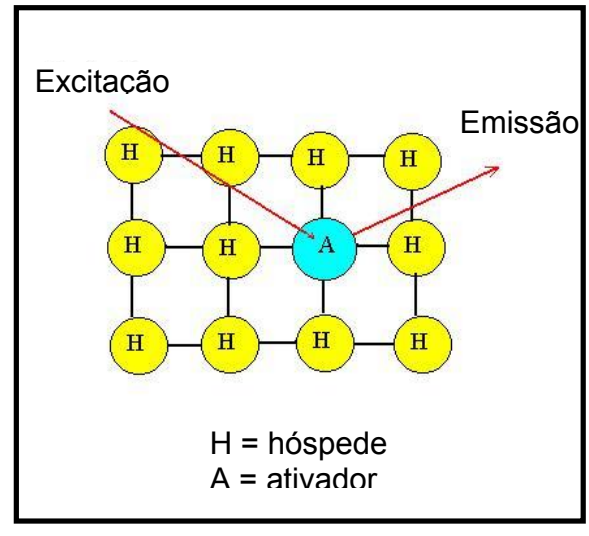

(a)

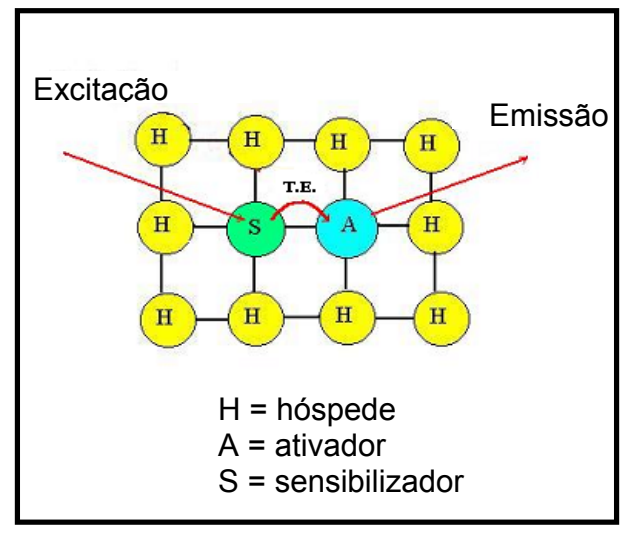

(b)

FIGURA 3.12 - Representação do processo de luminescência: a) um ativador (A) excitado diretamente em uma rede hospedeira $(H)$; b) emissão do ativador (A) excitado indiretamente pelo sensibilizador (S) em uma rede hospedeira $(H)$. 
A maior vantagem no uso de íon $\mathrm{TR}^{3+}$ como ativadores é que seus compostos geralmente possuem luminescência intensa na região do visível e seus espectros de emissão são caracterizados por apresentarem bandas extremamente finas, quando comparados com compostos de transição d. 


\section{REFERÊNCIAS BIBLIOGRÁFICAS}

[1] DORFNER, K. Ion Exchangers, New York, N.Y.: Walter de Gruyter Berlin, 1991.

[2] CLEARFIELD, A. Inorganic Ion Exchange Materials, Boca Raton, FL: CRC Press, 1982.

[3] CLEARFIELD, A.; STYNES, J. A. The preparation of crystalline zirconium phosphate and some observations on its ion exchange behavior. J. Inorg. Nucl. Chem. v. 26, n. 1, p. 117-129, 1964.

[4] KOIVULA R. Inorganic ion exchangers for decontamination of radioactive wastes generated by the nuclear power plants. 2003. Dissertação (Mestrado) University of Helsinki, Finland.

[5] MÖLLER T. Selective crystalline inorganic materials as ion exchanger in the treatment of nuclear waste solutions. 2002. Dissertação (Mestrado) - Faculty of Science of the University of Helsinki, Helsinki.

[6] OOI, K.; ABE, M. Ion-exchange equilibria of alkaline earth metal ions/hydrogen ions on tin(IV) antimonate. Solvent Extraction and Ion Exchange. v. 14, n. 6, p. 1137-1148, 1996.

[7] PAGANINI, P. P. Estudo da adsorção do gálio em trocadores iônicos inorgânicos a base de estanho. 2004. Monografia (Conclusão de curso de Engenharia Química) - Faculdades Oswaldo Cruz, São Paulo.

[8] Zeolite Molecular Sieve. Disponível em:

<http://www.gracedavison.com/eusilica/Adsorbents/product/zeolite_molecular_sieve.h tm>. Acesso em: 31 ago. 2007.

[9] Special Chem 4 polymer. Disponível em:

<http://www.specialchem4polymers.com/documentspa/indexables/editorial/articles/17 19/lon.jpg>. Acesso em: 31 ago. 2007.

[10] VESELÝ, V.; PEKÁREK, V. Synthetic inorganic íon-eschangers-I: hydrous oxides and acidic salts of multivalent metals. Talanta, v. 19, n. 3, p. 219-262, 1972. 
[11] SANTOS, J. L. Trocadores iônicos inorgânicos à base de manganês e potássio para recuperação e remoção de metais poluentes de efluentes aquosos. 2001. Dissertação (Mestrado) - Instituto de Pesquisas Energéticas e Nucleares, IPEN/CNEN-SP, São Paulo.

[12] VESELÝ, V.; PEKÁREK, V. Synthetic inorganic íon-eschangers-II: salts of heteropolyacids, insoluble ferrocyanides, synthetic aluminosilicates and miscellaneous exchangers. Talanta, v. 19, n. 11, p. 1245-1283, 1972.

[13] CLEARFIELD, A. Role of íon exchenge in solid-state chemistry. Chemical Reviews, v. 88, p. 125-148, 1988.

[14] VAN, J.; SMIT, R. J. Ion exchange on ammonium molybdophosphate-III: Preparation and properties of coarse ammonium heteropolyacid salts. Inorg. Nucl. Chem. v. 27, p. 227-228, 1965.

[15] QURESHI M., VARSHNEY K.G., Inorganic Ion Exchangers in Chemical Analysis, Boca Raton, FL: CRC press, 1991.

[16] RAWAT, J. P. SINGH, D. K. Synthesis, ion-exchange properties and analytical applications of iron (III) antimonate. Anal. Chim. Acta, v. 87, n. 1, p. 157-162, 1976.

[17] QURESHI, M. KUMAR, R. SHARMA, V. Synthesis of reproducible tin(IV)-based ion exchangers. Separation of lanthanum(III) from yttrium(III), europium(III), and lutenium(III), Anal. Chem. v. 46, n. 12, p. 1855-1858, 1974.

[18] NARBUTT, J.; BILEWICZ, A.; BARTOS, B. Composite ion exchangers: prospective nuclear applications. Journal of Radianalytical and Nuclear Chemistry Articles. v. 183, n. 1, p. 27-32, 1994.

[19] ABE, M.; ITO, T. Ion adsorptive properties of insoluble tetra-, penta-, hexa-valent metal hydrous oxides. Nippon Kagaku Zasshi (Chem. Soc. Japan.) v. 86, n. 12, p. 1259-1266, 1965.

[20] CLEARFIELD A. Inorganic ion exchangers: a technology ripe for development. Industrial and Engineering Chemistry Research. v. 34, p. 2865-2872, 1995.

[21] TAUSTER S. J.; FUNG, S. C.; BAKER, R. T. K.; HORSLEY, J. A. Stronginteractions in supported-metal catalysts. Science. v. 211, n. 4487, p. 1221-1125, 1981. 
[22] DONALDSON, J. D.; FULLER, M. J. Ion exchange proprieties of tin (IV) materials - I Hydrous tin (IV) oxide and its cation exchange properties, J. Inorg Nucl. Chem., v. 30, n. 4, p.1083-1092, 1968.

[23] DONALDSON, J. D.; FULLER, M. J. Ion exchange proprieties of tin (IV) materials - III Anion Exchange and further caton exchange studies on hydrous tin(IV) oxide, J. Inorg Nucl. Chem., v. 32, n. 5, p. 1703-1710, 1970.

[24] RENAULT, N., Fixation of elements of the first transition series on tin dioxide in hydroorganic media. Anal. Chim. Acta. v. 70, n. 2, p. 469-474, 1974.

[25] HEITNER-WIRGUI, C.; ALBU-YARON, A. Hydrous oxides and their cationexchange properties, J. Appl. Chem. (London), v.15, p. 445, 1965.

[26] SCHIEWER, E.; LEVI, H. W., Exchange of metal and hydrogen ions on hydrous titanium dioxide, in Radiochem. Cont., Abstr. Pap. Bratislava, v. 20, 1966.

[27] LEVI, H. W. AND SCHIEWER, E. Adsorption exchange of cations on $\mathrm{TiO}_{2}$, Radiochim. Acta, v. 5, p.126, 1966.

[28] LEVI, H. W. AND SCHIEWER, E. Exchange adsorption on hydrated titanium dioxide - III. Thalium-hidrogen exchange. Radiochim. Acta, v. 14, p. 43, 1970.

[29] SAHA, B.; GILL, R. J.; BAILEY, D. G.; KABAY, N.; ARDA, M.; Sorption of $\mathrm{Cr}(\mathrm{VI})$ from aqueous solution by Amberlite XAD-7 resin impregnated with Aliquat 336 . Reactive \& Funcional Polymers, v. 60, p. 223-244, 2004.

[30] ROHM AND HAAS COMPANY. Product Data Sheet - PDS 0529 A, p. 1-4, 2001. Apud: FERREIRA, F. A. Estudos da modificação da resina não-iônica Amberlite XAD-7 com monoetanolamina (MEA) para retenção de espécies de S(IV). 2007. Dissertação (Mestrado) - Instituto de Química, Universidade de São Paulo-USP, São Paulo.

[31] AMBERLITE XAD POLYMERIC RESINS. Sigma Prod. Nos. XAD-4, XAD-7, XAD-16, 1-0377,1-0393, and 1-0379. Disponível em:

<http://www.sigmaaldrich.com/sigma/product\%20information\%20sheet/xad7pis.pdf>. Acesso em: 31 jan. 2007

[32] ANDERSSON, B. ANDERSSON K. Use of Amberlite XAD-7 as a concentrator column in the analysis of endogenous plant growth hormones, Journal of Chromatography, v. 242, p. 353-358, 1982. 
[33] DUFFUS, J. H. "Heavy metals"-a meaningless term? (IUPAC Technical Report) Pure Appl. Chem. v. 74, n. 5, p. 793-807, 2002.

[34] BAIRD, C., Environmental chemistry. New York, N.Y. Freeman and Company, 1998. apud: GUEDESA, J. A.; LIMAD, R. F. S.; SOUZA, L. C. Metais pesados em água do rio Jundiaí - Macaíba/RN. Revista de Geologia, v.18, n. 2, p. 131-142, 2005.

[35] AZIZ, H.A. et al., Heavy metals (Cd, Pb, Zn, Ni, Cu and $\mathrm{Cr}(\mathrm{III})$ ) removal from water in Malaysia: Post treatment by high quality limestone. Bioresour. Technol. doi:10.1016/j.biortech.2007.04.007, 2007.

[36] RUSSELL J. B. Química Geral. v. 2. 2.ed. São Paulo, Makron books, 1994.

[37] VOGEL A. Química Analítica Qualitativa. São Paulo, Mestre, 1981.

[38] SOFTCIENCIAS. Tabela Periódica versão2.5. Disponível em:

<http://nautilus.fis.uc.pt/st2.5/scenes-p/elem/e04820.html> Acesso em: 8 out. 2006.

[39] TENORIO, J. A. S.; ESPINOSA, D. C. R. Reciclagem de Pilhas e Baterias.

Disponível em: <http://www.cepis.ops-oms.org/bvsare/e/proypilas/pilas.pdf> Acesso em: 8 out. 2006.

[40] WIKIPEDIA. Biblioteca virtual. Disponível em:

<http://pt.wikipedia.org/wiki/C\%C3\%A1dmio> Acesso em: 26 jan. 2007.

[41] ATKINS P.; JONES L. Princípios de Química - Questionando a Vida moderna e o meio Ambiente. 3.ed. Porto Alegre, Bookman, 2006.

[42] J. MIZUNO, The Crystal Structure of Nickel Chloride Hexahydrate, $\mathrm{NiCl}_{2} \cdot 6 \mathrm{H}_{2} \mathrm{O} \mathrm{J}$. Phys. Soc. Japan, v. 16, n. 8, p. 1574-1580, 1961.

[43] NICHOLLS, D. The chemistry of iron, cobalt and nickel. Vol. 24. Oxford: Pergamon Press, 1975.

[44] DE CARLI, Ligia et al . Study of stability of phytic acid with Ni(II) complex. Ciênc. Tecnol. Aliment. , Campinas, v. 26, n. 1,2006 . Disponível em: $<$ http://www.scielo.br/scielo.php?script=sci_arttext\&pid=S0101$20612006000100004 \&$ Ing=en\&nrm=iso>. Acesso em: 26 jan. 2007. 
[45] WIKIPEDIA. Biblioteca virtual. Disponível em:

<http://pt.wikipedia.org/wiki/N\%C3\%Adquel)26/01/2007> Acesso em: 26 jan. 2007.

[46] LANKEY R.L. Materials Management and Recycling for Nickel-Cadmium Batteries. 1998. Tese (Doutorado)- University Pittsburgh, PA.

[47] CASTRO K.C., FREITAS M. B. J. G. Reciclagem eletroquímica de níquel de baterias de Ni-MH de telefones celulares. REUNIÃO ANUAL DA SOCIEDADE BRASILEIRA DE QUÍMICA, 29., 19-22 maio, 2006, Águas de Lindóia. Química é energia: Transforma a vida e preserva o ambiente. Livro de resumos. São Paulo: Sociedade Brasileira de Química, 2006.

[48] PEREIRA, M. C.; CUNHA, F. L.; CLIQUeT Jr, A.; KASSAB Jr, F. Estudo Comparativo dos Meios de Alimentação de uma Prótese Multifunção para Membros Superiores. III CONGRESSO IBEROAMERICANO IBERDISCAP, 2004, São José. Tecnologias de Apoio a Portadores de Deficiência. Disponível em: $<$ http://www.gpec.ucdb.br/artigos/pereira_iberdiscap2004.pdf> Acesso em: 8 out. 2006.

[49] SOUZA R.M.P. LEAO, V. A.; PINA, P. S. Remoção de metais pesados sólidos: o caso das baterias de celulares. Rem: Rev. Esc. Minas, Ouro Preto, v.58, n.4 p.375379, 2005. Disponível em:

<http://www.scielo.br/scielo.php?script=sci_arttext\&pid=S0370-

44672005000400012\&lng=en\&nrm=iso>. Acesso em: 8 out. 2006.

[50] AFONSO, J. C. et al. Processamento da pasta eletrolítica de pilhas usadas. Quím. Nova., São Paulo, v. 26, n. 4, p. 573-577, 2003.

[51] II Cadmio: Proprietà ed Applicazioni. Metallurgia Italiana. v. 82, n. 1, p. 75-77, 1990. apud: TENORIO, J. A. S.; ESPINOSA, D. C. R. Reciclagem de Pilhas e Baterias. Disponível em: <http://www.cepis.ops-oms.org/bvsare/e/proypilas/pilas.pdf > Acesso em: 8 out. 2006.

[52] HEMENWAY, C.G., GILDERSLUVE, J.P., ISO 14000 - O que é ?, IMAM, 1995. apud: TENORIO, J. A. S.; ESPINOSA, D. C. R. Reciclagem de Pilhas e Baterias. Disponível em: <http://www.cepis.ops-oms.org/bvsare/e/proypilas/pilas.pdf> Acesso em: 8 out. 2006.

[53] TAKADA, P. Pesquisas começam quando pilhas acabam. Disponível em: <http://www.usp.br/jorusp/arquivo/2001/jusp575/caderno/universidade1.html>. Acesso: 24 jan. 2007. 
[54] International Metals Reclamation Company (INMETCO). Disponível em: <http://www.rbrc.com/inmetco.htm> apud: TENORIO, J. A. S.; ESPINOSA, D. C. R. Reciclagem de Pilhas e Baterias. Disponível em: <http://www.cepis.opsoms.org/bvsare/e/proypilas/pilas.pdf> Acesso em: 8 out. 2006.

[55] DAVID, J. Nickel-cadmium battery recycling evolution in Europe. Journal of Power Sources, v. 57, n. 1-2, p. 71-73, 1995.

[56] JACKSON, E. Hydrometallurgical Extraction and Reclamation. New York: John Wiley \& Sons, 1986.

[57] CORNU, J-P. The NiCd Battery: A Must for the Public Transit. NiCad94, Report on Conference: Geneva, Switzerland, September 1994, Published by International Cadmium Association, London, January 1995, p. 39-44. apud: LANKEY R.L. Materials Management and Recycling for Nickel-Cadmium Batteries. 1998. Tese (Doutorado)- University Pittsburgh, PA.

[58] BARROS, M. A. S. D.; ARROYO, P. A. Métodos de adsorção. Métodos de Remoção de Cromo de Águas Residuais. Disponível em:

$<w w w . i c p . c s i c . e s / c y t e d / M o n o g r a f i a s / M o n o g r a f i a s T e n e r i a / c a p i t u l o v . p d f>$.Acesso em: 26 out. 2006.

[59] DAVIDSON J. H. and MCMURRY P. H. Adsorption. 2000 Disponível em: <http://www.me.umn.edu/education/courses/me5115/notes/Adsorption_1.pdf > Acesso em: 20 set. 2004

[60] ANTONIO, P. Adsorção de di-2-piridil cetona saliciloilhidrazona (DPKSH) em sílica-gel. 2003. Dissertação (Mestrado) - Instituto de Química, Universidade de São Paulo-USP, São Paulo.

[61] MEZZARI, I. A. Utilização de carvões adsorventes para o tratamento de efluentes contendo pesticidas. 2002. Dissertação (mestrado) - Universidade Federal de Santa Catarina, Florianópolis.

[62] RUTHVEN, D. M. Principles of Adsorption and Adsorption Process. New York: Ed. John Wiley\&Sons, 1984.

[63] SANTOS, M. A. S. Isoterma de adsorção. Universidade Federal de Santa Maria. Departamento de Física - CCNE. Disponível em:

<http://w3.ufsm.br/juca/adsorcao.pdf> Acesso em: 30 out. 2006. 
[64] LOPES, N. P.; QUEIROZ, M. E. L. R; NEVES A. A.; ZAMBOLIM, L. Influência da matéria orgânica na adsorção do fungicida triadimenol pelo solo. Química Nova. v. 25, n. 4, p. 544-547, 2002.

[65] SODRÉ, F. F.; LENZI, E.; COSTA, A. C. S. Utilização de modelos físicoquímicos de adsorção no estudo do comportamento do cobre em solos argilosos. Química Nova. v. 24, n. 3, p. 324-330, 2001.

[66] TEIXEIRA, V. G.; COUTINHO, F. M. B.; GOMES, A. S. Principais métodos de caracterização da porosidade de resinas à base de divinilbenzeno. Química nova. v. 24, n. 6, p. 808-818, 2001.

[67] FREUNDLICH, H. Z. Physik. Chem. v.57, p.444, 1906. Apud: ANTONIO, P. Adsorção de di-2-piridil cetona saliciloilhidrazona (DPKSH) em sílica-gel. 2003. Dissertação (Mestrado) - Instituto de Química, Universidade de São Paulo-USP, São Paulo.

[68] LANGMUIR, I. The adsorption of gases on plane surfaces of glass, mica and platinum. J. Am. Chem. Soc. v.40,n.9 1361-1403,1918.

[69] DUBININ, M. M.; RADUSHKEVICH, I. W.; Compt. Rend. Acad. Sci., URSS, v.55, p.327, 1947. Apud: ANTONIO, P. Adsorção de di-2-piridil cetona saliciloilhidrazona (DPKSH) em sílica-gel. 2003. Dissertação (Mestrado) - Instituto de Química, Universidade de São Paulo-USP, São Paulo.

[70] MCKAY, G. Use of adsorbents for the removal of pollutants from wastewaters. New York: CRC Press, Inc.,1996.

[71] RUPP, M. T. C. Utilização de Zeólitas no Tratamento de Efluentes Inorgânicos. 1996. Tese (Doutorado) - COPPE/UFRJ, Rio de Janeiro.

[72] FRITZ, W. and SCHLÜNDER, E. U.; Competitive adsorption of two dissolved organics onto activated carbon - I Adsorption Equilibria; Chemical Engineering Science. v. 36; p. 721-730; 1981.

[73] MASTRAL, A. M. et al. Measurements of Polycyclic Aromatic Hydrocarbon Adsorption on Activated Carbons at Very Low Concentrations. Ind. Eng. Chem. Res. v. 42, p.155-161, 2003.

[74] MOREIRA C. S. Adsorção competitiva de cádmio, cobre níquel e zinco em solos. 2004. Dissertação (Mestrado) - Universidade de São Paulo, Piracicaba. 
[75] ATKINS, P.W. Physical chemistry. Oxford, Oxford University Press, 1994.

[76] HARTER, R. Curve-fit errors in Langmuir adsorption maxima. Soil Sci. Soc. Am. J. v. 48, n. 4, p. 749-752, 1984.

[77] KILISLIOGLU, A.; BILGIN, B. Adsorption of uranium on halloysite. Radiochim Acta, v. 90, p. 155-160, 2002.

[78] SHEHA R.R.; METWALLY E. Equilibrium isotherm modeling of cesium adsorption onto magnetic materials. Journal of Hazardous Materials. v. 143, p. 354-361, 2007.

[79] RENGARAJ S. at all. Adsorption characteristics of $\mathrm{Cu}(\mathrm{II})$ onto ion exchange resins $252 \mathrm{H}$ and $1500 \mathrm{H}$ : Kinetics, isotherms and error analysis. Journal of Hazardous Materials. v. 143, p. 469-477, 2007.

[80] MA W.; QUN F.; HAN M.; WANG R. Characteristics of equilibrium, kinetics studies for adsorption of fluoride on magnetic-chitosan particle. Journal of Hazardous Materials. v. 143, p. 296-302, 2007.

[81] MALL I. D.; SRIVASTAVA V. C.; AGARWAL N. K. Adsorptive removal of Auramine-O: Kinetic and equilibrium study. Journal of Hazardous materials. v.143, p.386-395, 2007.

[82] MASTRAL, A. M. et al. Measurements of Polycyclic Aromatic Hydrocarbon Adsorption on Activated Carbons at Very Low Concentrations. Ind. Eng. Chem. Res. v. 42, p. 155-161, 2003.

[83] LIEC. Laboratório de cerâmica da universidade federal de São Carlos. Apresenta texto sobre Materiais luminescentes. Disponível em:

$<$ http://www.liec.ufscar.br/ceramica/pesquisa/luminescencia/page2.html>. Acesso em: 12 abr. 2000.

[84] BARROW, G. M., Introduction to Molecular Spectroscopy. New York: McGraw-Hill, 1962.

[85] CHEMKAEY. Site de química. Apresenta material didático sobre elementos de espectroscopia. Disponível em:

$<$ http://www.chemkeys.com/bra/md/ede_5/edl_14/aanrdu_2/aanrdu_2.htm>. Acesso em: 12 abr. 2000. 
[86] CHEMKAEY. Site de química. Apresenta material didático sobre elementos de espectroscopia. Disponível em:

$<$ http://www.chemkeys.com/bra/md/ede_5/edl_14/opde_24/opde_24.htm>. Acesso em: 12 abr. 2000.

[87] KARPLUS, M. and PORTER, R. N. Atoms and Molecules - An Introduction for Students of Physical Chemistry, London, The Benjamin, 1970.

[88] CHEMKAEY. Site de química. Apresenta material didático sobre elementos de espectroscopia. Disponível em:

<http://www.chemkeys.com/bra/md/ede_5/eede_11/oee_25/oee_25.htm>. Acesso em: 12 abr. 2000.

[89] LAKOWICZ, J. R., Principles of Fluorescence Spectroscopy. New York: 2nd edition, Kluwer Academic, 1999.

[90] CHEMKAEY. Site de química. Apresenta material didático sobre elementos de espectroscopia. Disponível em:

<http://www.chemkeys.com/bra/md/ede_5/eede_11/oede_24/oede_24.htm>.

[91] BIRKS, J. B., Photophysics of Aromatic Molecules. London: Wiley Interscience, 1970.

[92] CHEMKAEY. Site de química. Apresenta material didático sobre elementos de espectroscopia. Disponível em:

$<$ http://www.chemkeys.com/bra/md/ede_5/edl_14/eede_25/eede_25.htm>. Acesso em: 12 abr. 2000.

[93] CHEMKAEY. Site de química. Apresenta material didático sobre elementos de espectroscopia. Disponível em:

$<$ http://www.chemkeys.com/bra/md/ede_5/eede_11/oede_23/oede_23.htm>. Acesso em: 12 abr. 2000.

[94] LUTZ, D. The Quietly Expanding Rare-Earth Market. American Institute of Physics, 1996 Disponível em: <http://www.tipmagazine.com/tip/INPHFA/vol-2/iss3/p28.pdf> Acesso em: 26 jan. 2007.

[95] BROCK, W. H., The Norton History of Chemistry. $1^{\text {a }}$ ed., W.W. Norton \& Company, 1993. 
[96] BEQUEREL, J. Phys. Z., v.8, p.632, 1908. Apud: KODAIRA, C. A. Síntese e espectroscopia de sistemas contendo tungstatos e íons terras raras. 2003. Tese (Doutorado) - Universidade de São Paulo, USP, São Paulo.

[97] BETHE, H. Phys Z.. v.60, p.218, 1930. Apud: KODAIRA, C. A. Síntese e espectroscopia de sistemas contendo tungstatos e íons terras raras. 2003. Tese (Doutorado) - Universidade de São Paulo, USP, São Paulo.

[98] KRAMERS, H. A. Proc. Acad. Sci. Amsterdam, v.32, p.1176, 1930. Apud: KODAIRA, C. A. Síntese e espectroscopia de sistemas contendo tungstatos e íons terras raras. 2003. Tese (Doutorado) - Universidade de São Paulo, USP, São Paulo.

[99] BLASSE G., GRABMAIER B. C., Luminescence Materials; Springer Verlag; Heidelberg, 1994.

[100] JÜSTEL, T.; NIKOL, H.; RONDA, C.; New developments in the field of luminescent materials for lighting and displays. Angew. Chem., Int. Ed. Engl., v. 37, n. 22, p. 3085-3103, 1998.

[101] PIETERSON, V. L. Charge Transfer and $4 \mathrm{f}^{\mathrm{N}} \rightarrow 4 \mathrm{f}^{\mathrm{N}-1} \mathbf{5 d - L u m i n e s c e n c e ~ o f ~}$ Lanthanide Ions. 2001. Tese (Doutorado) - Universiteit Utrecht, Netherlands.

[102] BATISTA H. J. Novos Desenvolvimentos e Aplicações de Métodos de Química Quântica para Compostos de Coordenação com íons Lantanídeos. 2003. Tese (Doutorado) - Universidade Federal de Pernambuco, Recife.

[103] DIEKE G. H. Spectra and Energy Levels of Rare Earth lons in Crystals, Wiley, New York, 1968.

[104] WYBOURNE B. G., Spectroscopic properties of Rare Earths, Interscience, New York, 1965.

[105] CARO, P. Structure électronique des éléments de transition, Presses Universitaires de France, França, 1976.

[106] CARNALL, W.T.; CROSSWHITE, H. and CROSSWHITE, H. M. Energy Structure and Transition Probabilities of the Trivalent Lanthanides in $\mathrm{LaF}_{3}$, Argonne National Laboratory Report, unnumbered, 1977. 
[107] HÜFNER S., Optical Spectra of Transparent Rare Earth Compounds, Academic Press, New York, 1978.

[108] PORCHER, P.; CARO, P. Crystal-field parameters for eu3+ in ky3f10 2. intensity parameters. J. Chem. Phys. v. 68, n. 9, p. 4176-4182, 1978.

[109] MALTA O. L., A simple overlap model in lanthanide crystal-field. Chem. Phys. Lett. v. 87, p. 27-29, 1982.

[110] CARNALL W. T., CROSSWHITE H. The Chemistry of the Actindes Elements. v. 2. $2^{\text {a }}$ ed., New York, 1986.

[111] CARNALL W. T., GOODMAN G. L, RAJNAK K., RANA R.S. A Systematic Analysis of the Spectra of the Lanthanides doped into Single Crystal $\mathrm{LaF}_{3}$, Argonne National Laboratory Report, unnumbered, 1988.

[112] JUDD, B. R. Operator Techniques in spectroscopy. $2^{\mathrm{a}}$ ed., Ed. Mcgraw-Hill Book Company, USA, 1998.

[113] PUCHE R. S., CARO P. Rare Earths - cursos de verano de el escorial. Editorial Complutense, Madrid, 1998.

[114]. BÜNZLI J. C. G, CHOPPIN G. R., Lanthanide Probes in Life, Chemical and Earth Sciences: Theory and Practice. Elsevier, Amsterdam, 1989.

[115] JUDD. B. R. Optical absorption intensities of rare-earth ions. Phys. Rev. v. 127, n. 3, p. 750, 1962.

[116] OFELT G. S. Intensities of crystal spectra of rare-earth ions. J. Chem. Phys. v. 37, n. 3, p. 511, 1962.

[117] SILVA F. R. G. Estudo dos Processos de Transferência de Energia entre Ligante e Íon Lantanídio em Compostos de Coordenação. 1999. Tese (Doutorado) - Universidade Federal de Pernambuco, Recife.

[118] HILL C. G. A., Inorganic luminescent materials. Chem. Brit. v. 19, n. 9, p. 723-724, 1983.

[119] DELUCA, J. A. An introduction to luminescence in inorganic solids. J. Chem. Educ. v. 57, n. 8, p. 541-545, 1980. 


\section{PARTE EXPERIMENTAL}

Neste trabalho a parte experimental esta dividida em quatro itens distintos que são: a síntese dos trocadores iônicos inorgânicos, suas caracterizações, avaliação das propriedades espectroscópicas do trocador dopado com európio e avaliação do comportamento destes trocadores na retenção de íons.

\subsection{Reagentes}

As substâncias utilizadas neste trabalho foram empregadas sem tratamento prévio (exceto a resina XAD-7). Na TAB 4.1 encontra-se a relação das substâncias usadas e suas procedências.

TABELA 4.1 - Lista de reagentes utilizados nas etapas do trabalho.

\begin{tabular}{|c|c|c|}
\hline SUBSTÂNCIA & FÓRMULA & PROCÊDÊNCIA \\
\hline Estanho (granulado mesh 20) & Sn & Synth (PA) \\
\hline Ácido clorídrico & $\mathrm{HCl}$ & Caal (PA) \\
\hline Peróxido de hidrogênio & $\mathrm{H}_{2} \mathrm{O}_{2}$ & Synth (PA) \\
\hline Cloreto de titânio & $\mathrm{TiCl}_{3}$ & VETEC (PA) \\
\hline Hidróxido de amônio & $\mathrm{NH}_{4} \mathrm{OH}$ & Caal (PA) \\
\hline Óxido de európio & $\mathrm{Eu}_{2} \mathrm{O}_{3}$ & SIGMA (PA) \\
\hline Nitrato de prata & $\mathrm{AgNO}_{3}$ & Merck (PA) \\
\hline Resina Amberlit XAD-7 & Poliacrilato & Aldrich (PA) \\
\hline Metanol & $\mathrm{CH}_{3} \mathrm{OH}$ & Merck (PA) \\
\hline Óxido de cádmio & $\mathrm{CdO}$ & Caal (PA) \\
\hline Ácido nítrico & $\mathrm{HNO}_{3}$ & Merck (PA) \\
\hline Ácido acético & $\mathrm{CH}_{3} \mathrm{COOH}$ & Merck (PA) \\
\hline Acetato de amônio & $\mathrm{CH}_{3} \mathrm{COONH}_{4}$ & EGIBRA (PA) \\
\hline Acetato de sódio & $\mathrm{CH}_{3} \mathrm{COONa}$ & Backer (PA) \\
\hline Hidróxido de sódio & $\mathrm{NaOH}$ & Reagen (PA) \\
\hline Ditizona & $\mathrm{C}_{13} \mathrm{H}_{12} \mathrm{~N}_{4} \mathrm{~S}$ & Merck (PA) \\
\hline Clorofórmio & $\mathrm{CHCl}_{3}$ & Caal (grau espec.) \\
\hline Tartarato de sódio e potássio & $\mathrm{COOK}(\mathrm{CHOH})_{2} \mathrm{COONa} .4 \mathrm{H}_{2} \mathrm{O}$ & Carlo Erba (PA) \\
\hline Cloreto de níquel(II) & $\mathrm{NiCl}_{2} \cdot 6 \mathrm{H}_{2} \mathrm{O}$ & Merck (PA) \\
\hline Dimetilglioxima & $\mathrm{CH}_{3} \mathrm{C}(\mathrm{NOH}) \mathrm{C}(\mathrm{NOH}) \mathrm{CH}_{3}$ & Merck (PA) \\
\hline Etanol & $\mathrm{C}_{2} \mathrm{H}_{5} \mathrm{OH}$ & Caal (grau espec.) \\
\hline Persulfato de potássio & $\mathrm{K}_{2} \mathrm{~S}_{2} \mathrm{O}_{8}$ & Caal (PA) \\
\hline
\end{tabular}




\subsection{Sínteses}

\subsubsection{Síntese dos trocadores iônicos inorgânicos $\mathrm{SnO}_{2} / \mathrm{TiO}_{2}$ e $\mathrm{SnO}_{2} / \mathrm{TiO}_{2}$ : $\mathrm{Eu}^{3+}$}

$\mathrm{O}$ óxido composto de $\mathrm{SnO}_{2} / \mathrm{TiO}_{2}$ foi preparado dissolvendo-se, primeiramente, o estanho metálico com ácido clorídrico e oxidando-o à $\mathrm{Sn}^{4+}$ com peróxido de hidrogênio. A esta solução acrescentou-se $\mathrm{TiCl}_{3}$ e hidróxido de amônio foi adicionado à solução até neutralização, pH 7. As partículas foram deixadas envelhecer na solução licor por 48h. O precipitado obtido era muito fino, desta maneira, para a lavagem do mesmo optou-se pela migração de íons cloreto (diálise) utilizando-se membranas de celofane onde o gradiente para separação utilizado foi a diferença de concentração dos íons $\mathrm{Cl}^{-}$em solução. Para controle analítico dos íons cloreto optou-se pelo teste com $\mathrm{AgNO}_{3}$. Após eliminação dos íons cloreto, secou-se o material a $110^{\circ} \mathrm{C}$.

$\mathrm{O}$ óxido composto de $\mathrm{SnO}_{2} / \mathrm{TiO}_{2}$ dopado com európio foi preparado via mesma rota de síntese acrescentando-se à solução inicial de $\mathrm{TiCl}_{3} \circ \mathrm{EuCl}_{3} .6 \mathrm{H}_{2} \mathrm{O}$ obtido a partir da reação do óxido de európio com ácido clorídrico.

A composição molar da solução contendo os metais foi de $0,25 \mathrm{~mol} \mathrm{Sn}$, $0,03 \mathrm{~mol} \mathrm{Ti} \mathrm{e} 3,85 \times 10^{-4} \mathrm{~mol}$ Eu (FIG 4.1).

\subsubsection{Síntese dos trocadores híbridos $\mathrm{SnO}_{2} / \mathrm{TiO}_{2}$ e $\mathrm{SnO}_{2} / \mathrm{TiO}_{2}: \mathrm{Eu}^{3+}$}

Para a síntese dos compósitos dos trocadores híbridos $\mathrm{SnO}_{2} / \mathrm{TiO}_{2}$ e $\mathrm{SnO}_{2} / \mathrm{TiO}_{2}: \mathrm{Eu}^{3+}$, a matriz polimérica utilizada, Amberlite XAD-7 foi previamente tratada para remoção de monômeros não reacionais e de agentes de estabilização, com água e metanol sendo posteriormente secas a $40^{\circ} \mathrm{C}$ até peso constante.

Após secagem pesou-se $50 \mathrm{~g}$ deste e adicionou-se uma solução de $\mathrm{Sn}^{4+} \mathrm{e}$ $\mathrm{TiCl}_{3}$ já previamente preparada. Deixou-se em solução por aproximadamente $24 \mathrm{~h}$ e neutralizou-se com hidróxido de amônio até ph 7, deixando as partículas na solução licor em repouso por $48 \mathrm{~h}$. Para o polímero dopado com európio seguiu-se a mesma rota de síntese acrescentando o cloreto de európio à solução de $\mathrm{Sn}^{4+} / \mathrm{TiCl}_{3}$. Lavagens do trocador com acido e base foi método de condicionamento da resina para estocagem (FIG 4.2). 


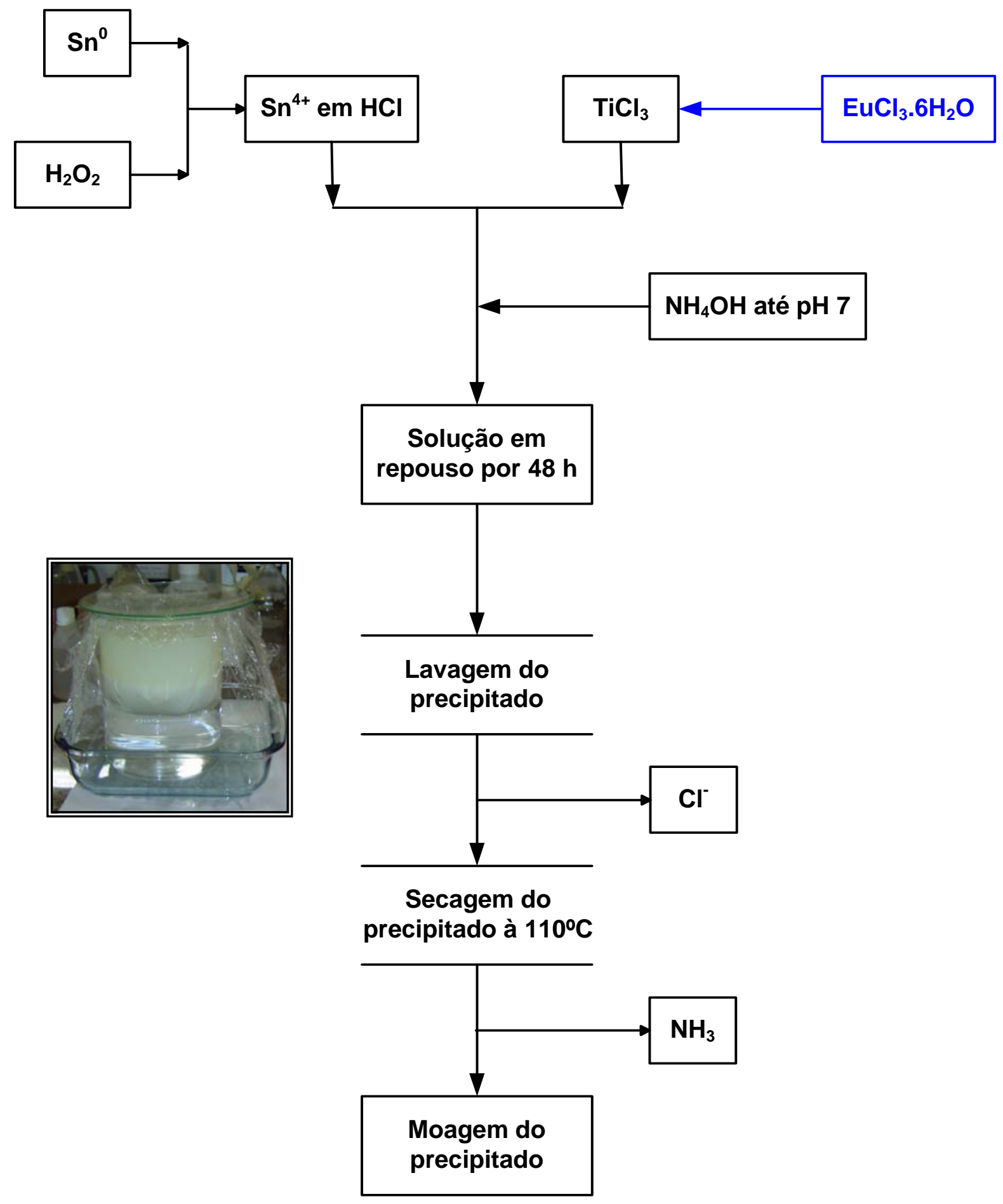

FIGURA 4.1- Fluxograma de síntese dos trocadores $\mathrm{SnO}_{2} / \mathrm{TiO}_{2}$ e $\mathrm{SnO}_{2} / \mathrm{TiO}_{2}$ : $\mathrm{Eu}^{3+} \mathrm{e}$ foto da lavagem do precipitado com membrana de celofane. 


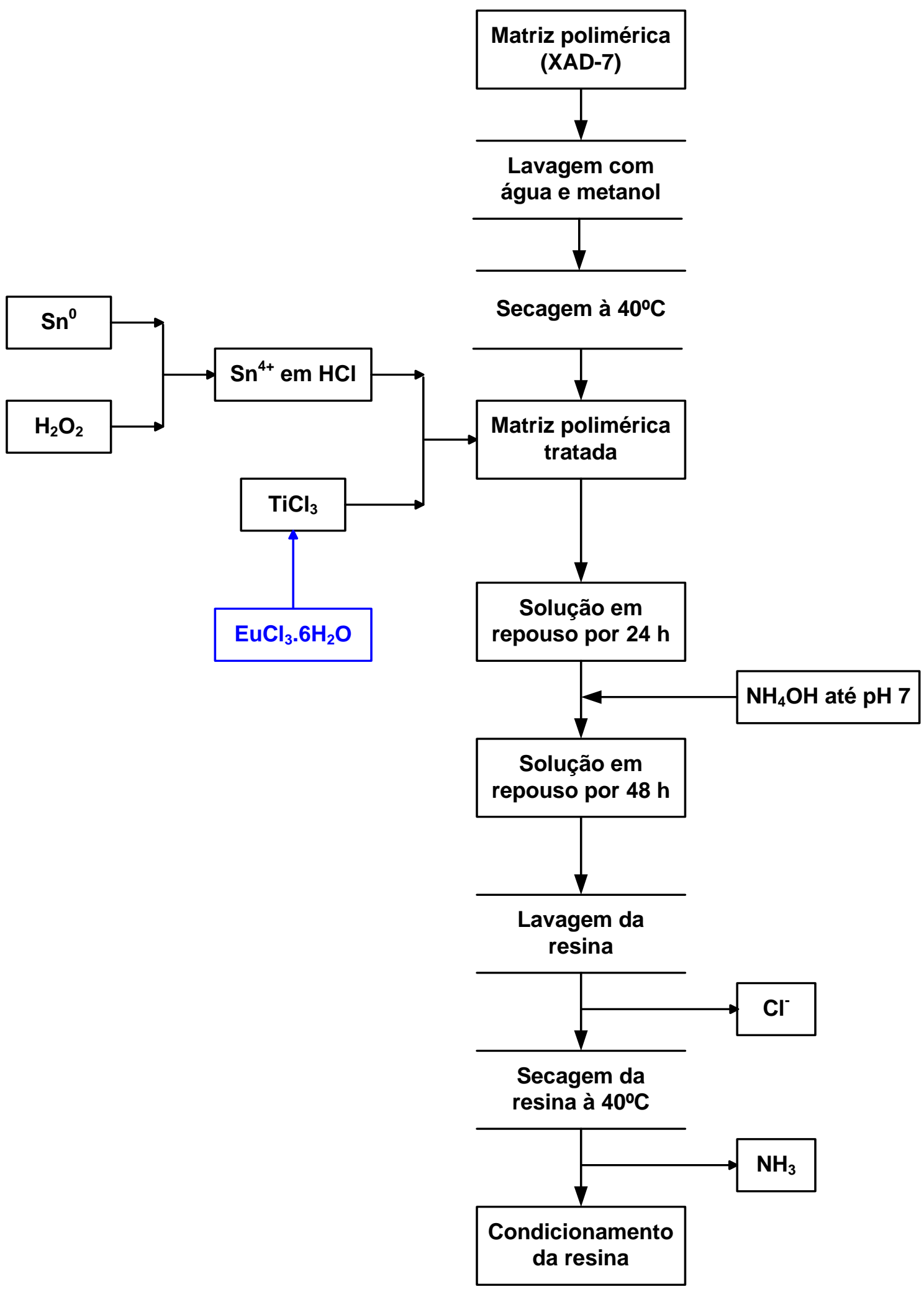

FIGURA 4.2- Fluxograma de síntese dos trocadores híbridos $\mathrm{SnO}_{2} / \mathrm{TiO}_{2}$ e $\mathrm{SnO}_{2} / \mathrm{TiO}_{2}: \mathrm{Eu}^{3+}$. 


\subsection{Caracterização}

A caracterização dos trocadores iônicos inorgânicos $\mathrm{SnO}_{2} / \mathrm{TiO}_{2}$ e $\mathrm{SnO}_{2} / \mathrm{TiO}_{2}: \mathrm{Eu}^{3+}$ foi realizada através de: espectroscopia de infravermelho, difração de raios- $X$, análise térmica, microscopia eletrônica de varredura. Na caracterização dos trocadores híbridos $\mathrm{SnO}_{2} / \mathrm{TiO}_{2}$ e $\mathrm{SnO}_{2} / \mathrm{TiO}_{2}$ : $\mathrm{Eu}^{3+}$ utilizaram-se as técnicas de análise térmica e microscopia eletrônica de varredura.

\subsubsection{Espectroscopia de infravermelho}

Os espectros de Infravermelho foram obtidos num espectrômetro de absorção na região do infravermelho com FTIR BOMEN 102 utilizando-se pastilhas de $\mathrm{KBr}$.

\subsubsection{Difração de raios- $X$}

Utilizou-se um Difratômetro de raios X Bruker-AXS modelo D8 Advance, com fonte de radiação $\mathrm{CuK}_{\alpha}$ As amostras foram dispersas em silicone em laminas de quartzo.

\subsubsection{Análise Térmica}

As curvas TGA foram obtidas em uma termobalança SDTA-822 (Mettler Toledo) usando amostras de aproximadamente $10 \mathrm{mg}$ em cadinho de alumina, sob atmosfera dinâmica de nitrogênio, com vazão de $50 \mathrm{~mL} \cdot \mathrm{min}^{-1}$ e razão de aquecimento de $10^{\circ} \mathrm{C} \cdot \mathrm{min}^{-1}$. As curvas DTGA foram obtidas a partir da diferenciação eletrônica do sinal TGA. As curvas de DSC foram registradas no calorímetro diferencial DSC $822^{\mathrm{e}}$ (Mettler Toledo) suporte acoplado a um amostrador Robot TSO 801RO, nas mesmas condições que as curvas TGA.

\subsubsection{Microscopia Eletrônica de Varredura}

Para se analisar a morfologia das amostras utilizou-se um microscópio eletrônico de varredura marca Philips modelo XR-30. As amostras foram pulverizadas sobre um suporte metálico adequado e recobertas com ouro pela técnica de "spputering". Esta técnica consiste em recobrir uma amostra, carregada 
positivamente em uma câmara de alto vácuo, através de elétrons ejetados que estão carregados negativamente. Por uma diferença de potencial aplicada, os elétrons aceleram para o eletrodo positivo, colidindo com uma molécula de gás, liberando íons e elétrons livres. Os íons positivos são então acelerados para o alvo, negativamente carregado, recobrindo assim a amostra.

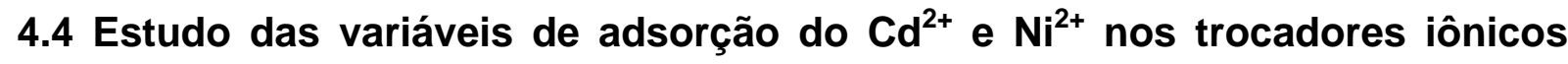 inorgânicos (TII)}

O desempenho dos trocadores $\mathrm{SnO}_{2} / \mathrm{TiO}_{2}$ e $\mathrm{SnO}_{2} / \mathrm{TiO}_{2}: \mathrm{Eu}^{3+}$ foi avaliado tendo-se como variáveis os seguintes fatores:

Influência do pH na adsorção do $\mathrm{Cd}^{2+}$ e do $\mathrm{Ni}^{2+}$

> Influência da concentração do $\mathrm{Cd}^{2+}$ e do $\mathrm{Ni}^{2+}$ na adsorção

$>$ Influência do tempo de contato na adsorção do $\mathrm{Cd}^{2+}$ e do $\mathrm{Ni}^{2+}$

$>$ Influência do $\mathrm{Cd}^{2+}$, como interferente, na adsorção do $\mathrm{Ni}^{2+}$

$>$ Estudo de dessorção do $\mathrm{Cd}^{2+}$ e do $\mathrm{Ni}^{2+}$

Todos os experimentos foram efetuados pelo sistema em batelada, com massa de trocador de aproximadamente $0,05 \mathrm{~g}$ e volume da fase aquosa de $1,5 \mathrm{~mL}$. As amostras foram colocadas em contato sob agitação por um tempo de 10 min em agitador elétrico e após separação das fases foram retiradas alíquotas pré-determinadas, para serem analisadas.

As amostras foram quantificados por método espectrofotométrico em espectrofotômetro modelo multispec 1501, marca SHIMADSU em cubetas de quartzo com caminho ótico de $1 \mathrm{~cm}$.

\subsubsection{Soluções}

\subsubsection{Análise de cádmio}

> Solução estoque de $\mathrm{Cd}^{2+} 1,1590 \mathrm{~g} \cdot \mathrm{L}^{-1}$ em ácido nítrico preparada a partir do óxido de cádmio estocada em pH 3 
> Solução de tartarato de sódio potássio a $20 \%$ em água

> Solução de hidróxido de sódio a 20\% em água

> Solução de hidróxido de sódio a 5\% em água

> Solução padrão estoque de ditizona a 0,01\% em clorofórmio. A solução de trabalho de $0,0025 \%$ foi preparada a partir da diluição em clorofórmio.

\subsubsection{Análise de níquel}

> Solução estoque de $\mathrm{Ni}^{2+} 1,0 \mathrm{~g} \cdot \mathrm{L}^{-1}$ em ácido clorídrico preparada a partir do cloreto de níquel(II), estocada em $\mathrm{pH} 3$

> Solução de tartarato de sódio potássio a $20 \%$ em água

> Solução de hidróxido de sódio a 20\% em água

$>$ Solução de dimetilglioxima $1 \%$ em etanol

$>$ Solução de persulfato de potássio $4 \%$ em água

\subsubsection{Estudos de adsorção de cádmio pelos trocadores iônicos inorgânicos}

\subsubsection{Estudo das variáveis}

$\mathrm{O}$ pH da solução de extração contendo o íon $\mathrm{Cd}^{2+}$ foi variado de 1 a 13 , com solução tampão de ácido acético/acetato de amônio/hidróxido de amônio, sendo a concentração de $\mathrm{Cd}^{2+}$ de 0,01159 g. $\mathrm{L}^{-1}$ e o tempo de contato de $10 \mathrm{~min}$.

A concentração foi variada de 0,01159 a 0,4 g. $\mathrm{L}^{-1}$ de $\mathrm{Cd}^{2+}$ em pH 4 e pH 9, com tempo de contato fixado em $10 \mathrm{~min}$.

As análises de tempo de contactação foram feitas com os trocadores na matriz híbrida, visto a grande dificuldade de decantação do trocador em forma de pó, em concentração de $0,01159 \mathrm{~g} \cdot \mathrm{L}^{-1}$ nos pH 4 e 9.

$\mathrm{O}$ estudo de dessorção do $\mathrm{Cd}^{2+}$ foi efetuado com os trocadores híbridos tendo o metal pré-adsorvido e colocou-se em contato essa fase trocadora com solução de ácido nítrico 1 mol. $\mathrm{L}^{-1}$. Os experimentos foram efetuados apenas com um contato. 


\subsubsection{Determinação espectrofotométrica do $\mathrm{Cd}^{2+}$}

O método de determinação consiste na extração do cádmio da fase aquosa, em meio fortemente alcalino, para a fase orgânica com formação do complexo pela agitação com ditizona em clorofórmio. ${ }^{[1]}$

Um volume pré-determinado $\left(0,4 \mathrm{~mL}\right.$ para $\left.\mathrm{C}_{\mathrm{Cd}^{2+}}=0,01159 \mathrm{~g} \cdot \mathrm{L}^{-1}\right)$ da amostra contendo cádmio foi colocado em um frasco de $15 \mathrm{~mL}$. Adicionou-se aproximadamente $0,4 \mathrm{~mL}$ de solução de tartarato de sódio e potássio a $20 \%$, para evitar precipitação do metal na forma de hidróxido. Adicionou-se solução de hidróxido de sódio $20 \%$ até obter solução alcalina de concentração final de $5 \%$. Extraiu-se o cádmio da fase aquosa com porções de $2 \mathrm{~mL}$ de ditizona em clorofórmio a 0,0025\% agitando-se as fases durante 5 minutos. Lavou-se os extratos orgânicos com uma porção de $2 \mathrm{~mL}$ de hidróxido de sódio 0,5\% para eliminação de excesso de ditizona. Transferiu-se o extrato orgânico para um balão volumétrico de $10 \mathrm{~mL}$ e completou-se o volume com clorofórmio. A absorbância foi medida contra a prova em branco, em comprimento de onda de $514 \mathrm{~nm}$ (comprimento escolhido pelo espectro de absorção do sistema cádimo-ditizona).

O complexo ditizonato de cádmio foi caracterizado por meio de seu espectro de absorção molecular (FIG. 4.3). Utilizou-se uma solução de $\mathrm{C}_{\mathrm{Cd}^{2+}}=0,01159 \mathrm{~g} \cdot \mathrm{L}^{-1} ; \mathrm{pH} \sim 4$ em temperatura ambiente com volume analisado de $0,4 \mathrm{~mL}$ e fez-se a varredura do comprimento de onda na faixa de 400 a $650 \mathrm{~nm}$.

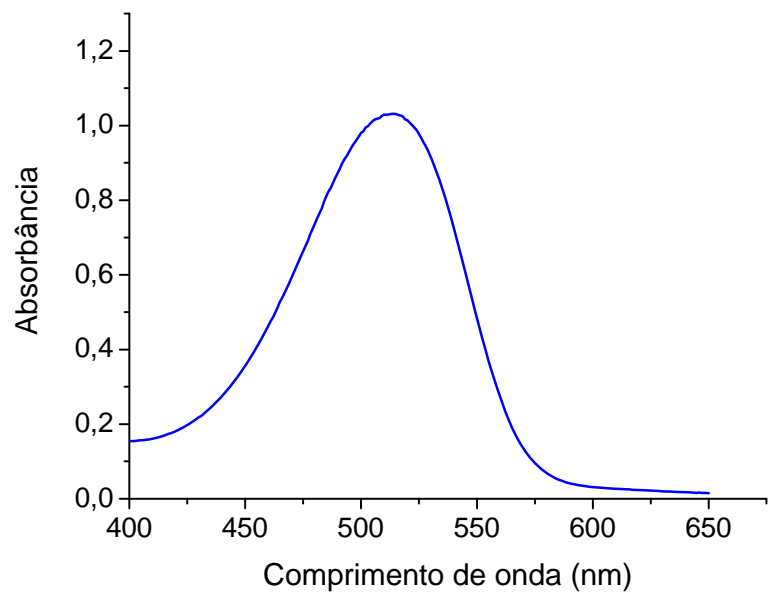

FIGURA 4.3 - Espectro de absorção do complexo ditizonato de cádmio. 
A curva de calibração (FIG. 4.4) foi obtida retirando-se, com pipetas volumétricas, alíquotas de 0,3 a $1,5 \mathrm{~mL}$ da solução padrão de $\mathrm{Cd}^{2+}$ (concentração igual a 0,01159 g. $\mathrm{L}^{-1}$ ) e analisando-se a concentração do metal de acordo com o método descrito acima. A equação de regressão linear obtida foi: $y=0,01098+0,59933 x$ com coeficiente de correção de 0,99841.

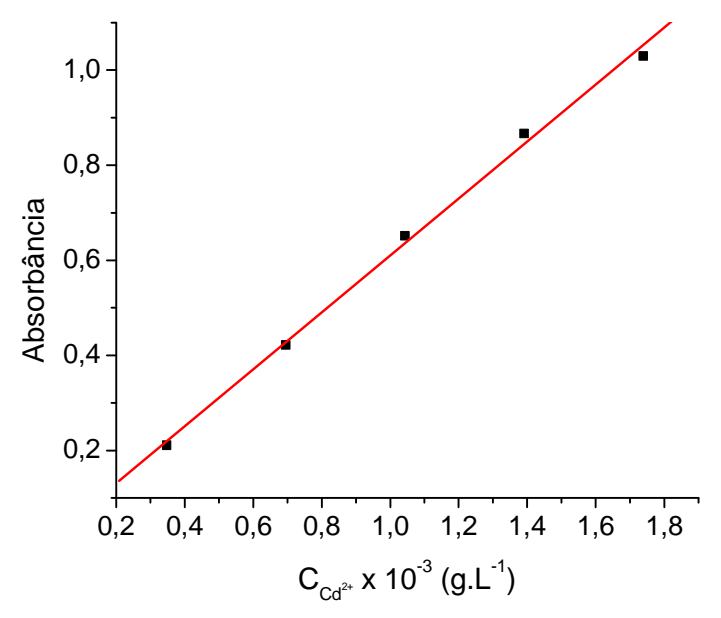

FIGURA 4.4 - Curva de calibração do $\mathrm{Cd}^{2+}$.

\subsubsection{Determinação por espectrometria de fluorescência de raios-X ("EDXRF")}

Utilizou-se um espectrômetro de fluorescência de raios- $X$ para a determinação da concentração de cádmio, pelo método de ensaio direto de amostras não-destrutivo. $O$ metal foi calculado por um software que permite a análise quantitativa das amostras utilizando uma biblioteca de dados de raios- $X$ que identifica diferentes metais. $O$ espectrômetro de fluorescência de raios- $X$ por energia dispersiva é um RAINNY-EDX-900HS da Shimadzu. A tensão do equipamento é de $50 \mathrm{kV}$ e corrente de $1000 \mu \mathrm{A}$ e com tubo de Rh.

\subsubsection{Estudos de adsorção de níquel pelos trocadores iônicos inorgânicos}

\subsubsection{Estudo das variáveis}

$\mathrm{O} \mathrm{pH}$ da solução de extração contendo o íon $\mathrm{Ni}^{2+}$ foi variado de 2 a 8, com solução tampão de ácido acético/acetato de sódio/hidróxido de sódio, sendo a concentração de $\mathrm{Ni}^{2+}$ de $0,3 \mathrm{~g} \cdot \mathrm{L}^{-1}$ e o tempo de contato de $10 \mathrm{~min}$. 
A concentração foi variada de 0,1 a $0,7 \mathrm{~g} \cdot \mathrm{L}^{-1}$ de $\mathrm{Ni}^{2+} \mathrm{em} \mathrm{pH} 7$, com tempo de contato fixado em 10 min.

As análises de tempo de contactação foram feitas com os trocadores na matriz híbrida, visto a grande dificuldade de decantação do trocador em forma de pó, em concentração de 0,3 g. $\mathrm{L}^{-1}$ nos $\mathrm{pH} 7$.

A influência do $\mathrm{Cd}^{2+}$, como íon interferente, na adsorção do $\mathrm{Ni}^{2+}$ foi estudada contactando-se soluções contendo os dois íons nas concentrações de $0,3 \mathrm{~g} \cdot \mathrm{L}^{-1}$ de $\mathrm{Ni}^{2+}$ para 0,$1 ; 0,3$ e $0,5 \mathrm{~g} \cdot \mathrm{L}^{-1}$ de $\mathrm{Cd}^{2+}$ em $\mathrm{pH} 7$.

$\mathrm{O}$ estudo de dessorção do $\mathrm{Ni}^{2+}$ foi efetuado com os trocadores híbridos tendo o metal pré-adsorvido e colocou-se em contato essa fase trocadora com solução de ácido clorídrico $1 \mathrm{~mol} \mathrm{~L}^{-1}$. Os experimentos foram efetuados apenas com um contato.

\subsubsection{Determinação espectrofotométrica do $\mathrm{Ni}^{2+}$}

O método de determinação do níquel é feito pela complexação do mesmo com dimetilglioxima em meio fortemente alcalino na presença do oxidante, persulfato de potássio. ${ }^{[2]}$

Um volume pré-determinado $\left(0,4 \mathrm{~mL}\right.$ para $\left.\mathrm{C}_{\mathrm{Ni}^{2+}}=0,3 \mathrm{~g} \cdot \mathrm{L}^{-1}\right)$ da amostra contendo níquel foi colocado em um balão volumétrico de $10 \mathrm{~mL}$. Adicionou-se aproximadamente $0,4 \mathrm{~mL}$ de solução de tartarato de sódio e potássio a $20 \%$, para evitar precipitação do metal na forma de hidróxido, $0,3 \mathrm{~mL}$ de hidróxido de sódio $20 \%, 0,4 \mathrm{~mL}$ de dimetilglioxima $1 \%$ em etanol, $0,4 \mathrm{~mL}$ de persulfato de potássio $4 \% \mathrm{e}$ $1 \mathrm{~mL}$ de hidróxido de amônio concentrado nesta ordem. Completou-se o volume para $10 \mathrm{~mL}$ com água bidestilada. Após $10 \mathrm{~min}$ a absorbância foi medida contra prova em branco, em comprimento de onda de 470nm (comprimento escolhido pelo espectro de absorção do sistema níquel-dimetilglioxima).

O complexo dimetilglioximato de níquel foi caracterizado por meio de seu espectro de absorção molecular (FIG. 4.5). Utilizou-se uma solução de $\mathrm{C}_{\mathrm{Ni}^{2+}}=0,3 \mathrm{~g} \cdot \mathrm{L}^{-1} ; \mathrm{pH} \sim 4$ em temperatura ambiente com volume analisado de $0,4 \mathrm{~mL}$ e fez-se a varredura do comprimento de onda na faixa de 350 a $650 \mathrm{~nm}$. 


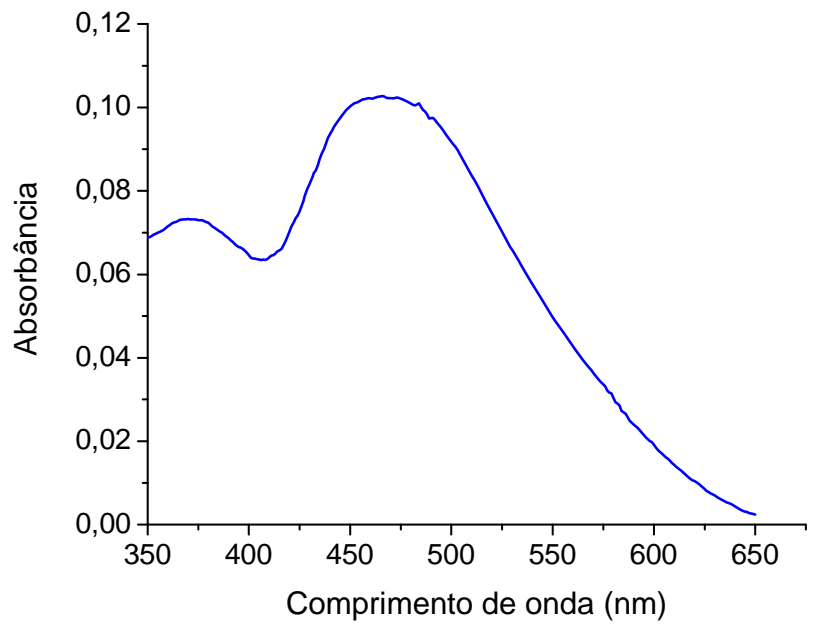

FIGURA 4.5 - Espectro de absorção do complexo dimetilglioximato de níquel.

A curva de calibração (FIG. 4.6) foi obtida retirando-se alíquotas de 0,03 a $0,08 \mathrm{~mL}$ da solução padrão de $\mathrm{Ni}^{2+}$ concentração igual a $1,0 \mathrm{~g} \cdot \mathrm{L}^{-1}$ com pipetas volumétricas e analisando-se a concentração do metal de acordo com o método descrito acima. A equação de regressão linear obtida foi: $y=0,05713+0,23888 x$ com coeficiente de correção de 0,99939.

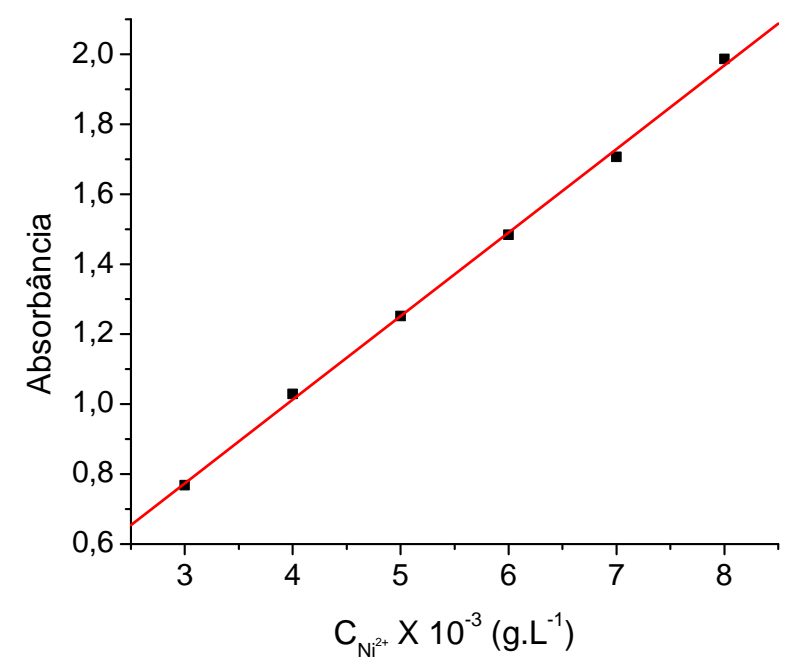

FIGURA 4.6 - Curva de calibração do $\mathrm{Ni}^{2+}$. 


\subsection{Espectroscopia de luminescência}

Os espectros de excitação e emissão à temperatura ambiente (298 K) e do nitrogênio líquido $(77 \mathrm{~K})$, das amostras dopadas com $\mathrm{Eu}^{3+}$, foram obtidos em um espectrofluorímetro SPEX FLUOROLOG 2 com monocromadores duplos $0.22 \mathrm{~m}$ do tipo SPEX 1680, utilizando-se lâmpada de xenônio contínua de 450W, como fonte de radiação. Todo este aparato é totalmente controlado por um sistema do tipo DM3000F. A curva de decaimento radiativo foi obtida usando-se um fosforimetro (SPEX 1934D) acoplado ao espectrofluorímetro à $298 \mathrm{~K}$. 


\section{REFERÊNCIAS BIBLIOGRÁFICAS}

[1] SANTOS, J. L. Trocadores iônicos inorgânicos à base de manganês e potássio para recuperação e remoção de metais poluentes de efluentes aquosos. 2001. Dissertação (Mestrado) - Instituto de Pesquisas Energéticas e Nucleares, IPEN/CNEN-SP, São Paulo.

[2] MARCZENKO, Z. Separation and spectrophotometric determination of elements. New York, N. Y.: Ellis Horwood, 1986. 


\section{RESULTADOS E DISCUSSÕES}

\subsection{Composto de $\mathrm{SnO}_{2} / \mathrm{TiO}_{2}$ e $\mathrm{SnO}_{2} / \mathrm{TiO}_{2}: \mathrm{Eu}^{3+}$ preparado pelo método sol-gel}

A produção de óxidos metálicos por reações de precipitação entre um sal metálico e uma base não é direta. ${ }^{[1,2]}$ Acredita-se que ocorra um esquema de reações complexas onde os cátions metálicos inicialmente precipitem na forma de hidróxidos poliméricos (gel) e com o passar do tempo, estes hidróxidos sofrem desidratação para formar estruturas cristalinas de óxidos metálicos. O período de digestão é necessário para induzir a recristalização durante a coprecipitação. As duas reações que especificamente levam os sais metálicos para óxidos metálicos são a hidrólise e a desidratação. ${ }^{[3,4]}$

$$
\begin{aligned}
& \mathrm{M}\left(\mathrm{Cl}^{-}\right)_{\mathrm{x}}+\mathrm{xH}_{2} \mathrm{O} \rightarrow \mathrm{M}(\mathrm{OH})_{\mathrm{x}}+\mathrm{xHCl} \\
& \mathrm{M}(\mathrm{OH})_{\mathrm{x}} \rightarrow \mathrm{MO}_{\mathrm{x} / 2}+1 / 2 \mathrm{xH}_{2} \mathrm{O}
\end{aligned}
$$

Nesse trabalho, como descrito no item 4.2 estes óxidos foram obtidos segundo reação de precipitação de soluções contendo os cloretos destes metais com hidróxido de amônio para formação dos óxidos misto. Na FIG. 5.1 tem-se o material obtido após secagem ao ar e temperatura de $110^{\circ} \mathrm{C}$.

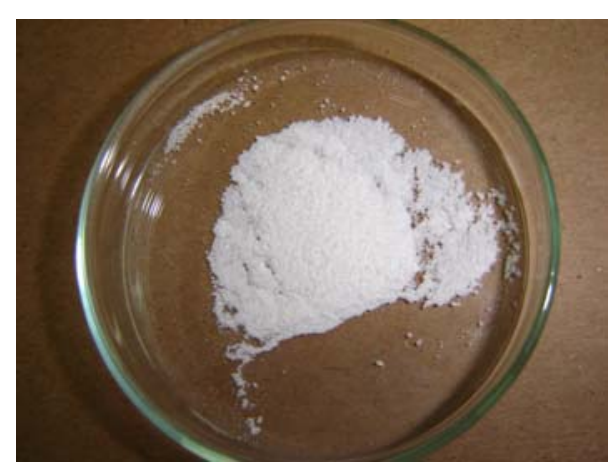

FIGURA 5.1 - Foto do trocador $\mathrm{SnO}_{2} / \mathrm{TiO}_{2}: \mathrm{Eu}^{3+}$ sintetizado no formato pó. 
Já os materiais compósitos foram obtidos usando a resina amberlite XAD-7 como suporte dos trocadores iônicos inorgânicos. Os óxidos mistos foram precipitados tendo como template a resina polimérica e os materiais obtidos são mostrados na FIG. 5.2.

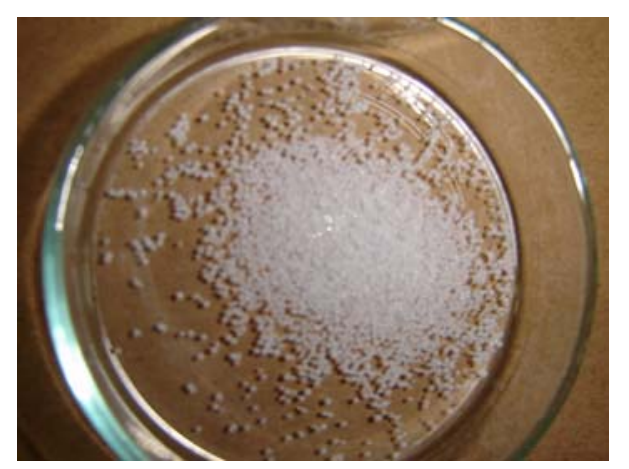

FIGURA 5.2 - Foto do trocador $\mathrm{SnO}_{2} / \mathrm{TiO}_{2}$ na matriz polimérica amberlite XAD-7.

\subsection{Caracterização dos óxidos mistos $\mathrm{SnO}_{2} / \mathrm{TiO}_{2}$ e $\mathrm{SnO}_{2} / \mathrm{TiO}_{2}: \mathrm{Eu}^{3+}$ e dos compósitos $\mathrm{TiO}_{2} / \mathrm{SnO}_{2}$ e $\mathrm{TiO}_{2} / \mathrm{SnO}_{2}: \mathrm{Eu}^{3+}$ preparados pelo método sol-gel}

\subsubsection{Espectroscopia de infravermelho}

A radiação de infravermelho refere-se, de modo geral, à parte do espectro eletromagnético que está compreendida entre regiões do visível e microondas. $\mathrm{O}$ espectro de infravermelho permite, por meio de determinadas freqüências, localizar a presença ou não de um certo grupo funcional. ${ }^{[5]}$ Entretanto, alguns grupos absorvem na mesma freqüência, apresentando sobreposição de bandas, o que ocorre comumente em estruturas complexas.

Os espectros de infravermelho dos óxidos mistos $\mathrm{SnO}_{2} / \mathrm{TiO}_{2}$ e $\mathrm{SnO}_{2} / \mathrm{TiO}_{2}: \mathrm{Eu}^{3+}, \mathrm{FIG} .5 .3$, apresentaram bandas largas na região de $3413-3190 \mathrm{~cm}^{-1}$ de intensidade forte, atribuídas ao estiramento $\mathrm{vOH}$ da água e hidroxilas ligadas aos diferentes metais ${ }^{[6,7]}$, Uma banda de intensidade media em $\sim 1636 \mathrm{~cm}^{-1}$ foi atribuída à deformação angular $\delta \mathrm{HOH}$ em ambos os trocadores iônicos inorgânicos (TIls). Na região de $1026 \mathrm{~cm}^{-1}$ as bandas foram atribuídas ao estiramento $v \mathrm{Sn}$-O e na região de 
-662 e $564 \mathrm{~cm}^{-1}$ estas foram relacionadas à deformação $\delta S n-O-S n$ [6] e ao estiramento $v$ Ti-O ${ }^{[7]}$ respectivamente.

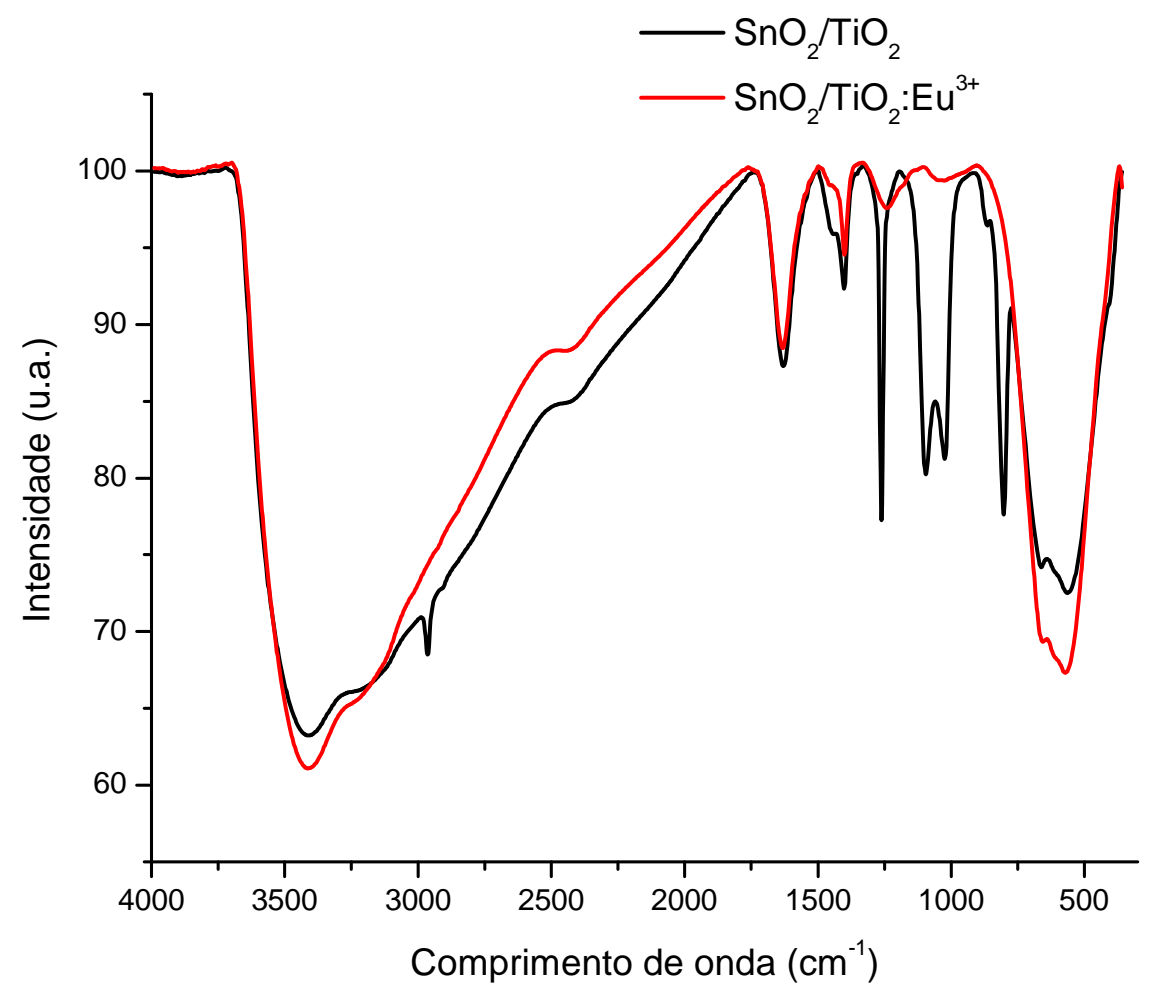

FIGURA 5.3 - Espectros de infravermelho dos trocadores $\mathrm{SnO}_{2} / \mathrm{TiO}_{2}$ e $\mathrm{SnO}_{2} / \mathrm{TiO}_{2}: \mathrm{Eu}^{3+}$.

\subsubsection{Difração de raios- $X$}

A difração de raios-X é uma técnica que estuda e identifica a estrutura cristalina dos materiais. Os raios-X são gerados quando uma partícula de alta energia cinética é rapidamente desacelerada. O método mais utilizado para produzir raios-X é fazer com que um elétron de alta energia (gerado no catodo do tubo catódico) colida com um alvo metálico (ânodo). ${ }^{[8,9]}$

Os difratogramas de raios- $\mathrm{X}$ dos óxidos mistos $\mathrm{SnO}_{2} / \mathrm{TiO}_{2}$ e $\mathrm{SnO}_{2} / \mathrm{TiO}_{2}: \mathrm{Eu}^{3+}$, apresentados na FIG. 5.4, mostram picos largos o que sugere que embora os trocadores sejam cristalinos eles apresentam tamanhos de cristalitos nanométricos. $\mathrm{O}$ óxido misto $(\mathrm{Ti}, \mathrm{Sn}) \mathrm{O}_{2}$ apresenta fase majoritária de estrutura Anastásia. ${ }^{[10]}$ Neste trabalho observaram-se linhas de difração em 20: $27,25\left(\mathrm{TiO}_{2}\right)$ 
(JCPDS 34-0180), 52,35( $\mathrm{Ti}_{2} \mathrm{O}_{3}$ ) (JCPDS 12-0754) que estão de acordo com os dados de padrões ICDD ${ }^{[11]}$ e 34,4 $\left(\mathrm{SnO}_{2}\right), 38,2\left(\mathrm{SnO}_{2}\right)$ (JCPDS 41-1445). ${ }^{[12-16]}$

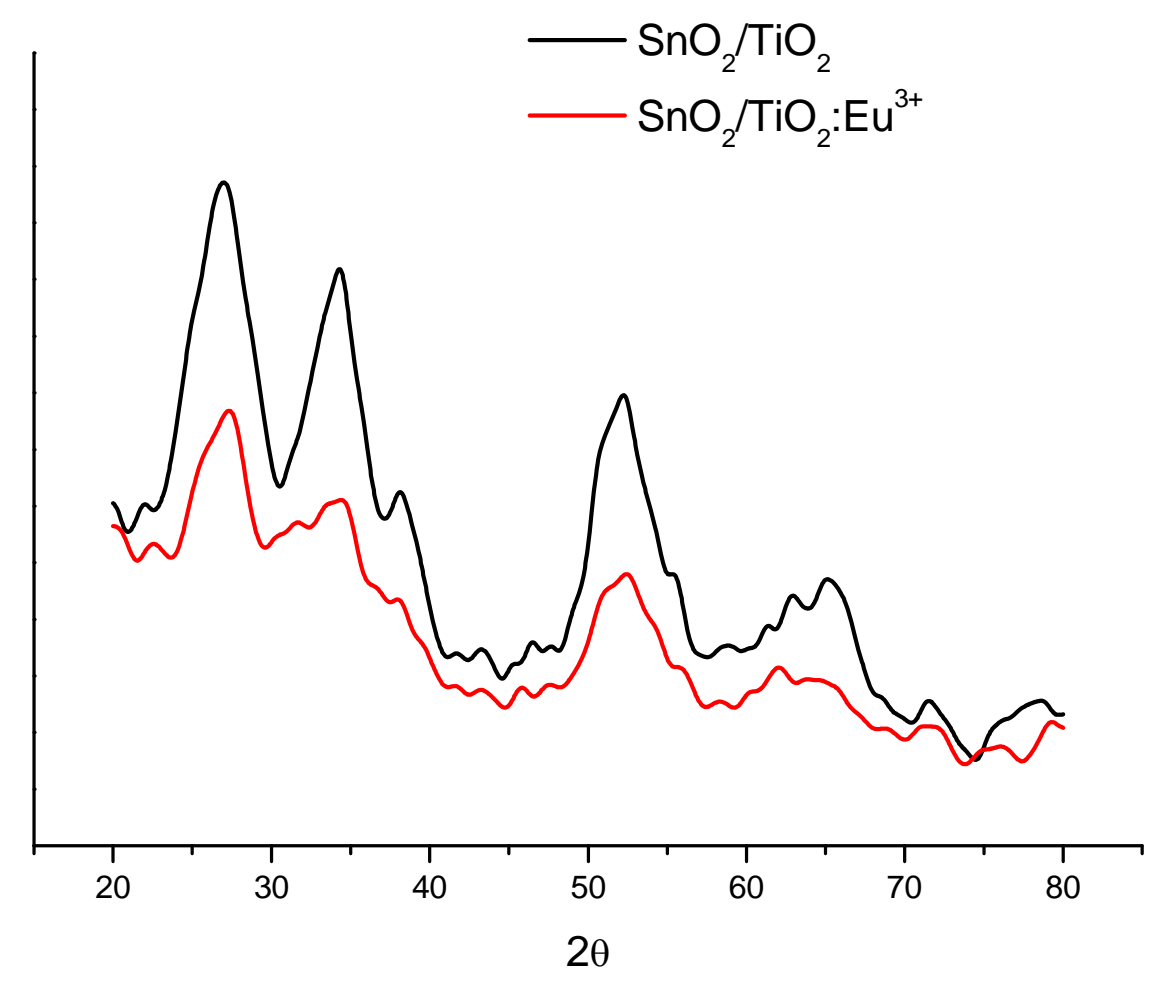

FIGURA 5.4 - Difratogramas de raios-X dos trocadores $\mathrm{SnO}_{2} / \mathrm{TiO}_{2}$ e $\mathrm{SnO}_{2} / \mathrm{TiO}_{2}$ : $\mathrm{Eu}^{3+}$.

A medida do diâmetro do cristalito pode ser determinada a partir da medida da largura do pico a meia altura através da fórmula de Scherrer: ${ }^{[17]}$

$$
d=\frac{0.94 \lambda}{\Delta(2 \theta) \cos \theta}
$$

Onde: $\lambda$ é o comprimento de onda da radiação em nm, $\Delta(2 \theta)$ é a largura a meia altura da linha em radianos na escala $2 \theta, \theta$ é o ângulo de difração.

Os difratogramas foram refinados pelo método dos mínimos quadrados e foi então calculado o diâmetro médio de ambos os trocadores observando-se o valor de $\mathrm{d} \sim 5 \mathrm{~nm}$ para os dois TII. 


\subsubsection{Análise Térmica}

A análise térmica é definida como um grupo de técnicas nas quais uma propriedade física (variação de massa, temperatura, entalpia, etc) da substância (e/ou seus produtos de reação) é medida como função da temperatura, enquanto a substância é submetida a um programa controlado de temperatura. ${ }^{[18-20]}$ As técnicas mais utilizadas são aquelas relacionadas às variações de massa em uma substância como a termogravimetria/termogravimetria derivada (TGA/DTGA), às variações de energia (entalpia) como a calorimetria exploratória diferencial (DSC) e a análise térmica diferencial (DTA). ${ }^{[18,19]}$

Na FIG. 5.5 observam-se as curvas de TGA e DTGA dos trocadores $\mathrm{SnO}_{2} / \mathrm{TiO}_{2}$ e $\mathrm{SnO}_{2} / \mathrm{TiO}_{2}: \mathrm{Eu}^{3+}$. Os dois trocadores apresentam boa estabilidade térmica com dois eventos de perda de massa que foram atribuídos à desidratação e a perda de água de cristalização juntamente com perdas de hidroxilas respectivamente. ${ }^{[20-23]}$ Para o trocador sem európio estas perdas ocorrem no intervalo de 32 a $133^{\circ} \mathrm{C}(6,12 \%)$ e 132 a $493^{\circ} \mathrm{C}(5,83 \%)$ e para o trocador dopado estas perdas ocorrem no intervalo de 33 a $133^{\circ} \mathrm{C}(8,82 \%)$ e 131 a $551^{\circ} \mathrm{C}$ $(5,96 \%){ }^{[10,24]}$

Para os trocadores híbridos, observa-se na FIG. 5.6 que o evento de desidratação continua apesar de ocorrer perdas de massa menores comparadas aos trocadores fora da matriz. Para o trocador sem európio essa perda é de 5,1748\% (33 a $109^{\circ} \mathrm{C}$ ) e para o trocador dopado 4,96\% (39 a $108^{\circ} \mathrm{C}$ ). Observam-se também dois eventos em 107 a $362^{\circ} \mathrm{C}(26,19 \%)$ para o trocador não dopado e em 108 a $361^{\circ} \mathrm{C}(26,64 \%)$ para o trocador dopado atribuídos às perdas de $\mathrm{OH}$ e a decomposição da matriz polimérica em aproximadamente $400^{\circ} \mathrm{C}$ para ambos os trocadores. 

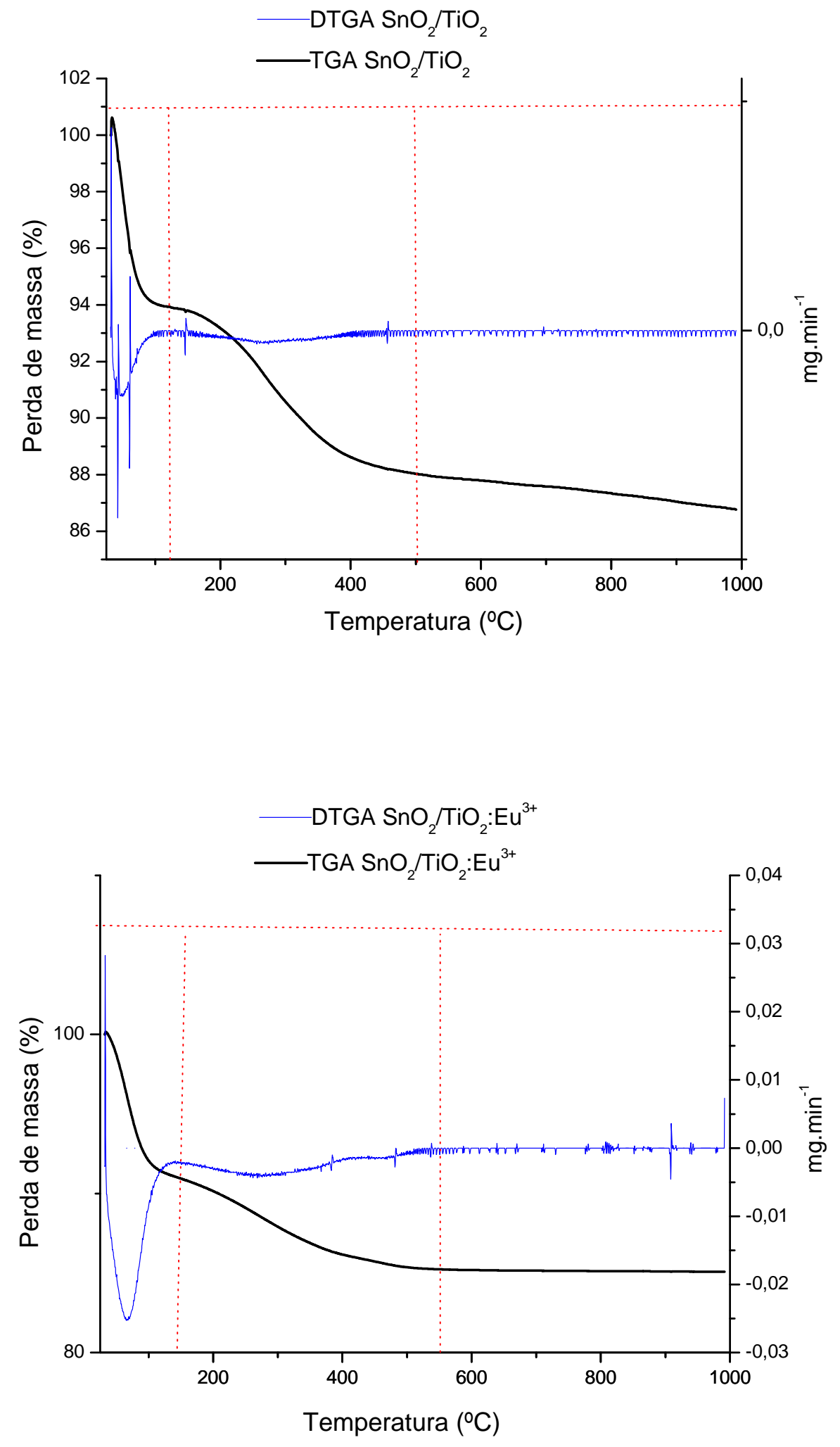

FIGURA 5.5 - Curvas TGA e DTGA dos trocadores estudados. 

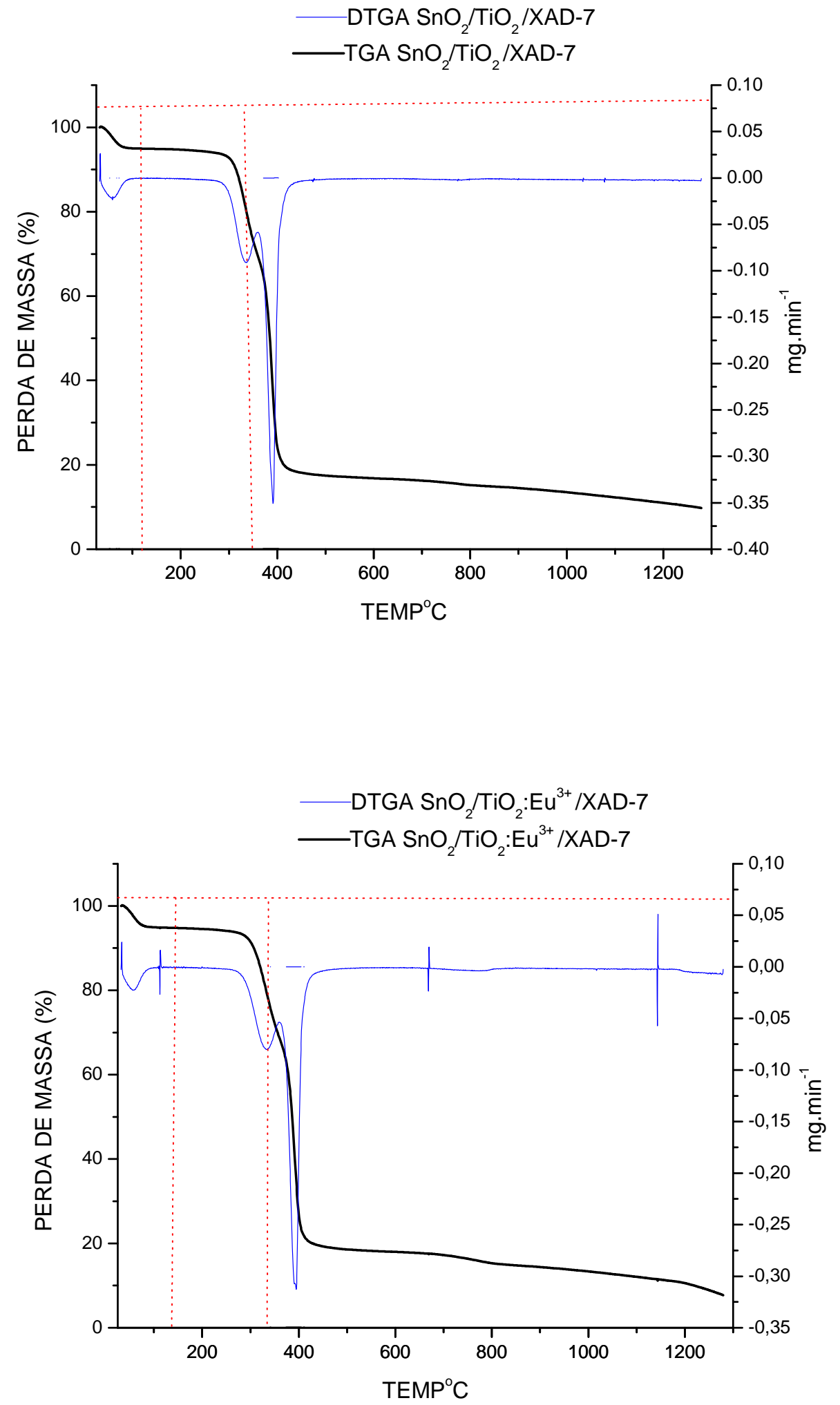

FIGURA 5.6 - Curvas TGA e DTGA dos trocadores híbridos. 
As curvas de DSC apresentadas na FIG. 5.7 mostram eventos em $119^{\circ} \mathrm{C}(-1381,94 \mathrm{~mJ})$ e em $283^{\circ} \mathrm{C}(-183,44 \mathrm{~mJ})$ para o trocador sem európio e em $126^{\circ} \mathrm{C}(-3422,04 \mathrm{~mJ})$ e $294^{\circ} \mathrm{C}(-82,48 \mathrm{~mJ})$ para o trocador dopado. Eles mostram o caráter endotérmico do processo de perda de moléculas de $\mathrm{H}_{2} \mathrm{O}$ e rearranjo cristalino dos sistemas estudados.
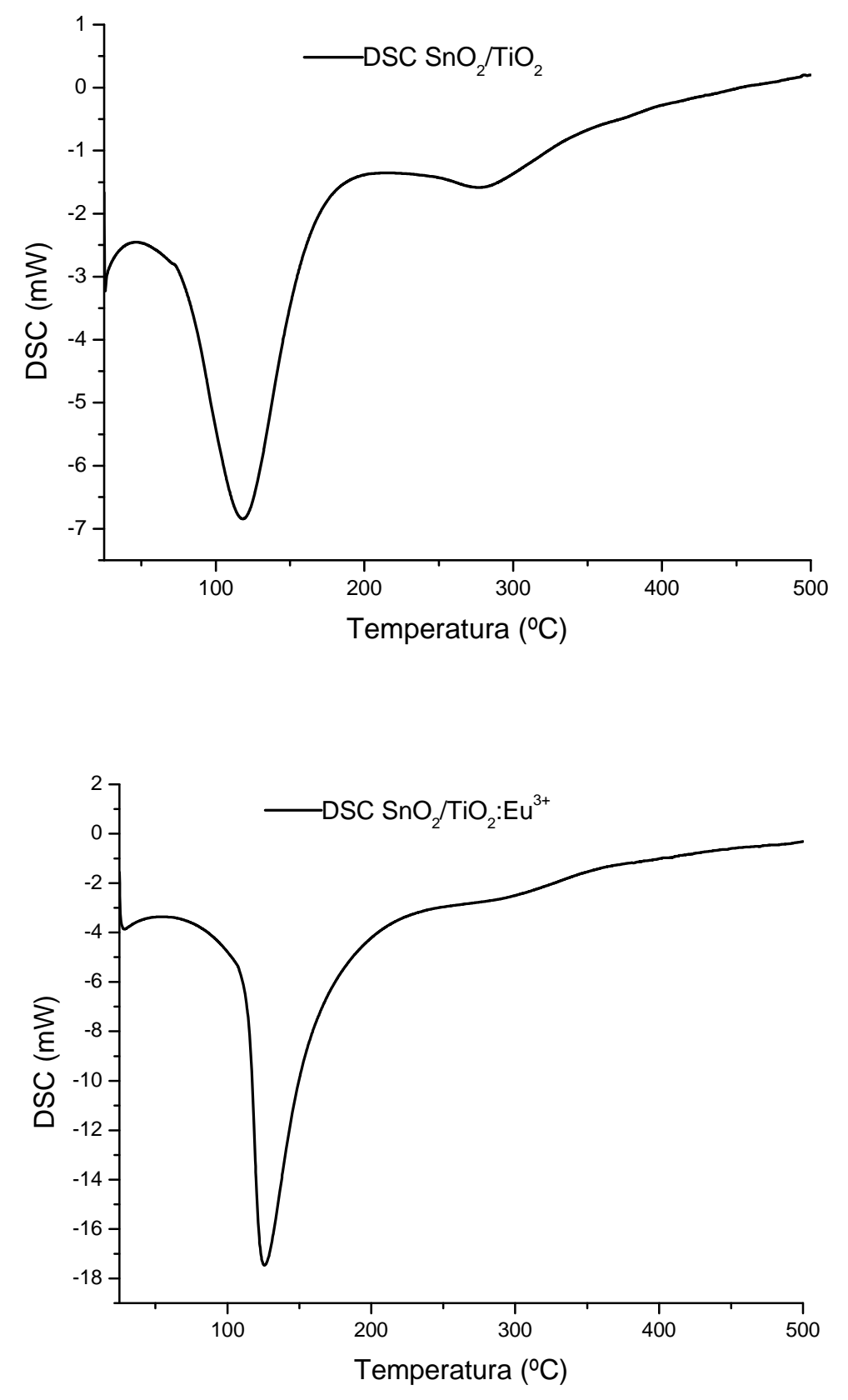

FIGURA 5.7 - Curvas DSC dos trocadores estudados. 
Nas endotermas dos trocadores híbridos, FIG. 5.8, pode-se observar um deslocamento dos eventos e uma redução na intensidade dos picos em comparação com os trocadores não híbridos. O trocador híbrido sem európio apresenta pico em $97^{\circ} \mathrm{C}(-510,77 \mathrm{~mJ})$ e $\mathrm{o}$ trocador dopado apresenta pico em $140^{\circ} \mathrm{C}$ $(-1274,56 \mathrm{~mJ})$. Os picos em $401^{\circ} \mathrm{C}(-2269,90 \mathrm{~mJ})$ e em $404^{\circ} \mathrm{C}(-2846,92 \mathrm{~mJ})$ para os trocadores sem dopagem e com dopagem respectivamente, representam o processo endotérmico de decomposição da matriz polimérica e evidenciam que a estabilidade térmica da matriz aumenta com a adição do Eu.
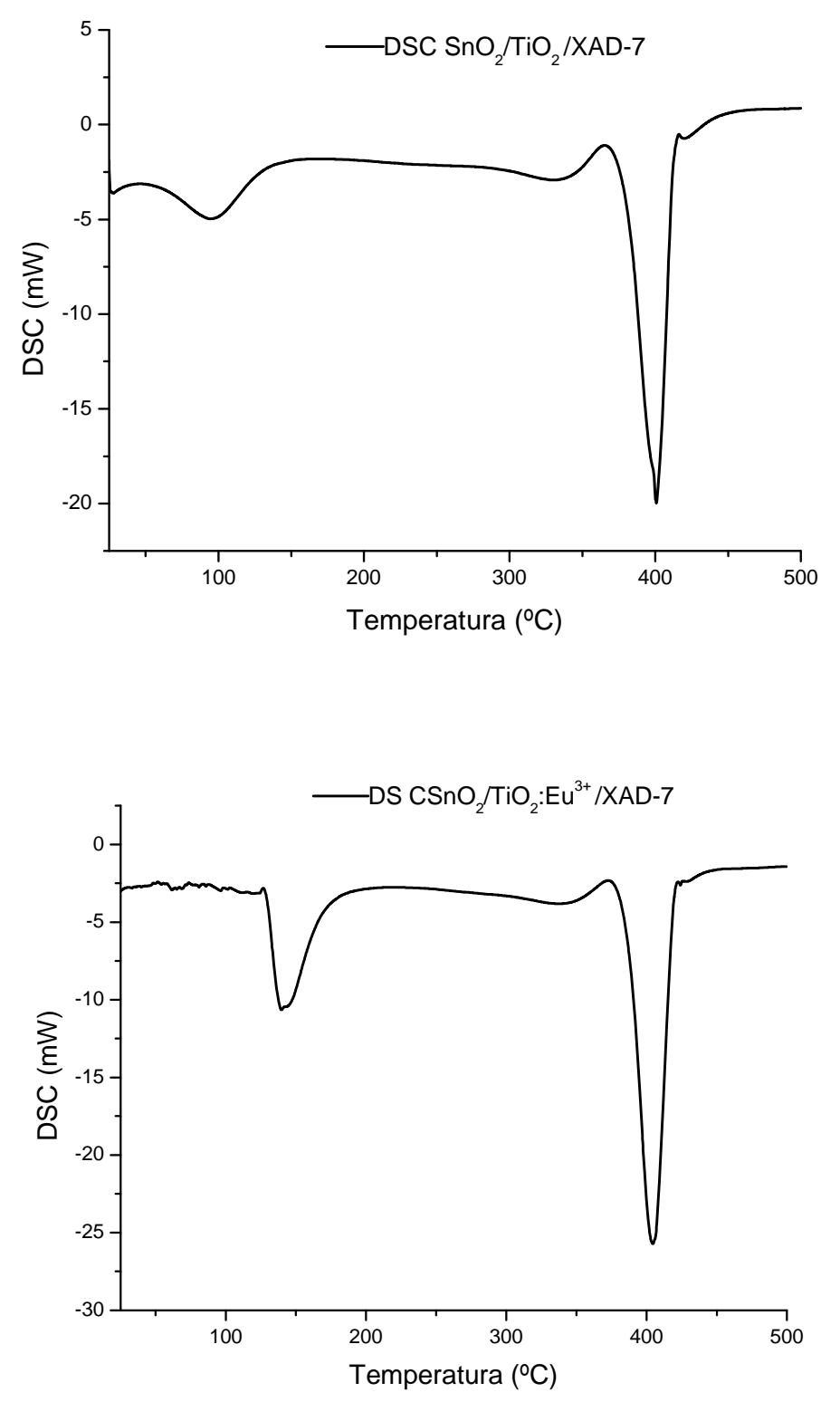

FIGURA 5.8 - Curvas DSC das matrizes suportadas com os trocadores estudados. 


\subsubsection{Microscopia Eletrônica de Varredura}

A microscopia eletrônica de varredura (MEV) é utilizada para observações de superfícies irregulares. Apresenta imagem tridimensional, resultado da grande profundidade de foco, 300 vezes melhor que do microscópio óptico. Através desta técnica pode-se obter informações da composição, topografia, cristalografia e outras propriedades. ${ }^{[25]}$

As micrografias dos trocadores estudados, apresentadas na FIG. 5.9, indicam que estes se apresentam em forma de aglomerados com superfícies homogêneas. Os aglomerados cristalinos se distribuem de forma heterogênea e em sua maioria com diâmetros menores que $20 \mu \mathrm{m} .{ }^{[26,27]}$
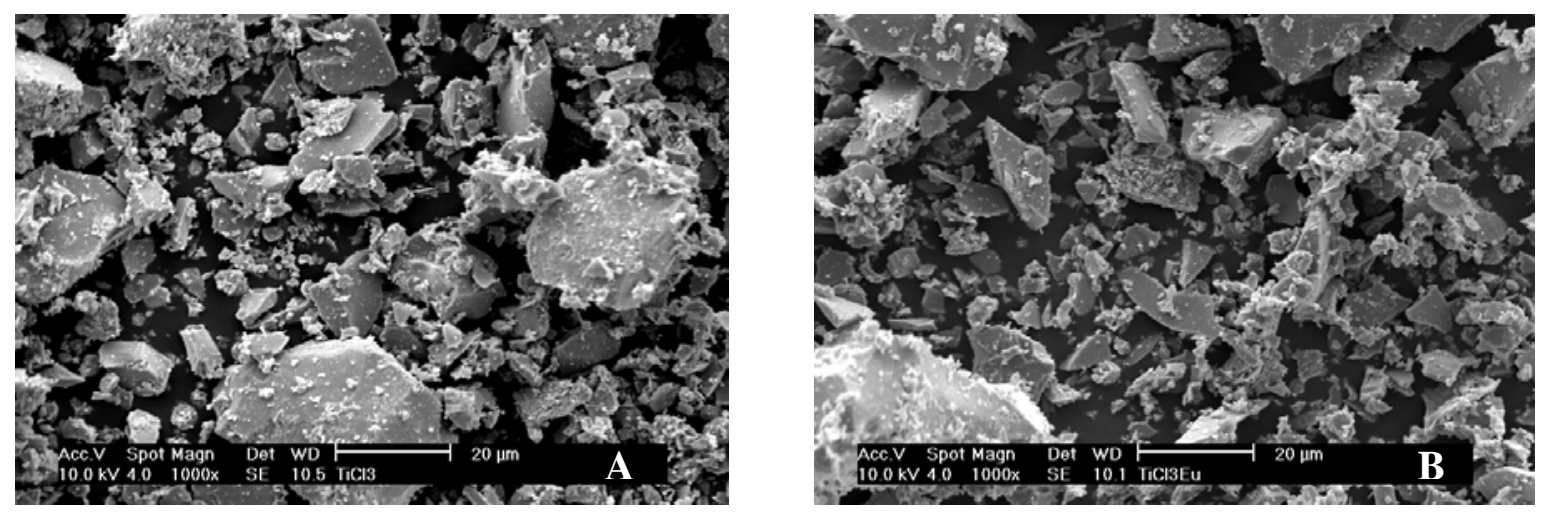

FIGURA 5.9 - MEVs dos trocadores $\mathrm{SnO}_{2} / \mathrm{TiO}_{2}(\mathrm{~A})$ e $\mathrm{SnO}_{2} / \mathrm{TiO}_{2}: \mathrm{Eu}^{3+}(\mathrm{B})$.

Na FIG. 5.10 estão representadas as micrografias dos trocadores na matriz polimérica. Pode-se observar que os trocadores na sua maioria aderiram as perolas da matriz polimérica e o excesso de trocador ficou em alguns pontos da superfície, principalmente para o trocador dopado com európio (B). Nas micrografias de aumento 2000X, (C) e (D), observa-se que os trocadores (parte clara) possuem partículas muito pequenas quando comparado a matriz polimérica (parte escura) e a distribuição dos mesmos na matriz ocorre de uma maneira não uniforme. 

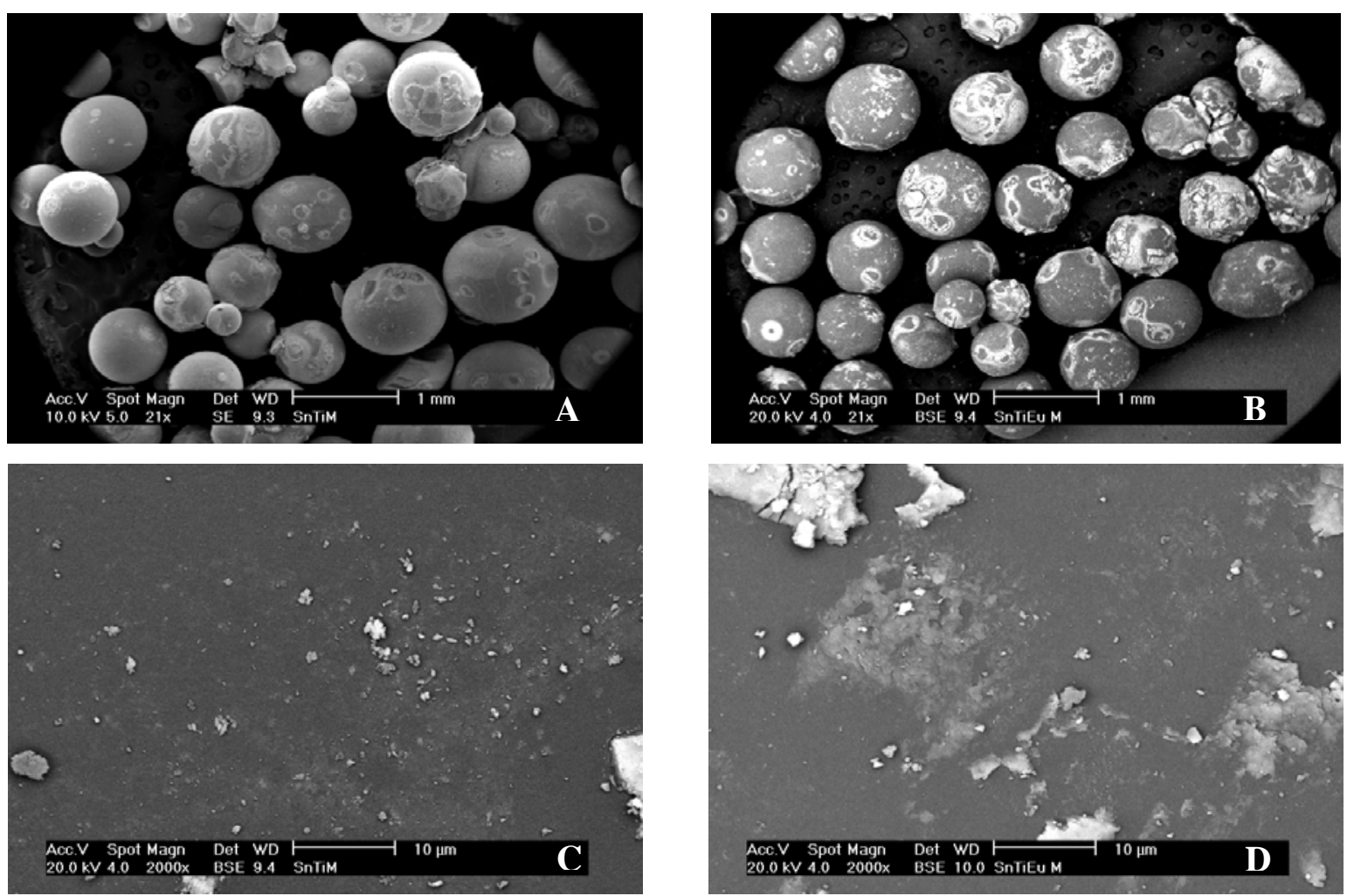

FIGURA 5.10 - MEVs da matriz polimérica suportada com os trocadores $\mathrm{SnO}_{2} / \mathrm{TiO}_{2}(\mathrm{~A}),(\mathrm{C})$ e $\mathrm{SnO}_{2} / \mathrm{TiO}_{2}: \mathrm{Eu}^{3+}(\mathrm{B}),(\mathrm{D})$.

\subsection{Estudos de Adsorção}

Os estudos de adsorção foram projetados para se estudar a adsorção dos íons $\mathrm{Cd}^{2+}$ e $\mathrm{Ni}^{2+}$ nos trocadores iônicos inorgânicos e materiais híbridos, visando a utilização dos mesmos no tratamento de efluentes do processo de reciclagem de baterias, via hidrotermal. Os estudos mostram os resultados obtidos para a adsorção de $\mathrm{Cd}^{2+}$ e $\mathrm{Ni}^{2+}$ nos trocadores e o comportamento do trocador frente a soluções sintéticas de efluentes.

\subsubsection{Estudos de adsorção de $\mathrm{Cd}^{2+}$ pelos trocadores iônicos inorgânicos}

As análises de extração do cádmio foram feitas em batelada, com massa de trocador de aproximadamente 0,05 g contactadas, em agitador mecânico, com um volume de $1,5 \mathrm{~mL}$ de fase aquosa .

Determinou-se o coeficiente de distribuição $K_{d}$ ou razão de distribuição Dw do $\mathrm{Cd}^{2+}$ nos trocadores, segundo a equação: 


$$
D w=\frac{\frac{C_{O}-C_{S}}{W}}{\frac{C_{S}}{V}}
$$

Onde $D_{w}$ é a razão de distribuição em peso ( $\left.\mathrm{mL} / \mathrm{g}_{\text {suporte }}\right), \mathrm{C}_{0}$ e $\mathrm{C}_{\mathrm{S}}$ são as concentrações (ou atividades) dos metais antes e depois do equilíbrio, W é a massa da resina e $\vee$ é o volume de solução contendo o metal utilizado na contactação. ${ }^{\text {[28] }}$

Foram estudados os parâmetros: influência do pH, da concentração de íons $\mathrm{Cd}^{2+}$, do tempo de contactação e do tamanho da partícula.

\subsubsection{Influência do pH para $\mathrm{Cd}^{2+}$}

$\mathrm{O}$ pH da solução contendo o íon $\mathrm{Cd}^{2+}$ foi variado de 1 a 13, com solução tampão de ácido acético/acetato de amônio/hidróxido de amônio, sendo a concentração de $\mathrm{Cd}^{2+}$ de $0,01159 \mathrm{~g} \cdot \mathrm{L}^{-1}$ e o tempo de contato de $10 \mathrm{~min}$.

Os gráficos representados na FIG. 5.11 mostram os perfis de adsorção dos trocadores para todas as faixas de $\mathrm{pH}$ tendo pequenas variações entre os dois trocadores estudados. Analisando-se o comportamento dos trocadores em termos de porcentagem de adsorção pode-se observar o excelente desempenho dos mesmos na remoção de cádmio de efluentes em uma ampla faixa de $\mathrm{pH}$. 

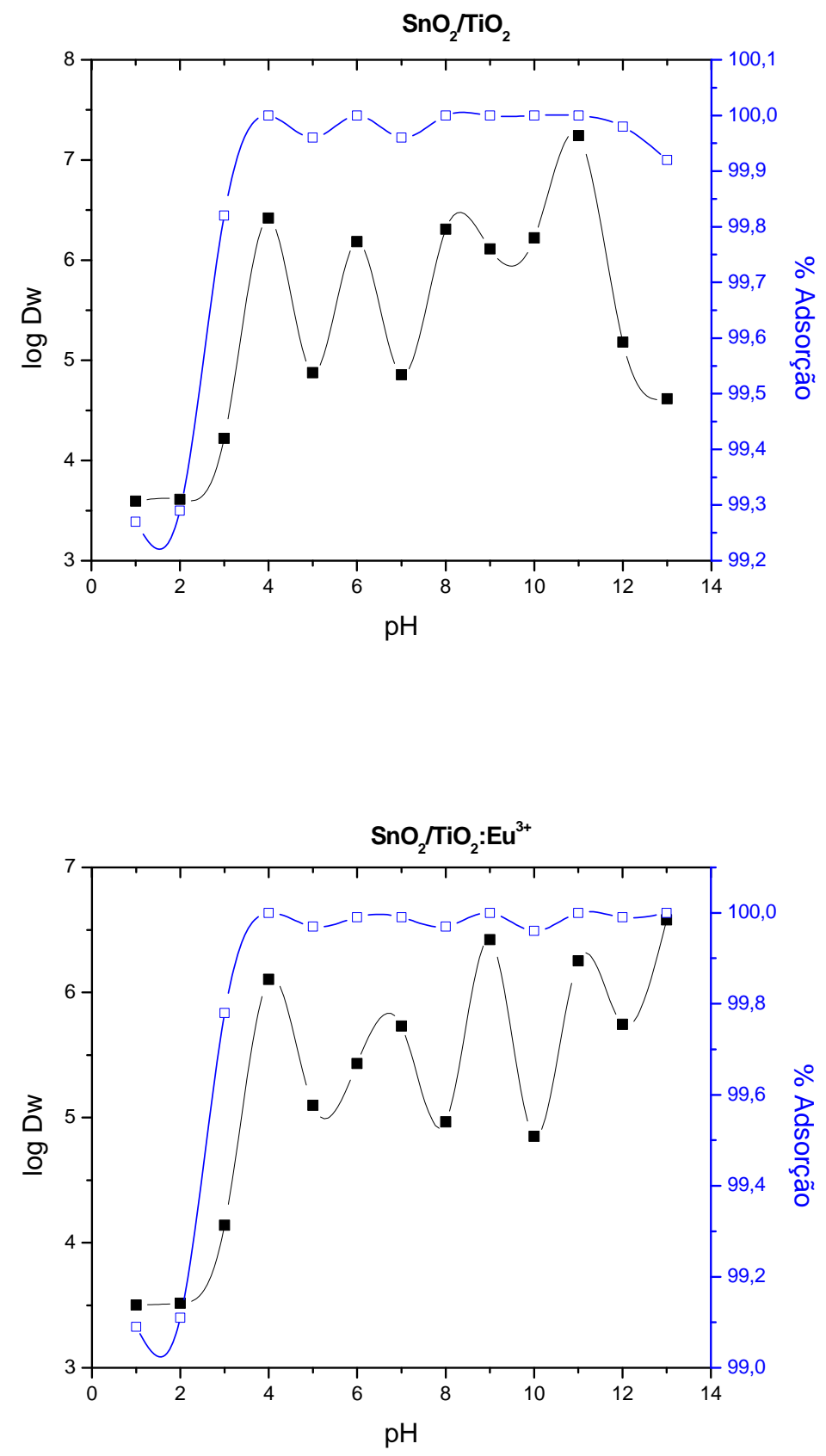

FIGURA 5.11- Variação do pH em função do log Dw e da \% Adsorção para o Cd ${ }^{2+}$.

\subsubsection{Influência da concentração de íons $\mathrm{Cd}^{2+}$}

A partir dos estudos de adsorção variando o pH escolheram-se e fixaramse dois pHs para os estudos de influência da concentração de íons $\mathrm{Cd}^{2+}$ na adsorção e variou-se a concentração do mesmo. Os pH escolhidos foram 4 e 9 que 
apresentaram a melhor os resultados de adsorção para ambos os trocadores. A concentração de $\mathrm{Cd}^{2+}$ foi variada de 0,01159 a $0,4 \mathrm{~g} \cdot \mathrm{L}^{-1}$ de $\mathrm{Cd}^{2+}$ e o tempo de contato foi fixado em $10 \mathrm{~min}$.

Os gráficos mostrados na FIG. 5.12 indicam uma diminuição, dos valores de Dw com o aumento da concentração de $\mathrm{Cd}^{2+}$ e nenhuma alteração significativa da porcentagem de adsorção em pH 4.
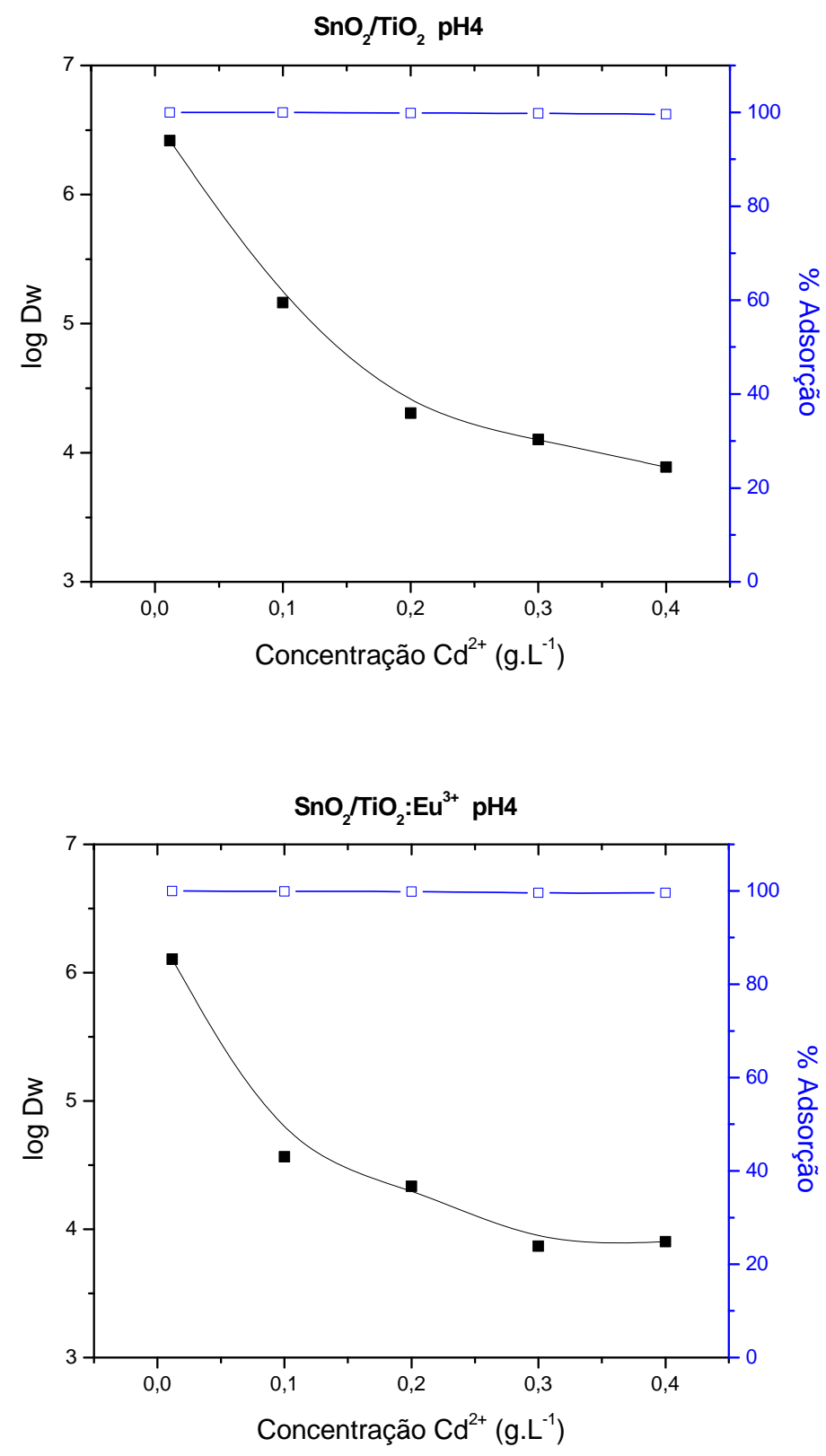

FIGURA 5.12 - Variação da concentração de $\mathrm{Cd}^{2+}$ em função do $\log \mathrm{Dw}$ e da \% Adsorção em pH 4 para os trocadores não híbridos. 
Na FIG. 5.13 observa-se que para o pH 9, as concentrações de 0,01159; 0,2 e 0,4 g.L $\mathrm{L}^{-1}$ de $\mathrm{Cd}^{2+}$ apresentam melhores valores de coeficiente de distribuição para o trocador $\mathrm{SnO}_{2} / \mathrm{TiO}_{2}$ já para o trocador dopado as concentrações de 0,1 e 0,2 g. $\mathrm{L}^{-1}$ foram de valores de Dw máximos, o trocador dopado com $\mathrm{Eu}^{3+}$ é o que apresentou o maior valor de log Dw $\sim 7,5$. Do ponto de vista de porcentagem de adsorção, nenhuma alteração significativa foi registrada.
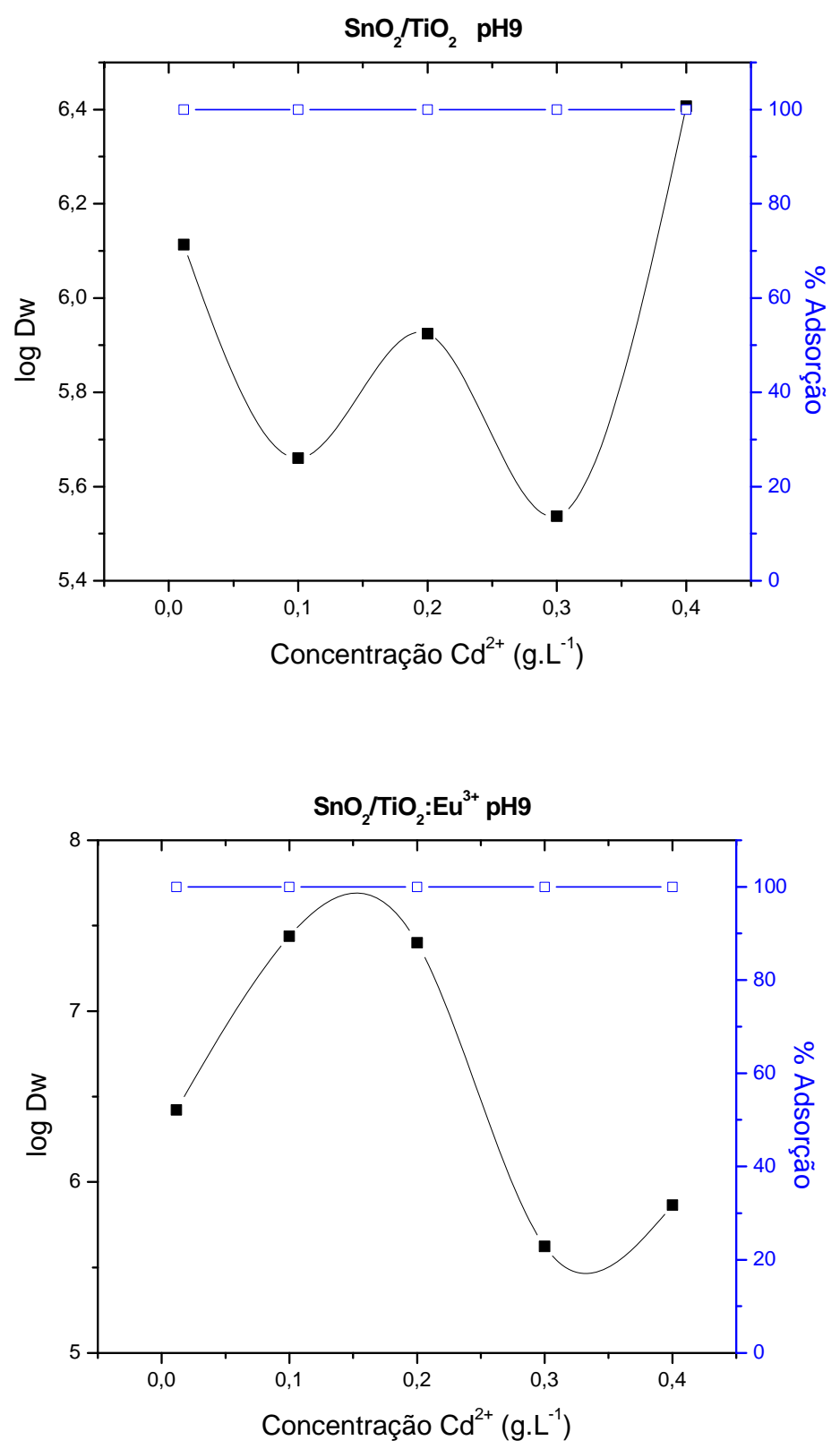

FIGURA 5.13 - Variação da concentração de $\mathrm{Cd}^{2+}$ em função do $\log$ Dw e da \% Adsorção em pH 9 para os trocadores não híbridos. 


\subsubsection{Influência do tempo de contactação para $\mathrm{Cd}^{2+}$}

As análises de tempo de contactação foram feitas com os trocadores na matriz híbrida, visto a grande dificuldade de decantação do trocador em forma de pó, e com concentração de $\mathrm{Cd}^{2+}$ igual a 0,01159 g.L $\mathrm{L}^{-1}$. Na FIG. 5.14 estão representados os gráficos de variação de tempo de equilíbrio controlando a adsorção em meio pH 4 . Observa-se que para ambos os trocadores o melhor tempo de contato é de $25 \mathrm{~min}$ com 99,6\% adsorção. A redução da porcentagem de adsorção em relação aos outros estudos realizados anteriormente atribui-se a diminuição da área superficial de troca.
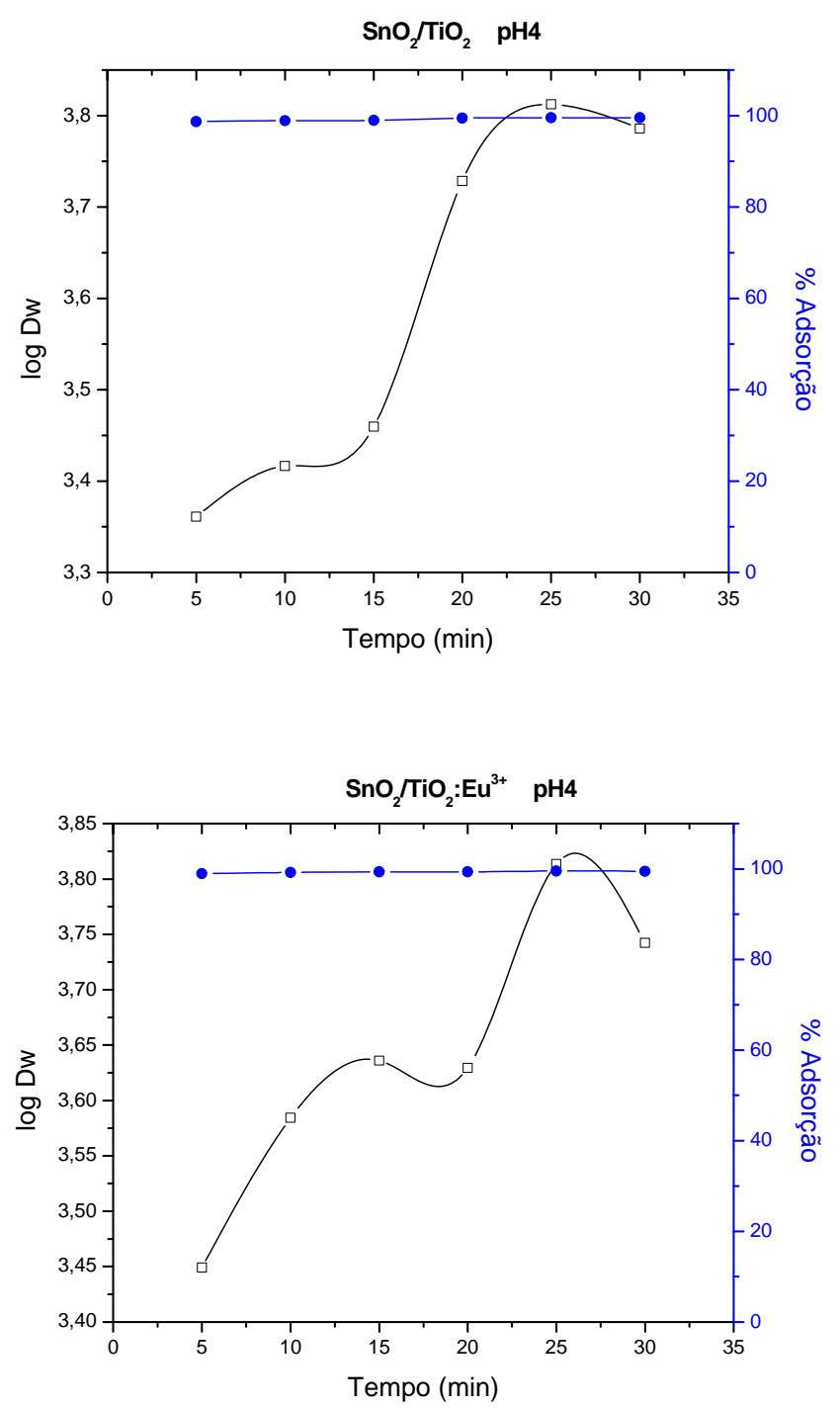

FIGURA 5.14 - Variação do tempo de contato em função do $\log$ Dw e da \% Adsorção para o $\mathrm{Cd}^{2+} \mathrm{em} \mathrm{pH} 4$ nos trocadores híbridos. 
Para os trocadores em pH 9 (FIG. 5.15) a cinética de adsorção apresenta comportamentos diferentes, no trocador $\mathrm{SnO}_{2} / \mathrm{TiO}_{2}$ os tempos de maiores coeficientes de distribuição 5 e 15 min com aproximadamente 99,7\% adsorção, já para o trocador dopado os tempos de 5 e 25 min mostram porcentagem de adsorção da ordem de $99,8 \%$ e maiores valores de Dw.
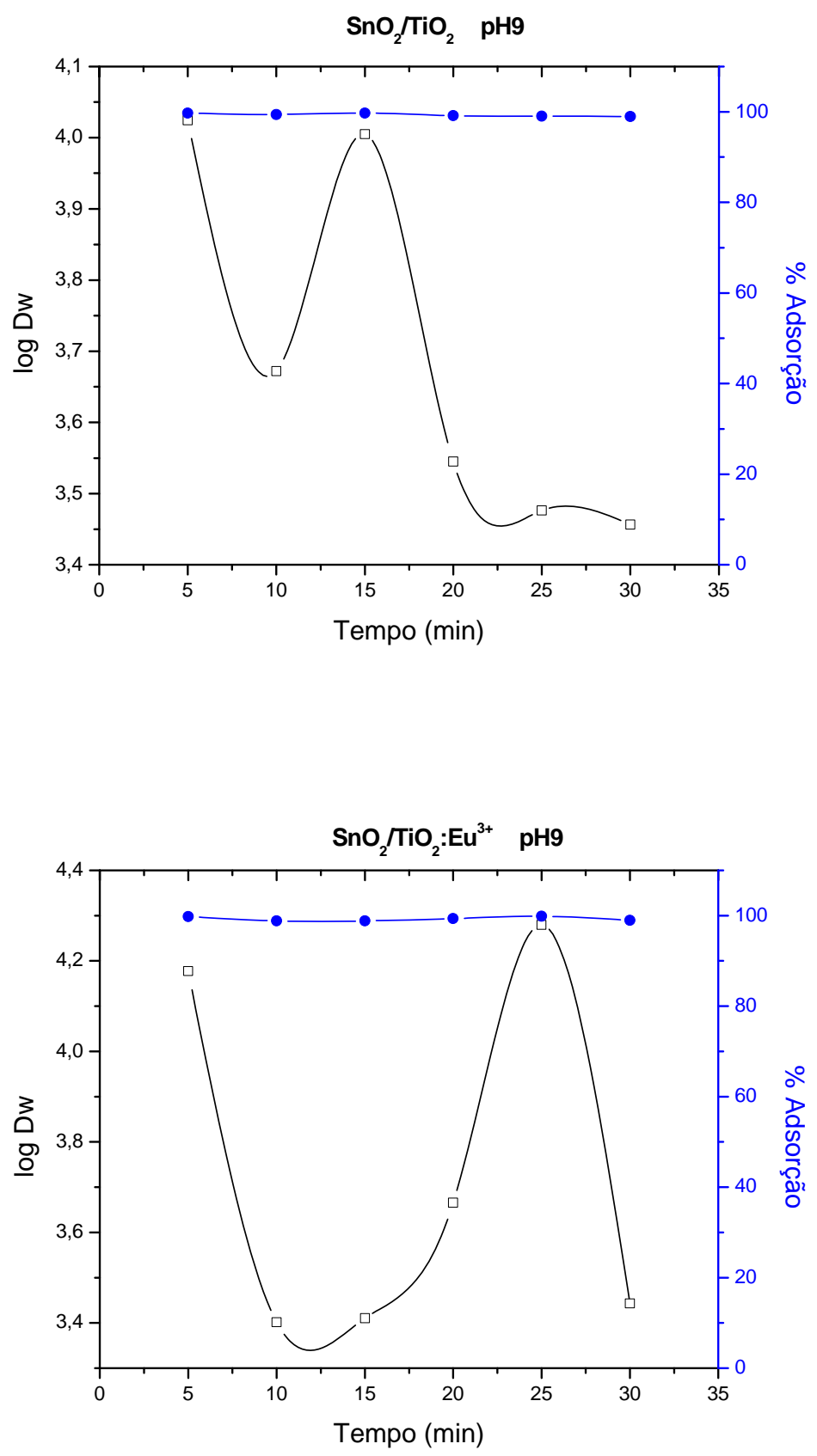

FIGURA 5.15 - Variação do tempo de contato em função do $\log$ Dw e da \% Adsorção para o $\mathrm{Cd}^{2+} \mathrm{em}$ pH 9 nos trocadores híbridos. 


\subsubsection{Influência do tamanho de partícula para $\mathrm{Cd}^{2+}$}

Nas FIG. 5.16 e 5.17 mostram-se os resultados obtidos do estudo sobre a influência do tamanho do trocador na adsorção de $\mathrm{Cd}^{2+}$. Este estudo foi executado para concentração de $\mathrm{Cd}^{2+}$ igual a 0,01159 g. $\mathrm{L}^{-1}$ e tempo de contato de $10 \mathrm{~min}$ em meio ácido $(\mathrm{pH} 4)$ e alcalino $(\mathrm{pH}$ 9). Os trocadores utilizados foram os óxidos mistos (forma de pó) e partículas destes óxidos suportadas no leito polimérico com dois tamanhos de diâmetro: $\mathrm{d}<0,55 \mathrm{~mm}$ e $0,55>\mathrm{d}<1,18 \mathrm{~mm}$. Para ambos os trocadores $\mathrm{SnO}_{2} / \mathrm{TiO}_{2}$ e $\mathrm{SnO}_{2} / \mathrm{TiO}_{2}: \mathrm{Eu}^{3+}$ e pHs (4 e 9) observou-se uma diminuição das porcentagem de adsorção e de $\mathrm{DW}_{\mathrm{Cd}^{2+}}$ com o aumento do diâmetro das partículas. De acordo com os perfis das FIG. 5.16 e 5.17, e visando o uso dos trocares em coluna, pode-se estabelecer que granulometria média $(<0,55 \mathrm{~mm})$ são as melhores condições para adsorção do $\mathrm{Cd}^{2+}$ nos dois trocares sendo que o trocador $\mathrm{SnO}_{2} / \mathrm{TiO}_{2}: \mathrm{Eu}^{3+}$ é mais favorável à adsorção nas condições de acidez e o trocador não dopado em condições de alcalinidade. 

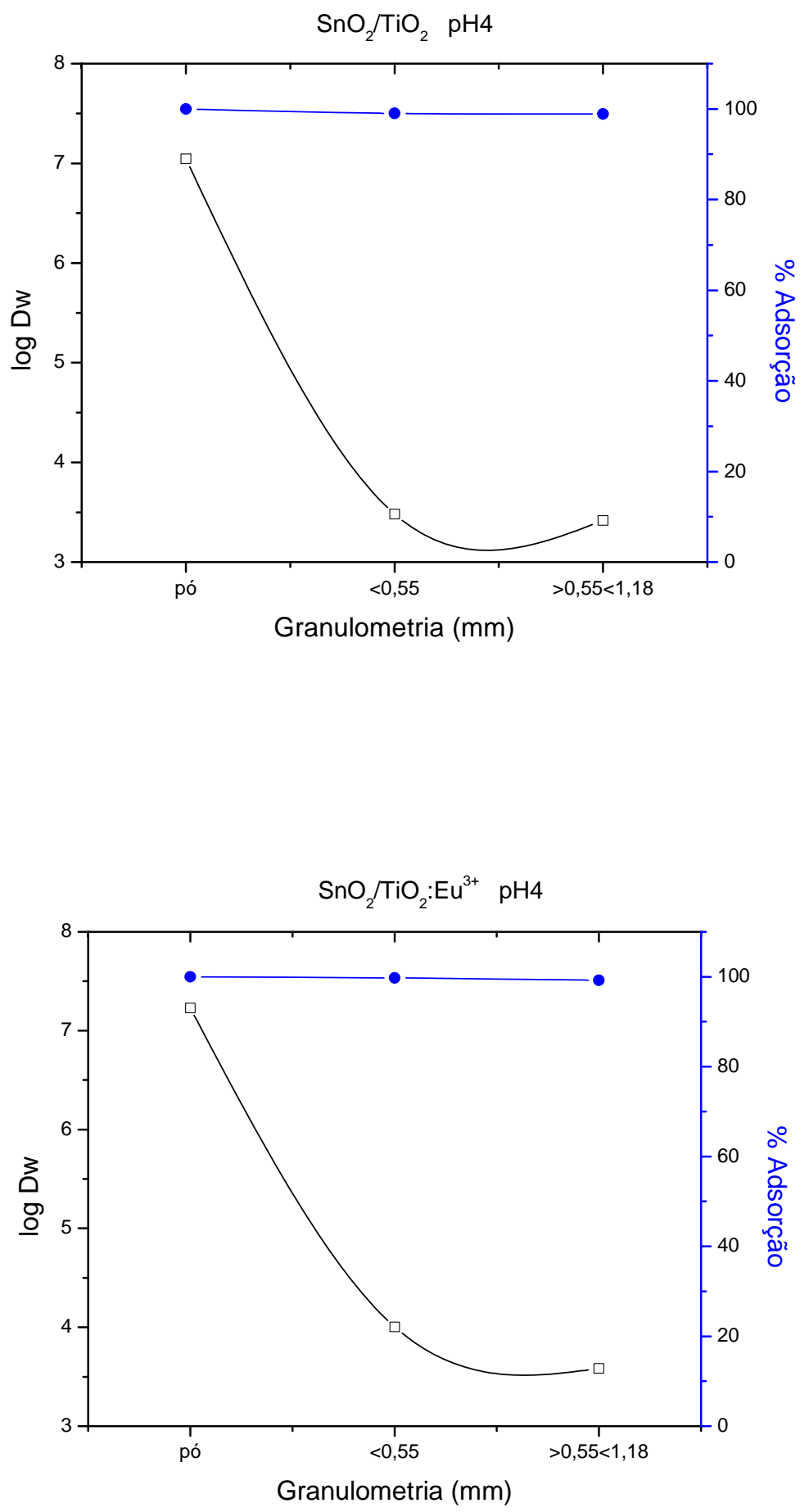

FIGURA 5.16 - Variação da granulometria em função da adsorção do $\mathrm{Cd}^{2+} \mathrm{em} \mathrm{pH} 4$. 

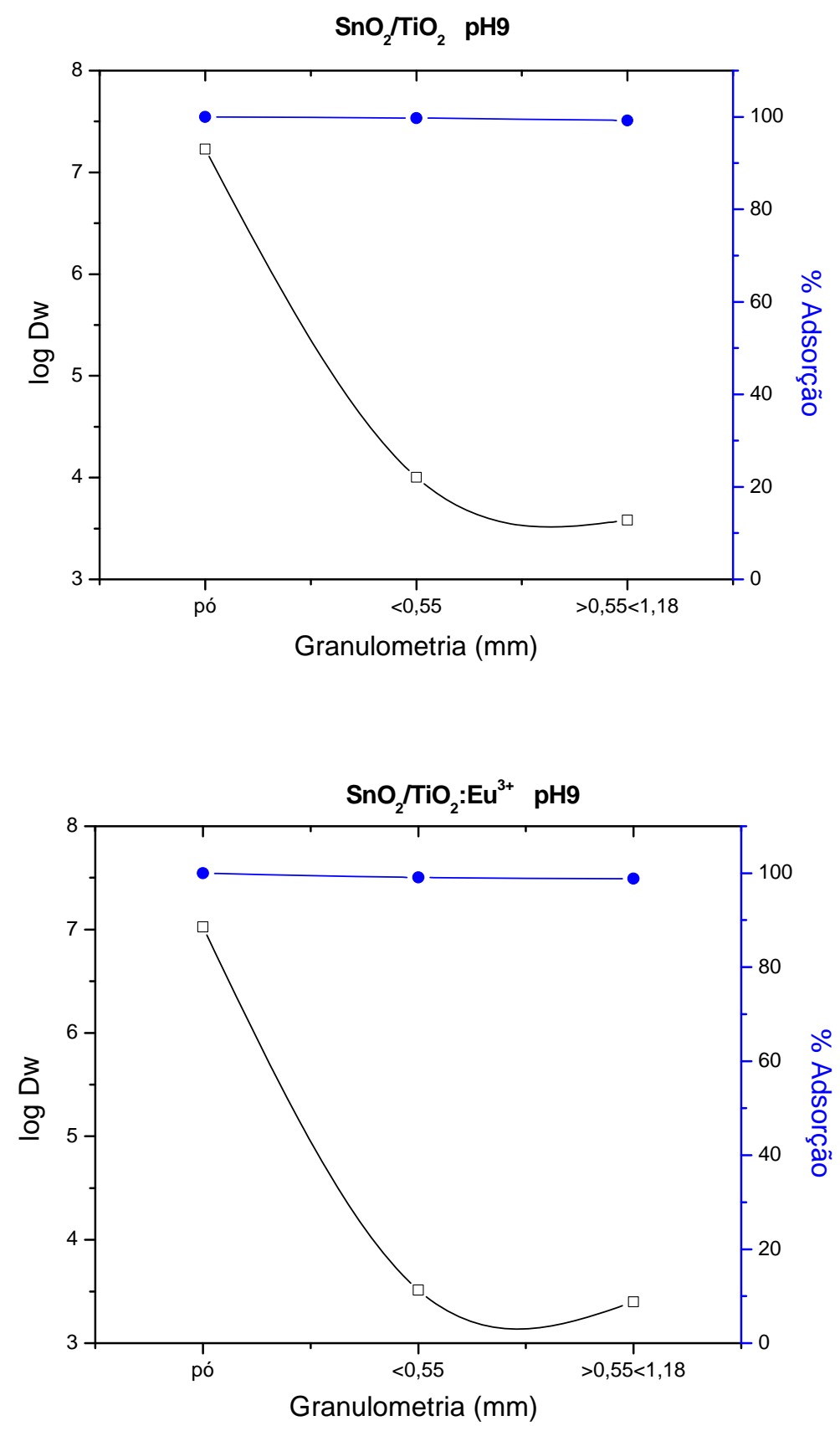

FIGURA 5.17 - Variação da granulometria em função da adsorção do $\mathrm{Cd}^{2+} \mathrm{em} \mathrm{pH} 9$.

\subsubsection{Estudo da cinética de adsorção do $\mathrm{Cd}^{2+}$}

O estudo cinético foi realiza com intuito de encontrar o tempo de agitação necessário para que ocorra a máxima adsorção do $\mathrm{Cd}^{2+}$ nos trocadores híbridos. A concentração de $\mathrm{Cd}^{2+}$ utilizada foi 0,01159 g..'-1. 
Na FIG. 5.18 mostra-se a variação da massa de $\mathrm{Cd}^{2+}$ adsorvida por massa de resina em função do tempo nos pH 4 e 9. Pode-se verificar que a variação da quantidade ( $\mathrm{g}$ ) de $\mathrm{Cd}^{2+}$ adsorvida por grama de trocador em função do tempo não sofre alteração significativa em toda a variação de tempo estudada (5-30 min) estando em torno de $0,34 \cdot 10^{-3} \mathrm{~g}_{\text {metal }} / \mathrm{g}_{\text {trocador }}$ para os dois $\mathrm{pH}$ estudados. Sendo assim, o tempo mínimo de contato da solução de $\mathrm{Cd}^{2+}$ com o trocador para que ocorra a máxima adsorção foi considerado como 5 min.
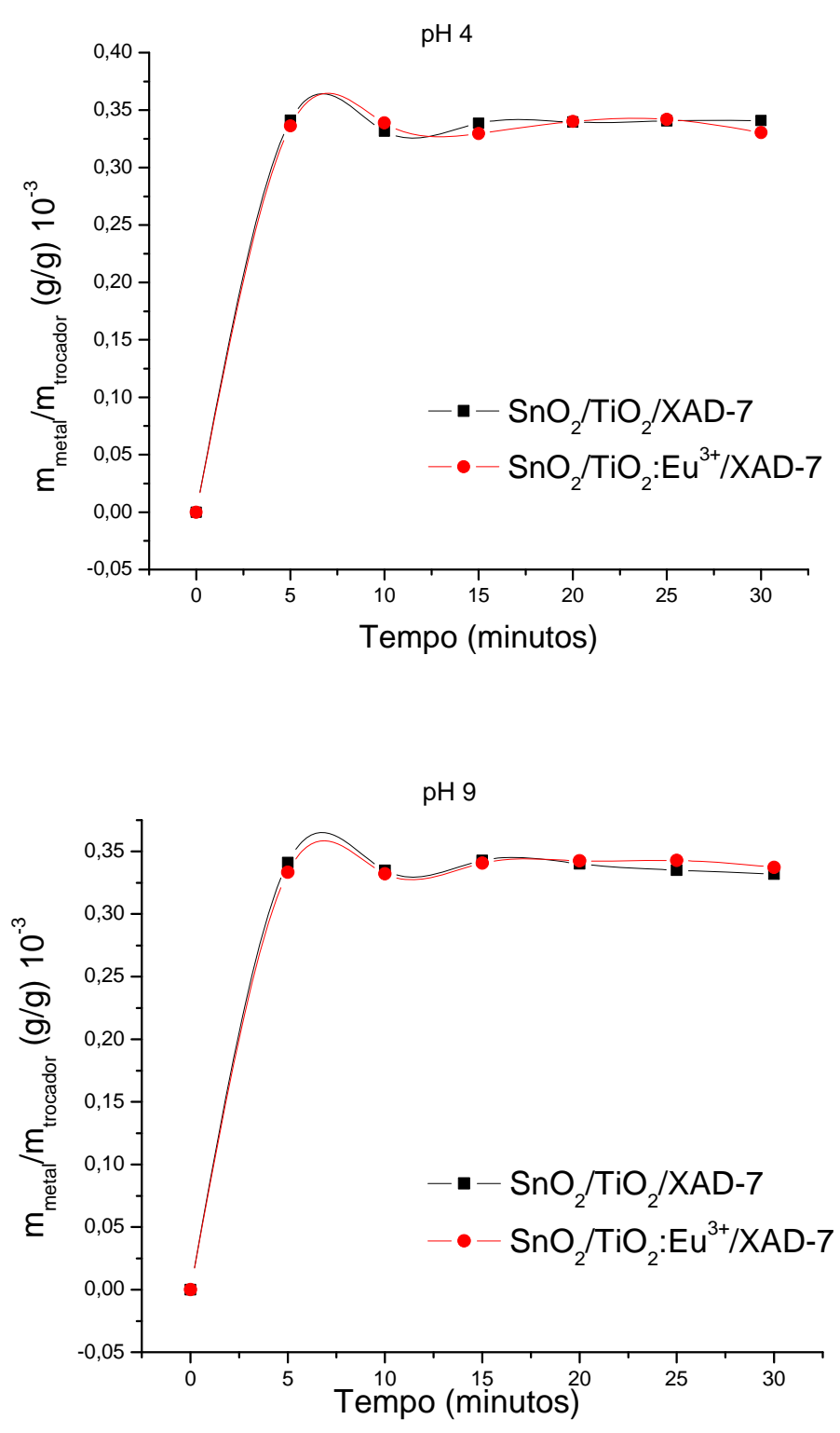

FIGURA 5.18 - Variação da massa de $\mathrm{Cd}^{2+}$ adsorvida por massa de trocador (g/g) em função do tempo. 
Para determinação da massa adsorvida de $\mathrm{Cd}^{2+}$ nos trocadores, utilizou-se a concentração encontrada nos sobrenadantes após o tempo de contato subtraindose este valor do valor inicial da concentração de $\mathrm{Cd}^{2+}$ colocada em contato com $\mathrm{O}$ trocador $\left(C=0,01159 \mathrm{~g}^{-1} \mathrm{~L}^{-1}\right.$ ), obtendo-se a concentração de $\mathrm{Cd}^{2+}$ adsorvida e com este dado calculou-se a massa adsorvida, sendo esta normalizada para $1 \mathrm{~g}$ de trocador híbrido. ${ }^{[29]}$

\subsubsection{Aplicação do modelo cinético de Pseudo-Primeira Ordem para $\mathrm{Cd}^{2+}$}

O modelo de pseudo-primeira ordem, que pode ser escrito conforme a equação 5.5 ou por sua forma linearizada representada na equação $5.6{ }^{[30]}$,assume que o adsorbato liga-se a um único sítio ativo da superfície do adsorvente. ${ }^{[1]}$

$$
\begin{gathered}
\frac{d q_{t}}{d t}=k_{1}\left(q_{\text {calc }}^{\max }-q_{t}\right) \\
\log \left(q_{\max }-q_{t}\right)=\log q_{\text {calc }}^{\max }-\frac{k_{1}}{2,303} t
\end{gathered}
$$

$q_{\max }=$ valor experimental da massa máxima adsorvida por grama de trocador $q_{t}=$ massa adsorvida de metal por grama de trocador em cada tempo $(\mathrm{t})$

$q_{\text {calc }}^{\max }=$ valor calculado da massa máxima adsorvida de metal por $\mathrm{g}$ trocador $k_{1}=$ constante de pseudo-primeira ordem

Partindo da equação 5.6, utilizando os dados experimentais, e construindo uma curva de log $\left(q_{\max }-q_{t}\right)$ versus $t$ (FIG. 5.19 e 5.20) é possível calcular a massa máxima de $\mathrm{Cd}^{2+}$ que pode ser adsorvida por grama de trocador, $q_{\text {calc }}^{\max }$, a constante cinética de primeira ordem $k_{1}$ e verificar se os dados obtidos se ajustam ao modelo cinético.

Nas FIG. 5.19 e 5.20 observa-se que a variação de $\log \left(q_{\max }-q_{t}\right)$ em função do tempo não segue um comportamento linear, desta forma pode-se concluir que os dados experimentais não se ajustam ao modelo de pseudo-primeira ordem. 

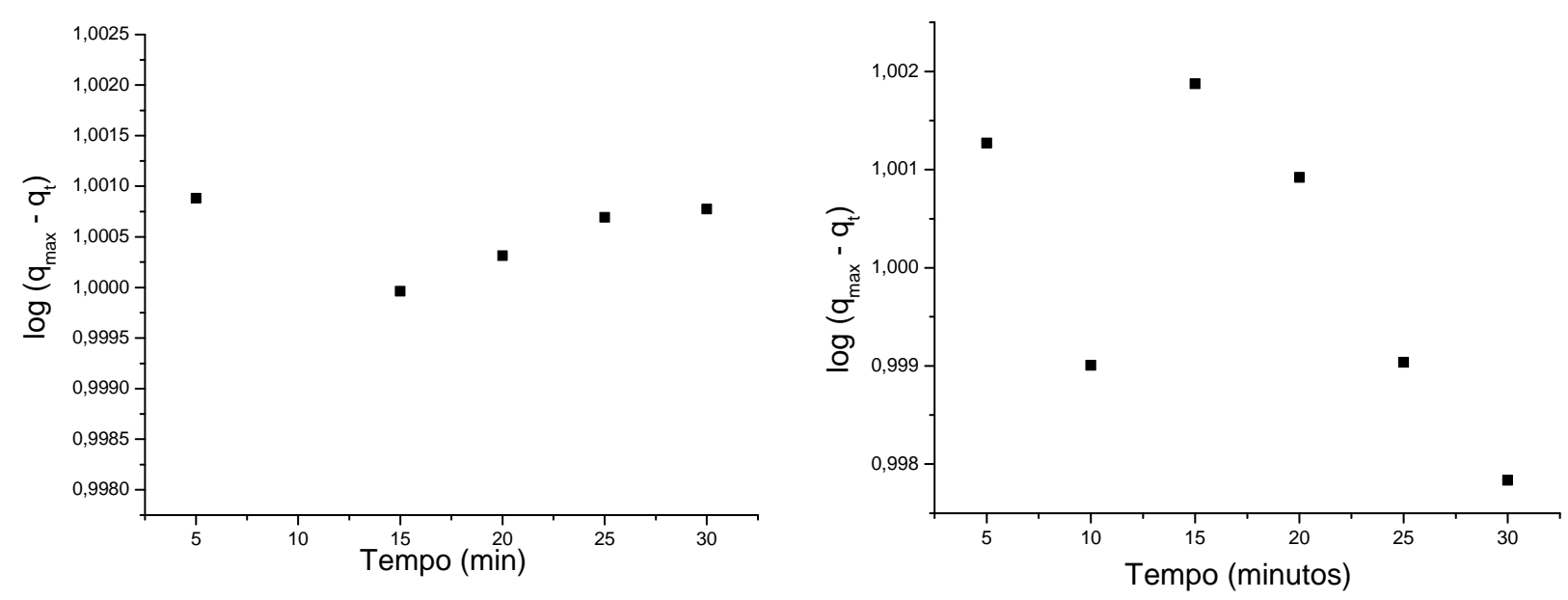

FIGURA 5.19 - Modelo de pseudo-primeira ordem para o trocador híbrido $\mathrm{SnO}_{2} / \mathrm{TiO}_{2}$ em $\mathrm{pH} 4$ e $\mathrm{pH} 9$ respectivamente para o $\mathrm{Cd}^{2+}$.
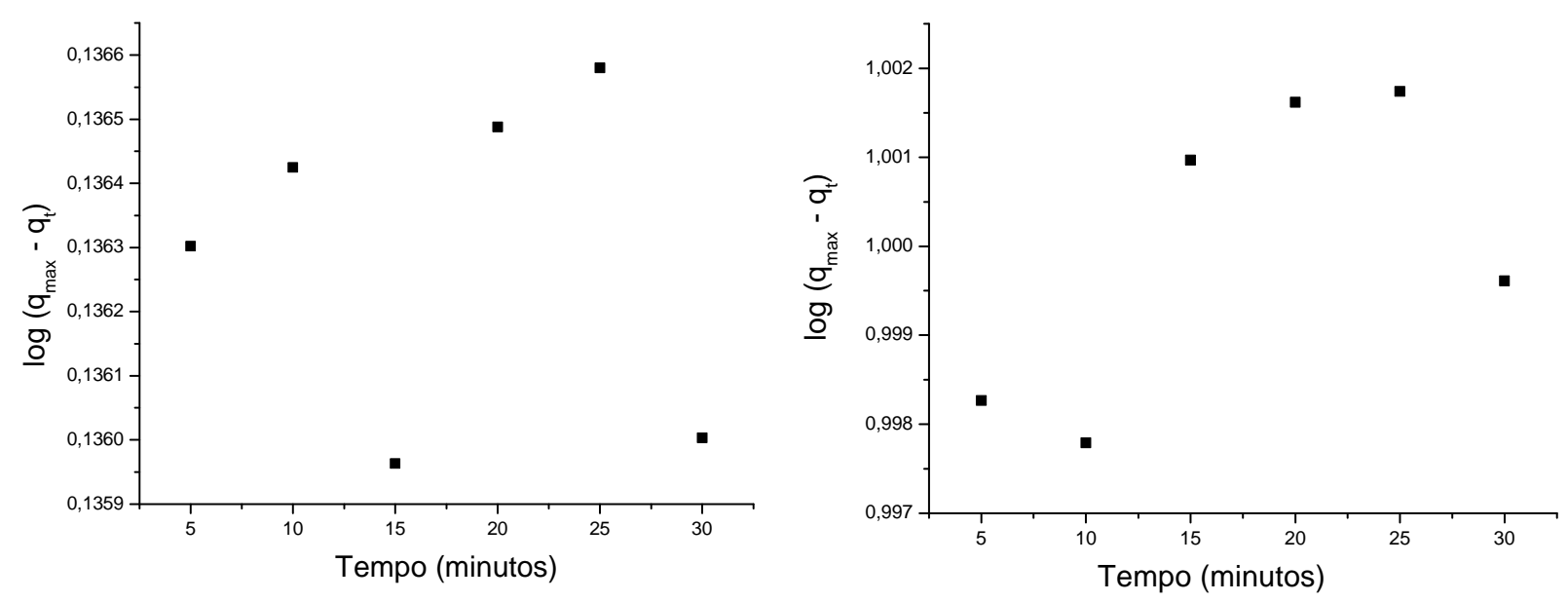

FIGURA 5.20 - Modelo de pseudo-primeira ordem para o trocador híbrido $\mathrm{SnO}_{2} / \mathrm{TiO}_{2}: \mathrm{Eu}^{3+}$ em $\mathrm{pH} 4$ e $\mathrm{pH} 9$ respectivamente para o $\mathrm{Cd}^{2+}$.

\subsubsection{Aplicação do modelo cinético de Pseudo-Segunda Ordem para $\mathrm{Cd}^{2+}$}

A equação 5.7 define o modelo de pseudo-segunda ordem e a equação 5.8 apresenta sua forma linearizada. ${ }^{[30]}$ Este modelo admite que no processo de adsorção o adsorbato liga-se a dois sítios ativos da superfície do adsorvente. ${ }^{[32]}$

$$
\frac{d q_{t}}{d t}=k_{2}\left(q_{\text {calc }}^{\max }-q_{t}\right)
$$




$$
\frac{t}{q_{t}}=\frac{1}{k_{2} \cdot q_{\text {calc }}^{\max ^{2}}}+\frac{1}{q_{\text {calc }}^{\max }} t
$$

$q_{t}=$ massa adsorvida de metal por grama de trocador em cada tempo ( $\left.\mathrm{t}\right)$

$q_{\text {calc }}^{\max }=$ valor calculado da massa máxima adsorvida de metal por $\mathrm{g}$ trocador

$k_{2}=$ constante de pseudo-segunda ordem

O modelo de pseudo-segunda ordem permite calcular a massa máxima de $\mathrm{Cd}^{2+}$ que pode ser adsorvida por grama de trocador, $q_{\text {calc }}^{\max }$, a constante cinética de segunda ordem $k_{2}$, bem como pode-se verificar se os dados obtidos se ajustam ao modelo cinético em questão.

Utilizando a equação 5.8, construiu-se uma curva de $\left(t / q_{t}\right)$ versus $t$ (FIG. 5.21 e 5.22) para o $\mathrm{Cd}^{2+}$ nos $\mathrm{pH} 4$ e pH 9 referente aos trocadores híbridos $\mathrm{SnO}_{2} / \mathrm{TiO}_{2}$ e $\mathrm{SnO}_{2} / \mathrm{TiO}_{2}: \mathrm{Eu}^{3+}$.
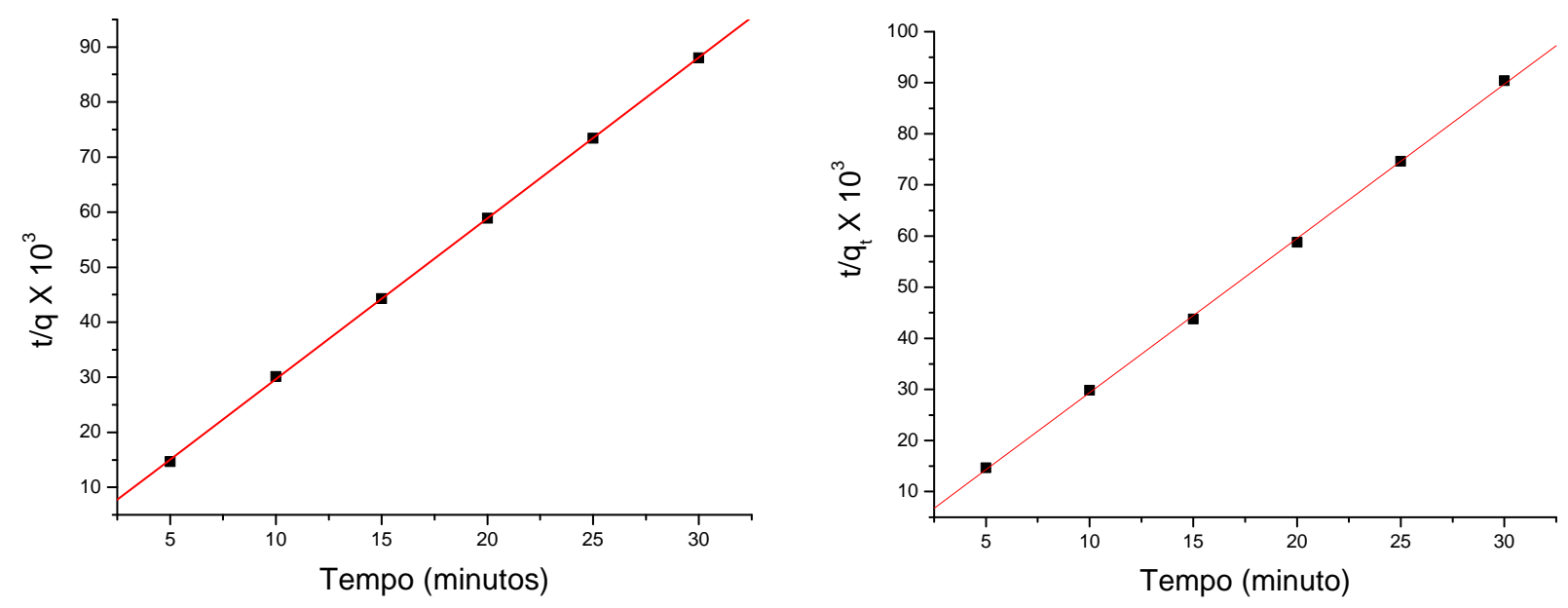

FIGURA 5.21 - Modelo de pseudo-segunda ordem para o trocador híbrido $\mathrm{SnO}_{2} / \mathrm{TiO}_{2}$ em $\mathrm{pH} 4$ e $\mathrm{pH} 9$ respectivamente para o $\mathrm{Cd}^{2+}$. 

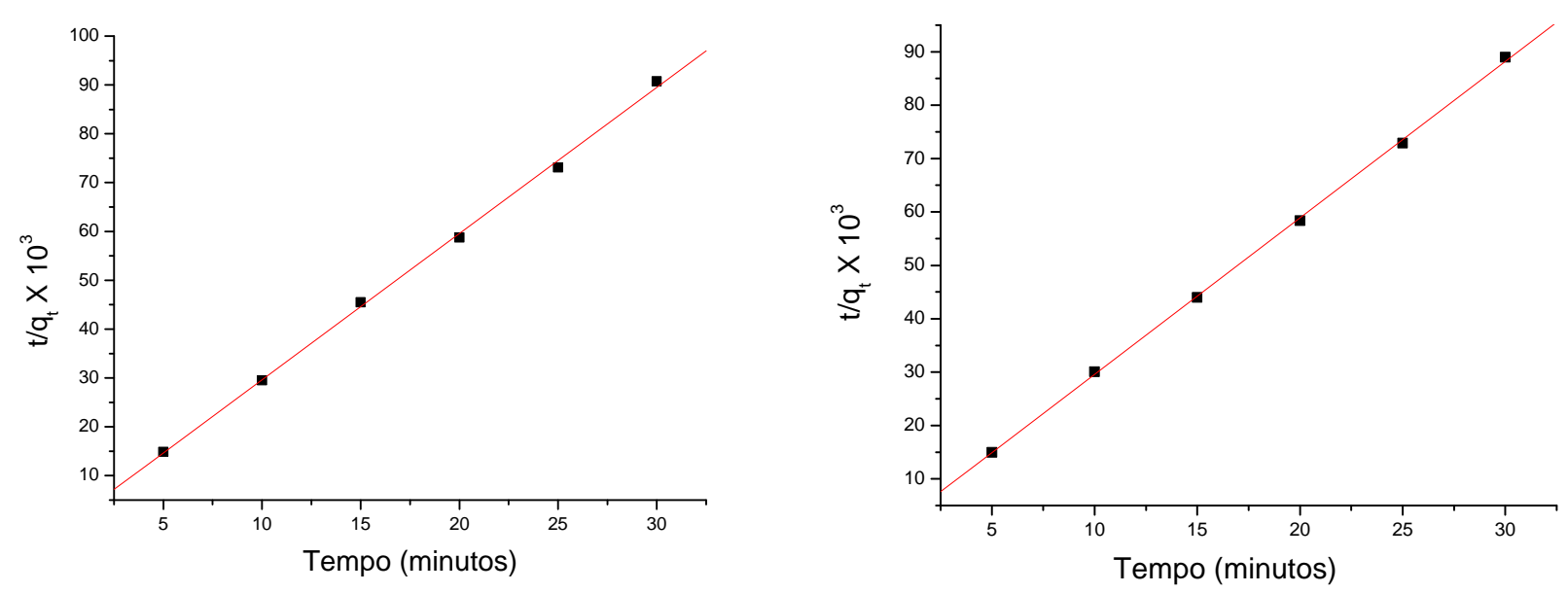

FIGURA 5.22 - Modelo de pseudo-segunda ordem para o trocador híbrido $\mathrm{SnO}_{2} / \mathrm{TiO}_{2}: \mathrm{Eu}^{3+}$ em pH 4 e pH 9 respectivamente para o $\mathrm{Cd}^{2+}$.

O tratamento dos dados por regressão linear para cada conjunto de dados forneceu os parâmetros da equação 5.8 e o respectivo coeficiente de correlação (TAB. 5.1). O coeficiente linear da curva é o termo $\left(1 /\left(k_{2} . q_{\text {calc }}^{\max }\right)\right)$ e o coeficiente $\operatorname{angular}\left(1 / q_{\text {calc }}^{\max }\right)$.

TABELA 5.1 - Parâmetros da equação de pseudo-segunda ordem para os trocadores híbridos na adsorção do $\mathrm{Cd}^{2+}$.

\begin{tabular}{cccccc}
\hline \multirow{2}{*}{ Trocador híbrido } & $\begin{array}{c}\mathbf{k}_{\mathbf{2}} \\
\left(\mathbf{m i n}^{-1} \mathbf{g}_{\text {trod }} / \mathbf{g}_{\text {met }}\right)\end{array}$ & $q_{\text {calc }}^{\max }(\mathrm{g} / \mathrm{g})$ & $q_{\mathrm{exp}}^{\max }(\mathrm{g} / \mathrm{g})$ & $\mathbf{R}$ \\
\hline \multirow{2}{*}{$\mathrm{SnO}_{2} / \mathrm{TiO}_{2}$} & $\mathrm{pH} 4$ & $2,61 \times 10^{-10}$ & $3,42 \times 10^{-4}$ & $3,39 \times 10^{-4}$ & 0,99995 \\
& $\mathrm{pH} 9$ & $-1,39 \times 10^{-10}$ & $3,31 \times 10^{-4}$ & $3,38 \times 10^{-4}$ & 0,99976 \\
& & & & & \\
$\mathrm{SnO}_{2} / \mathrm{TiO}_{2}: \mathrm{Eu}^{3+}$ & $\mathrm{pH} 4$ & $-4,13 \times 10^{-10}$ & $3,34 \times 10^{-4}$ & $3,36 \times 10^{-4}$ & 0,99936 \\
& $\mathrm{pH} 9$ & $4,07 \times 10^{-10}$ & $3,41 \times 10^{-4}$ & $3,38 \times 10^{-4}$ & 0,99979 \\
\hline
\end{tabular}

Observando na TAB. 5.1 os coeficientes de correlação, R, calculados, pode-se concluir que os dados experimentais ajustaram-se perfeitamente ao modelo de pseudo-segunda ordem. Os valores das massas máximas de adsorbato adsorvido 
por grama de adsorvente calculados, $q_{\text {calc }}^{\max }$, a partir do modelo cinético, concordam com os valores determinados experimentalmente.

A constante de pseudo-segunda ordem, $\mathrm{k}_{2}$, maior em $\mathrm{pH} 4$ para o trocado não dopado e em pH 9 para o dopado.

O modelo de pseudo-segunda ordem admite que a adsorção do adsorbato no adsorvente ocorre por dois sítios ativos. Após a análise dos resultados pode-se dizer que a adsorção do $\mathrm{Cd}^{2+}$ pelos trocadores híbridos $\mathrm{SnO}_{2} / \mathrm{TiO}_{2}$ e $\mathrm{SnO}_{2} / \mathrm{TiO}_{2}: \mathrm{Eu}^{3+}$, ocorre segundo este modelo, via dois sítios conforme equação:

$$
2 \text { Trocador }_{(\text {sólido) }}+\text { Metal }_{(\text {aquoso) }} \rightarrow \text { (Trocador) }_{2} \text { Metal (fase adsorvida) }
$$

sítios ativos

\subsubsection{Aplicação do modelo cinético de Difusão intrapartícula para $\mathbf{C d}^{2+}$}

A difusão intrapartícula é um processo de adsorção no qual o adsorbato é transportado da solução em contato com o adsorvente para os poros no interior da superfície. ${ }^{[33]}$ Este modelo possibilita a obtenção da constante de difusão $k_{p}$, a partir da equação: ${ }^{[30,33]}$

$$
q_{t}=k_{p} t^{1 / 2}
$$

$t=$ tempo de contato entre trocador e metal

$q_{t}=$ massa adsorvida de metal por grama de trocador em cada tempo $(\mathrm{t})$

$k_{p}=$ constante de difusão

A partir da equação 5.10 construiu-se uma curva de $q_{t}$ versus $t^{1 / 2}$ conforme FIG. 5.23. De acordo com este modelo o gráfico deve mostrar uma reta que passa pela origem para então poder assumir que o mecanismo de adsorção envolve a difusão do adsorbato e a inclinação da reta é a constante de velocidade do transporte intrapartícula $\left(\mathrm{k}_{\mathrm{p}}\right)$. 
Na FIG. 5.23 observam-se que para todos os sistemas estudados, apesar de apresentarem linearidade, a reta não passa pela origem podendo-se concluir que não ocorre difusão intrapartícula para estes sistemas.

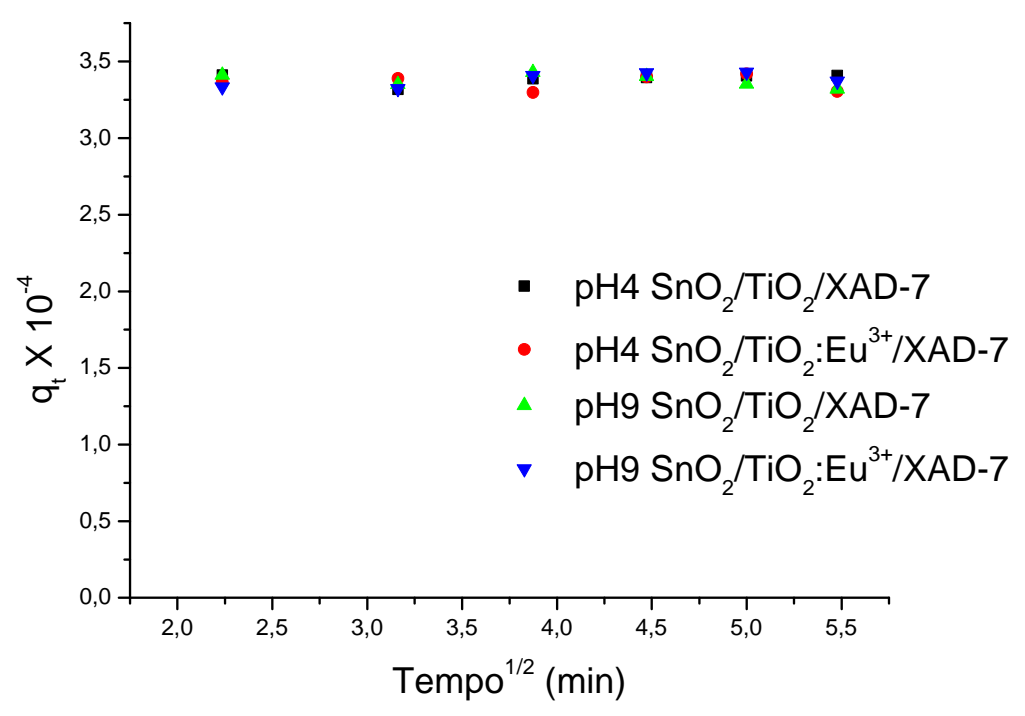

FIGURA 5.23 - Modelo de difusão intrapartícula para os trocadores híbridos em pH 4 e pH 9 para o $\mathrm{Cd}^{2+}$.

\subsubsection{Isotermas de adsorção do $\mathrm{Cd}^{2+}$}

As isotermas derivadas teóricas ou empíricas podem, freqüentemente, ser representadas por equações simples (3.7; 3.9 e 3.13) que relacionam diretamente o volume/massa adsorvido em função da pressão e/ou concentração do adsorbato.

O estudo das isotermas de adsorção foi realizado variando-se a concentração de $\mathrm{Cd}^{2+}$ de 0,01159 até $0,4 \mathrm{~g} \cdot \mathrm{L}^{-1}$. Os resultados mostraram que a adsorção do cádmio depende da concentração do mesmo na solução de alimentação.

Os dados dos trocadores utilizados neste trabalho foram analisados segundo modelos de Feundlich, Langmuir e Dubinin-Radushkevich (DR) e as constantes obtidas para os mesmos estão nas TAB. 5.2, 5.3 e 5.4. 


\subsubsection{Isoterma de Freundlich (I-F) para $\mathrm{Cd}^{2+}$}

O modelo de I-F foi aplicado aos dados experimentais. O modelo é definido pela equação 3.6 ou por sua forma linearizada equação 3.7 , onde utilizando este modelo foi possível determinar os parâmetros $\mathrm{K}_{\mathrm{F}}$ e $\mathrm{n}$ para adsorção do $\mathrm{Cd}^{2+}$ nos trocadores.

Nas FIG. 5.24 e 5.25 apresentam-se os perfis das isotermas de Freundlich para os dois trocadores em questão.
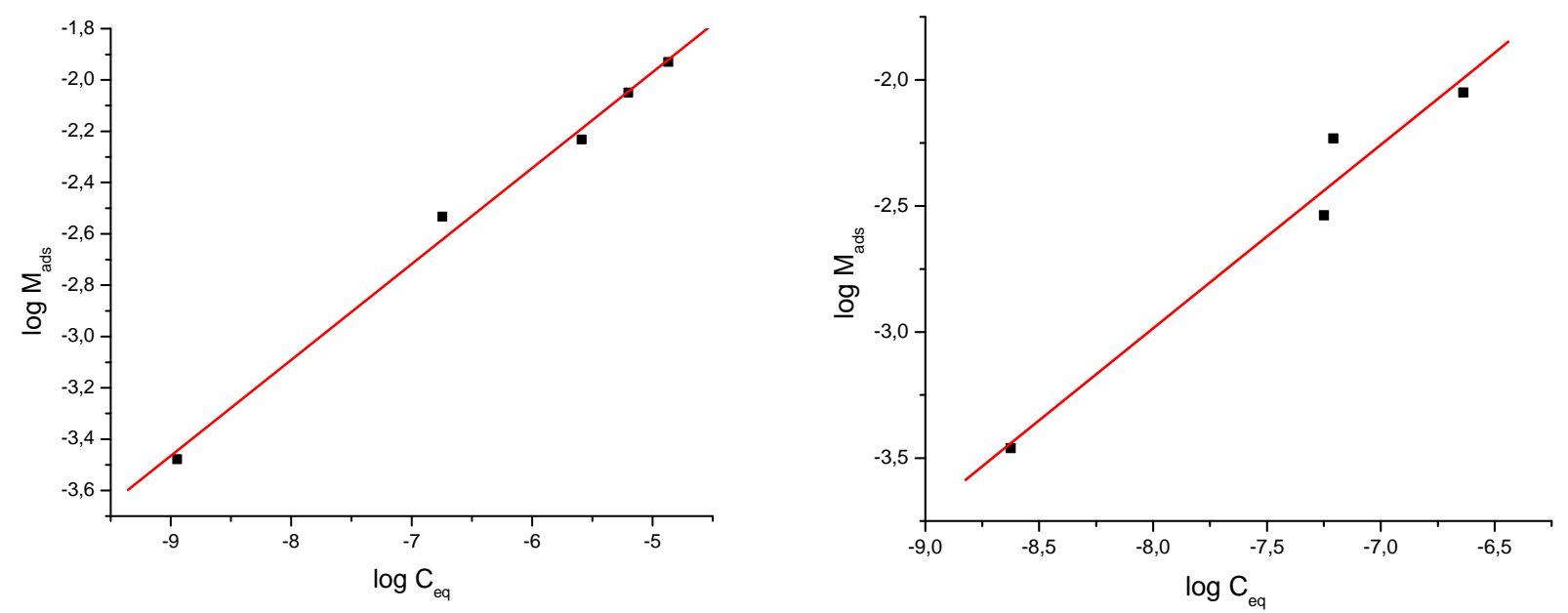

FIGURA 5.24- Isotermas de Freundlich para o trocador $\mathrm{SnO}_{2} / \mathrm{TiO}_{2}$ em pH $4 \mathrm{pH} 9$ respectivamente para o $\mathrm{Cd}^{2+}$.
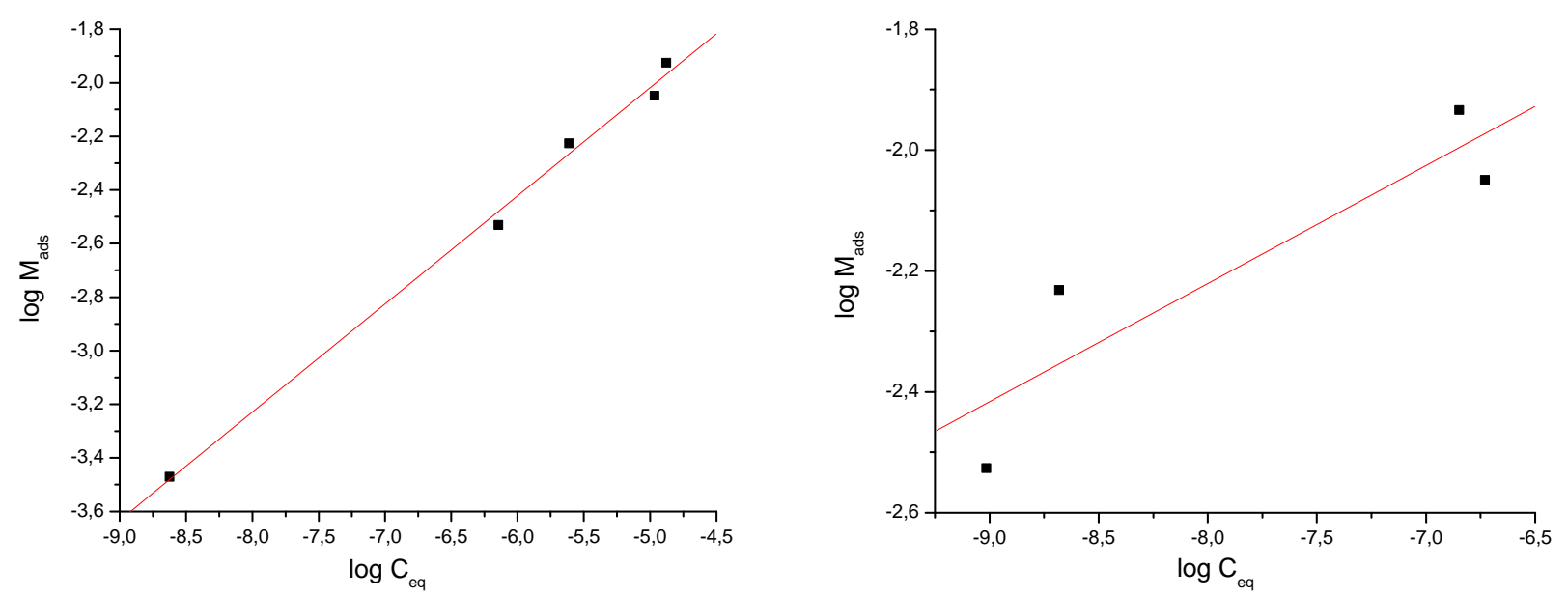

FIGURA 5.25- Isotermas de Freundlich para o trocador $\mathrm{SnO}_{2} / \mathrm{TiO}_{2}: \mathrm{Eu}^{3+}$ em pH 4 e $\mathrm{pH} 9$ respectivamente para o $\mathrm{Cd}^{2+}$. 
O parâmetro $\mathrm{n}$ indica como estão distribuídos os sítios de adsorção quanto à sua energia. Se o parâmetro $n$ é maior que 1 , tem-se a indicação de que estes sítios são heterogêneos do ponto de vista energético. Caso todos os sítios tenham a mesma energia (sistema homogêneo), obtém-se uma reta, pois todos os sítios estão ocupados da mesma forma. Das análises das isotermas de Freundlich nas FIG. 5.24 e 5.25 foi possível observar que os materiais estudados apresentam superfície energeticamente heterogênea com valores de $\mathrm{n}$ maior ou aproximadamente iguais a 1 (TAB. 5.2), e os dados podem ser ajustados ao modelo teórico, segundo Freundlich ${ }^{[34,35]}$ com coeficientes de correlação igual ou maior que 0,90 .

TABELA 5.2 - Parâmetros da equação de Freundlich para os trocadores na adsorção do $\mathrm{Cd}^{2+}$.

\begin{tabular}{|c|c|c|c|c|}
\hline \multicolumn{2}{|c|}{ Trocador } & \multirow{2}{*}{$\begin{array}{c}\mathbf{K}_{\mathbf{F}} \\
0,79279\end{array}$} & \multirow{2}{*}{$\frac{\mathbf{n}}{2,67544}$} & \multirow{2}{*}{$\frac{\mathbf{R}}{0,99644}$} \\
\hline SnO/TiR & $\mathrm{pH} 4$ & & & \\
\hline 20 & $\mathrm{pH} 9$ & 698,232 & 1,37225 & 0,98099 \\
\hline \multirow{2}{*}{$\mathrm{SnO}_{2} / \mathrm{TiO}_{2}: \mathrm{Eu}^{3+}$} & $\mathrm{pH} 4$ & 0,99699 & 2,47868 & 0,99735 \\
\hline & pH 9 & 0,21993 & 5,11849 & 0,90519 \\
\hline
\end{tabular}

A constante de Freundlich $\left(\mathrm{K}_{\mathrm{F}}\right)$ está relacionada com a energia média de adsorção, ou seja, analisando os resultados apresentados na TAB. 5.2, o trocador $\mathrm{SnO}_{2} / \mathrm{TiO}_{2}$ : $\mathrm{Eu}^{3+} \mathrm{em} \mathrm{pH} 4$ é o que apresenta uma interação mais forte com o íon $\mathrm{Cd}^{2+}$ tendo em vista que o trocador $\mathrm{SnO}_{2} / \mathrm{TiO}_{2}$ em $\mathrm{pH} 9$ apresentou um valor de constante muito diferente dos demais.

\subsubsection{Isoterma de Langmuir para $\mathrm{Cd}^{2+}$}

Os dados experimentais obtidos na determinação das isotermas foram aplicados ao modelo de Langmuir; definido pela equação 3.8 ou pela sua forma linearizada equação 3.10 .

Nas FIG. 5.26 e 5.27 apresentam-se os perfis das isotermas de Langmuir para os dois trocadores estudados e em dois pHs 4 e 9. 

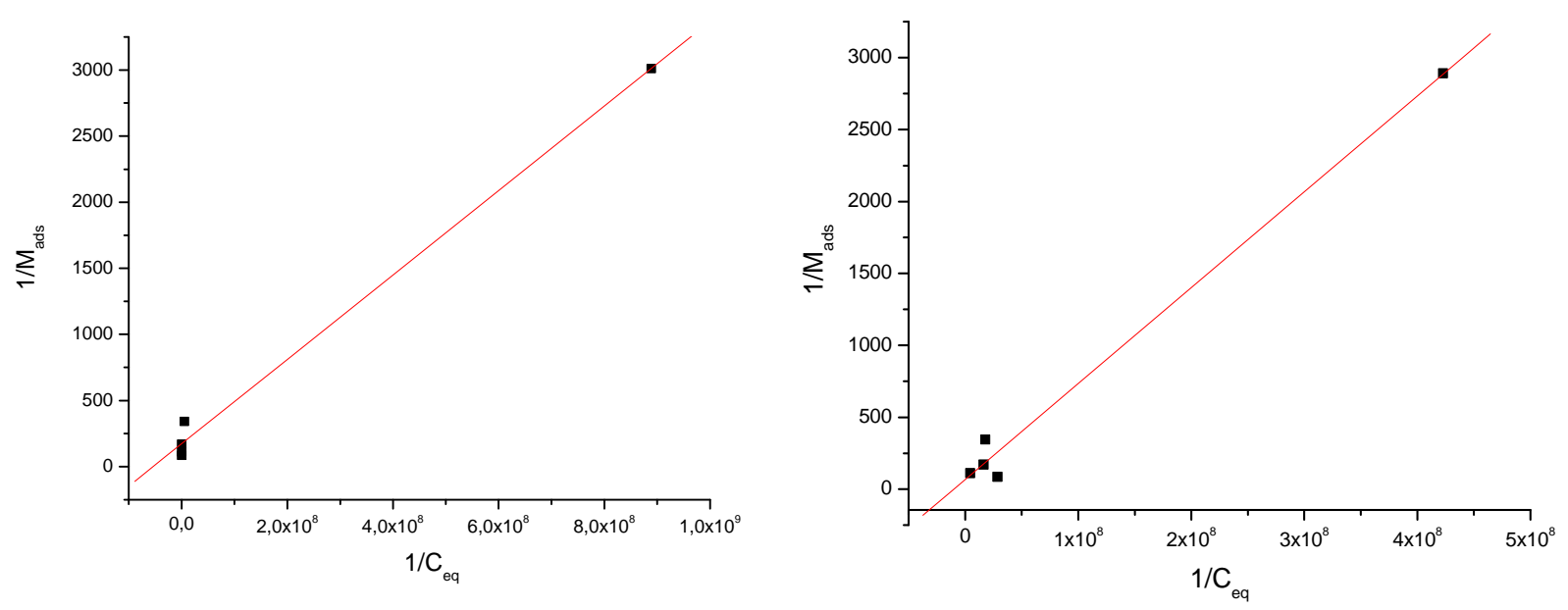

FIGURA 5.26- Isotermas de Langmuir para o trocador $\mathrm{SnO}_{2} / \mathrm{TiO}_{2}$ em pH 4 e $\mathrm{pH} 9$ respectivamente para o $\mathrm{Cd}^{2+}$.
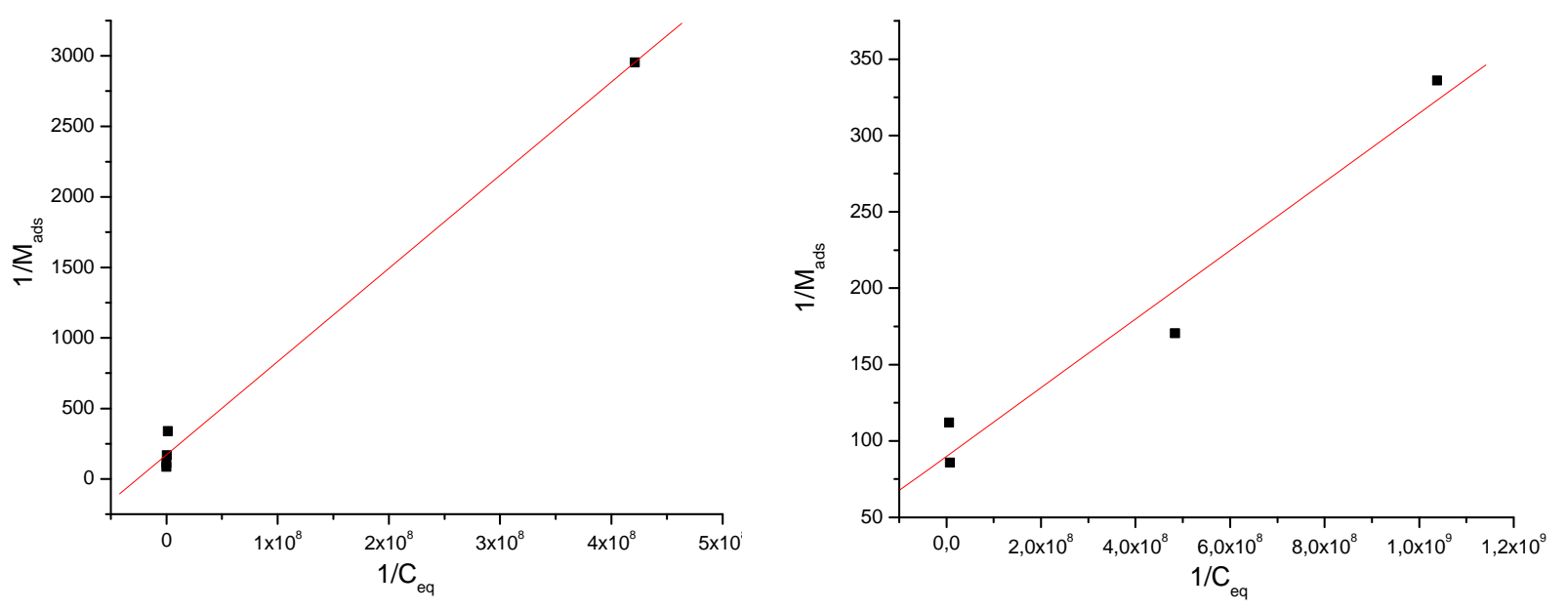

FIGURA 5.27-Isotermas de Langmuir para o trocador $\mathrm{SnO}_{2} / \mathrm{TiO}_{2}: \mathrm{Eu}^{3+}$ em $\mathrm{pH} 4$ e $\mathrm{pH} 9$ respectivamente para o $\mathrm{Cd}^{2+}$.

$\mathrm{Na}$ TAB. 5.3 apresentam-se os resultados das constantes deste modelo para os trocadores estudados. Com base no valor de $\mathrm{K}_{\mathrm{L}}$, que está relacionado com a capacidade de adsorção, pode-se dizer que para um mesmo sistema a adsorção do $\mathrm{Cd}^{2+}$ em função do $\mathrm{pH}$ o trocador ácido tem maior capacidade de troca.

Pelas constantes de Langmuir ( $\mathrm{K}_{\mathrm{L}}$ ) (FIG. 5.26 e 5.27) foi também possível calcular a variação de energia livre do sistema estudado e observou-se que a adsorção neste caso é um processo espontâneo, $\Delta G^{0}<0$ (TAB. 5.3). Pode-se 
observar também que quanto maior a constante de Langmuir, maior a massa máxima adsorvida. Para todos os sistemas, o ajuste dos dados experimentais ao modelo mostram coeficientes de correlação de ordem de 0,98.

TABELA 5.3 - Parâmetros da equação de Langmuir para os trocadores na adsorção do $\mathrm{Cd}^{2+}$.

\begin{tabular}{cccccc}
\hline \multicolumn{2}{c}{ Trocador } & \multicolumn{1}{c}{$\mathbf{K}_{\mathbf{L}}$} & $M_{a d s}^{\max }(\mathbf{g} / \mathbf{g})$ & $\mathbf{R}$ & $\Delta \mathbf{G}^{\circ}(\mathrm{KJ} / \mathbf{m o l})$ \\
\hline \multirow{2}{*}{$\mathrm{SnO}_{2} / \mathrm{TiO}_{2}$} & $\mathrm{pH} 4$ & $5,4 \times 10^{6}$ & 0,00581 & 0,99736 & $-44,10680$ \\
& $\mathrm{pH} 9$ & $10,2 \times 10^{6}$ & 0,01465 & 0,99536 & $-39,99220$ \\
& & & & & \\
$\mathrm{SnO}_{2} / \mathrm{TiO}_{2}: \mathrm{Eu}^{3+}$ & $\mathrm{pH} 4$ & $26,1 \times 10^{6}$ & 0,005795 & 0,99706 & $-42,31270$ \\
& $\mathrm{pH} 9$ & $400,9 \times 10^{6}$ & 0,011111 & 0,98109 & $-49,07880$ \\
\hline
\end{tabular}

\subsubsection{Isoterma de Dubinin-Radushkevich (D-R) para $\mathrm{Cd}^{2+}$}

O modelo de Dubinin-Radushkevich (D-R), definido pela equação 3.10 ou pela sua forma linearizada 3.13, foi aplicado aos dados experimentais com o intuído de diferenciar uma possível adsorção química ou física para o sistema adsorvente/adsorbato. Nas FIG. 5.28 e 5.29 apresentam-se os perfis das isotermas de D-R para os dois trocadores estudados nos pHs 4 e 9.
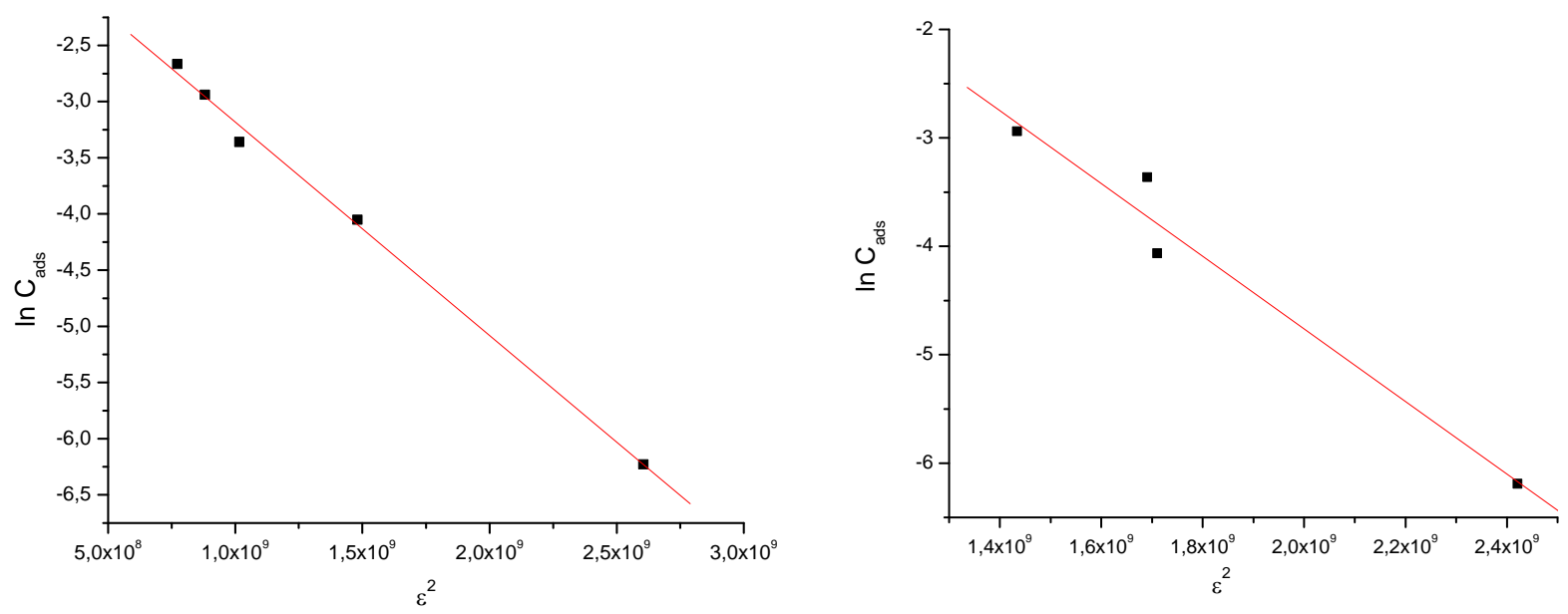

FIGURA 5.28- Isotermas de D-R para o trocador $\mathrm{SnO}_{2} / \mathrm{TiO}_{2}$ em $\mathrm{pH} 4$ e pH 9 respectivamente para o $\mathrm{Cd}^{2+}$. 

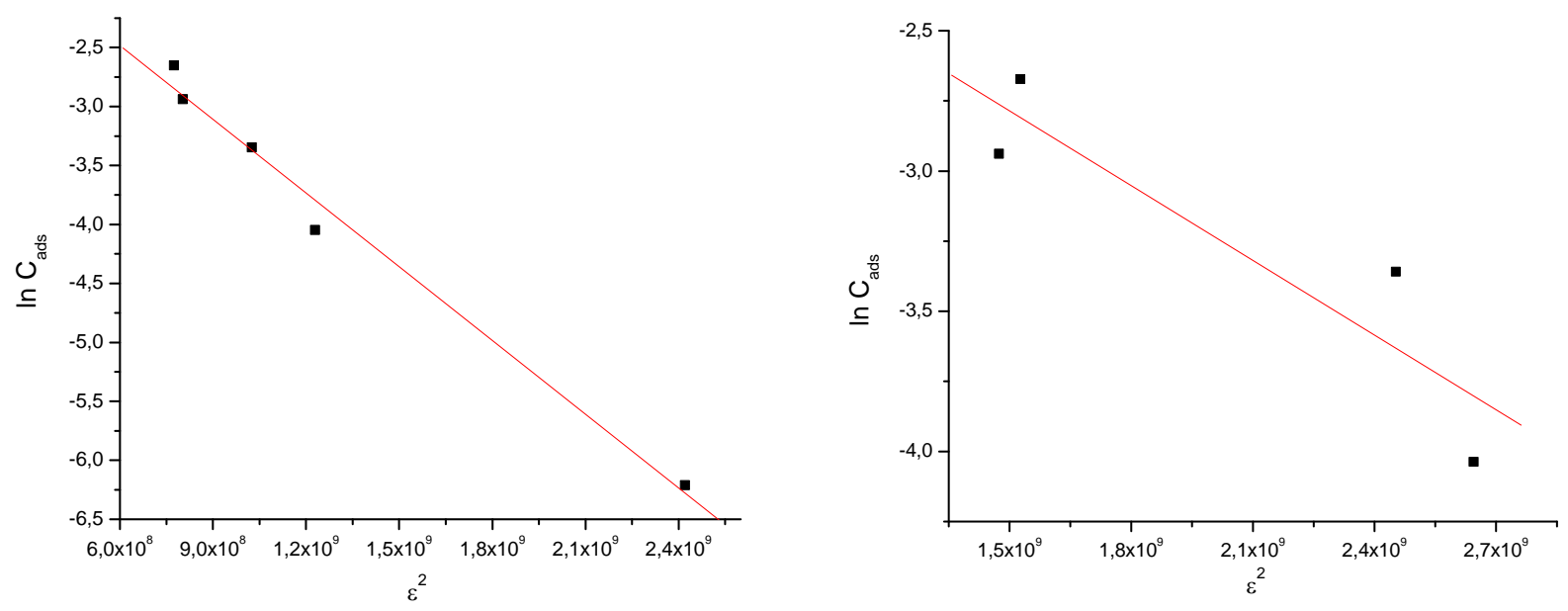

FIGURA 5.29- Isotermas de D-R para o trocador $\mathrm{SnO}_{2} / \mathrm{TiO}_{2}: \mathrm{Eu}^{3+}$ em $\mathrm{pH} 4$ e $\mathrm{pH} 9$ respectivamente para o $\mathrm{Cd}^{2+}$.

A constante $\mathrm{K}_{\mathrm{DR}}$ considerada relativa à massa máxima adsorvida de $\mathrm{Cd}^{2+}$ por grama de adsorvente, apresenta valores muito próximos com exceção do trocador $\mathrm{SnO}_{2} / \mathrm{TiO}_{2}$ em pH 9 (TAB. 5.4).

TABELA 5.4 - Parâmetros da equação de Dubinin-Radushkevich (D-R) para os TII na adsorção do $\mathrm{Cd}^{2+}$.

\begin{tabular}{|c|c|c|c|c|c|}
\hline \multicolumn{2}{|c|}{ Trocador } & \multirow{2}{*}{$\begin{array}{c}\mathbf{K}_{\mathrm{DR}} \\
0,27718\end{array}$} & \multirow{2}{*}{$\begin{array}{c}\text { B } \\
-1,90 \times 10^{-9}\end{array}$} & \multirow{2}{*}{$\begin{array}{c}\begin{array}{c}\mathrm{E} \\
\text { (kcal/mol) }\end{array} \\
3,88\end{array}$} & \multirow{2}{*}{$\begin{array}{c}\mathbf{R} \\
-0,99814\end{array}$} \\
\hline Cn /Tin & $\mathrm{pH} 4$ & & & & \\
\hline $\mathrm{SnO}_{2} / 11 \mathrm{U}_{2}$ & $\mathrm{pH} 9$ & 6,92398 & $-3,35 \times 10^{-9}$ & 2,92 & $-0,98278$ \\
\hline \multirow{2}{*}{$\mathrm{SnO}_{2} / \mathrm{TiO}_{2}: \mathrm{Eu}^{3+}$} & $\mathrm{pH} 4$ & 0,29143 & $-2,08 \times 10^{-9}$ & 3,71 & $-0,99331$ \\
\hline & $\mathrm{pH} 9$ & 0,23379 & $-8,88 \times 10^{-10}$ & 5,68 & $-0,91159$ \\
\hline
\end{tabular}

Com relação ao parâmetro $B$, considerado uma constante energética, observa-se na TAB. 5.4 que os valores obtidos são bem diferentes. Estes valores foram utilizados para calcular a energia média de adsorção (E). Conforme estabelecido por Teixeira, ${ }^{[36]}$ quando a energia de adsorção encontra-se na faixa aproximada de 2 a $6 \mathrm{Kcal} \mathrm{mol}^{-1}$, a adsorção é considerada física. Para adsorção química os valores desta energia raramente são menores que $10 \mathrm{Kcal} \mathrm{mol}^{-1}$. Portanto 
os resultados evidenciam que tipo de adsorção para todos os trocadores é adsorção física. ${ }^{[34]}$

\subsubsection{Estudo da dessorção do $\mathrm{Cd}^{2+}$}

O estudo de dessorção do metal cádmio foi feito em batelada, contactando-se durante 10 min uma solução de $0,2 \mathrm{~g}^{-\mathrm{L}^{-1}}$ de $\mathrm{Cd}^{2+}$ em pH 4 com massa de trocador de aproximadamente 0,05 g. Após o contato separou-se as fases. A fase aquosa foi analisada para determinação da quantidade de cádmio retido no trocador a ser usada no cálculo de dessorção. A fase sólida foi colocada em contato durante 24 horas com $2,5 \mathrm{~mL}$ de ácido nítrico $1 \mathrm{~mol} \cdot \mathrm{L}^{-1}$. Após este período analisaram-se alíquotas da solução por fluorescência de raios-X para determinar a concentração do metal na fase aquosa e assim determinar a porcentagem de dessorção do $\mathrm{Cd}^{2+}$ nos trocadores. Os resultados estão apresentados na TAB. 5.5 e pode-se observar uma boa dessorção do metal para os dois trocadores.

TABELA 5.5 - Dessorção do $\mathrm{Cd}^{2+}$.

\begin{tabular}{cc}
\hline TROCADOR & DESSORÇÃO (\%) \\
\hline $\mathrm{SnO}_{2} / \mathrm{TiO}_{2}$ & 89,80 \\
$\mathrm{SnO}_{2} / \mathrm{TiO}_{2}: \mathrm{Eu}^{3+}$ & 99,99 \\
\hline
\end{tabular}

\subsubsection{Estudos de adsorção de $\mathrm{Ni}^{2+}$ pelos trocadores iônicos inorgânicos}

As análises de extração do níquel também foram feitas em batelada, com massa de trocador de aproximadamente 0,05 g contactadas, em agitador mecânico, com um volume de $1,5 \mathrm{~mL}$ de fase aquosa. Determinou-se o coeficiente de distribuição $K_{d}$ ou razão de distribuição $D w$ e a porcentagem de adsorção. As variáveis estudadas para se estabelecer os parâmetros de adsorção foram às mesmas para o $\mathrm{Cd}^{2+}$.

\subsubsection{Influencia do $\mathrm{pH}$ para $\mathrm{Ni}^{2+}$}

No estudo da variação do $\mathrm{pH}$ da solução contendo o íon $\mathrm{Ni}^{2+}$ foi variado de 2 a 8, com solução tampão de ácido acético/acetato de sódio/hidróxido de sódio, 
sendo a concentração de $\mathrm{Ni}^{2+}$ foi de $0,3 \mathrm{~g} \cdot \mathrm{L}^{-1}$ e o tempo de contato para equilíbrio de 10 min.

Os gráficos representados na FIG. 5.30 mostram os perfis de adsorção dos trocadores para essa faixa de $\mathrm{pH}$. Pode-se observar que os resultados de extração apresentam uma grande semelhança, tanto para os valores de log Dw, como para porcentagem de adsorção, sendo o pH 7 o de melhor resposta de adsorção, 99,94\% e 99,96\% para os TII sem e com európio respectivamente o que demonstra o excelente desempenho dos mesmos na remoção de níquel de efluentes aquosos.
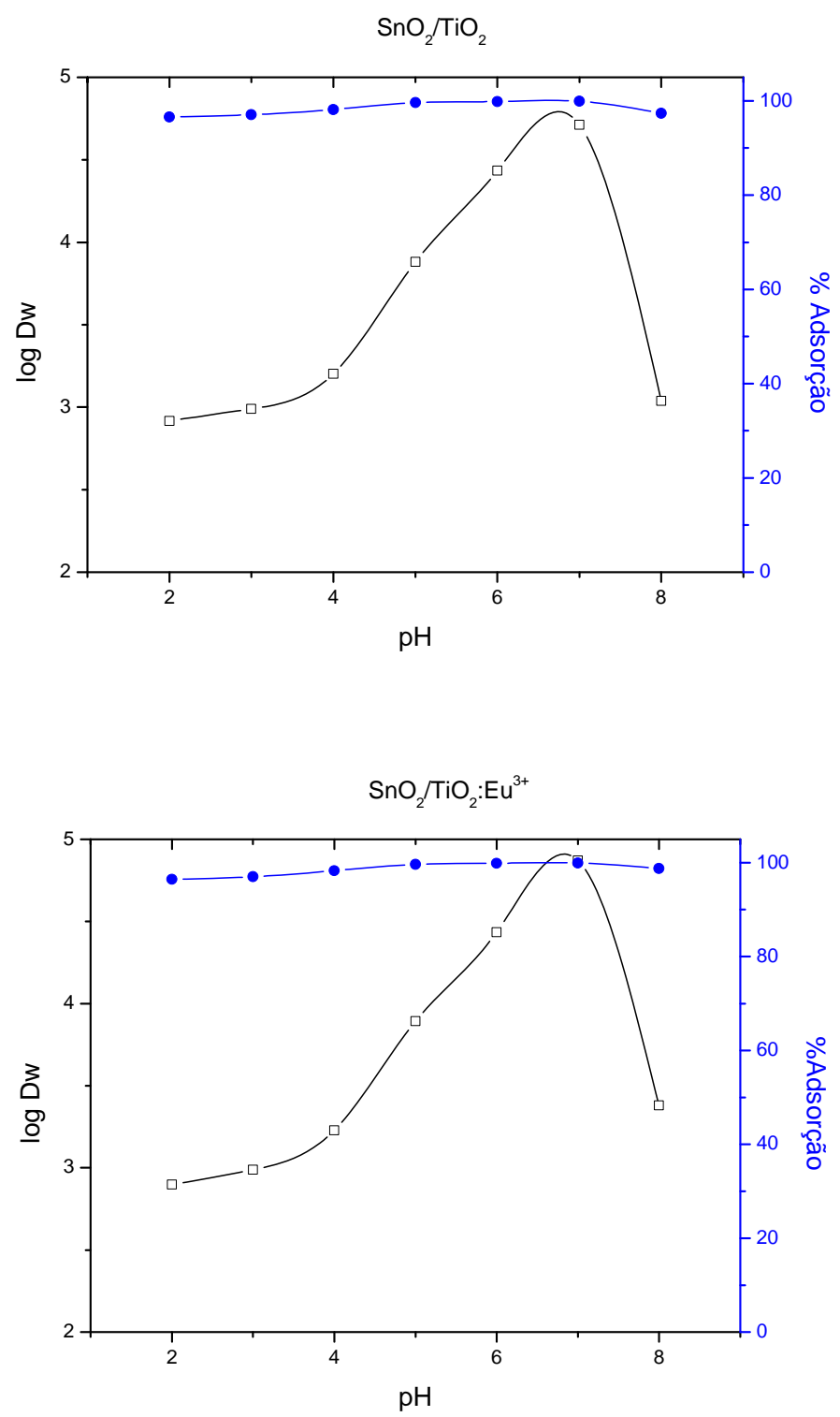

FIGURA 5.30 - Variação de pH em função do log Dw e da \% Adsorção para o Ni ${ }^{2+}$. 


\subsubsection{Influência da concentração de íons $\mathrm{Ni}^{2+}$}

Para os estudos de influencia da concentração de íons $\mathrm{Ni}^{2+}$, variou-se a concentração do mesmo de 0,1 a 0,7 g. $\mathrm{L}^{-1}$, utilizando-se $\mathrm{o} \mathrm{pH}$ que apresentou a melhor porcentagem de adsorção, $\mathrm{pH} 7$ e tempo de contato de 10 min.

Analisando-se os perfis da FIG. 5.31 observa-se uma diminuição dos valores de Dw para o níquel quando a concentração do mesmo aumenta. De acordo com os dados de porcentagem de adsorção, observa-se uma saturação dos trocadores com o aumento da concentração de $\mathrm{Ni}^{2+}$.
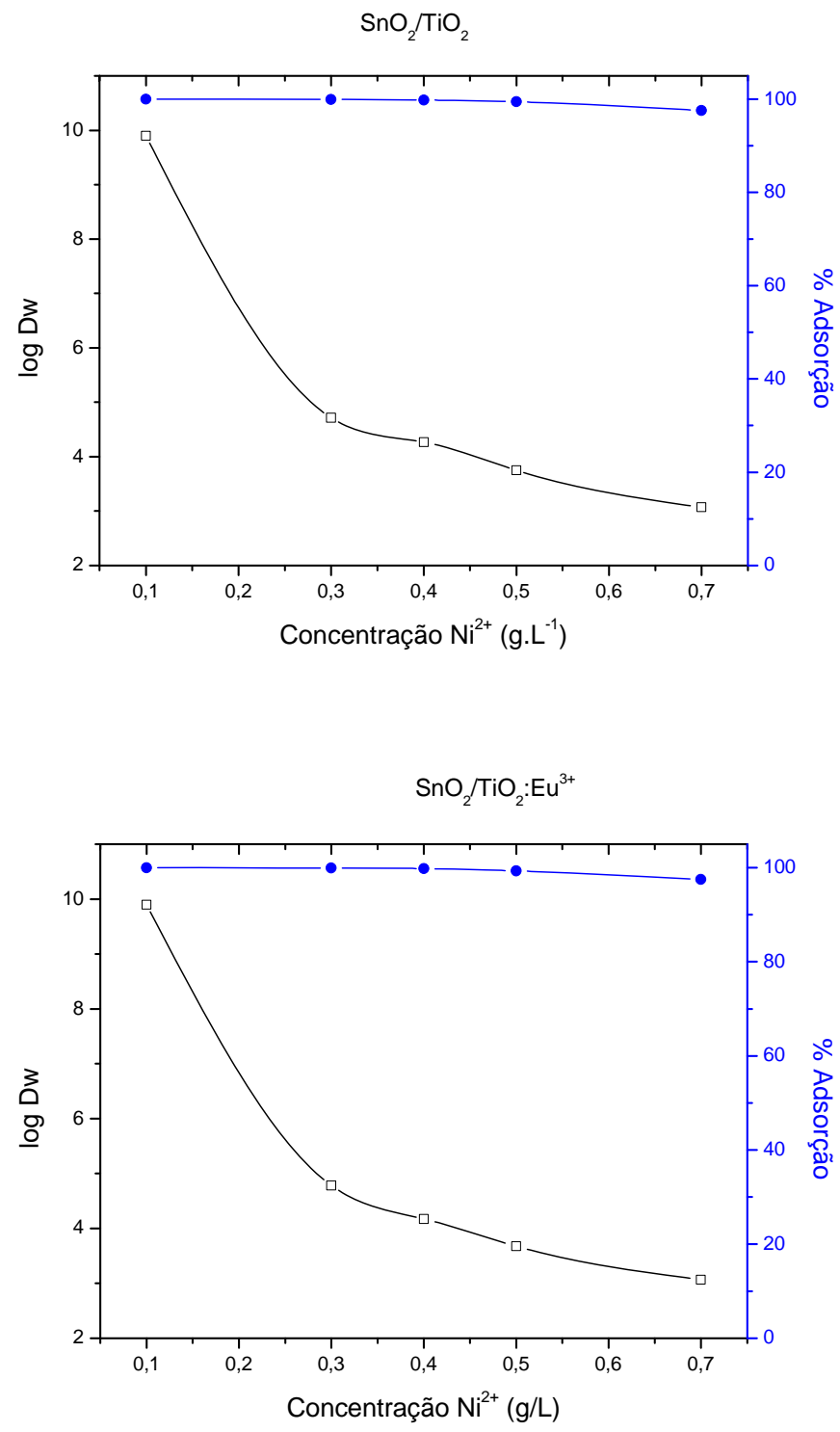

FIGURA 5.31 - Variação da concentração em função do log Dw e da \% Adsorção em $\mathrm{pH} 7$ para os trocadores estudados para o $\mathrm{Ni}^{2+}$. 


\subsubsection{Influência do tempo de contactação para $\mathrm{Ni}^{2+}$}

Como para os experimentos com o $\mathrm{Cd}^{2+}$, as análises de tempo de contactação, FIG. 5.32, foram feitas com os trocadores na matriz híbrida, visto a grande dificuldade de decantação do trocador em forma de pó, e com concentração de $\mathrm{Ni}^{2+}$ 0,3 g. $\mathrm{L}^{-1} \mathrm{em} \mathrm{pH}$ 7. Observa-se que para ambos os trocadores, a variação de tempo não teve influência significativa, ficando a porcentagem de adsorção em torno de $97 \%$. A redução da porcentagem de adsorção em relação aos outros estudos realizados anteriormente atribui-se à diminuição da área superficial de troca. 0 log Dw também não mostrou variação significativa, ficando em torno de 3.
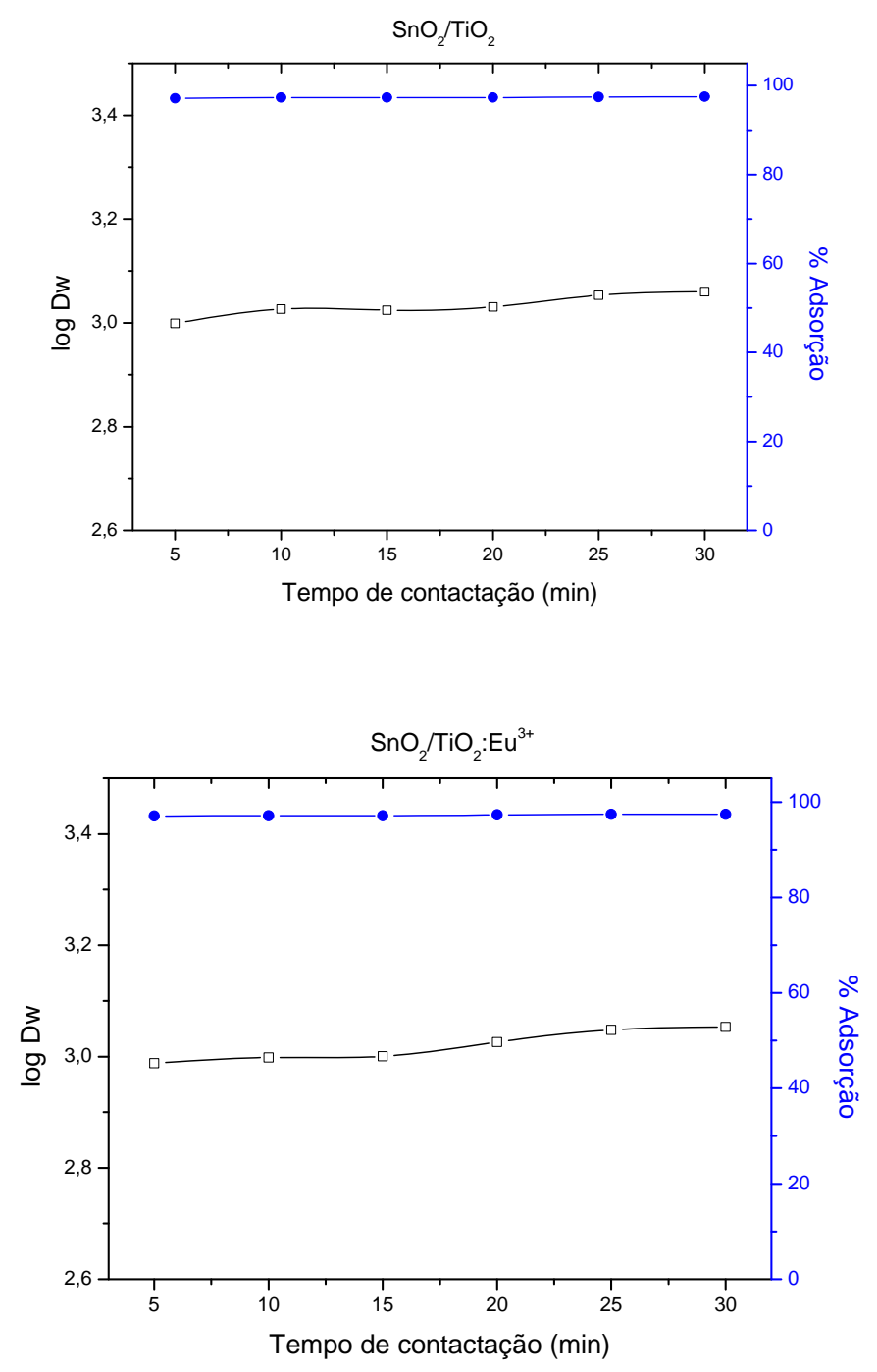

FIGURA 5.32- Variação do tempo de contato em função do log Dw e da \% Adsorção em $\mathrm{pH} 7$ para os trocadores estudados para o $\mathrm{Ni}^{2+}$. 


\subsubsection{Influência do tamanho de partícula para $\mathrm{Ni}^{2+}$}

Na FIG. 5.33 apresentam-se os resultados do estudo sobre a influência do tamanho das partículas do trocador na adsorção do $\mathrm{Ni}^{2+}$. Estes experimentos foram feitos nas condições descritas a seguir: concentração de $\mathrm{Ni}^{2+}$ igual a $0,3 \mathrm{~g} \cdot \mathrm{L}^{-1} \mathrm{e}$ tempo de contactação de $10 \mathrm{~min}$. Para ambos os trocadores observa-se uma diminuição da porcentagem de adsorção com o aumento do diâmetro dos trocadores, isso se explica pelo fato da área superficial de troca diminuir com o aumento do mesmo, pode-se considerar o diâmetro médio $(<0,55 \mathrm{~mm})$ para utilização em coluna, com porcentagem de adsorção em torno de $97 \%$ para ambos TII.
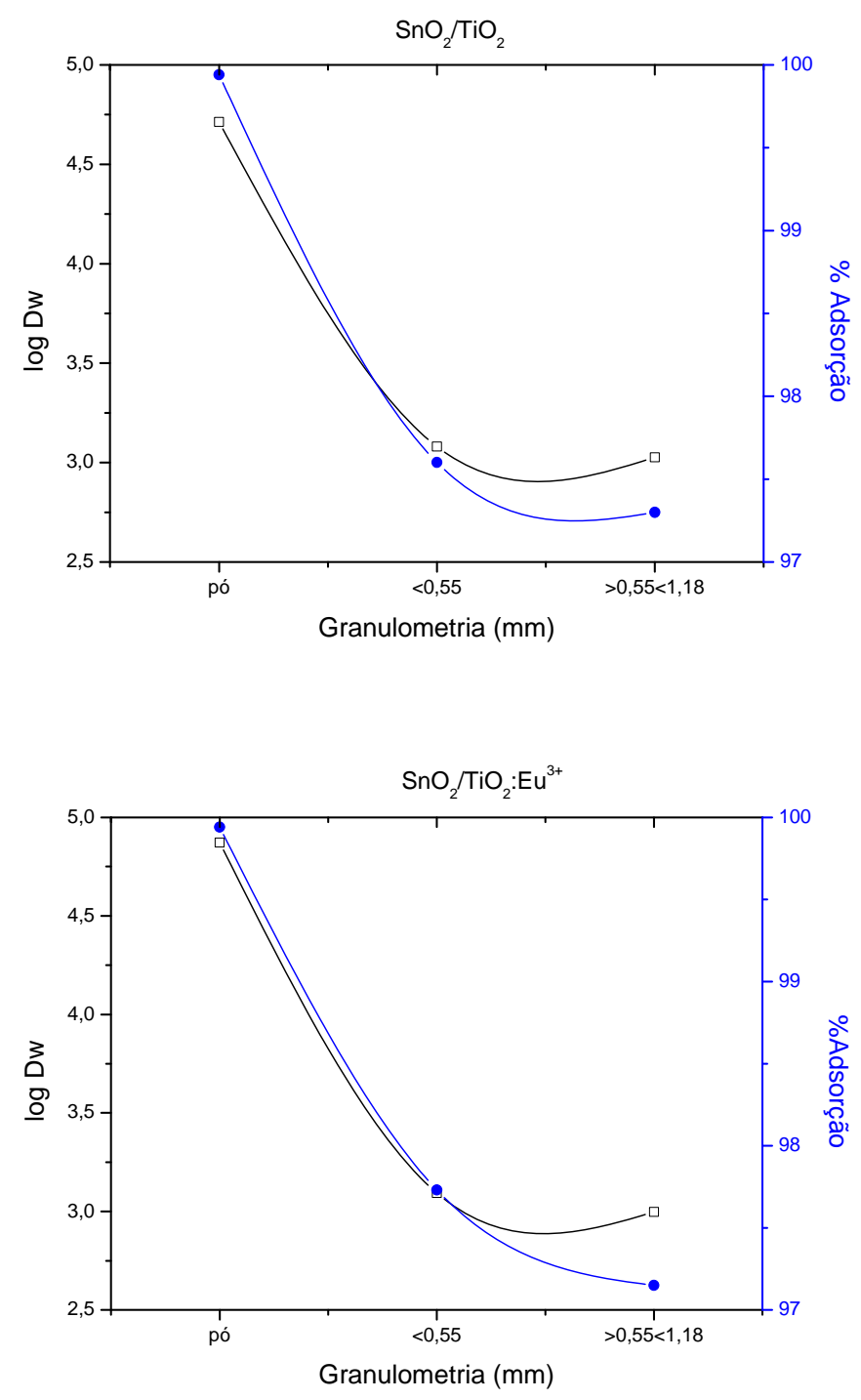

FIGURA 5.33 - Variação da granulometria em função da adsorção em pH 7. 


\subsubsection{Estudo da cinética de adsorção do $\mathrm{Ni}^{2+}$}

Na FIG. 5.34 mostra-se a variação da massa de $\mathrm{Ni}^{2+}$ adsorvida por massa de resina em função do tempo em $\mathrm{pH} 7$ e concentração de $0,3 \mathrm{~g} \cdot \mathrm{L}^{-1}$. Pode-se verificar que a variação da quantidade $(\mathrm{g})$ de $\mathrm{Ni}^{2+}$ adsorvida por grama de trocador em função do tempo não sofre alteração significativa em toda a variação de tempo estudada (5-30 min) estando em torno de 0,34.10 $0^{-3} \mathrm{~g}_{\text {metal }} / \mathrm{g}_{\text {trocador. }}$ Sendo assim, o tempo mínimo de contato da solução de $\mathrm{Ni}^{2+}$ com o trocador para que ocorra a máxima adsorção foi considerado como 5 min.

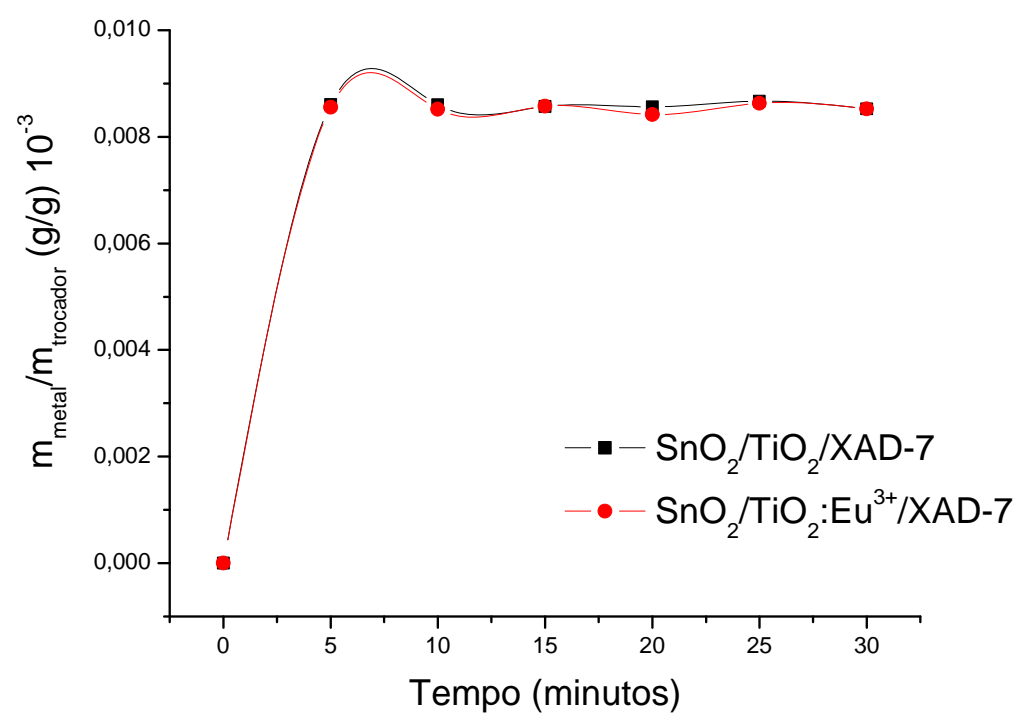

FIGURA 5.34 - Variação da massa de $\mathrm{Ni}^{2+}$ adsorvida por massa de trocador (g/g) em função do tempo.

Para determinação da massa adsorvida de $\mathrm{Ni}^{2+}$ nos trocadores, fez-se o mesmo calculo feito na determinação para o $\mathrm{Cd}^{2+}$ utilizando-se a concentração inicial de $\mathrm{Ni}^{2+}$ igual a $0,3 \mathrm{~g} \cdot \mathrm{L}^{-1}$.

\subsubsection{Aplicação do modelo cinético de Pseudo-Primeira Ordem para $\mathrm{Ni}^{2+}$}

Partindo da equação 5.6, utilizando os dados experimentais, e construindo uma curva de log $\left(q_{\max }-q_{t}\right)$ versus $t$ (FIG. 5.34) é possível calcular a massa máxima de $\mathrm{Ni}^{2+}$ que pode ser adsorvida por grama de trocador, $q_{\text {calc }}^{\max }$, a constante cinética de primeira ordem $k_{1}$ e verificar se os dados obtidos se ajustam ao modelo cinético. 
Na FIG. 5.35 observa-se que a variação de $\log \left(q_{\max }-q_{t}\right)$ em função do tempo não segue um comportamento linear, desta forma pode-se concluir que os dados experimentais não se ajustam ao modelo de pseudo-primeira ordem.
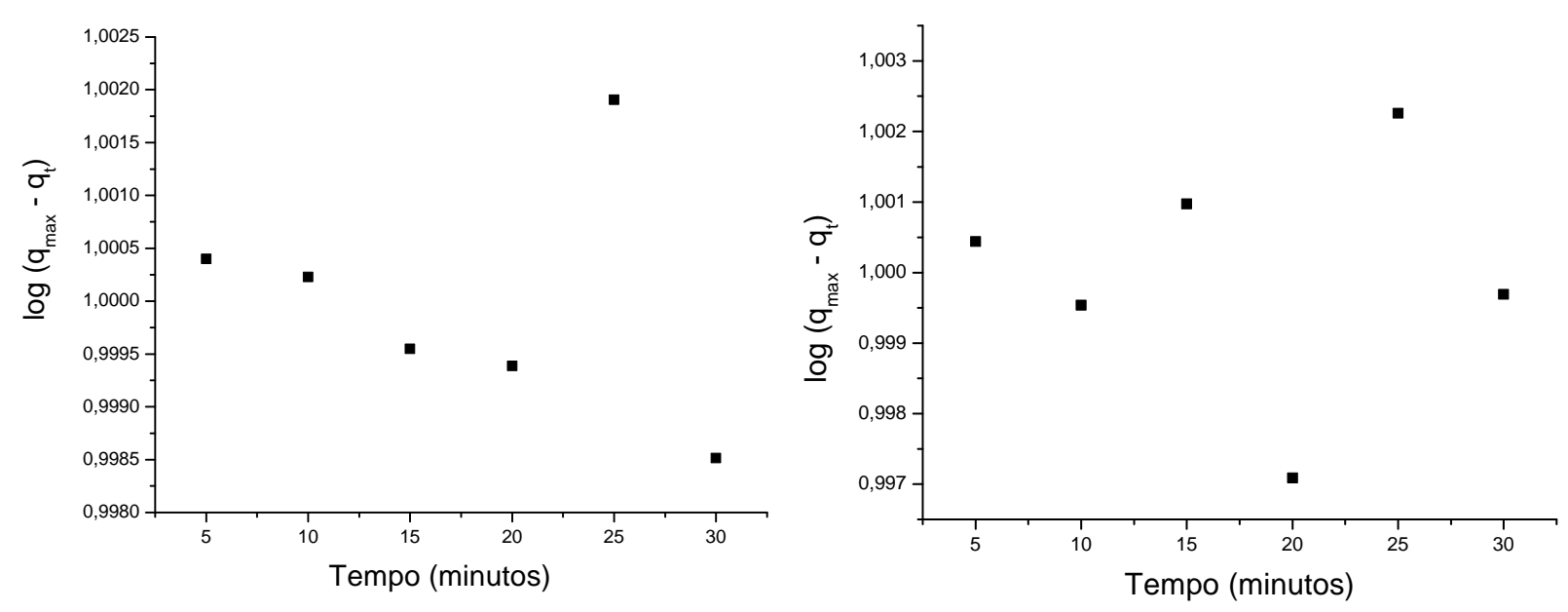

FIGURA 5.35 - Modelo de pseudo-primeira ordem para os trocadores híbridos $\mathrm{SnO}_{2} / \mathrm{TiO}_{2}$ e $\mathrm{SnO}_{2} / \mathrm{TiO}_{2}: \mathrm{Eu}^{3+}$ respectivamente em $\mathrm{pH} 7$ para o $\mathrm{Ni}^{2+}$.

\subsubsection{Aplicação do modelo cinético de Pseudo-Segunda Ordem para $\mathrm{Ni}^{2+}$}

Utilizando a equação 5.8, construiu-se uma curva de $\left(t / q_{t}\right)$ versus $t$ (FIG. 5.36) para o $\mathrm{Ni}^{2+}$ no $\mathrm{pH} 7$ referente aos trocadores híbridos $\mathrm{SnO}_{2} / \mathrm{TiO}_{2}$ e $\mathrm{SnO}_{2} / \mathrm{TiO}_{2}: \mathrm{Eu}^{3+}$.
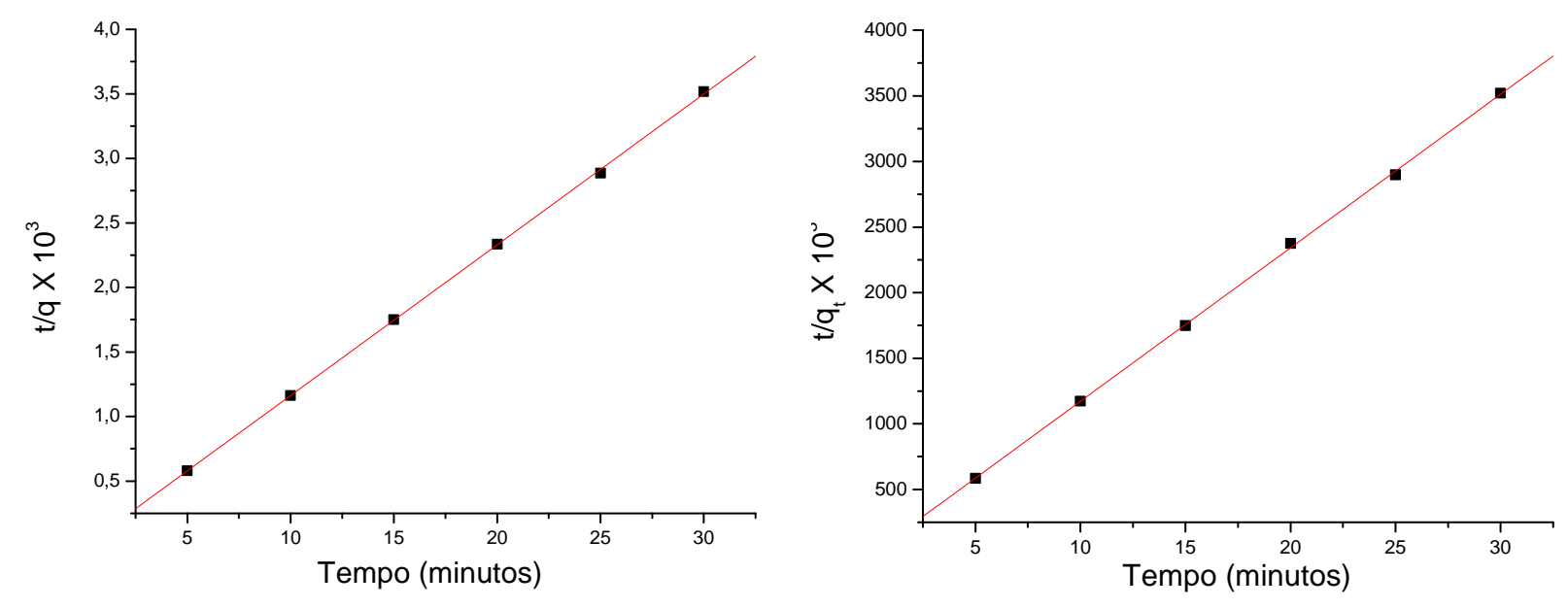

FIGURA 5.36 - Modelo de pseudo-segunda ordem para os trocadores híbridos $\mathrm{SnO}_{2} / \mathrm{TiO}_{2}$ e $\mathrm{SnO}_{2} / \mathrm{TiO}_{2}: \mathrm{Eu}^{3+}$ respectivamente em $\mathrm{pH} 7$ para o $\mathrm{Ni}^{2+}$. 
O tratamento dos dados por regressão linear para cada conjunto de dados forneceu os parâmetros da equação 5.8 e o respectivo coeficiente de correlação (TAB. 5.6).

TABELA 5.6 - Parâmetros da equação de pseudo-segunda ordem para os trocadores na adsorção do $\mathrm{Ni}^{2+}$.

\begin{tabular}{cccccc}
\hline Trocador híbrido & $\begin{array}{c}\mathbf{k}_{\mathbf{2}} \\
\left(\mathbf{m i n}^{-\mathbf{1}} \mathbf{g}_{\text {trod }} / \mathbf{g}_{\text {met }}\right)\end{array}$ & $q_{\text {calc }}^{\max }(g / g)$ & $q_{\mathrm{exp}}^{\max }(\mathrm{g} / \mathrm{g})$ & $\mathbf{R}$ \\
\hline $\mathrm{SnO}_{2} / \mathrm{TiO}_{2}$ & $\mathrm{pH} 7$ & $-1,6 \times 10^{-5}$ & $8,56 \times 10^{-3}$ & $8,59 \times 10^{-3}$ & 0,99989 \\
& & & & & \\
$\mathrm{SnO}_{2} / \mathrm{TiO}_{2}: \mathrm{Eu}^{3+}$ & $\mathrm{pH} 7$ & $2,58 \times 10^{-5}$ & $8,55 \times 10^{-3}$ & $8,54 \times 10^{-3}$ & 0,99982 \\
\hline
\end{tabular}

Observando na TAB. 5.6 os coeficientes de correlação, R. calculados, pode-se concluir que os dados experimentais ajustaram-se perfeitamente ao modelo de pseudo-segunda ordem. Os valores das massas máximas de adsorbato adsorvido por grama de adsorvente calculados, $q_{\text {calc }}^{\max }$, a partir do modelo cinético, concordam com os valores determinados experimentalmente. A constante de pseudo-segunda ordem, $\mathrm{k}_{2}$, é maior para o trocado dopado.

Após a análise dos resultados pode-se dizer que a adsorção do $\mathrm{Ni}^{2+}$ pelos trocadores híbridos $\mathrm{SnO}_{2} / \mathrm{TiO}_{2}$ e $\mathrm{SnO}_{2} / \mathrm{TiO}_{2}: \mathrm{Eu}^{3+}$, ocorre segundo este modelo de pseudo-segunda ordem, portanto, via dois sítios ativos.

\subsubsection{Aplicação do modelo cinético de Difusão Intrapartícula para $\mathrm{Ni}^{2+}$}

A partir da equação 5.10 construiu-se uma curva de $q_{t}$ versus $t^{1 / 2}$ conforme FIG. 5.37 onde observam-se que para todos os sistemas estudados, apesar de apresentarem linearidade, a reta não passa pela origem podendo-se concluir que não ocorre difusão intrapartícula para estes sistemas. 


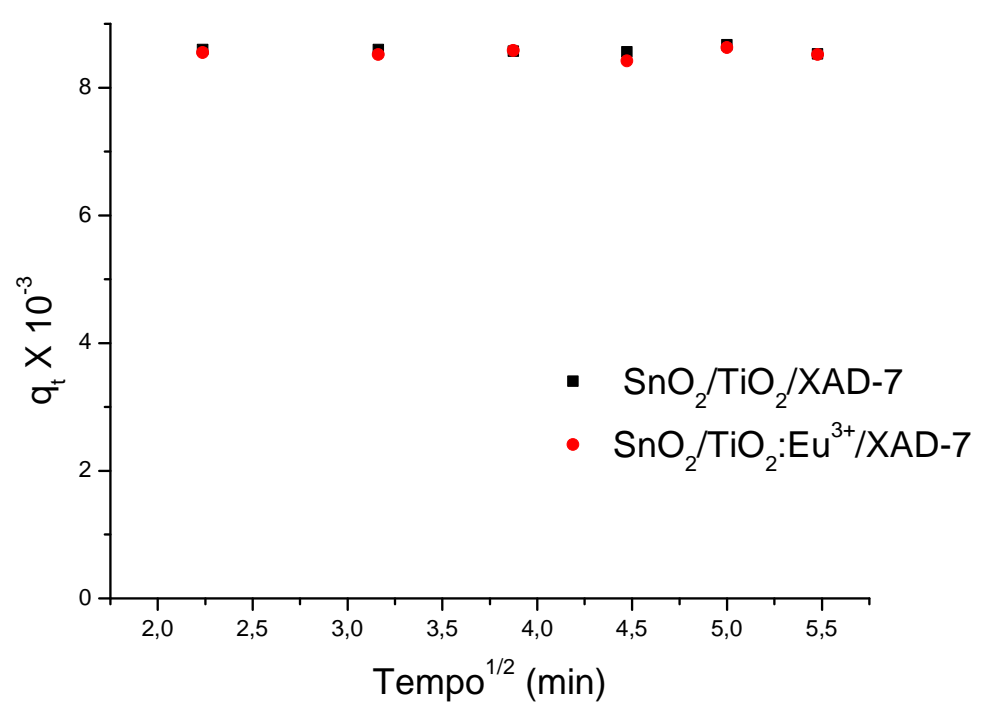

FIGURA 5.37 - Modelo de difusão intrapartícula para os trocadores híbridos em pH 7 para o $\mathrm{Ni}^{2+}$.

\subsubsection{Isotermas de adsorção do $\mathrm{Ni}^{2+}$}

Para o estudo da influência da concentração do $\mathrm{Ni}^{2+}$ no processo de adsorção nos trocadores, variou-se à concentração do metal no intervalo de 0,3 a 0,7 g.L-1 em pH 7. Os resultados mostraram que a adsorção do níquel depende da concentração do mesmo na solução de alimentação.

As isotermas calculadas para a adsorção do níquel estão representadas nas FIG. 5.37, 5.38, 5.39, e foram também analisadas segundo modelos de Feundlich, Langmuir e Dubinin-Radushkevich (DR).

\subsubsection{Isoterma de Freundlich (I-F) para $\mathrm{Ni}^{2+}$}

Das análises das isotermas de Freundlich na FIG. 5.38 foi possível observar que os dados experimentais ajustam-se ao modelo teórico, segundo Freundlich. O coeficiente de correlação foi maior que 0,99 para os dois trocadores estudados. A partir dos dados experimentais foi possível fazer a parametrização do modelo e efetuar a obtenção dos parâmetros $K_{F}$ e $n$ a partir dos coeficientes angulares e lineares. 

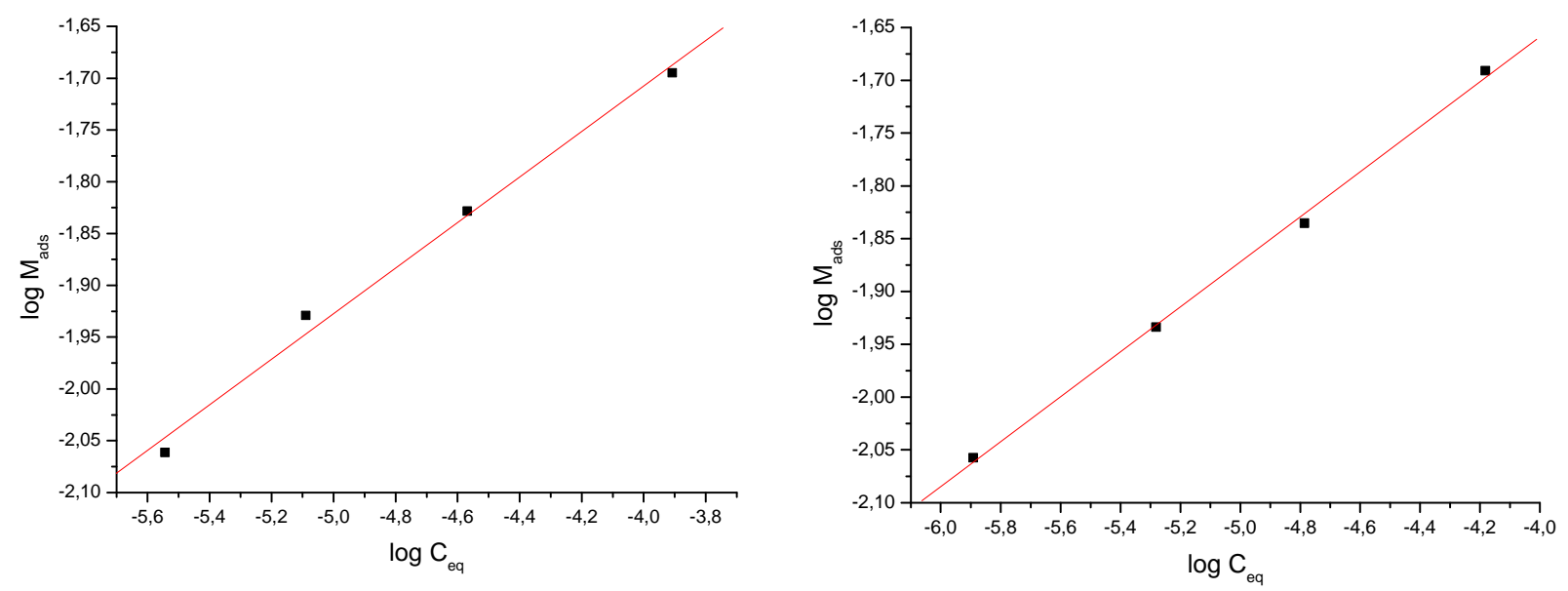

FIGURA 5.38 - Isotermas de Freundlich para os trocadores $\mathrm{SnO}_{2} / \mathrm{TiO}_{2}$ e $\mathrm{SnO}_{2} / \mathrm{TiO}_{2}: \mathrm{Eu}^{3+}$ respectivamente, em $\mathrm{pH} 7$ para $\mathrm{Ni}^{2+}$.

Analisando os resultados obtidos e apresentados na TAB. 5.7 observa-se que o parâmetro $\mathrm{n}$ é maior que 1 indicando que os sítios são energeticamente heterogêneos, ${ }^{[34]}$ concordando com os dados obtidos para o cádmio. A constante de Freundlich $\left(\mathrm{K}_{\mathrm{F}}\right)$ apesar de apresentar valores próximos para os trocadores, é maior para o trocador dopado, indicando que neste sistema a interação metal-trocador é mais forte que no trocador sem $\mathrm{Eu}^{3+}$. Este comportamento também foi observado para a adsorção de $\mathrm{Cd}^{2+}$ em $\mathrm{pH} 4$.

TABELA 5.7 - Parâmetros da equação de Freundlich para os trocadores na adsorção do $\mathrm{Ni}^{2+}$.

\begin{tabular}{ccccc}
\hline \multicolumn{2}{c}{ Trocador } & $\mathbf{K}_{\mathbf{F}}$ & $\mathbf{n}$ & $\mathbf{R}$ \\
\hline $\mathrm{SnO}_{2} / \mathrm{TiO}_{2}$ & $\mathrm{pH} 7$ & 0,14846 & 4,55001 & 0,99577 \\
& & & & \\
$\mathrm{SnO}_{2} / \mathrm{TiO}_{2}: \mathrm{Eu}^{3+}$ & $\mathrm{pH} 7$ & 0,156031 & 4,694395 & 0,99895 \\
\hline
\end{tabular}

\subsubsection{Isoterma de Langmuir para $\mathrm{Ni}^{2+}$}

O modelo Langmuir é definido pela equação 3.8 ou sua forma linearizada (equação 3.9) podendo-se determinar a constante $K_{L}$ e a energia livre de Gibbs $\left(\Delta G^{\circ}\right)$ para os dados experimentais de adsorção do $\mathrm{Ni}^{2+}$ nos trocadores. 

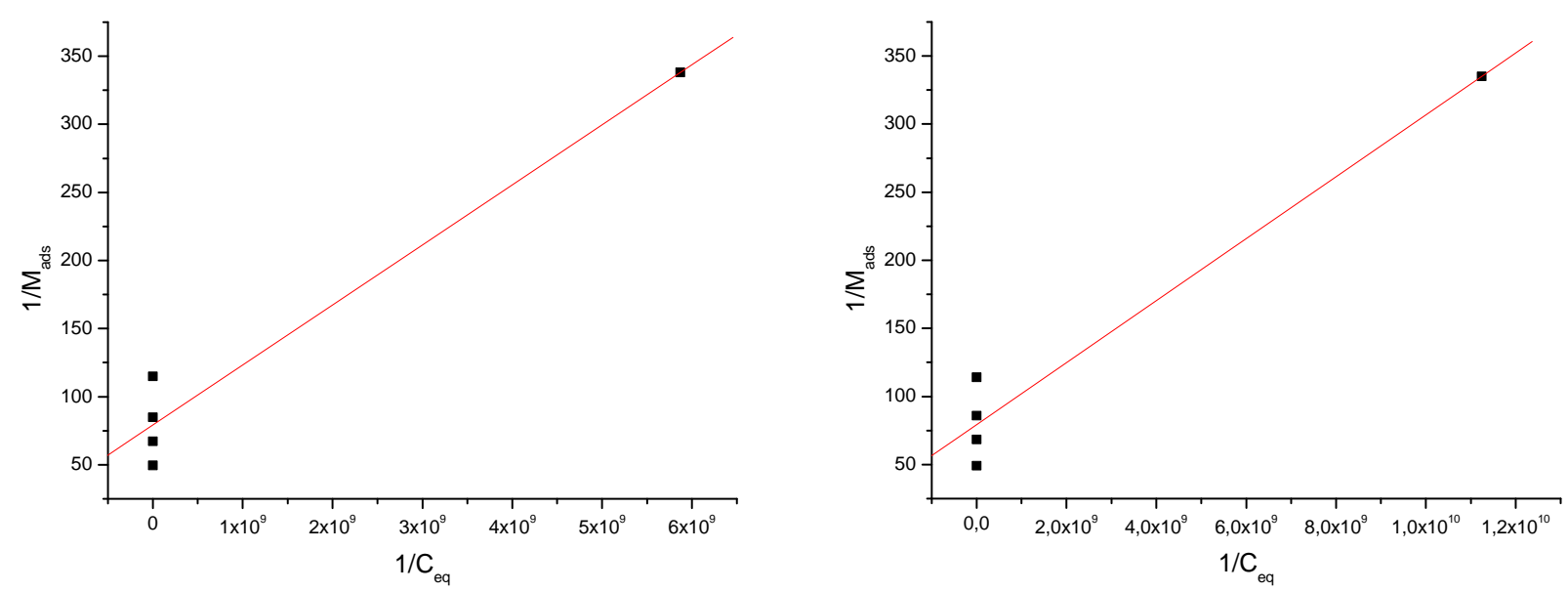

FIGURA 5.39 - Isotermas de Langmuir para os trocadores $\mathrm{SnO}_{2} / \mathrm{TiO}_{2}$ e $\mathrm{SnO}_{2} / \mathrm{TiO}_{2}: \mathrm{Eu}^{3+}$ respectivamente, em $\mathrm{pH} 7$ para $\mathrm{Ni}^{2+}$.

Na TAB. 5.8 apresentam-se os parâmetros de Langmuir calculados a partir das retas representadas na FIG. 5.39. O coeficiente de correlação, para ambos os trocadores estudados foi igual a 0,98. As constantes de Langmuir ( $\left.\mathrm{K}_{\mathrm{L}}\right)$ mostram-se com valores próximos evidenciando uma massa máxima de adsorção do $\mathrm{Ni}^{2+}$ muito semelhante para os dois trocadores. Através da constante $K_{L}$ também foi possível obter a energia livre do sistema e os resultados indicaram que a adsorção do $\mathrm{Ni}^{2+}$ também é um processo espontâneo, $\Delta \mathrm{G}^{\circ}<0$.

TABELA 5.8 - Parâmetros da equação de Langmuir para os trocadores na adsorção do $\mathrm{Ni}^{2+}$.

\begin{tabular}{cccrcr}
\hline \multicolumn{2}{c}{ Trocador } & $\mathrm{K}_{\mathrm{L}}$ & $M_{a d s}^{\max }(\mathbf{g} / \mathbf{g})$ & $\mathbf{R}$ & $\Delta \mathbf{G}^{\circ}(\mathrm{KJ} / \mathbf{m o l})$ \\
\hline $\mathrm{SnO}_{2} / \mathrm{TiO}_{2}$ & $\mathrm{pH} 7$ & $1,8 \times 10^{9}$ & 0,0126 & 0,9789 & $-52,794$ \\
& & & & & \\
$\mathrm{SnO}_{2} / \mathrm{TiO}_{2}: \mathrm{Eu}^{3+}$ & $\mathrm{pH} 7$ & $3,49 \times 10^{9}$ & 0,0126 & 0,9789 & $-54,440$ \\
\hline
\end{tabular}

\subsubsection{Isoterma de Dubinin-Radushkevich (D-R) para $\mathrm{Ni}^{2+}$}

Das análises das isotermas D-R na FIG. 5.40 foi possível observar que os dados experimentais ajustam-se ao modelo teórico. 

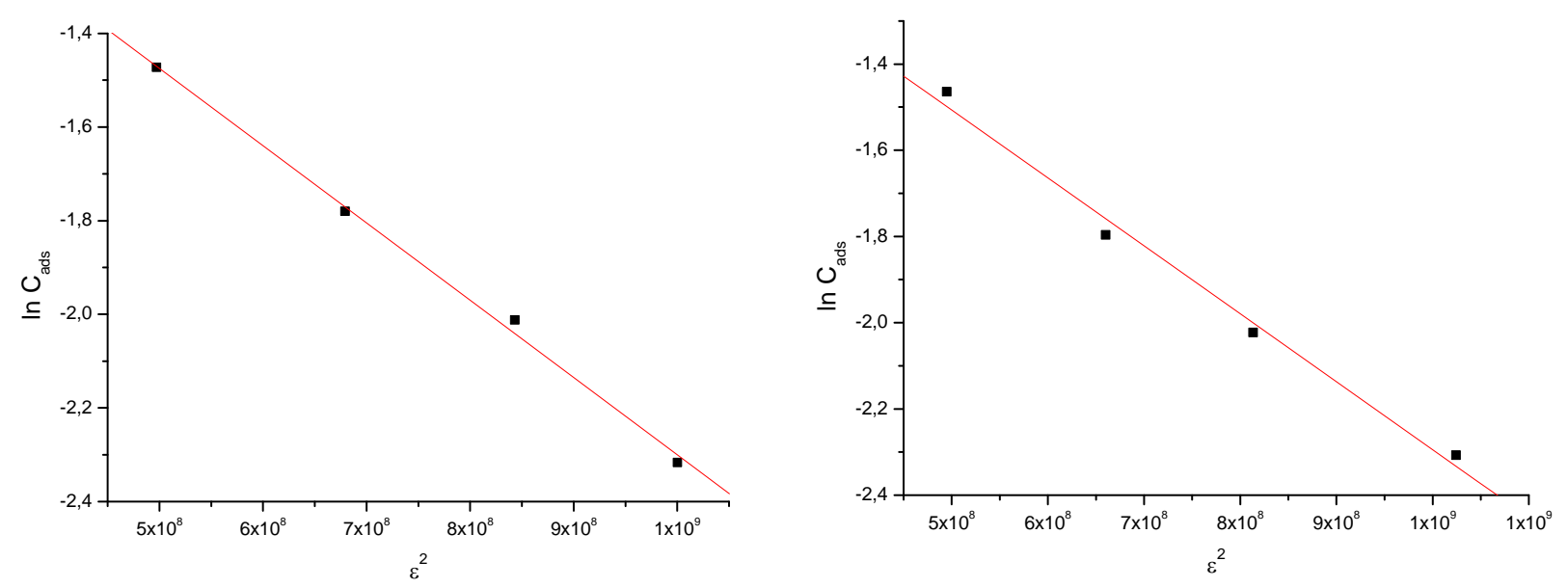

FIGURA 5.40 - Isotermas de D-R para os trocadores $\mathrm{SnO}_{2} / \mathrm{TiO}_{2}$ e $\mathrm{SnO}_{2} / \mathrm{TiO}_{2}: \mathrm{Eu}^{3+}$ respectivamente, em $\mathrm{pH} 7$.

A constante $K_{D R}$ considerada relativa à massa máxima adsorvida de $\mathrm{Ni}^{2+}$ por grama de adsorvente, apresenta valores muito próximos para ambos os trocadores (TAB. 5.9).

Com relação ao parâmetro $\mathrm{B}$, considerado uma constante energética, observa-se na TAB. 5.9 que os valores obtidos também têm valores próximos e através destes, calculo-se a energia média de adsorção (E) que apresentou valores na faixa de 2 a $6 \mathrm{Kcal} \mathrm{mol}^{-1}$ evidenciando também para este sistema uma adsorção física. O coeficiente de correlação foi maior que 0,99 para os dois trocadores estudados.

TABELA 5.9 - Parâmetros da equação de Dubinin-Radushkevich (D-R) para os trocadores na adsorção do $\mathrm{Ni}^{2+}$.

\begin{tabular}{cccccc}
\hline Trocador & & $\mathbf{K}_{\mathrm{DR}}$ & $\mathbf{B}$ & $\mathbf{E}$ (kcal/mol) & $\mathbf{R}$ \\
\hline $\mathrm{SnO}_{2} / \mathrm{TiO}_{2}$ & $\mathrm{pH} 7$ & 0,52254 & $-1,65 \times 10^{-9}$ & 4,16 & $-0,99840$ \\
& & & & & \\
$\mathrm{SnO}_{2} / \mathrm{TiO}_{2}: \mathrm{Eu}^{3+}$ & $\mathrm{pH} 7$ & 0,48729 & $-1,58 \times 10^{-9}$ & 4,26 & $-0,99508$ \\
\hline
\end{tabular}

\subsubsection{Estudo da dessorção do $\mathrm{Ni}^{2+}$}

O estudo de dessorção do metal níquel foi feito em batelada, contactandose durante 10 min uma solução de $0,3 \mathrm{~g} \cdot \mathrm{L}^{-1}$ de $\mathrm{Ni}^{2+}$ em pH 7 com massa de trocador 
de aproximadamente 0,05 g. Após o contato separaram-se as fases. A fase aquosa foi analisada para determinação da quantidade de níquel retido no trocador a ser usada no cálculo de dessorção. A fase sólida foi colocada em contato durante 24 horas com $3 \mathrm{~mL}$ de ácido clorídrico $1 \mathrm{~mol}^{-L^{-1}}$. Após este período analisaram-se alíquotas da solução para determinar a porcentagem de dessorção do $\mathrm{Ni}^{2+}$ nos trocadores e os resultados estão apresentados na TAB. 5.10. Pode-se observar uma baixa dessorção do metal para os dois trocadores.

TABELA 5.10 - Dessorção do $\mathrm{Ni}^{2+}$

\begin{tabular}{cc}
\hline TROCADOR & DESSORÇÃO (\%) \\
\hline $\mathrm{SnO}_{2} / \mathrm{TiO}_{2}$ & 1,77 \\
$\mathrm{SnO}_{2} / \mathrm{TiO}_{2}: \mathrm{Eu}^{3+}$ & 2,44 \\
\hline
\end{tabular}

\subsubsection{Influência do $\mathrm{Cd}^{2+}$, como interferente, na adsorção do $\mathrm{Ni}^{2+}$}

$\mathrm{O}$ estudo da influência do $\mathrm{Cd}^{2+}$ como interferente na adsorção do $\mathrm{Ni}^{2+}$, foi feito em batelada, com soluções contendo os dois íons, fixando-se a concentração de $\mathrm{Ni}^{2+}$ em 0,3 g. $\mathrm{L}^{-1}$ e variando-se a concentração de $\mathrm{Cd}^{2+}$ e permanecendo em $\mathrm{pH} 7$.

Na FIG. 5.41 observam-se os perfis de evolução da adsorção do $\mathrm{Ni}^{2+}$ com o aumento da concentração de $\mathrm{Cd}^{2+}$ como um interferente no processo em ambos os trocadores. Tendo como base a porcentagem de adsorção, uma pequena variação na mesma foi observada, enquanto que os valores de log Dw mostram uma redução de 1,1 unidades para os dois trocadores. 

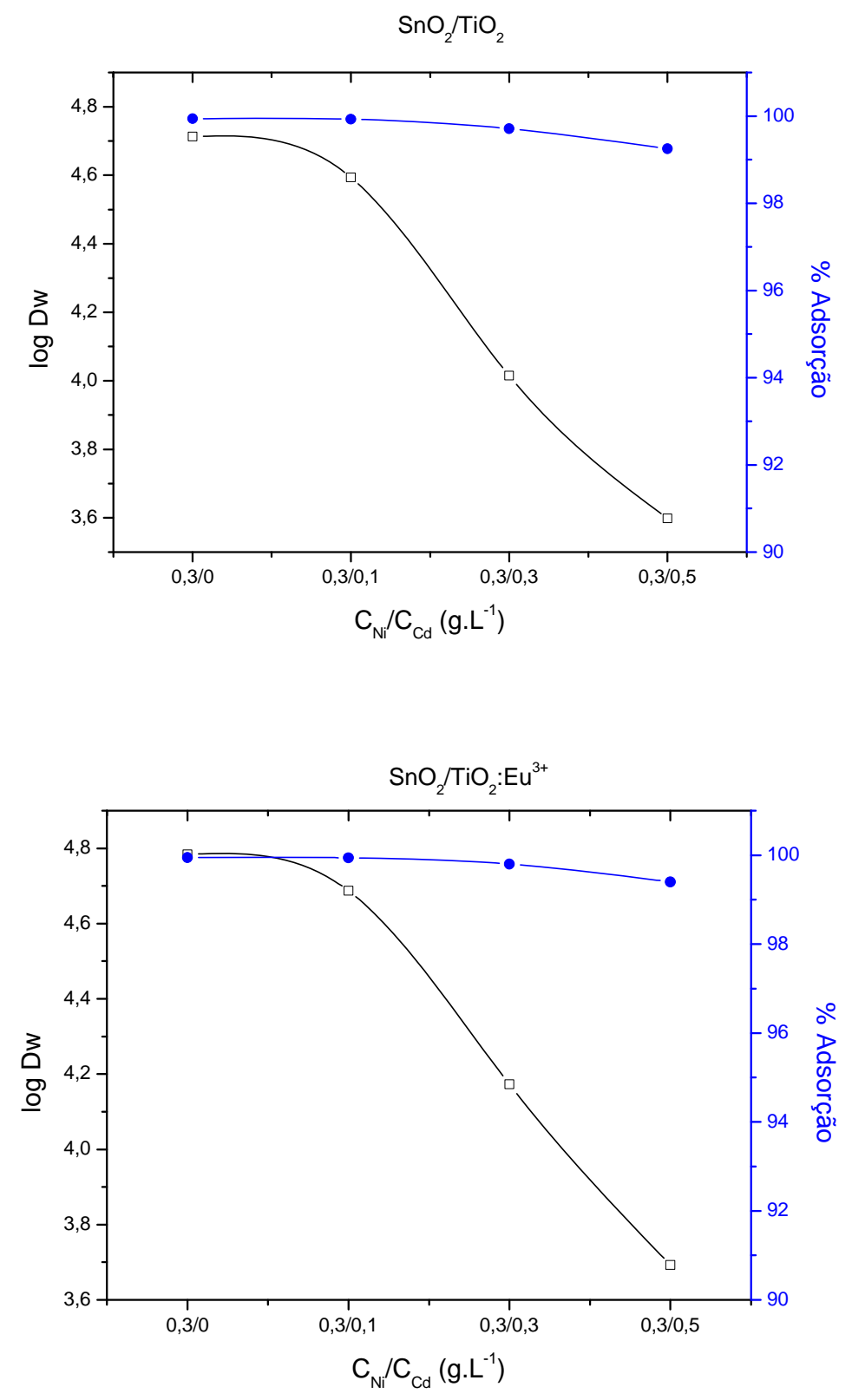

FIGURA 5.41 - Estudo da influência da concentração de $\mathrm{Cd}^{2+}$ na adsorção de $\mathrm{Ni}^{2+}$.

\subsection{Espectros de luminescência}

Os compostos contendo o íon $\mathrm{Eu}^{3+}$ (configuração [Xe]4f $)$ têm sido extensivamente estudados por apresentarem alta luminescência monocromática de cor vermelha. Sabe-se que a partir de seus espectros de emissão pode-se obter informações acerca do desdobramento do campo ligante, processos de transferência 
de energia e eficiência quântica do estado emissor ${ }^{[37-40]}$. Os espectros exibidos pelos compostos de $\mathrm{Eu}^{3+}$ apresentam, principalmente, bandas oriundas das transições intraconfiguracionais ${ }^{5} \mathrm{D}_{0} \rightarrow{ }^{7} \mathrm{~F}_{\mathrm{J}}$ (onde $\mathrm{J}=0-6$ ), sendo que as transições ${ }^{5} \mathrm{D}_{0} \rightarrow{ }^{7} \mathrm{~F}_{5} \mathrm{e}$ ${ }^{5} D_{0} \rightarrow{ }^{7} F_{6}$ apresentam intensidade muito baixa e dificilmente são observadas nos espectros. O principal nível emissor ${ }^{5} \mathrm{D}_{0}$ é não degenerado e não desdobra para qualquer simetria em torno do íon metálico. ${ }^{[1]}$ Assim sendo, o número máximo de bandas resultantes de uma transição ${ }^{5} \mathrm{D}_{0} \rightarrow{ }^{7} \mathrm{~F}_{\mathrm{J}}$ é dado pela regra de $(2 \mathrm{~J}+1)$ componentes. O número de bandas que está associado a cada transição depende da simetria pontual ao redor do íon $\mathrm{TR}^{3+}$ e pode ser determinada usando a teoria de grupos. ${ }^{[42]}$

Quando um espectro apresenta número de picos maior do que da regra $(2 \mathrm{~J}+1)$-componentes isto evidencia a presença de mais de um sítio de simetria para o ín metálico ou a impureza do mesmo. Por exemplo em sistemas dinucleares sem centro de inversão, ou mistura de isômeros, ou ainda o aparecimento de transições vibrônicas devido à interação dos níveis eletrônicos e estados de densidade fônons. Este último fenômeno resulta na presença de "bandas satélites" e é observado principalmente nas transições ${ }^{5} \mathrm{D}_{0} \rightarrow{ }^{7} \mathrm{~F}_{2}$, considerando que o nível ${ }^{7} \mathrm{~F}_{2}$ encontra-se na região espectral correspondente as freqüências de estiramentos $v(C=O), v(C=C)$ e $v(\mathrm{~N}=\mathrm{O})$ presentes nos ligantes orgânicos. ${ }^{[40]}$

As transições ${ }^{5} \mathrm{D}_{0} \rightarrow{ }^{7} \mathrm{~F}_{0,3,5}$ são proibidas pelas regras de seleção de dipoloelétrico forçado e dipolo-magnético. A primeira regra de seleção não obstante, pode ser relaxada pelo campo ligante conduzindo aos efeitos de misturas dos J's e, conseqüentemente, apesar de pequeno, existe um momento de transição diferente de zero. A intensidade da transição ${ }^{5} \mathrm{D}_{0} \rightarrow{ }^{7} \mathrm{~F}_{0}$ tem sido caracterizada como sendo, principalmente, devido à mistura do estado ${ }^{7} F_{2}$ dentro do estado ${ }^{7} F_{0}$, e essa mistura é expressa em termos do parâmetro $\mathrm{R}_{02}$, definido como a razão entre as intensidades das bandas oriundas das transições ${ }^{5} \mathrm{D}_{0} \rightarrow{ }^{7} \mathrm{~F}_{0}$ e ${ }^{5} \mathrm{D}_{0} \rightarrow{ }^{7} \mathrm{~F}_{2}$. Por outro lado, a transição ${ }^{5} \mathrm{D}_{0} \rightarrow{ }^{7} \mathrm{~F}_{1}$ é permitida somente por dipolo-magnético e sua intensidade é praticamente impassível ao ambiente químico nas vizinhanças do íon $\mathrm{Eu}^{3+}$, portanto, essa transição tem sido tomada como um padrão de referência interna. ${ }^{[43]}$ 
As transições ${ }^{5} \mathrm{D}_{0} \rightarrow{ }^{7} \mathrm{~F}_{2,4}$ são permitidas por dipolo-elétrico forçado, sendo que a transição ${ }^{5} \mathrm{D}_{0} \rightarrow{ }^{7} \mathrm{~F}_{2}(\sim 612 \mathrm{~nm})$, hipersensível ao ambiente químico ao redor do íon central, é geralmente dominante em compostos não-centrossimétricos. As transições fornecem informações se o grupo pontual em torno do íon $\mathrm{Eu}^{3+}$ apresenta centro de inversão, considerando que em compostos centrossimétricos as transições ${ }^{5} \mathrm{D}_{0} \rightarrow{ }^{7} \mathrm{~F}_{2,4}$ são estritamente proibidas por mecanismo de dipolo elétrico.

Uma vez que as bandas de emissão do íon $\mathrm{Eu}^{3+}$ na região do visível são de fácil interpretação, devido à estrutura dos seus níveis de energia, este íon tem sido utilizado como sonda espectroscópica na obtenção de valiosas informações em sistemas bioinorgânicos, tais como: i) a determinação do número de ambientes químicos ao redor do íon $\mathrm{Eu}^{3+}$ através do número de bandas relativo à transição ${ }^{5} \mathrm{D}_{0} \rightarrow{ }^{7} \mathrm{~F}_{0}$; ii) Constante de ligação dos íons biomolécula-Eu $\mathrm{u}^{3+}$, determinada por curvas de titulação e iii) distância doador-receptor (R), normalmente assumindo o mecanismo de acoplamento dipolo-dipolo fraco. ${ }^{[44]}$

\subsubsection{Espectros de excitação da matriz $\mathrm{SnO}_{2} / \mathrm{TiO}_{2}: \mathrm{Eu}^{3+}$}

Os estudos fotoluminescentes do $\mathrm{SnO}_{2} / \mathrm{TiO}_{2}: \mathrm{Eu}^{3+}$, neste trabalho, foram feitos com base nos espectros de excitação e emissão registrados a temperatura ambiente $(\sim 298 \mathrm{~K})$ e a $77 \mathrm{~K}$. Os espectros de excitação foram registrados no intervalo de $250 \mathrm{a}$ $590 \mathrm{~nm}$, com emissão monitorada na transição hipersensível ${ }^{5} \mathrm{D}_{0} \rightarrow{ }^{7} \mathrm{~F}_{2}(\sim 614 \mathrm{~nm})$ (FIG. 5.42). Enquanto que os espectros de emissão foram obtidos com excitação no íon $\mathrm{TR}^{3+}(\sim 393 \mathrm{~nm})$ no intervalo de 420 a $720 \mathrm{~nm}$, correspondente às transições intraconfiguracionais ${ }^{5} \mathrm{D}_{0} \rightarrow{ }^{7} \mathrm{~F}_{0-4}$. É importante salientar, que houve diferenças significativas entre os espectros de excitação registrados a 298 e 77 K. Para o espectro à temperatura ambiente observou-se uma banda de baixa intensidade na região de 300 a $400 \mathrm{~nm}$ atribuída à transferência de carga LMCT do O $\rightarrow \mathrm{Sn}$ e $\mathrm{O} \rightarrow \mathrm{Eu}^{3+}$ respectivamente. Estas bandas estão sobrepostas pelas bandas fixas em 352 ; 360,5; 376 e $393 \mathrm{~nm}$ que correspondem às transições ${ }^{7} \mathrm{~F}_{0}-{ }^{5} \mathrm{D}_{\mathrm{J}},{ }^{5} \mathrm{~L}_{\mathrm{J}}$, do íon $\mathrm{Eu}^{3+}$. Como pode-se observar, os espectros de excitação, a temperatura ambiente, apresentam ainda linhas consistentes com as transições ${ }^{7} \mathrm{~F}_{1} \rightarrow{ }^{5} \mathrm{~L}_{\mathrm{J}}(\mathrm{J}=0-3)$ do íon $\mathrm{Eu}^{3+}$. No espectro registrado a $77 \mathrm{~K}$ observou-se o surgimento de uma banda larga 
centrada em 318,7nm que foi atribuída a banda de condução do $\mathrm{SnO}_{2}$. Comparandose os espectros a temperatura ambiente e $77 \mathrm{~K}$ observa-se que no espectro a $77 \mathrm{~K}$ desaparecem algumas bandas oriundas da configuração $4 \mathrm{f}-4 \mathrm{f}$ do íon európio como é o caso das linhas em 360,$5 ; 414$ e 525,5 que foram atribuídas à ${ }^{7} F_{1} \rightarrow{ }^{5} D_{4} ;{ }^{7} F_{1} \rightarrow{ }^{5} D_{3}$ e ${ }^{7} F_{1} \rightarrow{ }^{5} D_{0}$ respectivamente (TAB. 5.11) devido ao rearranjo estrutural. ${ }^{[45]}$

Para confirmar se a banda presente em $310 \mathrm{~nm}$ era realmente referente à transição da banda de condução um espectro de excitação do trocador sem európio foi tirado nas mesmas condições (FIG. 5.43) e comprovou a presença da mesma.

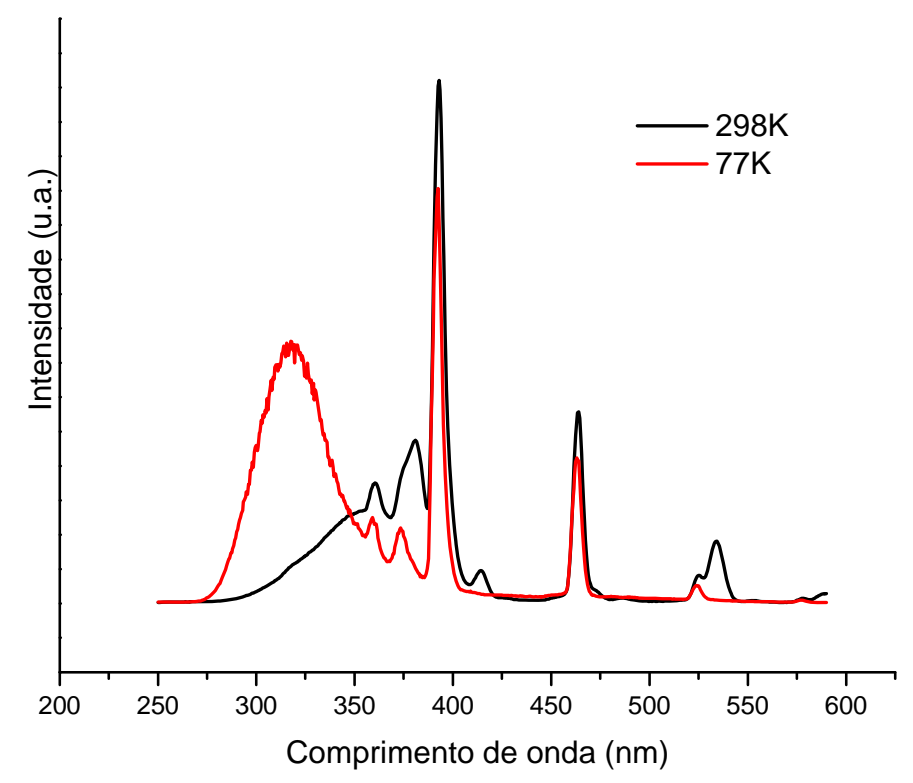

FIGURA 5.42 - Espectro de excitação com emissão monitorada em 614nm.

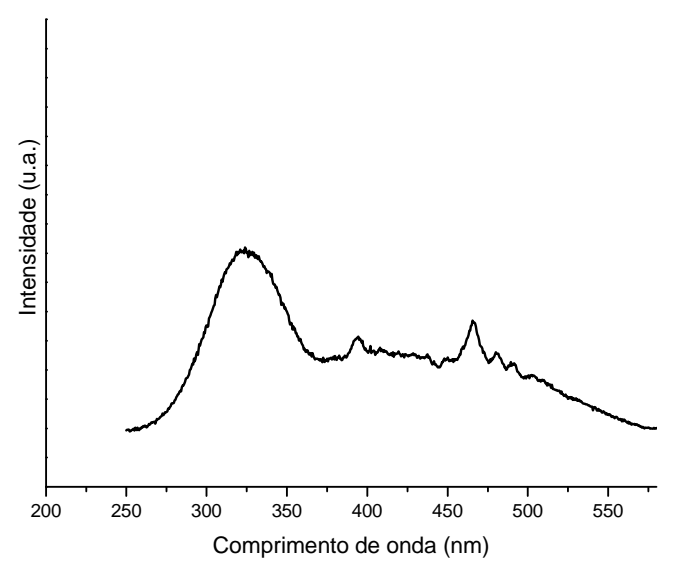

FIGURA 5.43 - Espectro de excitação com emissão monitorada em $614 \mathrm{~nm}$ para o trocador sem európio. 
TABELA 5.11 - Energias de transições dos microestados ${ }^{5} D_{\mathrm{J}} \leftarrow{ }^{7} \mathrm{~F}_{\mathrm{J}}\left(\mathrm{em} \mathrm{cm}^{-1}\right)$ observadas nos espectros de excitação.

\begin{tabular}{|c|c|c|c|}
\hline \multicolumn{2}{|c|}{ Temperatura ambiente } & \multicolumn{2}{|c|}{ Temperatura 77K } \\
\hline Transição & Energia $\left(\mathrm{cm}^{-1}\right)$ & Transição & Energia $\left(\mathrm{cm}^{-1}\right)$ \\
\hline${ }^{7} \mathrm{~F}_{0} \rightarrow{ }^{5} \mathrm{D}_{4}$ & 28409 & ${ }^{7} \mathrm{~F}_{0} \rightarrow{ }^{5} \mathrm{H}_{3}$ & 31496 \\
\hline & & ${ }^{7} \mathrm{~F}_{0} \rightarrow{ }^{5} \mathrm{D}_{4}$ & 27855 \\
\hline${ }^{7} \mathrm{~F}_{0} \rightarrow{ }^{5} \mathrm{~L}_{7}$ & $\begin{array}{l}26560 \\
26247\end{array}$ & ${ }^{7} \mathrm{~F}_{0} \rightarrow{ }^{5} \mathrm{~L}_{6}$ & 26774 \\
\hline${ }^{7} \mathrm{~F}_{0} \rightarrow{ }^{5} \mathrm{~L}_{6}$ & 25445 & ${ }^{7} \mathrm{~F}_{0} \rightarrow{ }^{5} \mathrm{~L}_{8}$ & 25478 \\
\hline${ }^{7} \mathrm{~F}_{0} \rightarrow{ }^{5} \mathrm{D}_{3}$ & 24155 & ${ }^{7} F_{0} \rightarrow{ }^{5} D_{1}$ & 21598 \\
\hline & 21552 & ${ }^{7} \mathrm{~F}_{0} \rightarrow{ }^{5} \mathrm{D}_{3}$ & 19084 \\
\hline${ }^{7} \mathrm{~F}_{0} \rightarrow{ }^{5} \mathrm{D}_{2}$ & $\begin{array}{l}21164 \\
20597\end{array}$ & ${ }^{7} \mathrm{~F}_{0} \rightarrow{ }^{5} \mathrm{D}_{0}$ & 17316 \\
\hline${ }^{7} \mathrm{~F}_{0} \rightarrow{ }^{5} \mathrm{D}_{1}$ & $\begin{array}{l}19030 \\
18727 \\
18100\end{array}$ & & \\
\hline${ }^{7} \mathrm{~F}_{0} \rightarrow{ }^{5} \mathrm{D}_{0}$ & 17376 & & \\
\hline
\end{tabular}

\subsubsection{Espectros de Emissão da matriz $\mathrm{SnO}_{2} / \mathrm{TiO}_{2}: \mathrm{Eu}^{3+}$}

Na FIG. 5.44 apresentam-se os espectros de emissão a temperatura ambiente e $77 \mathrm{~K}$ para a matriz $\mathrm{SnO}_{2} / \mathrm{TiO}_{2}: \mathrm{Eu}^{3+}$. Estes espectros foram registrados com excitação monitorada na transição ${ }^{7} \mathrm{~F}_{0} \rightarrow{ }^{5} \mathrm{~L}_{6}$, na região do vermelho no intervalo de 420 a $750 \mathrm{~nm}$ e apresentam bandas provenientes dos níveis emissores ${ }^{5} D_{\mathrm{J}}(\mathrm{J}=0$ e 1) sendo que o registrado a temperatura do $N_{2}$ líquido apresenta uma melhor resolução. O perfil das bandas é característico de matrizes vítreas, dopadas com lantanídeos e a banda de condução do $\mathrm{SnO}_{2}$ desaparece comprovando a eficiência do processo de transferência de energia. 


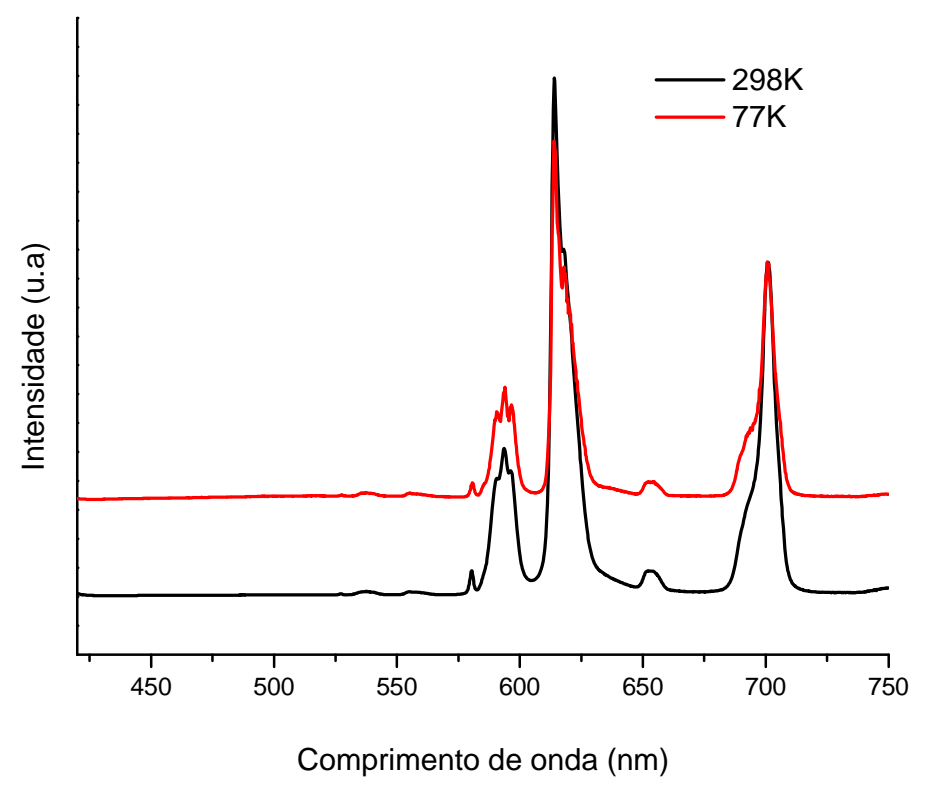

FIGURA 5.44 - Espectro de emissão com excitação monitorada em 393nm.

Quatro grupos de linhas centradas em $\sim 580, \quad 591,614$ e 692nm correspondendo às transições dentro da configuração $4 f$ entre o estado ${ }^{5} D_{0}$ para os níveis de energia mais baixos ${ }^{7} \mathrm{~F}_{\mathrm{J}}(\mathrm{J}=0,1,2$, 4). As bandas em $591 \mathrm{~nm}$ são atribuídas à transição ${ }^{5} \mathrm{D}_{0} \rightarrow{ }^{7} \mathrm{~F}_{1}$, (TAB. 5.12) que é permitida por dipolo magnético e o coeficiente de transição para esta transição não se altera com a modificação no sítio de simetria (a probabilidade de ocorrer transição ${ }^{5} \mathrm{D}_{0} \rightarrow{ }^{7} \mathrm{~F}_{1}$ não é afetada pela simetria porque é permitida por regra de seleção de paridade). O pico em $\sim 580 \mathrm{~nm}$ é proibido por dipolo elétrico e magnético e está presente em simetrias do tipo $C_{n v}, C_{n}$ e $C_{s}$ devido a mistura dos estados eletrônicos $\mathrm{J}$ ( $\mathrm{J}$ - mixing).

A transição dominante em $\sim 614 \mathrm{~nm}$ responsável pela emissão no vermelho é atribuída a transição permitida por dipolo elétrico ${ }^{5} \mathrm{D}_{0} \rightarrow{ }^{7} \mathrm{~F}_{2}$. A transição ${ }^{5} \mathrm{D}_{0} \rightarrow{ }^{7} \mathrm{~F}_{2}$ geralmente é muito mais intensa que a transição ${ }^{5} \mathrm{D}_{0} \rightarrow{ }^{7} \mathrm{~F}_{0}$ quando a simetria em redor do íon $\mathrm{Eu}^{3+}$ não possui centro de inversão, é chamada transição hipersensível e sua intensidade pode variar por ordem de magnitude, dependendo da simetria local. A transição ${ }^{5} D_{0} \rightarrow{ }^{7} F_{4}$ centrada em $692 \mathrm{~nm}$ está relacionada aos parâmetros de intensidade de quarta ordem. Suas intensidades são menos afetadas por regra de seleção de simetria do que as transições ${ }^{5} D_{0} \rightarrow{ }^{7} F_{2}$. Nos espectros também são 
observadas transições proveniente do primeiro nível excitado de emissão ${ }^{5} D_{1}$ para os níveis ${ }^{7} F_{1,2}$, com baixíssima intensidade, nas regiões de $537 \mathrm{~nm}$ e $558 \mathrm{~nm}$ respectivamente. Estas bandas são suprimidas devido, provavelmente, aos processos de relaxação cruzada $\left({ }^{5} D_{J} \rightarrow{ }^{5} D_{0}\right) \rightarrow\left({ }^{7} F_{0} \rightarrow{ }^{7} F_{J}\right)$.

TABELA 5.12 - Energias de transições dos microestados ${ }^{5} D_{\mathrm{J}}-{ }^{7} \mathrm{~F}_{\mathrm{J}^{\prime \prime}}\left(\mathrm{em} \mathrm{cm}^{-1}\right)$ observadas nos espectros de emissão.

\begin{tabular}{|c|c|c|c|}
\hline \multicolumn{2}{|c|}{ Temperatura ambiente } & \multicolumn{2}{|c|}{ Temperatura $77 \mathrm{~K}$} \\
\hline Transição & Energia $\left(\mathrm{cm}^{-1}\right)$ & Transição & Energia $\left(\mathrm{cm}^{-1}\right)$ \\
\hline${ }^{5} D_{1} \rightarrow^{7} F_{0}$ & 18968 & ${ }^{5} \mathrm{D}_{1} \rightarrow^{7} \mathrm{~F}_{0}$ & 18954 \\
\hline${ }^{5} D_{1} \rightarrow^{7} F_{1}$ & $\begin{array}{l}18664 \\
18615 \\
18505\end{array}$ & ${ }^{5} \mathrm{D}_{1} \rightarrow{ }^{7} \mathrm{~F}_{1}$ & $\begin{array}{l}18671 \\
18601 \\
18532\end{array}$ \\
\hline${ }^{5} D_{1} \rightarrow^{7} F_{2}$ & $\begin{array}{l}18012 \\
17986 \\
17928 \\
17883 \\
17825\end{array}$ & ${ }^{5} \mathrm{D}_{1} \rightarrow^{7} \mathrm{~F}_{2}$ & $\begin{array}{l}18005 \\
17973 \\
17921\end{array}$ \\
\hline${ }^{5} \mathrm{D}_{0} \rightarrow^{7} \mathrm{~F}_{0}$ & 17230 & ${ }^{5} \mathrm{D}_{0} \rightarrow^{7} \mathrm{~F}_{0}$ & 17224 \\
\hline${ }^{5} D_{0} \rightarrow^{7} F_{1}$ & $\begin{array}{l}16932 \\
16846 \\
16773\end{array}$ & ${ }^{5} D_{0} \rightarrow^{7} F_{1}$ & $\begin{array}{l}16932 \\
16835 \\
16762\end{array}$ \\
\hline${ }^{5} D_{0} \rightarrow^{7} F_{2}$ & $\begin{array}{l}16287 \\
16186\end{array}$ & ${ }^{5} D_{0} \rightarrow^{7} F_{2}$ & $\begin{array}{l}16292 \\
16181 \\
16124\end{array}$ \\
\hline${ }^{5} D_{0} \rightarrow{ }^{7} F_{3}$ & 15333 & ${ }^{5} D_{0} \rightarrow^{7} F_{3}$ & 15291 \\
\hline${ }^{5} \mathrm{D}_{0} \rightarrow^{7} \mathrm{~F}_{4}$ & $\begin{array}{l}14451 \\
14269\end{array}$ & ${ }^{5} D_{0} \rightarrow^{7} F_{4}$ & $\begin{array}{l}14447 \\
14273 \\
14261\end{array}$ \\
\hline
\end{tabular}

\subsubsection{Parâmetros de intensidade experimentais do íon $\mathrm{Eu}^{3+}$}

A intensidade de luminescência (I) das transições provenientes do nível emissor ${ }^{5} D_{0}$ para os níveis ${ }^{7} F_{J},(J=0,1,2,3$ e 4) do íon európio trivalente pode ser expressa pela equação: 


$$
\mathrm{I}_{0 \rightarrow \mathrm{J}}=\hbar \omega_{0 \rightarrow \mathrm{J}} \mathrm{A}_{0 \rightarrow \mathrm{J}} \mathrm{N}_{0}
$$

Onde: $A_{0 \rightarrow \mathrm{J}}$ é o coeficiente de emissão espontânea de Einstein

$\mathrm{N}_{0}$ é a população do nível emissor $\left({ }^{5} \mathrm{D}_{0}\right)$.

O coeficiente de emissão espontânea, associado a uma transição a partir do nível emissor J para J' é dado pela equação:

$$
\mathrm{A}_{\mathrm{JJ}}=\frac{4 \mathrm{e}^{2} \omega^{3}}{3 \hbar \mathrm{c}^{3}}\left[\frac{\mathrm{n}\left(\mathrm{n}^{2}+1\right)^{2}}{9} \sum_{\lambda} \Omega_{\lambda}\left\langle\alpha \mathrm{J}\left\|\mathrm{U}^{(\lambda)}\right\| \alpha^{\prime} \mathrm{J}^{\prime}\right\rangle^{2}+\frac{\mathrm{n}^{3} \hbar^{2}}{4 \mathrm{mc}^{2}}\left\langle\alpha \mathrm{J}\|\mathrm{L}+2 \mathrm{~S}\| \alpha^{\prime} \mathrm{J}^{\prime}\right\rangle^{2}\right]
$$

onde $\omega$ é a freqüência angular da transição $\alpha \mathrm{J} \rightarrow \alpha^{\prime} \mathrm{J}$,

e é a carga do elétron,

c é a velocidade da luz, os termos $\sum_{\lambda} \Omega_{\lambda}\left\langle\alpha J\left\|\mathrm{U}^{(\lambda)}\right\| \alpha^{\prime} J^{\prime}\right\rangle^{2}$ e $\left\langle\alpha J\|L+2 S\| \alpha^{\prime} J^{\prime}\right\rangle^{2}$ representam as forças de dipolo elétrico e dipolo magnético para a transição;

$\Omega_{\lambda}$ são os parâmetros de intensidade que possuem contribuições dos mecanismos de dipolo elétrico forçado e acoplamento dinâmico. ${ }^{[39,46]}$

Os coeficientes $A_{0 \rightarrow 2,4,6}$ apresentam uma relação direta com os elementos de matriz reduzidos $\left\langle{ }^{7} \mathrm{~F}_{\lambda}\left\|\mathrm{U}^{(\lambda)}\right\|^{5} \mathrm{D}_{0}\right\rangle$ conseqüentemente os parâmetros de intensidade $\Omega_{2}, \Omega_{4}$ e $\Omega_{6}$ podem ser determinados a partir dos respectivos valores de emissão espontânea (A) de acordo com a seguinte equação:

$$
\Omega_{\lambda}=\frac{4 \mathrm{e}^{2} \omega^{3} \mathrm{~A}_{0 \rightarrow \lambda}}{3 \hbar \mathrm{c}^{3} \chi\left\langle{ }^{7} \mathrm{~F}_{\lambda}\left\|\mathrm{U}^{(\lambda)}\right\|^{5} \mathrm{D}_{0}\right\rangle^{2}}
$$

Onde $\chi$ é a correção de Lorentz para o campo local, o qual é dado por $\chi=\mathrm{n}\left(\mathrm{n}^{2}+2\right)^{2} / 9 \mathrm{e}\left\langle{ }^{7} \mathrm{~F}_{\lambda}\left\|\mathrm{U}^{(\lambda)}\right\|^{5} \mathrm{D}_{0}\right\rangle^{2}$ são os quadrados dos elementos reduzidos cujos 
valores são 0,0032, 0,0023 e 0,0002 para $\lambda=2$, 4 e 6, respectivamente. ${ }^{[37]}$ Neste trabalho, não será considerado o valor de $\Omega_{6}$, uma vez que a transição ${ }^{5} D_{0} \rightarrow{ }^{7} F_{6}$ não foi registrada.

O tempo de vida e as taxas de decaimento não radiativos $\left(A_{\text {nrad }}\right)$ e radiativos $\left(A_{\text {rad }}\right)$ se relacionam através da equação apresentada abaixo:

$$
A_{\text {total }}=\frac{1}{\tau}=A_{\text {rad }}+A_{\text {nrad }}
$$

Onde $A_{\text {rad }}$ é obtido pela somatória das taxas radiativas

$\mathrm{A}_{0 \mathrm{~J}}$ para cada transição ${ }^{5} \mathrm{D}_{0} \rightarrow{ }^{7} \mathrm{~F}_{\mathrm{J}}\left(A_{\text {rad }}=\sum_{J} A_{0 J}\right)$.

A eficiência quântica do nível emissor ${ }^{5} D_{0}$ pode ser obtida através da equação apresentada abaixo:

$$
\eta=\frac{A_{\text {rad }}}{A_{\text {rad }}+A_{\text {rad }}}
$$

Com base nas equações 5.8 e 5.9 e nos dados espectrais, foram determinados os valores dos parâmetros de intensidade experimentais $\Omega_{2}$ e $\Omega_{4}, A_{\text {rad }}$ e $A_{\text {nrad, }}$, para o trocador $\mathrm{SnO}_{2} / \mathrm{TiO}_{2}: \mathrm{Eu}^{3+}$ comparando o mesmo a outros dois trocadores já estudados em trabalhos anteriores (TAB. 5.13). Como pode ser observado, os valores do parâmetro de intensidade $\Omega_{2}$ é menor do que para os outros trocadores estudados pelo grupo ${ }^{[47,48]}$. Esses dados indicam que o íon $\mathrm{Eu}^{3+}$ nessa matriz encontra-se em um ambiente químico menos polarizável.

Os valores de $\Omega_{4}$ apresentam-se maiores do que $\Omega_{2}$ mostrando que as interações de quarta ordem são importantes no sistema utilizado.

Os valores de eficiência quântica do estado emissor ${ }^{5} D_{0}(\eta)$ encontram-se na TAB. 5.10. O valor de $\eta$ para o trocador $\mathrm{SnO}_{2} / \mathrm{TiO}_{2}$ : $\mathrm{Eu}^{3+}$ é menor do que os valores de eficiência dos outros dois trocadores a base de estanho $\left(\mathrm{SnO}_{2} / \mathrm{SiO}_{2}: \mathrm{Eu}^{3+}\right.$,e $\left.\mathrm{SnO}_{2} / \mathrm{Y}_{2} \mathrm{O}_{3}: \mathrm{Eu}^{3+}\right)$. 
TABELA 5.13 - Parâmetros de intensidades experimentais e tempos de vida do estado emissor ${ }^{5} \mathrm{D}_{0}$ dos trocadores a base de estanho dopados com $\mathrm{Eu}^{3+}$.

\begin{tabular}{|c|c|c|c|c|c|c|c|}
\hline TII & $\begin{array}{c}\Omega_{2} \\
\left(10^{-20} \mathrm{~cm}^{2}\right)\end{array}$ & $\begin{array}{c}\Omega_{4} \\
\left(10^{-20} \mathrm{~cm}^{2}\right)\end{array}$ & $\begin{array}{c}\tau \\
(\mathrm{ms})\end{array}$ & $\begin{array}{l}A_{\text {total }} \\
\left(\mathrm{s}^{-1}\right)\end{array}$ & $\begin{array}{l}A_{\text {rad }} \\
\left(s^{-1}\right)\end{array}$ & $\begin{array}{l}A_{\text {nrad }} \\
\left(s^{-1}\right)\end{array}$ & $\begin{array}{c}\eta \\
(\%)\end{array}$ \\
\hline $\mathrm{SnO}_{2} / \mathrm{SiO}_{2}: \mathrm{Eu}^{3+}$, & 4,79 & 7,80 & 0,329 & 3031 & 322 & 2709 & 11 \\
\hline $\mathrm{SnO}_{2} / \mathrm{Y}_{2} \mathrm{O}_{3}: \mathrm{Eu}^{3+}$, & 5,64 & 9,29 & 0,285 & 3508 & 357 & 3151 & 10 \\
\hline $\mathrm{SnO}_{2} / \mathrm{TiO}_{2}: \mathrm{Eu}^{3+}$, & 5,46 & 8,89 & 0,263 & 3806 & 342 & 3464 & 9 \\
\hline
\end{tabular}




\section{REFERENCIAS BIBLIOGRÁFICAS}

[1] DING, J.; LIU, X.Y.; WANG, J.; SHI, Y. Ultrafine ferrite particles prepared by coprecipitation, mechanical milling. Mater. Lett., v. 44, p. 19-22, 2000.

[2] AMMAR, S., HELFEN, A., JOUINI, N., FIÉVET, F., ROSENMAN, I., VILLAIN, F., MOLINIÉ, P., DANOT, M. Magnetic properties of ultrafinae cobalt ferrite particles synthesized by hydrolysis in a polyol medium. J. Mater. Chem., v. 11, p. 186-192, 2001.

[3] COTE, L. J., TEJA, A.S., WILKINSON, A.P., ZHANG, Z.J. Continuous hydrothermal synthesis of $\mathrm{CoFe} 2 \mathrm{O} 4$ nanoparticles. Fluid Phase Equilibria, v. 210, p. 307-317, 2003.

[4] CAMILO, R. L. Síntese e caracterização de nanopartículas magnéticas de ferrita de cobalto recobertas por 3-aminopropiltrietoxissilano para uso como material híbrido em nanotecnologia. 2006. Tese (Doutorado) - Instituto de Pesquisas Energéticas e Nucleares, São Paulo.

[5] GAUBEUR, I. Desenvolvimento de métodos espectrofotométricos em condição estacionária e em fluxo para determinação de zinco em amostras biológicas e farmacêuticas. 2001. Tese (Doutorado). - Universidade de São Paulo, São Paulo.

[6] COSTA, A. C. F. M.; VILAR, M. A.; LIRA, H. L.; KIMINAMI, R. H. G. A.; GAMA, L. Síntese e caracterização de nanopartículas de $\mathrm{TiO}_{2}$. Cerâmica, v. 52, p. 255-259, 2006.

[7] CARDOSO, W. S. Óxido misto de $\mathrm{SiO}_{2} / \mathrm{SnO}_{2}, \mathrm{SiO}_{2} / \mathrm{SnO}_{2} /$ Fosfato: propriedades e aplicações. 2005. Tese (Doutorado) - Universidade Estadual de Campinas, Campinas.

[8] GOMES, C. B. Técnicas analíticas instrumentais aplicadas à geologia. São Paulo: Edgard Blucher, 1984.

[9] CULLITY, B. D. Elements of X-Ray Diffraction. London, Addison-Wesley, 1967. 
[10] SCHNITZLER, D.C.;MERUVIA, M. S.; HU"MMELGEN, I. A.; ZARBIN, A. J. G.; Preparation and Characterization of Novel Hybrid Materials Formed from $(\mathrm{Ti}, \mathrm{Sn}) \mathrm{O}_{2}$ Nanoparticles and Polyaniline. Chemistry Material. v. 15, p. 4658-4665, 2003.

[11] 50 International Centre for Diffraction Data. Power Diffraction File. Newton Square. CD-ROM, 1994. apud: ALENCAR, A. C. Estudo das modificações na superfície do Ti cp titânio comercialmente puro e da liga Ti-6Al-4V usados como biomateriais utilizando-se deposição por plasma spray. 1999. Tese (Doutorado) - Instituto de Química, UNESP, Araraquara.

[12] CAI, D.; SUT, Y.; CHEN, Y.; JIANG, J.; HE, Z.; CHEN, L.; Synthesis and photoluminescence properties of novel $\mathrm{SnO}_{2}$ asterisk-like nanostructures. Materials Letters, v. 59, p.1984-1988, 2005.

[13] KUMAR, P. M.; BADRINARAYANAN, S.; SASTRY, M. Nanocrystalline $\mathrm{TiO}_{2}$ studied by optical, FTIR and X-ray photoelectron spectroscopy: correlation to presence of surface states. Thin Solid Films, v. 358, p.122-130, 2000.

[14] ZHAO, L.; YU, J.; CHENG, B. Preparation and characterization os $\mathrm{SiO}_{2} / \mathrm{TiO}_{2}$ composite microspheres with microporous $\mathrm{SiO}_{2}$ core/mesoporous $\mathrm{TiO}_{2}$ shell. Journal of Solid State Chemistry, v. 178, p.1818-1824, 2005.

[15] ALENCAR, A. C. Estudo das modificações na superfície do Ti cp titânio comercialmente puro e da liga Ti-6Al-4V usados como biomateriais utilizandose deposição por plasma spray. 1999. Tese (Doutorado) - Instituto de Química, UNESP, Araraquara.

[16] CAI, D.; SU, Y.; CHEN, Y.; JIANG, J.; HE, Z.; CHEN, L. Synthesis and photoluminescence properties of novel $\mathrm{SnO}_{2}$ asterisk-like nanostructures. Materials Letters, v.59, p.1984-1988, 2005.

[17] CULLITY, B. D. Elements of X-rays diffraction. Addison Wesley Publishing Company, 1972.

[18] GIOLITO, I.; IONASHIRO,M. A nomenclatura em análise térmica. Cerâmica, v. 34, p. 163-164, 1988.

[19] IONASHIRO, M.; GIOLITO, I. Nomenclatura, padrões e apresentação dos resultados em análise térmica. Cerâmica, v. 26, n. 121, p.17-24, 1980.

[20] WENDLANDT, W. W. Thermal analysis. 3. ed. New York, N. Y.: John Wiley, 1986. 
[21] BROWN, M. E.; Introduction to thermal analysis techniques and applications, Company and Hall, London, 1988.

[22] HAINES, P. J.; Thermal methods of analysis principles, applications and problems. Blackie Academic and Professional, Glasgow, 1995

[23] CHARSLEY, E. O.; WARRINGTON, S.B.; Thermal analysis techniques and applications. Hart Noll Ltda., boodnim, Cambridge, 1992.

[24] READ, J.; FOSTER, D.; WOLFENSTINE; BEHL, W. $\mathrm{SnO}_{2}$-carbon composites for lithium-ion battery anodes. Journal of Power Souces, v.96, p.277-287, 2001.

[25] GOLDSTEIN, J. I.; NEWBURY, D. E.; ECHLIN, P.; JOY, D. C.; ROMIG JR, A. D.; LUMAN, C. E.; FIORI, C.; LIFSHIN, E. Scanning electron microscopy and X-ray microanalysis: a text for biologists, materials scientists and geologists. 2 ed. New York, N. Y.: Plenum Press, 1992.

[26] BARBAROTO, P. R. Microscópio Eletrônico de Varredura: Medidas para caracterização e análise de materiais. Disponível em:

<http://www.dsif.fee.unicamp.br/ furio/IE607A/SEM.pdf> Acesso em: 25 out. 2006.

[27] GOLDSTEIN J. Scanning Electron Microscopy and X-Ray Microanalysis. New York, N. Y.: Plenum Press, 1984.

[28] MOLLER, T. Selective crystalline inorganic materials as ion exchangers in the treatment of nuclear waste solutions. 2002. Dissertação (Mestrado) - Faculty of Science of the University of Helsinki, Helsinki.

[29] FERREIRA, F. A. Estudos da modificação da resina não-iônica Amberlite XAD-7 com monoetanolamina (MEA) para retenção de espécies de S(IV). 2007. Dissertação (Mestrado) - Instituto de Química, Universidade de São Paulo-USP, São Paulo.

[30] KARADAG, D. D.; KOC, Y.; TURAN, M.; ARMAGAN, B. Removal of ammonium ion from aqueous solution using natural Turkish clinoptilolite. Journal of Hazardous Materials, v. B136, p. 604-609, 2006.

[31] VILAR, V. J. P.; BOTELHO, C. M. S.; BOAVENTURA, R. A. R. Equilibrium and Kinetic modelling of $\mathrm{Cd}(\mathrm{II})$ biosorption by algae Gelidium and Agar extraction algal waste. Water Research, v. 40, p. 291-302, 2006. 
[32] CHEUNG, C. W.; PORTER, J. F.; MCKAY, G. Sorption kinectic analysis for the removal of cadmium ions from effluents using bone char. Water Research, v. 35, n. 3, p. 605-612, 2001.

[33] ANNADURAI, G.; JUANG, R. S.; LEE, D. J. Use of cellulose-based wastes for adsorption of dyes from aqueous solutions. Journal of Hazardous materials, v. B92, p. 263-274, 2002.

[34] ANTONIO, P. Adsorção de di-2-piridil cetona saliciloilhidrazona (DPKSH) em sílica-gel, 2003,158p. Dissertação (Mestrado) - Instituto de Química, Universidade de São Paulo-USP, São Paulo.

[35] AZIZ, H. A. et al. Heavy metals (Cd, $\mathrm{Pb}, \mathrm{Zn}, \mathrm{Ni}, \mathrm{Cu}$ and $\mathrm{Cr}(\mathrm{III})$ ) removal from water in Malaysia: Post treatment by high quality limestone. Bioresour. Technol. doi:10.1016/j.biortech.2007.04.007, 2007.

[36] TEIXEIRA, V. G.; COUTINHO, F. M. B.; GOMES, A. S. Principais Métodos de Caracterização da Porosidade de Resinas a Base de Divinilbenzeno. Química Nova, v. 24, n. 6 , p. 808-818, 2001.

[37] CARNALL, W. T.; CROSSWITHE, H.; CROSSWITHE, H. M.; Energy Level Structure and transition probabilities of the Trivalent Lanthanide in LaF3, Argone National Lab. Argonne Illinos, 4493, 1977.

[38] FOSBERG, J. H.; Complexes of lanthanide (III) ions with nitrogen donor ligands. Coord. Chem. Rev., v. 10, n. 1-2, p. 195-226, 1973.

[39] DE SA, G. F.; MALTA, O. L.; DONEGA, C. D.; SIMAS, A. M.; LONGO, R. L.; SANTA-CRUZ, P. A.; DA SILVA, E. F. Spectroscopic properties and design of highly luminescent lanthanide coordination complexes. Coord. Chem. Rev., v.196, p.165-195, 2000.

[40] TEOTONIO, E. E. S. Síntese e Investigação das Propriedades Fotoluminescentes de Dispositivos Moleculares Conversores de Luz (DMCL) de Complexos Dicetonatos de Terras Raras com Ligantes Amidas. 2004. Tese (Doutorado) - Universidade de São Paulo, São Paulo.

[41] MALTA, O. L.; BRITO, H. F.;MENEZES, J. F. S.; GONÇALVES E SILVA, F. R.; ALVES JR, S.;FARIAS JR,F.S.; ANDRADE, A.V.M.; Spectroscopic properties of a new light-converting device $\mathrm{Eu}$ (thenoyltrifluoroacetonate) ${ }_{3} 2_{2}$ (dibenzyl sulfoxide). A theoretical analysis based on structural data obtained from a sparkle model. J. Lumin., v. 75, n. 3. p. $255-268,1997$. 
[42] COTTON, F. A; Chemical Application of Group Theory, Wiley-Intercience, New York, 1971.

[43] BÜNZLI, J. C. G.; CHOPPIN, G.R. Lanthanide Probes in Life, Chemical and Earth Sciences - Theory and Practice, Elsevier, Amsterdam,1989.

[44] RICHARDSON, F. S.; Terbium(III) and europium(III) ions as luminescent probes and stains for biomolecular systems. Chem.Rev., v. 82, n. 5, p. $541-552,1982$.

[45] KODAIRA, C. A.; BRITO, H. F.; MALTA, O.L.; SERRA, O.A. Luminescence and energy transfer of the europium (III) tungstate obtained via the Pechini method. J. Lumin., v. 101, p. 11-21, 2003.

[46] JUDD, B.R. Ionic transitions hypersensitive to environment. J. Chem. Phys. v. 70, n. 11, p. 4830-4833, 1979.

[47] PAGANINI, P. P.; TEOTONIO, E. E. S.; BRITO, H. F.; FELINTO M. F. C.; MALTA, O.L. Materiais nanoestruturados a base de estanho e ítrio dopados com európio. Investigação de propriedades espectroscópicas. In: REUNIÃO ANUAL DA SOCIEDADE BRASILEIRA DE QUÍMICA, 26., 26-29 maio, 2003, Poços de Caldas. A química torna sua vida melhor. Livro de resumos. São Paulo: Sociedade Brasileira de Química, 2003.

[48] PAGANINI, P. P.; TEOTONIO, E. E. S.; BRITO, H. F.; FELINTO M. F. C.; MALTA, O.L. Investigação estrutural da matriz SnSiO:Eu ${ }^{3+}$ pela técnica de luminescência. In: SIMPÓSIO INTERNACIONAL DE INICIAÇÃO CIENTÍFICA DA USP, 10., 6-8 NOV., 2002, São Carlos. Anais 2002 SIICUSP. São Carlos: USP, 2002. CD-ROM. 


\section{CONCLUSÕES}

As sínteses dos trocadores $\mathrm{SnO}_{2} / \mathrm{TiO}_{2}, \mathrm{SnO}_{2} / \mathrm{TiO}_{2}: \mathrm{Eu}^{3+}$ e dos trocadores híbridos foram efetivas. A rota de síntese é simples e de baixo custo o que viabiliza o processo.

Os trocadores $\mathrm{SnO}_{2} / \mathrm{TiO}_{2}, \mathrm{SnO}_{2} / \mathrm{TiO}_{2}: \mathrm{Eu}^{3+}$ mostraram-se cristalinos, com diâmetro de partícula de aproximadamente $5 \mathrm{~nm}$, apresentando-se em forma de aglomerados de superfícies homogêneas. São principalmente formados com a estrutura anastásia e apresentam rearranjo cristalino no trocador dopado.

Nos trocadores híbridos houve a adesão das partículas de $\mathrm{SnO}_{2} / \mathrm{TiO}_{2}$, e $\mathrm{SnO}_{2} / \mathrm{TiO}_{2}: \mathrm{Eu}^{3+}$ à matriz polimérica e o excesso de trocador foi observado em alguns pontos da superfície segundo análise de MEV.

Todos os trocadores estudados apresentaram decomposição térmica com caráter endotérmico e boa estabilidade térmica. A matriz polimérica se decompõe em aproximadamente $400^{\circ} \mathrm{C}$.

Os trocadores mostraram ter uma cinética rápida de troca para o $\mathrm{Cd}^{2+}$ e 0 $\mathrm{Ni}^{2+}$ e foram efetivos na adsorção dos mesmos, apresentando porcentagem de adsorção elevada para todos os sistemas estudados (influência de pH, concentração e tempo de contato). Nos trocadores híbridos a porcentagem de adsorção reduziu muito pouco, não sendo significativa. A adsorção dos metais pelos trocadores ocorre via dois sítios ativos e não ocorre a difusão do adsorbato intrapartícula. A dessorção dos íons $\mathrm{Cd}^{2+}$ e $\mathrm{Ni}^{2+}$, nas condições estudadas, apresentou-se efetiva para o cádmio e não efetiva para o níquel.

Os estudos de adsorção foram aplicados aos modelos de isoterma de Freundlich, Langmuir e Dubinin-Radushkevich (D-R). Os três modelos apresentaram 
ajustes favoráveis para a faixa de concentração considerada nos dois metais (Cd e Ni). O modelo de Freundlich permitiu obter as constantes de Freundlich e o parâmetro $\mathrm{n}$ que apresentou valores maiores que 1 indicando heterogeneidade energética da superfície dos trocadores.

O modelo de Langmuir além de permitir o cálculo das constantes indicou que a adsorção é espontânea para os dois sistemas estudados ( $\mathrm{Cd}$ e Ni).

O modelo D-R permitiu o cálculo dos parâmetros da isoterma e assim calcular os valores das energias médias de adsorção que apresentaram valores abaixo de $6 \mathrm{Kcal}^{\mathrm{mol}}{ }^{-1}$ evidenciando uma adsorção física.

Nas isotermas de adsorção do $\mathrm{Cd}^{2+}$ o sistema: $\mathrm{SnO}_{2} / \mathrm{TiO}_{2} ; \mathrm{pH}$; apresentou para o modelo de Freundlich e D-R parâmetros muito diferente dos demais sistemas estudados, com valores de $K_{F}$ e $E$ que sugerem uma adsorção química além de física.

O espectro de excitação à temperatura ambiente evidenciou a banda de transferência de carga ligante metal LMCT $\left(\mathrm{O} \rightarrow \mathrm{Sn}\right.$ e $\left.\mathrm{O} \rightarrow \mathrm{Eu}^{3+}\right)$. No espectro registrado a $77 \mathrm{~K}$ observou-se a banda de condução do $\mathrm{SnO}_{2}$.

Os espectros de emissão do $\mathrm{SnO}_{2} / \mathrm{TiO}_{2}: \mathrm{Eu}^{3+}$ exibiram bandas finas oriunda das transições ${ }^{5} \mathrm{D}_{0} \rightarrow{ }^{7} \mathrm{~F}_{0-4}\left(\mathrm{Eu}^{3+}\right)$, dominados pelas transições hipersensíveis ${ }^{5} \mathrm{D}_{0} \rightarrow{ }^{7} \mathrm{~F}_{2} \quad(\sim 612 \mathrm{~nm})$. Os desdobramentos dessas transições, de um modo geral, estão concordantes com um ambiente químico de baixa simetria ao redor do íon $\mathrm{TR}^{3+}$. O $\mathrm{SnO}_{2} / \mathrm{TiO}_{2}: \mathrm{Eu}^{3+}$ emite na cor vermelha com pico máximo em $\sim 614 \mathrm{~nm}$ atribuído a transição permitida por dipolo elétrico ${ }^{5} D_{0} \rightarrow{ }^{7} F_{2}$ e apresenta comportamento não centrossimétrico caracterizado pela alta intensidade luminescente da transição hipersensível, que é proibida por dipolo elétrico em sistemas com centro de inversão. O perfil das bandas é característico de matrizes vítreas, dopadas com lantanídeos e a banda de condução do $\mathrm{SnO}_{2}$ desaparece comprovando a eficiência do processo de transferência de energia.

$\mathrm{O}$ estudo deste trocador dopado indicou que o íon $\mathrm{Eu}^{3+}$ nessa matriz encontra-se em um ambiente químico mais polarizável quando comparada a outros trocadores e que o mesmo possui rendimento quântico satisfatório e poderá ser utilizado como material fotoluminescente. 


\section{PESPECTIVAS FUTURAS}

> Estudar os trocadores em coluna de troca iônica partindo dos melhores parâmetros.

Partir dos metais $\mathrm{Ni}$ e $\mathrm{Cd}$ retirando-os diretamente das baterias $\mathrm{Ni}-\mathrm{Cd}$.

> Desenvolver o estudo do trocador dopado utilizando-o como material fotoluminescente. 